\title{
Housing market detections
}

Citation for published version (APA):

Langen, M. (2019). Housing market detections: externalities \& images. [Doctoral Thesis, Maastricht University]. ProefschriftMaken. https://doi.org/10.26481/dis.20191219ml

Document status and date:

Published: 01/01/2019

DOI:

10.26481/dis.20191219ml

Document Version:

Publisher's PDF, also known as Version of record

\section{Please check the document version of this publication:}

- A submitted manuscript is the version of the article upon submission and before peer-review. There can be important differences between the submitted version and the official published version of record.

People interested in the research are advised to contact the author for the final version of the publication, or visit the DOI to the publisher's website.

- The final author version and the galley proof are versions of the publication after peer review.

- The final published version features the final layout of the paper including the volume, issue and page numbers.

Link to publication

\footnotetext{
General rights rights.

- You may freely distribute the URL identifying the publication in the public portal. please follow below link for the End User Agreement:

www.umlib.nl/taverne-license

Take down policy

If you believe that this document breaches copyright please contact us at:

repository@maastrichtuniversity.nl

providing details and we will investigate your claim.
}

Copyright and moral rights for the publications made accessible in the public portal are retained by the authors and/or other copyright owners and it is a condition of accessing publications that users recognise and abide by the legal requirements associated with these

- Users may download and print one copy of any publication from the public portal for the purpose of private study or research.

- You may not further distribute the material or use it for any profit-making activity or commercial gain

If the publication is distributed under the terms of Article $25 \mathrm{fa}$ of the Dutch Copyright Act, indicated by the "Taverne" license above, 


\section{$(-2,1)$}

Dis

$\$ 1(161)$

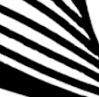

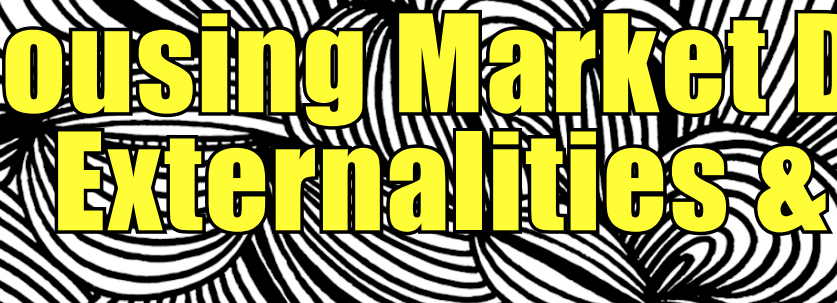
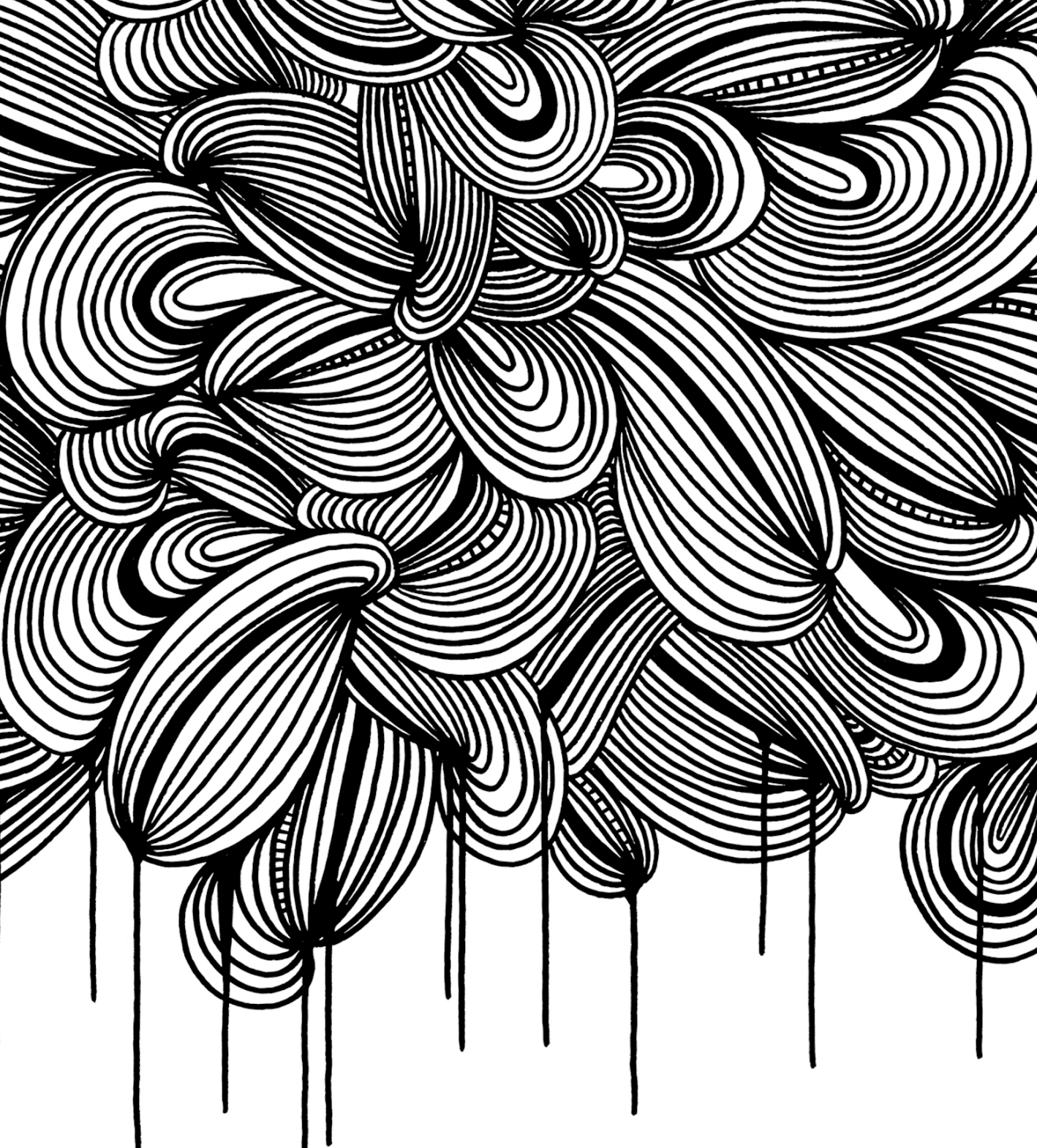

배욤ำ 


\title{
Housing Market Detections Externalities \& Images
}

\author{
Mike Stephan Langen
}


About the Cover Artist:

Born in Aachen (Germany), KEF! has started with graffiti when he was 14 years old. At the age of 19 he began to expand his work on other surfaces as canvas and paper. Nowadays, he works with galleries on projects all over the world. His work is based on making researches about the feelings of freedom, independence and harmony and how they can get manifested through his paintings in interior and exterior surroundings. For more information see: www.kefart.com

C)2019 Mike Stephan Langen

All rights reserved. No part of this publication may be reproduced, stored in a retrieval system, or transmitted, in any form, or by any means, electronic, mechanical, photocopying, record or otherwise, without the prior permission in witting from the author.

ISBN 978-94-6380-656-5

This book was typeset using $\mathrm{AT}_{\mathrm{E}} \mathrm{X}$

Printed by: ProefschriftMaken.nl 


\title{
Housing Market Detections Externalities \& Images
}

\author{
Dissertation
}

to obtain the degree of Doctor at Maastricht University,

on the authority of the Rector Magnificus Prof. df. Rianne M. Letschert in accordance with the decision of the Board of Deans, to be defended in public on Thursday 19th December 2019 at 16:00 hours

by

Mike Stephan Langen 


\section{Supervisor}

Prof. dr. Piet Eichholtz

\section{Co-supervisor}

Dr. Nils Kok

\section{Assessment Committee}

Prof. dr. Rachel Pownall (Chair)

Prof. dr. David Geltner (Massachusetts Institute of Technology)

Dr. Thies Lindenthal (University of Cambridge)

Dr. Paulo Rodrigues

Prof. dr. Peter Schotman 
"Jede Wissenschaft ist, unter anderem, ein Ordnen, ein Vereinfachen, ein Verdaulichmachen des Unverständlichen für den Geist" - Hermann Hesse 
Für meine Eltern 


\section{Acknowledgments}

Becoming an academic is like learning the game of Poker, a complex game consisting of skill and luck. The rules are relatively easy to learn and with a bit of luck, you will even win a few hands every now and then. However, to become a proper player you need to learn more than the rules of the game: a lot of statistics, emotional intelligence to read other players, consistency to let loose or bluff, and manage your available resources. These are the skills of the game and only by managing all of them, you have a chance to win in the long-run, becoming a successful player.

As a PhD candidate you are the rookie of the game, training to become a pro-player. You start overly enthusiastic and probably win a few hands by pure luck. The game seems easy, there are plenty of project ideas and your papers seem to fit well into top journals. At some point, however, you realise that there is more to the game than the rules. The beginners luck fades, projects don't work out, get stuck or get rejected. This is the point where most $\mathrm{PhDs}$ consider quitting. However, this is also the point at which $\mathrm{PhDs}$ start to develop their skills. These are the skills that help to understand the value of projects at a specific time, considering other players' moves and the required stakes. Once these skills are learned, you can call yourself a pro-player. The rest is practice and luck!

As with every game, true joy comes from playing together. Other players can make a good game bad and a bad game enjoyable. As a $\mathrm{PhD}$ candidate, you start with two mentors, experienced players who teach you the rules of the game and their tricks. Without proper mentors, it is difficult to succeed in the long-run. I therefore want to first thank my two outstanding supervisors, Piet Eichholtz and Nils Kok. Without you two, this thesis would not exist.

Piet Eichholtz brought me to the table. I wanted to apply for PhD programs, and first passed by his office to ask for a letter of recommendation. He not only offered me to write the letter, but also said I should apply for a $\mathrm{PhD}$ with him. Over the years I learned the strategy behind this move: always grab the opportunity, it can open doors you didn't even know exist! Piet taught me many skills. He is a master in project and bankroll management, allowing him to be involved in multiple projects and businesses at the same time. He understands the value of a project, how much effort/time to invest in it, and how to market it ("Best in the world..."). He is always open to new ideas and incredible well connected in the academic landscape.

However, what really impresses me, is Piet's lifestyle. While being involved in multiple projects at the same time, he never forgets about his work-life balance. Piet loves to enjoy life, cycling and good food. In the summer, he cycles several hundred kilometres a month. He knows all restaurants in Maastricht and reads approximately two books a week! Thank you Piet for showing me how to go through life at ease, managing problems and making decisions as if they would barely exist. Your lifestyle will always be an example to me. Good Stuff!

Nils Kok, my second supervisor, made my $\mathrm{PhD}$ possible through his NWO grant. Nils is some kind of super manager. I am still amazed how a person can be involved in so many projects across two continents while having three toddlers and still be successful overall. It was often hard to keep up with Nils' speed and professionalism. He set high standards and I was often pushed out of my comfort zone. However, in the end this 
leadership style let me grow stronger. Thank you for pushing me into Latex, Python, R and other tools in the shortest possible time ("Should not take long...").

Through Nils I learned to always be open to new ideas and show professionalism at any time. He is extremely curious and has the ability to see the big picture, while perfectly understanding which projects are rewarding, a true master skill. Although he knows nearly every top executive in the real estate industry, you can always call him for some help. Thank you Nils for everything! I hope that I can take some of your attitude, vision, and generosity along my way.

It were Piet and Nils who introduced me to other mentors along the way and I want to thank them in the order we met. I first want to thank Thies Lindenthal, who shares the same enthusiasm about machine learning as I do. Thank you Thies for bringing me to Cambridge, giving me the freedom to learn all about machine learning and making me addicted to good coffee (my expenses for coffee went up significantly after my visit). You are the most relaxed person I met during my journey and I wish you lots of success and happiness with the family. I hope we will stay in touch for future projects.

I further want to thank David Geltner and Andrea Chegut, who hosted me at MIT. David, I really enjoyed our discussions at Dunkin' and Muddy's. Thank you for always generously sharing your knowledge and keeping me in mind when you see job opportunities. I am really honoured about your support. Andrea, thank you for hosting me in your lab and giving me a glimpse in to the future of real estate. You taught me about the importance of visualisations and good advertising, helping to convince the industry. Furthermore, you showed me how to organise events at another level of professionalism. During my stay in the lab, I had the feeling I was visiting a family at their home. You care about every lab member and we had regular dinners and events. Creating such an atmosphere is the skill of a true leader. I hope the lab will keep on growing and you will keep going strong.

Alex van de Minne I am really happy that our paths crossed. Even though a technical mastermind, you are one of the most modest persons I met. I really enjoyed our conversations about football over a beer or more. Thank you for trusting me and inviting me to join your project ideas. I am happy to have you in my committee and hope there will be many more projects to come.

I want to thank my other committee members. Rachel Pownall, thank you for being so kind and supportive all the time. Thank you Peter Schotman and Paulo Rodrigues, the technical masters of the department. You always took time to explain everything in intuitive ways for me. Maarten Jennen, thank you for trusting in a young PhD student and supporting my course. It is always a pleasure to meet you. Thank you Marc Francke for your support and your investments in the ties between Maastricht and Amsterdam.

Unlike in Poker, you cannot succeed as an academic without the support of a strong institution. I especially thank the heart of the department: Francien, Carina, Els and Cecile. Without your guidance, patience and inside knowledge, I would often have been lost. Just the fact that even my supervisors often referred to ask you, shows your true power. Thank you for always being a reliable help!

Jaap Bos, you are a caring and fair department head. Thank you for always being there for a chat and generously supporting the last months of my PhD. I further want to thank Thomas Post and Paul Smeets, with whom you can always have a good chat. Paul, 
I hope we will manage to organise another round of poker in the future. I further want to thank Rob Bauer, Roger Otten, Stefan Straetmans, Jeroen Derwall, Peiran Jiao, Dennis Bams, Stefanie Kleimeier, Sanne Jongen, Carl Vandenboorn, and Sjoke Merk. Outside the department walls, I want to thank Erkan Yönder, Just Pereboom, Steffen Kuenn, Lex Borghans, Rudolf Mueller, Stan van Hoesel, Annemarie van Zeijl, and Rob Ruiter.

Playing a game of poker with only experienced players will eventually become boring. In contrast, learning a game together is fun and learning a game with a drink is the best as "Wine brings to light the hidden secrets of the soul" (Horace). Therefore, I want to thank my fellow rookies and colleagues of tomorrow.

First of all, I want to thank my paranymphs. Juan Palacios, it seemed that some invisible hand constantly let our paths cross. We started this adventure together, with the same supervisors, often shared a hotel room, did the same exchange and even lived together. I have to admit that it was not always easy for me. With your charming, southern European character and your hard-working attitude, it was often difficult for me to shine next to you. However, with your humble attitude you never saw this as a competition and even taught me that $\mathrm{PhDs}$ should never compare themselves. I have deep respect for you and hope that you will become super successful! Even though our paths split, I am confident that the invisible hand will let them cross again in future. The crocodile is patient...

Martijn Stroom, before you entered the department I felt that most PhDs are rather introverted personalities. You proofed me wrong! Being a local and always up for a drink, partying or just socialising, you know half of the city by name. Even though your jokes are never that funny (keep working on that please), your weekend stories are hilarious. You are a good friend to talk to and behind the cheeky and cool facade, you have a great heart. I wish you all the success for the last miles of your PhD!

I was very lucky to start in the biggest and most social $\mathrm{PhD}$ cohort the finance department has (probably) ever encountered. It allowed me to make more friends during my $\mathrm{PhD}$ and I hope I don't forget anyone here, I wish you all the best!

Matthijs Korevaar, I have no doubt that you will become one of the biggest Dutch academics one day. You are incredible modest (except for bikes), altruistic, social and adventurous (e.g. skiing on black piste after 3 days of training). I take my hat off for you, especially for having complete faith in the Georgian overland bus network. Tonno, you are just the kindest person out there. You cannot even say no to Martijn's shots, which evidentially killed you so many times. I really enjoyed our talks and parties and hope we manage to visit a festival together one day. Ramsifasi, I really miss how we always laughed over our dinners (your spirit is still there ;). You have a great sense of humor and I am happy that we became friends. Tobi, it was hard to keep up with your (après) skiing. Thank you for all these rides, I enjoyed our talks and still wonder how a shared flat would have looked like. Clarissa, thank you for closing the Alla together, best night ever!

Marc Godart, you are living the true real estate life and are always up for some spontaneous adventure. Nagi, thanks for bringing some female power into the real estate group. Addy the eagle, thank you for teaching me so much about Ethiopia and Africa, may your family be always healthy and happy. Ming, you always made me laugh with your stories. I hope you will become China's new star! Luuk, you were always up for a 
chat with your friendly soul. May your trip continue forever. Colinski, I hope you will manage the 500 beers until your defense. Rogier H., thank you for all the help and for passing on all your knowledge. With you the real estate meetings were always more fun.

Thank you to all of the power girls, who landed great positions and were always up for party. Inka, you are extremely kind, helpful and always beat me at the bar. Nora, you are a true fighter and you will have a great career ahead. All our trips were fun and I hope there will be more to come. Marina, it was great to party with you. You always bring some class with you. Irene, you impress us all with your attentive character. I enjoyed all our dinners and trips and wish you and Casper all the best for the future!

I further want to thank Wiebke, Iman, Alessandro, Patrick, Rogier Q., Judy, Arian, Hang, Shusen, Michael K., Anouk, Runliang, Joyce, Erdal, Annick, Marten, Katrin, Janek, Rasmus, Pomme, Bin, Alexander, Bram, and Marianna.

I also want to thank all the PhDs who made this journey enjoyable outside the department. Simon B. you made the time at MIT a great one! I hope you stop traveling at some point, so I can visit you. Dorinth and Felipe, it was always great to hang out and I am looking forward to meet you at all the events in the future. Thank you to all the SBE PhDs, who made all the parties great: Henrik, Hang, Pieter, Max, Tim, Timna, Sean, Hannah, Nina, Olga, Melline, Sanne, Kim, Diogo, Adam... Thank you also to all members of the social committee, who, by definition, were always up for some socialising. People always ask me when we organise another great party, so keep going strong!

"The deeper the roots, the greater the fruits." - I want to thank all my friends that are with me since pre-PhD times. You know me as I am and share countless stories with me, which could ruin my career. Therefore, I keep this part short and personal. You are the ones I can count on. Everyone of you is special to me and I highly value that we are friends. To you I can talk about the world and you show me that there is so much more than academia and careers. Without you, life would be colourless. Thank you, Marc, Pascal, Nils, Robert, Stefan, Florian, Dennis, Steffen, Marko, Judith, Kathi, Nicole, Nina, Olga, Sandra, Tanja, Jeannette, Mario, Johannes, Lisa, Frank, Maria, Daniel, Simon R., Christian, Madis, Matt, Nick, Sofia, Simon Q., Andrea, Janet, Eugen, Peter, Julian, Nicholas.

A special thank you goes to my families: Mama, Papa, Oma und Opa, ohne euch wäre das alles nicht möglich gewesen. Ihr vertraut mir immer blind und unterstützt mich mit allem was ihr habt, auch wenn ihr nicht wisst wohin die Reise geht (sowie bei dieser Dissertation). Auf euch kann ich mich immer zu 100\% verlassen. Ich kann nicht in Worte fassen, wie viel ihr mir bedeutet und wie dankbar ich euch bin. Ich hoffe ich konnte euch stolz machen.

Thank you to the Sol family for accepting me and treating me as one of your own. You always supported me and gave me the feeling of being at home. You became a fixed part of my life and I am really happy to know all of you.

Lastly, I want to thank Lidwien for whom I could write an entire acknowledgements section. For the time, effort and feedback you invested in my support; my $\mathrm{PhD}$ title should be shared with you. With your positive attitude, you broadened my horizon and changed my life for the better. You always believe in me and so do I in you. You are the light in my life and I love you. 


\section{Table of Content}

1 Introduction 1

1.1 Externalities in the Housing Market . . . . . . . . . . . . . . . 3

1.2 Overcoming Data Limitations . . . . . . . . . . . . . . . . . . . . . 6

2 Schools without boundaries:

Externalities of good and bad primary schools in free school choice systems.

2.1 Introduction . . . . . . . . . . . . . . . . . . . . . . 9

2.2 Literature Review . . . . . . . . . . . . . . . . . . . . . . . . . . . 10

2.3 Economic Framework . . . . . . . . . . . . . . . . . . . . . . 11

2.4 Empirical Strategy . . . . . . . . . . . . . . . . . . . . . . . . . . . . . . . . . . . . . . . . .

2.5 Data . . . . . . . . . . . . . . . . . . . . . . . 15

2.5.1 Housing Data . . . . . . . . . . . . . . . . . . 15

2.5.2 Neighborhood Controls . . . . . . . . . . . . . . . . . . 15

2.5.3 School Data . . . . . . . . . . . . . . . . . . 16

2.5.4 Descriptive Statistics . . . . . . . . . . . . . . . . 17

2.6 Results . . . . . . . . . . . . . . . . . . . . . . . . 18

2.6.1 Baseline Hedonic Regression . . . . . . . . . . . . . . . . . . 18

2.6.2 Estimation Results . . . . . . . . . . . . . . . . . . . . . 19

2.6.3 Robustness Checks . . . . . . . . . . . . . . . . . 23

2.7 Discussion \& Conclusion . . . . . . . . . . . . . . . . . . . . . 25

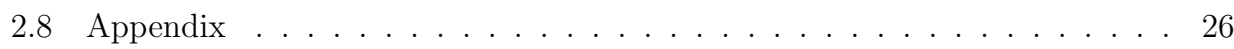

3 Clean Electricity, Dirty Electricity:

The Effect on Local House Prices $\quad 31$

3.1 Introduction . . . . . . . . . . . . . . . . . . . . . 31

3.2 Literature Review . . . . . . . . . . . . . . . . . . . . . . . 33

3.2.1 External effects of electricity generation . . . . . . . . . . . . . 33

3.2.2 Power plants and external effects on housing . . . . . . . . . . . . . . 34

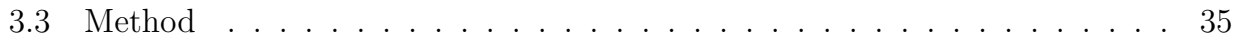

3.3.1 Theory \& sample construction . . . . . . . . . . . . . . . . 35

3.3.2 Difference-in-difference approach . . . . . . . . . . . . . 36

3.3.3 Repeat sales analysis . . . . . . . . . . . . . . . . . . . 39

3.4 Data . . . . . . . . . . . . . . . . . . . . . . 40

3.4.1 Power plants . . . . . . . . . . . . . . . . . . . . . . . . . . . . . . . . 40

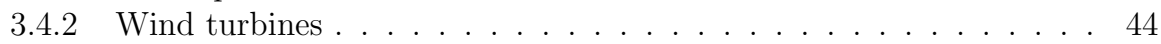

3.4.3 Housing transactions . . . . . . . . . . . . . . . . . . . 45

3.5 Results . . . . . . . . . . . . . . . . . . . 46

3.5.1 Difference-in-difference results . . . . . . . . . . . . . . . . . . . . . . 46

3.5.2 Repeated sales results . . . . . . . . . . . . . . . . . 51

3.6 Discussion and conclusion . . . . . . . . . . . . . . . . . . 52

3.7 Appendix . . . . . . . . . . . . . . . . . . . . 54

4 Getting High or Getting Low?

The External Effects of Coffeeshops on House Prices $\quad 61$

4.1 Introduction . . . . . . . . . . . . . . . . . . 61

4.2 Coffeeshops in the Netherlands . . . . . . . . . . . . . . 63 
4.2.1 Government Policy on Coffeeshops . . . . . . . . . . . . . . . . 63

4.2 .2 Effects on the Community . . . . . . . . . . . . . . 64

4.2.3 The Distance Criterion . . . . . . . . . . . . . . . . 65

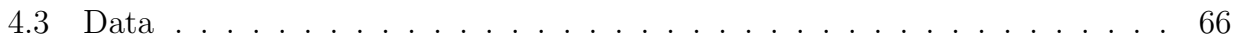

4.3 .1 Data Sources . . . . . . . . . . . . . . 66

4.3.2 Sample Selection and Descriptive Statistics . . . . . . . . . . . . 67

4.4 Methodology and Results . . . . . . . . . . . . . . . . . . 70

4.4.1 Difference-in-Difference Analysis . . . . . . . . . . . . . . . . . . . 70

4.4 .2 Repeated Sales Model . . . . . . . . . . . . . . . . . . . . . 75

4.5 Discussion - Channels \& Mechanisms . . . . . . . . . . . . . . . . . . 77

4.6 Implications \& Conclusion . . . . . . . . . . . . . . . . . . . . . . . . . . . 79

4.7 Appendix . . . . . . . . . . . . . . . . . . . . 81

4.7.1 Difference-in-Difference Analysis . . . . . . . . . . . . . . . . . . . . 84

4.7 .2 Repeated Sales Analysis . . . . . . . . . . . . . . . 85

5 Deep Learning in Real Estate:

$\begin{array}{lr}\text { Object Detection in the Built Environment } & 87\end{array}$

5.1 Introduction . . . . . . . . . . . . . . . . . . . 87

5.2 Review: Computer Vision \& Urban Applications . . . . . . . . . . . . . . . 89

5.2.1 Image Classification and Object Detection . . . . . . . . . . . . . . 89

5.2 .2 Computer Vision in the Urban Environment . . . . . . . . . . . . . 90

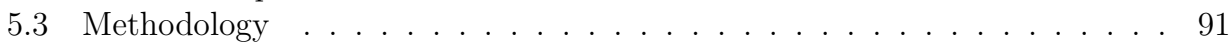

5.3.1 Model Selection and Training . . . . . . . . . . . . . 93

5.3.2 Estimating Structural Characteristics . . . . . . . . . . . . . . 94

5.4 Input Data . . . . . . . . . . . . . . . . . . . . . . . . . . . . . 96

5.5 Results . . . . . . . . . . . . . . . . . . . . . 98

5.5.1 Stylized facts and model performance . . . . . . . . . . . . . 98

5.5 .2 Floor Estimation . . . . . . . . . . . . . . . . . . . . . 101

5.5 .3 Window-Surface Ratio . . . . . . . . . . . . . . . . 103

5.5.4 Classification Comparison . . . . . . . . . . . . . 105

5.6 Discussion \& Conclusion . . . . . . . . . . . . . . . . . . . . . . . . . . . . . . . . . . . . . . . . . . . . . .

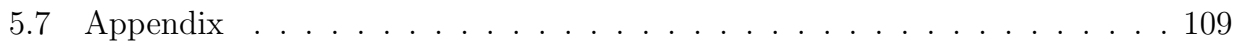

5.7 .1 IoU and mAP . . . . . . . . . . . . . . . . . 114

6 Concluding Remarks $\quad 117$

6.1 External Effects . . . . . . . . . . . . . . . . . . . . . . . . 117

6.2 Computer Vision . . . . . . . . . . . . . . . . . . . . . . . . . . . . . . 118

$\begin{array}{llr}7 & \text { Valorization } & 119\end{array}$

$\begin{array}{ll}\text { References } & 121\end{array}$ 


\section{List of Figures}

1.1 US Housing Market \& Economy . . . . . . . . . . . . . . . . . . . . . 2

1.2 Heatmap of Amsterdam House Prices 2013 and 2018 . . . . . . . . . . . . 2

1.3 Google Street View Coverage (blue) $2018 \ldots \ldots$. . . . . . . . . . . 7

2.1 Nonlinear school proximity effect over distance . . . . . . . . . . . . . 22

2.2 Additional quality effects for best and worst performing schools . . . . . . 23

2.3 Population Density and School Distance (2009) . . . . . . . . . . . . . 29

2.4 School Distance over Time . . . . . . . . . . . . . . . . . . . . 30

2.5 Relationship - Distance to school . . . . . . . . . . . . . . 30

3.1 Sample Construction Method . . . . . . . . . . . . . . . . 36

3.2 DID for areas - Setup . . . . . . . . . . . . . . . . . 37

3.3 Distribution of Wind Turbines, Power Plants and Population Density . . . 42

3.4 Yearly Installations of Power Generation Facilities . . . . . . . . . . . . . . 44

3.5 Percentage of Observations Affected by Externalities (per Year) . . . . . . 54

3.6 Simultaneous Trend Analysis Average price per $\mathrm{m}^{2}$ around facility openings \& closings . . . . . . . . . . . . . . . . 55

4.1 Property-Coffeeshop Distance Distribution . . . . . . . . . . . . . . 67

4.2 Illustration of Clustering . . . . . . . . . . . . . . . . . . . . . . . . . 68

4.3 Difference-in-Difference Setup . . . . . . . . . . . . . . . . . . 71

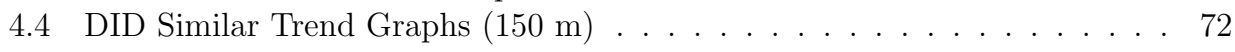

4.5 Post-closing coffeeshop location usage . . . . . . . . . . . . . . . . . 79

4.6 Street scene impressions of open coffeeshops . . . . . . . . . . . . . . . . . 81

4.7 Impressions of closed and vacant coffeeshops . . . . . . . . . . . . . . . . 82

4.8 Coffeeshop Distribution in Amsterdam, Rotterdam, and The Hague . . . . 83

4.9 Repeated sales - price difference over post-closing time $(<150 \mathrm{~m})$. . . . . 85

5.1 Illustration the difference of Image Classification and Object Detection . . 90

5.2 Process diagram: Model training and application . . . . . . . . . . . . 92

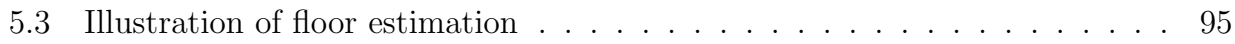

5.4 Example images of object detection results . . . . . . . . . . . . . . . 100

5.5 Detected houses - Application test sample . . . . . . . . . . . . . . 101

5.6 Floor estimation accuracy . . . . . . . . . . . . . . . . . . . . . . . 102

5.7 Window-surface ratio distribution . . . . . . . . . . . . . . . . . 104

5.8 Classification model accuracy - Number of floors . . . . . . . . . . . . . 107

5.9 Illustration of Neural Network Setup and Training . . . . . . . . . . . . . . 109

5.10 Example of annotated image . . . . . . . . . . . . . . . . . 110

5.11 Illustration of Faster R-CNN anchor boxes . . . . . . . . . . . . . . . . . 110

5.12 Geographical distribution samples . . . . . . . . . . . . . . . . . . . . . . . . . . . . . . . . . . . .

5.13 Examples of bad GSV outputs . . . . . . . . . . . . . . . . . . . . . . . . . . . . . . . . . . . . . . . . .

5.14 Data flow diagram . . . . . . . . . . . . . . . . . . . . . . . . . . . . . . . . . . . . . . . . . . .

5.15 Distribution number of floors . . . . . . . . . . . . . . . . . . . 113

5.16 Examples of floor deviations . . . . . . . . . . . . . . . . . 114

5.17 Classifications at different cut-off scores . . . . . . . . . . . . . . . . . 114

5.18 Illustration Intersection over Union . . . . . . . . . . . . . . . . . . . . . . . . . . . . . .

5.19 Precision-Recall $(\mathrm{PR})$ curve illustration . . . . . . . . . . . . 116 


\section{List of Tables}

2.1 Descriptive Statistics - Data Representativeness . . . . . . . . . . . . . . 18

2.2 Regression Outputs I - Distance to School and House Price . . . . . . . . . 20

2.3 Regression Outputs II - School Quality and House Price . . . . . . . . . . 21

2.4 Robustness checks - Adding distance to a local center and second best performing school . . . . . . . . . . . . . . . . . 24

2.5 Population Share and Housing Transactions per Province (2016, in \%) . . 26

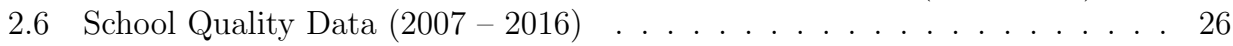

2.7 Hedonic Regression - Control Variables . . . . . . . . . . . . . . . . 27

2.8 Houses in proximity of worst performing schools and total housing stock . 28

3.1 Conventional Power Plants and Wind Turbines Characteristics by Primarily Fuel Type . . . . . . . . . . . . . . . . . . . . . . . 43

3.2 Descriptive Statistics: Housing Sample 1985 - 2015 . . . . . . . . . . . . . 46

3.3 Results Area DID opening . . . . . . . . . . . . . . . . . . . . . . . . . . . . . . . . . . .

3.4 Results Area DID opening . . . . . . . . . . . . . . . . . . . . . . . . . 49

3.5 Results Area DID closing . . . . . . . . . . . . . . . . . . . . 50

3.6 Results Repeated Sales . . . . . . . . . . . . . . . . . . . . . . . 52

3.7 Control Variables . . . . . . . . . . . . . . . . . . . 56

3.8 Time Clustering - Difference-in-Difference Approach . . . . . . . . . . . 57

3.9 Area DID Opening - Time Sub-tests . . . . . . . . . . . . . . . . . 58

3.10 Repeated Sales Control Variables . . . . . . . . . . . . . . . . . . . . 59

3.11 Repeated Sales - 3 km cut-off distance . . . . . . . . . . . . . . . . . . . . 60

4.1 Coffeeshop Sample Overview $(2000-2017) \ldots \ldots$. . . . . . . . . 66

4.2 Observations per distance, area and property type . . . . . . . . . . 69

4.3 Descriptive Statistics Housing Transactions Amsterdam, Rotterdam, The Hague $(2000-2017) \ldots \ldots \ldots$. . . . . . . . . . . . . . . 69

4.4 Difference-in-difference analysis . . . . . . . . . . . . . . . . . 73

4.5 DID Analysis - Controlling for other nuisance venues . . . . . . . . . . . . 74

4.6 DID Analysis - Heterogeneity of holdout period . . . . . . . . . . . . 75

4.7 Repeated sales analysis . . . . . . . . . . . . . . . . . . . 77

4.8 Vacancy analysis . . . . . . . . . . . . . . . . . . . . . . . . . . . . . . . . 79

4.9 Difference-in-Difference: Groupings . . . . . . . . . . . . . . . . 84

4.10 Observations by closing time and place $(150 \mathrm{~m}$ cut-off $) \ldots$. . . . . . . . 84

4.11 Difference-in-difference analysis - excluding The Hague . . . . . . . . . . . 85

4.12 Repeated Sales - Control Variables . . . . . . . . . . . . . . . . . . 86

5.1 Samples - Descriptive statistics . . . . . . . . . . . . . . . . . 98

5.2 Training sample - Object classes and number of records . . . . . . . . . . 98

5.3 Explaining window-surface ratio by structure . . . . . . . . . . . . . . 105

5.4 Mean floor deviation at floor levels . . . . . . . . . . . . . . . . . 113 


\section{Chapter 1}

\section{Introduction}

Residential real estate markets affect our daily lives and are important indicators of the national economy, social coexistence and the demand for space. The market mechanisms are simple: every one of us needs a place to live and therefore rents or buys property, creating demand for living space. Developers react to this demand by supplying space to the market at profitable conditions, either selling space or letting it out over time. Property prices and rents are determined by demand and supply, which are driven by factors such as expected population growth, income per capita and returns of alternative investments (DiPasquale \& Wheaton, 1996). Owning a house is considered one of the biggest dreams of many households, promising financial independence and a stable longterm investment. Due to its capital requirements, a house is usually the biggest household asset and often (partly) financed by debt, directly relating the socio-economic situation of households to the developments of real estate markets. Therefore, policy makers want to monitor and understand residential real estate markets, ensuring price stability and affordability.

To illustrate the important role of residential real estate within the economy, Figure 1.1a shows the Case-Shiller Home Price Index for the United States, including the two example cities, Detroit and Los Angeles. Highlighted in grey are the periods of the two biggest US recessions in recent years, the dot-com crisis and the global financial crisis (GFC) of 2007 - 2008. During both crises, the S\&P 500 stock market index, measuring the performance of the 500 biggest, listed US companies fell $46 \%$ and $53 \%$, respectively. However, the housing market behaved quite differently between the crises. During the dotcom crisis housing markets were stable, potentially preventing a severe economic crisis. In contrast, housing prices stagnated and started falling before the GFC, leading to a banking crisis and ultimately to a severe economic recession. Figure 1.1b shows these different outcomes, indicating that quarterly US GDP growth became negative during the GFC.

Within countries, housing markets shape the socio-economic characteristics of a society, as home ownership leads to higher wealth accumulation over time while low-income households face increasing housing costs (rents) (Piketty, 2014). Therefore, policy makers want to understand the demographics in the housing market, ensuring that housing affordability is equally distributed. However, examining demographics, Krivo and Kaufman (2004) find significant racial gaps in US home ownership rates, showing that blacks and Hispanics are less likely to own property compared to whites and Asians. Urbanization disproportionately increases house prices in urban areas, leading to the migration of lower income households (Gyourko et al., 2013). This trend particularly affects younger households - Choi et al. (2018) show that the home ownership rate among US millennials in 2015 was 8 percentage points lower than for Gen Xers and baby boomers at the same age. As housing cost increase over time, unequal ownership rates increase inequality. 
Figure 1.1

US Housing Market \& Economy

(a) S\&P/Case-Shiller U.S. National Home Price Index

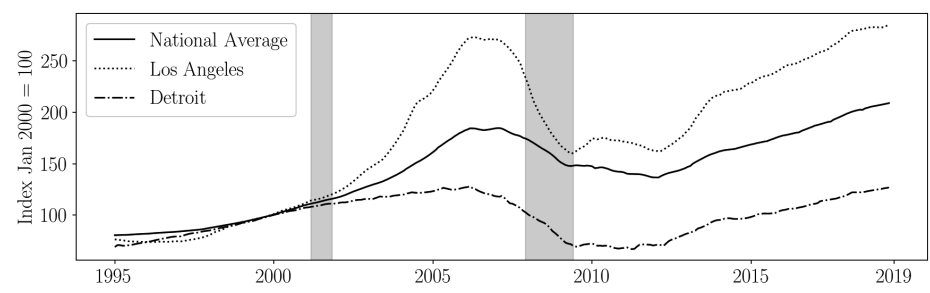

(b) US GDP growth (quarterly)

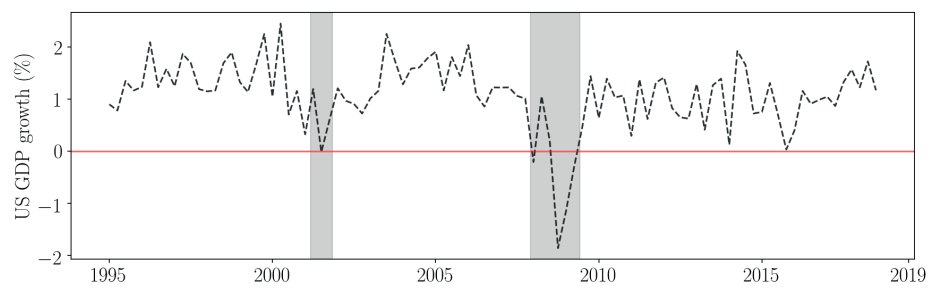

Notes: Figure 1.1a: Index January $2000=100$, seasonally adjusted. Data retrieved from: https://fred.stlouisfed.org/series/SPCS20RSA, August 2019. Criseses are defined by US business cycles defintions: http://www.nber.org/cycles/cyclesmain.html.

Figure 1.1b: Data retrieved from https://fred.stlouisfed.org/series/GDP

Figure 1.2

Heatmap of Amsterdam House Prices 2013 and 2018

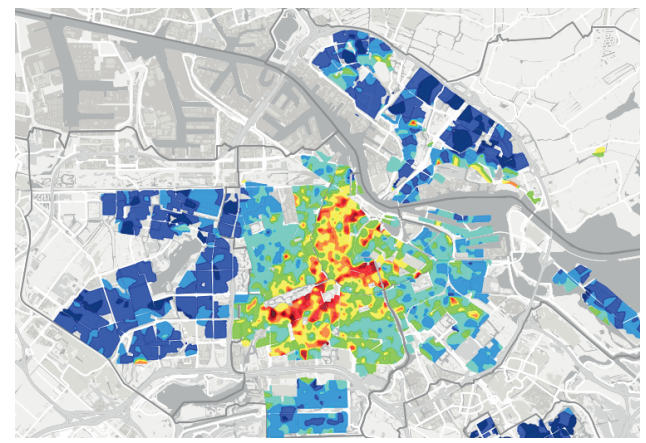

(a) Amsterdam house prices 2013

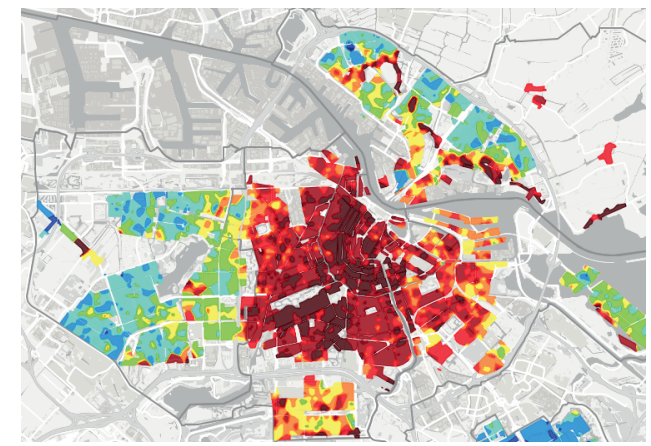

(b) Amsterdam house prices 2018

Notes: Source: Municipality of Amsterdam. Maps are for illustration of spatial heterogeneous price developments. 2013 is considered as the trough of the housing crisis, showing the lowest prices. Detailed price information are not reported but can be retrieved via: https://maps . amsterdam.nl/woningwaarde/?LANG=nl

Beyond providing insight into within-country trends, residential real estate markets also give a micro-level perspective on the value of individual locations. After all, according to a well-known saying, real estate prices are determined by "location, location, 
location". However, neighborhoods changes constantly and so does their location values. House price differences and changes in differences over time can provide valuable insights into location demand, potentially affecting housing affordability and mobility. As an illustration, Figure 1.2 shows two heatmaps of house prices in Amsterdam 5 years apart (dark red $=$ expensive, dark blue $=$ cheap). We can see that prices have not increased equally over time. Initially expensive areas, such as the center, became even more expensive, excluding low-income households and reducing labor mobility. In contrast, the western outskirts, initially lower priced, experienced moderate price increases, increasing inequality. Some price changes are intended by design, they are stimulated by locationbased policies such as gentrification. However, other changes are unintended, for example caused by the addition or removal of local amenities.

This thesis aims to shed light on housing price differences at the micro level to better understand what determines the value of "location". Especially sites that cause strong external effects, such as a manufacturing facility, shape surrounding location values in complex ways: A factory offers employment, while it might also cause noise and air pollution. Policy makers often struggle to understand the net-effects (combined effects) of externalities on location values, leading to short-sighted decision making. Systematic placements are not uncommon and can have significant effects on house price differences and income inequality: e.g. factories may be located systematically near lower-valued areas to stimulate employment, neglecting negative external effects. In this thesis, I examine the external effects of different sources of externailites on property prices, trying to better understand socio-economic effects. Due to potential systematic placements there might be issues of reversed causality (endogeneity). I address these issues with different methodologies used throughout the chapters of this thesis.

I focus on policy relevant topics, such as schooling, energy production and cannabis legalization, in the context of residential real estate markets: How do nearby facilities affect house prices? In the view of policy makers, house prices often play a secondary role when it comes to placement decisions. However, house prices offer a measure for the indirect costs and benefits of these amenities / disamenities. In contrast, estimating indirect costs and benefits otherwise, usually requires several assumptions; e.g. how do we quantify the cost of electricity production on society? As houses price data are usually the biggest limitation in the approach, my last Chapter deals with the question, how we can use modern technology to overcome data limitations.

The thesis is structured as following: Chapter 1 introduces the theoretical framework and limitations of the applied approach. Chapters 2, 3, and 4 examine the external effect of different sources, some heavily affected by policy interventions. I hereby improve from Chapter to Chapter on the methodology, illustrating the importance of the research design. Focusing on current limitations and looking ahead, Chapter 5 presents a new methodology to overcome current limitations and improve future studies in this field.

\subsection{Externalities in the Housing Market}

Residential real estate prices can be used to measure peoples' preferences, using the hedonic property pricing framework (Rosen, 1974). As illustrated in equation 1.1 below, property prices are determined by a function of structural $s$, neighborhood $n$, and environmental $e$ characteristics. Structural characteristics are property-specific while neigh- 
borhood and environmental characteristics are tied to location. By controlling for some characteristics, such as structural and neighborhood, it is possible to measure the effect of another characteristic - such as the environment - on housing prices.

$$
p_{i t}=f(s, n, e)
$$

As this model suggests, location values are determined by neighborhood characteristics, such as income, safety, and race, and by environmental characteristics, such as amenities and disamenities. Unfortunately, amenities and disamenities can often not be identified as such, as external effects on the neighborhood are often multilayered and human preferences are heterogeneous. For example, the presence of a playground might be considered an amenity for some people, while others perceive it as a source of nuisance. Since it is practically impossible to determine and measure all possible external effects, the more common approach is to use distance to the potential externality source, providing an unbiased view.

In Chapter 2, I examine the effect of proximity to primary schools on house prices, whilst controlling for school quality. Young families would tend to benefit from a short commute to schools. However, schools also can be a source of nuisance in their close surrounding, causing additional traffic and playing kids. Previous studies have examined school quality effects, showing that houses within school districts of high quality schools sell at a premium (e.g. Black, 1999; Gibbons et al., 2013). Contrary to many other countries there are no school districts in the Netherlands so parents are free to send their children to any school, eliminating, to some extent, the positive external effect of school districts on house prices.

The analysis shows that in the Netherlands high quality schools do not affect nearby housing prices positively, implying that people are not willing to pay more for living in proximity to better primary schools if they are free to choose. A very close proximity to schools results in negative property price effects, potentially caused by noise and traffic. The results suggest that people prefer not to live too close to schools, but are indifferent about their locations with respect to schools thereafter.

Examining the price effects of external factors on the housing market may be even more important for more controversial sources of externalities, such as power plants. Policy makers often overlook the local external consequences of their interventions while policy decisions, such as expanding on wind energy by building more wind turbines, might affect location values and consequently real estate prices.

In Chapter 3 I delve into the negative perceptions of the Dutch population against wind turbines, a classical NIMBY (Not In My Back Yard) problem. ${ }^{1}$ Energy production is unavoidable, and I compare the external effects of coal, gas, biomass and wind power production facilities on residential property prices.

This chapter focuses on the response of adding or removing such controversial sources of externalities. I can not use a hedonic pricing model since placement decisions can not be assumed to be completely random and a hedonic pricing model cannot capture changes

\footnotetext{
${ }^{1}$ In a NIMBY problem, the population is generally supporting a policy decision as long as they are not affected personally by it, such as building new telecommunication towers to improve mobile internet, but not building them nearby to avoid radiation or a restraint view.
} 
over time. To capture the effect of changes and control for ex-ante price effects, I use a difference-in-difference model for areas and a repeated sales model. I study the external effects of large-scale power generation facilities on local house prices and analyze data of all power plants and wind turbines in the Netherlands, combining it with house price data from 2.3 million housing transactions over 30 years.

The results indicate negative external price effects for gas plants and wind turbines, but positive effects for biomass plants, conditional on ex-ante lower priced locations. The results underline the complexity of externalities: in contrast to most conventional power plants, wind turbines are not necessarily placed in ex-ante lower priced areas, as the main determined for production is wind. Furthermore, wind turbines do not share the same positive local economic effects as conventional plants, such as job creation and infrastructure investments. Therefore, local residents do not gain from nearby wind turbines, creating strong local opposition. A potential solution for overcoming local opposition could be increased local project involvement (Loring, 2007).

Chapter 4 focuses on an even more controversial topic; "coffeeshops", i.e. Dutch cannabis sales facilities. I examine the external effect of proximity to these "coffeeshops" on property values. The legalization of cannabis is a hotly contested policy topic worldwide, and lacking reliable data on the societal costs. When examining this question, most studies focus on the direct effects for users and sellers, but less on the indirect effects on third parties. I examine the effect of cannabis dispensaries on local property prices, focusing on the three biggest Dutch cities, Amsterdam, Rotterdam and The Hague.

Due to the high probability of endogenous placement decisions, I employ a differencein-difference analysis around an exogenous closing shock to see the causal effect of the closure of the coffeeshop over time. As of 2012, the Dutch government recommended to close all coffeeshops within the vicinity of schools (within $250 \mathrm{~m}$ ) as teenagers should not be exposed to cannabis sales. The decision did not consider the previous relationship between coffeeshops and their neighborhoods, neglecting potential affects on housing markets. As different cities implemented the policy at different moments in time, the setup provides an exogenous shock unaffected by confounding time effects.

The results are intuitively surprising but in line with the existing literature. Compared to properties near to coffeeshops, I document negative price effects for properties nearby closing coffeeshops. The negative closing effects increase with closeness to coffeeshops and are robust to various entertainment venues nearby, such as bars and nightclubs. My findings show that contrary to the common perception, the closing of Dutch cannabis sales facilities had a negative effect on property values nearby.

In summary, these chapters aim to contest common beliefs. It is shown that in the absence of school boundaries, school quality is not priced in property values, energy production is not equal in perception, and peoples' attitudes towards living close to cannabis sales are not necessarily detrimental to the value of their homes. For many of the analyzed sources, pinning down and quantifying external effects is practically impossible using traditional data sources. However, as people "vote with their feet", housing markets provide a measure to quantify the combined external effects. Policy makers can learn from these findings, as they reflect the price responses to policy interventions. Ultimately, the hidden costs and benefits of policy interventions are revealed through real estate markets, helping to understand the full consequences of future interventions. 


\subsection{Overcoming Data Limitations}

Examining external effects in the housing market seems a straight-forward task. However, there is a key impediment for a proper understanding, namely: asymmetric information.

Residential property markets are characterized by information asymmetries. Since every house is different, real estate is an heterogeneous asset, requiring valuation on a case-by-case base. Additionally, markets are different (heterogeneous), requiring local knowledge to understand local market dynamics. Therefore real estate agents exist as local intermediaries, having a better feeling for property prices and evidentially reaching higher prices (Levitt \& Syverson, 2008). As a consequences of information asymmetries, Case and Shiller (1989) show in a seminal paper in the field that real estate markets are less efficient than other asset markets. Transactions are characterized by higher transaction costs due to intermediaries and arbitrage opportunities exist, increasing the risk of mispricing (Quigley, 2002).

Data limitations are an important driver of asymmetric information. Characteristically, real estate is an asset that people tend not to transact in too frequently, hence taking long times to observe repeated sales. People do not move frequently, further limiting transactions. Additionally, property transactions are usually private, complicating our ability to observe transaction prices even further. However, to cleanly analyze the effect of hedonic characteristics, such as externality effects, it would be necessary to control properly for other characteristics, requiring sufficient information to be available. Data limitations can therefore be considered as a major bottleneck when using hedonic property pricing models.

Policy makers are similarly affected by limited information, especially on a microlevel. Even though many governments publicly provide transaction prices via land registries, the information is often limited to a minimum, such as the transaction price, date, and basic data on the structure of the dwelling. As a result, it is often not possible to use hedonic property pricing models to understand property prices. Instead, price assessments, such as for property tax purposes, are carried out by costly intermediaries, such as tax assessors in the US. Avoiding intermediaries, German policy makers assess property taxes based on historic valuations from 1964 and are currently uncertain how to update valuations for an upcoming reform. ${ }^{2}$

To address these concerns, in Chapter 5 I present a new method to collect property data, using machine learning. Recently, machine learning is entering research in various disciplines. It can offer support in finding hidden data patterns or to automate tedious tasks. A popular machine learning technique is computer vision, making computers understand digital image content. Computer vision is already successfully used in autonomous driving and to detect skin cancer based on images (Esteva et al., 2017). With the increasing availability of urban images, computer vision could also be used to overcome property data limitations, potentially reducing asymmetric information. Figure 1.3 illustrates the global coverage of Google Street View, a dataprovider for street scene images.

Using such techniques, I present a new approach to collect structural real estate data from property images. I develop a model using object detection, which is able to collect

\footnotetext{
${ }^{2}$ https://bit.ly/2KiTzqh
} 
property characteristics based on Google Street View images. At a preliminary stage the model already shows a decent accuracy. The model is trained to detect simple property characteristics on images, such as windows, facades and roofs and outperforms simpler models in robustness to confounding factors. Through the relative location and size of objects, researchers can approximate multiple property characteristics as I demonstrate in two simple examples, in this chapter.

This study shows that property data can be collected based on location and images only, independently of institutional constraints. The approach could be used more widespread to collect new property aspects in a cost-efficient manner, such as the share of solar panels or exterior maintenance quality. Furthermore, the approach could also help to complement structural databases, reducing estimation errors in hedonic property pricing models. Lastly, the approach could be used to study property markets in foreign countries, such as in developing countries, without the need to travel.

Figure 1.3

Google Street View Coverage (blue) 2018

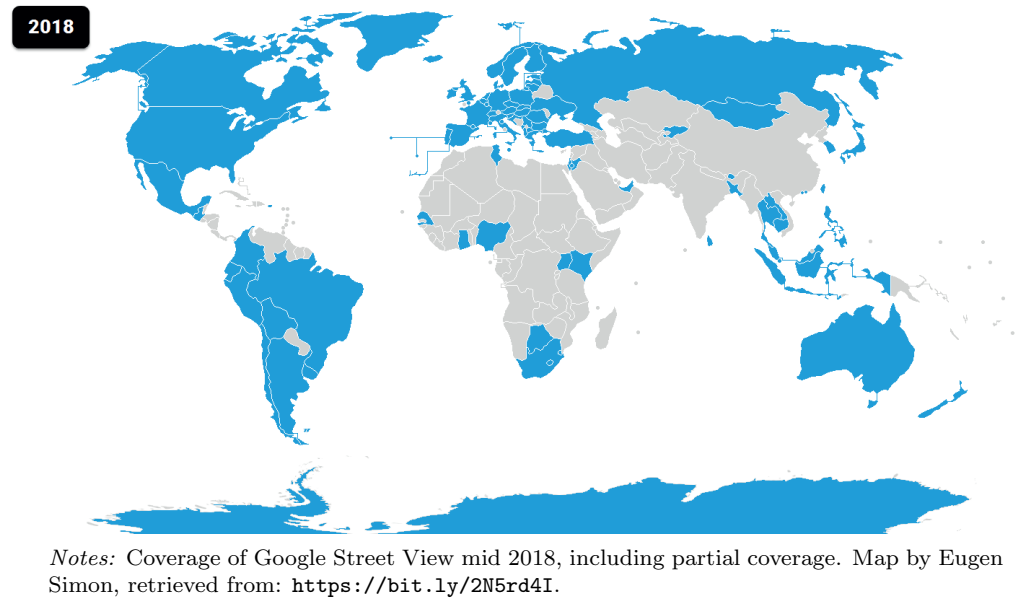




\section{Chapter 2}

\section{Schools without boundaries: Externalities of good and bad primary schools in free school choice systems.*}

\section{$2.1 \quad$ Introduction}

There is strong evidence that schools have a substantial influence on peoples' housing choices. Schools usually only accept pupils living within a school's predefined catchment area, forcing parents to move into the boundaries of catchment areas if they want to send their children to specific schools. Children living outside catchment areas are required to attend different schools. This construct creates a demand for locations relative to schools, potentially affecting housing prices. Empirical evidence shows that people are willing to pay up to $7.2 \%$ more for homes in catchment areas of high quality schools (Bayer et al., 2007; Clapp et al., 2008; Fack \& Grenet, 2010).

The question arises, whether school proximity loses its value, once catchment areas are non-existing and it is interesting to understand the effect of school proximity without the need to have to control fro catchment area. It could be argued that parents still value proximity to schools, as it limits daily commuting times. However, parents might not be willing to pay as much for school proximity. People may even dislike living very close to a school, due to potential negative externalities caused by noise and increased traffic during peak hours.

In this study, we investigate peoples ${ }^{6}$ willingness to pay for school proximity in a free school choice system. Primary schools in the Netherlands do not have catchment areas, giving parents the freedom to choose any school they want for their children, independent of their home location. Using a national dataset of Dutch residential property transactions over a ten-year period, we examine house price differences in the vicinity to primary schools, controlling for their relative location to the school. We employ a hedonic property pricing framework and differentiate for school quality, using the annual results of standardized educational tests.

We focus on the Netherlands due to the Dutch educational system, which enables parents to send their children to any chosen school, and not necessarily the nearest. Due to the availability of large-scale data, we can control for unobserved heterogeneity using spatial fixed effects on neighborhood level (Kuminoff et al., 2010). The whole of the Netherlands is centrally classified by the Central Statistics Bureau of the Netherlands (CBS) into unique neighborhoods following the principle that neighborhoods are generally homogenous in income levels, employment, crime rates, age composition, and other unobserved characteristics.

According to a recent report by the OECD, Dutch schools enjoy a high degree of autonomy, and are granted "freedom of education" that gives any natural or legal person

*This chapter is co-authored with Lex Borghans (Maastricht University), Olga Meshcheriakova (Maastricht University) and Juan F. Palacios Temprano (Maastricht University). 
the right to set up a school and implement the appropriate teaching method (Nusche et al., 2014). ${ }^{2}$ As stated earlier, parents are not legally bound to send their children to the closest school and it is feasible not to do so, given the coverage of schools.

Our results show that in a free school choice setup there is no effect of distance to schools on housing prices for an average or even for top performing schools. Our finding suggests that distance to average and best performing schools does not affect local housing prices. However, for worst performing schools we find a discount of up to 1.6 percent for houses within $200 \mathrm{~m}$, which means that negative externalities of worst performing schools affect nearby housing prices.

The paper relates to the literature on effects of school quality on housing prices. Treating schools as a local public good (Bayer et al., 2004; Tiebout, 1956) and using housing prices to measure individuals' willingness to pay for these goods, many papers conclude that in catchment zones with a better school residential real estate prices are higher (Bayer et al., 2007; Black, 1999; Fack \& Grenet, 2010). At the same time analogous to classical public goods, schools produce local externalities. Existing literature suggests that these externalities are higher closer to schools and fade out with distance (Emerson, 1972; Sah et al., 2016). To our knowledge, all existing studies explore school catchment area settings. This is the first paper exploring the willingness-to-pay for schooling without school catchment areas. We show that in such a setting, negative local external effects dominate.

\subsection{Literature Review}

School boundary systems divide spatial areas into different school districts. A prime example is the U.S., where residents of a school district are only allowed to send their children to public schools in the corresponding district. If parents want to send their children to specific schools, they must move to the respective district. To examine the willingness-to-pay (WTP) for schooling, Black (1999) first introduced a boundary discontinuity approach (BDA), comparing house prices on both sides of contiguous district boundaries. Under the key assumption that houses only differ in school districts, the price difference between houses should only be driven by school characteristics. (Bayer et al., 2007; Fack \& Grenet, 2010). Black (1999) finds that "parents are willing to pay 2.5 percent more for a 5 percent increase in school test scores."

As the key assumption of Black (1999) is quite strong, different studies examine the heterogeneity of the results. Fack and Grenet (2010) develop a matching framework for neighborhood characteristics, documenting a 1.4 to 2.4 percent increase in prices for one standard deviations increase in performance. Hwang et al. (2019) use a finite mixture model to examine preference heterogeneity of households with different socio-economic status, documenting that higher-income households value education more. Gabriel et al. (2016) show that school quality effects differ throughout housing cycles, but that good schools lead to a robust price premium on average. Kane et al. (2006) and ZahirovicHerbert and Turnbull (2009) examine the change of school district boundaries as the basis of a natural experiment approach, documenting that school improvements are priced while reassignments are not priced (Zahirovic-Herbert \& Turnbull, 2009). Overall, empirical

\footnotetext{
${ }^{2}$ This freedom is complemented with a high-quality monitoring system that guarantees the schools meet the standard of quality and provide the knowledge considered appropriate by the central government.
} 
findings show that there is a significant positive relationship between school quality and housing prices increasing by below 4 percent for one-standard deviation increase in quality (Nguyen-Hoang \& Yinger, 2011).

Since BDA identification takes place at school district boundaries, most studies do not address price differences as a function of distance to schools. While school benefits, such as access to education, are the same for all houses in the district, costs are not equally distributed. The presence of externalities such as noise, generate heterogeneity in the (non-monetary) costs of schools over the district (Sah et al., 2016). ${ }^{3}$ Another factor is commuting times, which are longer for parents living at the district boundaries. The net benefits of schools should therefore not be equally distributed within districts.

Sah et al. (2016) adopted a theoretical framework set up by Li and Brown (1980) to model four potential price net effect scenarios of schools over distance. All scenarios show an inverted U-shaped curve for the net-effects of schools on housing prices over distance, indicating that an optimal location is not too close nor too far from the school. However, the different scenarios suggest different findings within close proximity of schools, where potential local external effects are strongest, ranging from a smaller premium to a discount, relative to the district boundary. Sah et al. (2016) document a significant proximity discount of between 6.7 to 14.4 percent for homes within 500 feet $(151 \mathrm{~m})$ of public and private elementary schools, respectively. However, the authors do not control for school quality, which might explain the difference in findings. Other studies find evidence for a positive net-effect scenario, indicating rather a schooling premium. However, these studies use less sophisticated spatial fixed-effects or smaller datasets (Chin \& Foong, 2006; Rosiers et al., 2001; Owusu-Edusei et al., 2007).

We contribute to the current literature by focusing on the effect of school quality on housing prices in a setting without the existence of school districts, theoretically allowing parents to send their children to any school. We use an extensive, national dataset of residential housing transactions and primary schools. Our data contain information on almost all Dutch primary schools and around 950,000 housing transactions between 2007 - 2016, reflecting 75 percent of the Dutch market, including an abundance of control variables. We consider school quality, using the results of the standardized test score CITO, which is a national test and which all children are required to take, subsequently affecting the available secondary education choice.

\subsection{Economic Framework}

Similar to previous studies, we assume that access to schools and the quality of schools is part of the pricing function of houses. This process is modeled in equation 2.1, where $Z$ represents a vector of other, price-determining factors. We expect that, similarly as in boundary settings, people in a free school choice setup value schools of different quality differently. Schools grant access to education, and when deciding where to send their children, parents value better schools more (Borghans et al., 2015).

$$
p=f(Z, \text { school, school quality })
$$

\footnotetext{
${ }^{3}$ This framework was firstly introduced by Li and Brown (1980) and has been widely use to value a lot of public and non-marketed goods (e.g. air pollution/quality).
} 
To illustrate the process of valuing school access, we model a simple utility function for parents. We assume a simple utility function for schooling of individual parent household $i$ as shown in equation 2.2. The utility of schooling is modeled as a function of three parts, the quality of school $q_{i j}$, the exposure to negative school externalities measured by $\alpha$, and the cost of commuting $\gamma$, where the latter two are dependent on school distance $x$ to school $j$.

$$
u_{i}=q_{i j}-\alpha_{i j} \frac{1}{x_{j}}-\gamma_{i} x_{j}
$$

In a school district setting, it can also be expected that utility $u_{i}$ is negatively affected by the higher housing costs in the corresponding district of school $j$, as shown in equation 2.3. Black (1999) and others in the BDA setting focus on the magnitude of $\beta_{i}$, the willingness to pay for higher education. ${ }^{4}$ However, in a setting without school districts, parent households have a larger choice set as they do not have to locate themselves in any district. As illustrated in equation 2.2, the utility of schooling is therefore not affected by districts, but only by the trade-off between commuting costs and negative external effects.

$$
u_{i}=q_{i j}-\alpha_{i j} \frac{1}{x_{j}}-\gamma_{i} x_{j}-\beta_{i} d_{j}\left(q_{j}\right)
$$

It can be assumed that commuting costs are not dependent on school quality. ${ }^{5}$ School choice is rather a tradeoff between school quality and commuting costs. However, the question arises whether local external effects of schools are dependent on quality. Schools produce negative externalities, such as noise or increased traffic during peak hours, and it is assumed that exposure to those externalities decreases with distance. In addition, low quality schools might produce even worse external effects, such as from troublesome children, gathering in the evening. We therefore extend the utility model as illustrated in equation 2.4, where schooling utility is dependent on some function, describing the interaction of exposure to external effects and quality.

$$
u_{i}=q_{i j}-f\left(\alpha_{i j} q_{j}\right) \frac{1}{x_{j}}-\gamma_{i} x_{j}
$$

In our analysis, we focus on the optimal school distance $x$ for different levels of school quality. We expect that commuting costs are linearly increasing with distance. The closer parents live next schools, the less time they must spend bringing their children or children have to walk / bike. If parents prefer to save traveling time or want to minimize the commuting risk of their children, they will chose a house nearby a school. We do not assume commuting cost to be varying with school quality.

To get an idea of how big the premium could be, we perform an back of the envelope calculation using the average alternative costs of time parents would spend traveling to school per year in the Netherlands. The estimation is based on the average salary and

\footnotetext{
${ }^{4}$ We do not specify a functional form for the willingness to pay for higher education in the BDA setup.

${ }^{5}$ Especially in the Netherlands where most children cycle to school. Hence, it is unlikely for distance to play a major role. However, the closer families live to school, the less risky it is for children to cycle safely to school.
} 
number of children per family in 2015, the latest available information from the StatLine database of the CBS. ${ }^{6}$ Taking 4 minutes as an average time needed to bike $1 \mathrm{~km}$ as a benchmark, we calculate total traveling time of 2 return trips to school per day $(4 \mathrm{~km} *$ 4 minutes $* 20$ days $* 10$ months) to be 3,200 minutes or 53.3 hours per year. Multiplying it by the average hourly wage gives 949 Euros of alternative costs of traveling to school $1 \mathrm{~km}$ away per year. Taking into account that in the Netherlands parents bring their children to school for approximately first 4 years of school and that average number of children per family is 1.66 , we get an upper bound (if children have at least 4 year age gap) estimate of a best performing school premium of 6,299 Euros. ${ }^{7}$ This means that, all other characteristics equal, an average house (see Table 2.1) $1 \mathrm{~km}$ closer to a best performing school is expected to be $2.4 \%$ more expensive (3.2\% for an average apartment). Consequently, a rough estimate of the slope of the regression line from regressing house price on distance to best performing school is approximately - 0.026 (weighted average of the price premiums calculated above).

\subsection{Empirical Strategy}

We use linear distances as a proxy to measure the exposure to nearby primary schools. To calculate linear distances, we first use Bing Maps through an Application Programming Interface (API) in order to determine geographical coordinates (longitude and latitude) for addresses of each housing transaction and each school. Then, we calculate linear distances between each house and each school. Employing a hedonic property pricing model, we follow Rosen (1974) to decompose house price into the marginal willingness to pay for available house characteristics and nearby amenities in the equilibrium. Here, we are interested in the relationship between distance to the nearest school and residential real estate prices.

It has been shown that linear specifications in hedonic pricing regressions outperform other more flexible specifications in case of omitted variables (Cropper et al., 1988). Therefore, in this paper we estimate simple log-linear specifications. However, this does not per se solve an omitted variable bias, which is a widely-recognized problem with hedonic analysis (Abbott \& Klaiber, 2011; Black, 1999; Heintzelman \& Tuttle, 2012a). In our case it would arise because of unobserved neighborhood characteristics that are likely to be correlated with school quality. For example, school quality can be correlated with average income of the neighborhood, either because of sorting or higher available resources. However, controlling only for an average income level is not enough, since there could be more unobserved or difficult-to-measure neighborhood characteristics. A way to deal with this problem is to employ spatial fixed effects model. The main challenge with this method is that spatial fixed effects should be applied at the same geographical scale as the suspected unobserved heterogeneity (Abbott \& Klaiber, 2011).

As mentioned in the data section, in the Netherlands neighborhoods are defined at the level of a small residential unit of a few streets with access to main amenities within its borders. Therefore, we expect each neighborhood to be homogeneous in their unobserved characteristics. Segregation is quite unlikely, since our sample is restricted to residential areas, which are small and densely populated. Consequently, applying spatial fixed effects

\footnotetext{
${ }^{6}$ Statistics from CBS StatLine: http://statline.cbs.nl/

${ }^{7}$ Centraal Bureau voor de Statistiek, 2015: http://statline.cbs.nl.
} 
at the neighborhood level, we exploit variation in distances to school for houses within one neighborhood, holding all other characteristics constant.

We start by assuming that the relationship between distance to school and prices is linear, and later we relax this assumption to allow for nonlinear non-monotonic relationship.

As a baseline model, we use the classic hedonic property pricing model by Rosen (1974). It describes property prices as a function of structural, environmental, and neighborhood aspects of the property and the surrounding area, reflected in equation 2.5:

$$
y_{i}=\beta_{0}+s_{i} \beta_{1}+n_{i} \beta_{2}+\beta_{31} \text { distSchool }_{i}+e_{i} \beta_{3}+T \beta_{4}+\epsilon_{i}
$$

where $y_{i}$ is the natural logarithm of the price of property $i, s_{i}$ is a $1 \times \mathrm{KK}$ vector of structural variables, $n_{i}$ is a $1 \mathrm{xG}$ vector of neighborhood variables (including spatial fixed effects at neighborhood level), and $e_{i}$ is a $1 \mathrm{xZ}$ vector of environmental variables. $T$ is the time fixed effect, a $\mathrm{t} x 1$ vector of year dummies, and $\epsilon_{i}$ is the standard error.

The element we are mostly interested in, distance to school distSchool, , is included as the distance from property to the nearest school in kilometers. Here we calculate linear distances between schools and houses using geographical coordinates of each school and each housing transaction.

As mentioned in Section 3.2, we use the average CITO exit test score per school as a proxy for school quality. The CITO test is taken by all students in the final year and outcomes determine secondary school choices. We define 'best' $\left(S Q_{b i}\right)$ and 'worst' $\left(S Q_{w i}\right)$ performing schools based on their position in the yearly average normalized CITO exit test score distribution, considering the schools within the upper quartile as best and the ones from the lower quartile as worst performing. To account for outliers (e.g. due to very bad or very good years), we also use the three year average CITO exit test scores and its distribution. We include school quality into our regression by interacting the dummies with the distance to school variable as indicated in equation 2.6.

$$
\begin{array}{r}
y_{i}=\beta_{0}+s_{i} \beta_{1}+n_{i} \beta_{2}+e_{i} \beta_{3}+\beta_{31} \text { distSchool }_{i}+\beta_{32} S Q_{b i}+\beta_{33} S Q_{w i}+ \\
\beta_{34}\left(\text { distSchool }_{i} * S Q_{b i}\right)+\beta_{35}\left(\text { distSchool }_{i} * S Q_{w i}\right)+T \beta_{4}+\epsilon_{i}
\end{array}
$$

However, as mentioned before, we suspect that the relationship between house price and distance to a worst performing school is nonlinear. To test this assumption and to capture the form of the relationship more precisely for both best and worst performing schools, we do not impose any requirements on the form of our regression and use distance interval dummies instead. We form 20 intervals of $50 \mathrm{~m}$ length up to $1.1 \mathrm{~km}$, while we reserve the first $100 \mathrm{~m}$ as a reference group (for each transaction at most one dummy is equal to one; e.g. if for a certain transaction distance to the nearest school is $460 \mathrm{~m}$, then the dummy "distance to nearest school between $450 \mathrm{~m}$ and $500 \mathrm{~m}$ " is equal to one). Based on school distance, observations are sorted into the respective intervals. The underlying model is shown in equation 2.7, where $\sum_{x=1}^{20} S_{\text {chool }}$ ri represents the sum of the 20 school proximity dummy variables, and $\sum_{x=1}^{20}\left(\operatorname{School}_{x i} * S Q_{* i}\right)$ represent the interactions of school quality and distance intervals for both the best $\left(S Q_{b i}\right)$ and the worst $\left(S Q_{w i}\right)$ performing schools: 


$$
\begin{gathered}
y_{i}=\beta_{0}+s_{i} \beta_{1}+n_{i} \beta_{2}+e_{i} \beta_{3}+\sum_{x=1}^{20} \beta_{x 1} \text { School }_{x i}+ \\
\sum_{x=1}^{20} \beta_{x 2}\left(\text { School }_{x i} * S Q_{b i}\right)+\sum_{x=1}^{20} \beta_{x 3}\left(\text { School }_{x i} * S Q_{w i}\right)+T \beta_{4}+\epsilon_{i}
\end{gathered}
$$

\subsection{Data}

We combine three datasets. First, we use a housing transactions dataset, containing detailed information on the characteristics of houses and some neighborhood information. Second, we obtained a complete neighborhood classification, which specifies for each house in the Netherlands to which neighborhood it belongs. Third, we have locations of nearly all Dutch primary schools, and average test scores per school per year, which is used as a proxy for school quality.

\subsubsection{Housing Data}

The residential housing transaction database that we use has been provided by the Dutch Association of Real Estate Agents NVM (Nederlandse Vereniging van Makelaars). Our data consist of 950,000 housing transactions between 2007 - 2016, accounting for $75 \%$ of all residential real estate sales in the Dutch market. We obtained information about apartment and houses for residential use. The dataset contains addresses, transaction prices, detailed information about characteristics of the house and some environmental information.

We have information about the following characteristics: house size, number of rooms, bathrooms, floors, availability of different amenities (parking lot, garden, roof terrace), type of house/flat, condition of interior/exterior, type of heating, level of isolation, construction periods and age of building, distance to highway, park, forest. To determine longitude and latitude information per address we use Bing Maps through an Application Programming Interface (API) to determine. We exclude repeated sales, outliers in terms of price (bottom and top 2 percentile of price distribution) and land size (top 1 percentile), and observations with incomplete information.

The transaction data are distributed evenly over space. Appendix Figure 2.3a shows a population density map of the Netherlands for year 2009. As one of the most densely populated metropolitan regions in central Europe, the three Randstad provinces of NoordHolland, Zuid-Holland and Utrecht account for $42 \%$ of all transactions in the database. Appendix Table 2.5 provides the percentage of inhabitants per province and the number of transactions per province for 2016, showing that house transactions are closely following the population distribution, with only Limburg showing less frequent sales.

\subsubsection{Neighborhood Controls}

Information about neighborhood classification is provided by the Central Statistics $\mathrm{Bu}-$ reau of the Netherlands CBS (Centraal Bureau voor de Statistiek). There are 13,141 neighborhoods at the end of 2017. Since neighborhoods borders are relatively stable over 
time, we assume that allocation of houses to neighborhoods is the same over the time span of our analysis. An advantage of this classification is that a neighborhood is narrowly defined as a complete geographical unit with its own infrastructure and including all main amenities (schools, supermarkets, playgrounds, etc.). Typically, one neighborhood includes a few streets, and therefore, its borders are defined territorially and not by postcodes.

For example, there are 486 neighborhoods in Amsterdam, out of which $78 \%$ are represented in our transaction data with up to 10 primary schools within $1.1 \mathrm{~km}$ from their borders (257 schools in total).

\subsubsection{School Data}

We collect a complete profile for each primary school in the Netherlands. The data, retrieved from the Dutch inspectorate of education (Onderwijsinspectie), include the exact location based on actual address and the computed geographical coordinates of each primary school. ${ }^{8}$ In our sample we have geographical and quality information on 7,770 school buildings between 2007 to 2016, allowing to calculate the linear distance between properties and schools. We have the average CITO exit test scores of most primary schools in the Netherlands between 2007 and 2016 and use it as a proxy for the output quality of schools.

Student performance in the Netherlands is assessed at the end of primary education (at the age of 11 or 12), by means of a compulsory standardized test, covering all subjects. Even though there exist different exit tests, the CITO exit test is the major test taken, adapted by approximately $80 \%$ of primary schools. The CITO exit test score therefore captures unobserved school characteristics correlated with school quality, such as teacher quality, peer quality and parental behavior (Black, 1999). ${ }^{9}$ The results of the test are a major determinant for the level of eligible secondary education. ${ }^{10}$

CITO test scores rank from 500 to 550 and secondary school cut-off scores vary yearly. On average, a score of 545 and higher will most likely allow students to enter the highest form of secondary education (VWO), while a score of at least 535 should lead to the second-highest form of secondary education (HAVO). The average CITO exit test score per final year per school is publicly accessible and used by many parents as an indicator of school performance. Based on their CITO score and the yearly national CITO average, children receive a ranking, relating their score into a performance. There are between 4 and 5 letter-based ranks (e.g. ranging from $\mathrm{A}$ to $\mathrm{E}$ ), with each rank representing 20 to $25 \%$ of the distribution. This rank is usually used as a reference in the secondary education advise. ${ }^{11}$

We use the average CITO exit test scores per year per school and sort them into quartiles. We consider the top 25 percent as best performing schools and the bottom 25 percent as worst performing schools. Translated in the ranking system, best performing

\footnotetext{
${ }^{8}$ See https://bit.1y/2KXонYB

${ }^{9}$ Responsible organization: CITO Eindtoets Basisonderwijs until 2015, and Centrale Eindtoets since 2015.

${ }^{10} \mathrm{~A}$ second factor is the teacher's advice. However, reports by the Dutch Inspectorate of Education indicate that CITO exit test scores are among the best predictors for children's secondary school level (The Dutch Inspectorate of Education, 2014)

${ }^{11}$ https://wij-leren.nl/cito-score.php
} 
schools have a yearly average CITO score in the highest ranks, while worst performing schools in the lowest ranks. Appendix Table 2.6 shows the average CITO exit test score per year in our sample, as well as the cut-off levels for "worst performing" (below Q1 cut-off) and "best performing" (above Q3 cut-off) schools.

\subsubsection{Descriptive Statistics}

In the analysis, we restrict the sample to houses within urbanized areas to make them comparable. By urbanized areas we mean houses with a nearest primary school within 1.1 $\mathrm{km}$. It seems plausible that for houses with a nearest school further away, other potentially unobserved characteristics affect price setting. Moreover, we only keep observations for which the average CITO exit test score of the nearest school is available. According to our data this is around $80 \%$ of all primary schools. Other schools use one of four other available tests. Those results are not comparable to the CITO exit test score, and therefore transactions for which the quality of the nearest school is unknown are excluded from the analysis. As a result, our sample reduces from approximately 950,000 observations to around 800,000 .

Table 2.1 shows the average characteristics of transactions in our sample. Two thirds of our sample consists of houses, which are on average larger than apartments, in terms of square meters $\left(\mathrm{m}^{2}\right)$, number of rooms and number of levels. In absolute prices, houses are more expensive than apartments. However, in terms of price per squared meter, apartments are more expensive. In terms of outside and inside quality, apartments and houses are rather similar. Table 2.1 also compares our analyzed sample (only with school of known quality) to the original sample. We argue that the used sample represents the initial one well, mitigating concerns of sample selection biases. The only noticeable difference is in apartment prices, with the ones in our sample being $0.6 \%$ more expensive than average in the original sample.

Appendix Figure 2.3b shows the average distance to the nearest primary school per municipality for 2009. The distance distribution is similar to the population distribution in Appendix Figure 2.3a. Furthermore, distances are very short on average, having a maximum average distance of $2.5 \mathrm{~km}$ in the most rural areas. In urban areas, the distance is around $375 \mathrm{~m}$ on average. Appendix Figure 2.4 shows that the average distance between houses and primary schools is rather constant over time, with a slight increase after 2013, which can be explained by an increased number of schools (buildings). 
Table 2.1

Descriptive Statistics - Data Representativeness

\begin{tabular}{|c|c|c|c|c|}
\hline \multirow[b]{2}{*}{ Observations } & \multicolumn{2}{|c|}{ Analyzed sample } & \multicolumn{2}{|c|}{ Original sample } \\
\hline & $\begin{array}{c}\text { Houses } \\
529,394 \\
\end{array}$ & $\begin{array}{c}\text { Apartments } \\
260,691\end{array}$ & $\begin{array}{l}\text { Houses } \\
568,856 \\
\end{array}$ & $\begin{array}{c}\text { Apartments } \\
282,867\end{array}$ \\
\hline Size & 131 & 85 & 131 & 85 \\
\hline (in $\mathrm{m}^{2}$ ) & {$[41]$} & {$[27]$} & {$[41]$} & {$[27]$} \\
\hline Floors & 2.8 & 1.3 & 2.8 & 1.3 \\
\hline (number) & {$[0.6]$} & {$[0.5]$} & {$[0.6]$} & {$[0.6]$} \\
\hline Rooms & 5 & 3.2 & 5 & 3.2 \\
\hline (number) & {$[1.3]$} & {$[1.0]$} & {$[1.3]$} & {$[1.0]$} \\
\hline Price & 264,845 & 199,762 & 265,010 & 198,647 \\
\hline (in Euro) & {$[152,160]$} & {$[116,785]$} & {$[152,578]$} & {$[115,740]$} \\
\hline Price per $\mathrm{m}^{2}$ & 1,987 & 2,369 & 1,991 & 2,351 \\
\hline (in Euro) & {$[699]$} & {$[1,020]$} & {$[701]$} & {$[1,006]$} \\
\hline Housing inside quality & 3.1 & 2.9 & 3.1 & 2.9 \\
\hline$(1=$ worst, $9=$ best $)$ & {$[1.1]$} & {$[1.1]$} & [1.1] & {$[1.1]$} \\
\hline Housing outside quality & 3 & 2.8 & 3 & 2.8 \\
\hline$(1=$ worst, $9=$ best $)$ & {$[1.0]$} & {$[0.8]$} & {$[1.0]$} & {$[0.8]$} \\
\hline
\end{tabular}

Notes: Source: own analysis. Reported numbers are mean values, standard deviation in brackets. Comparison of the sample including only houses with nearest school of known quality (analyzed sample) and the full original sample with all transactions in residential areas.

\subsection{Results}

\subsubsection{Baseline Hedonic Regression}

In order to estimate the price effect of proximity to schools, we first run a baseline hedonic regression with only control variables. Appendix Table 2.7 shows the estimation results of our baseline hedonic regression without accounting for distance to school. Overall, the results are in line with previous studies (e.g. see Brounen \& Kok, 2011; Dröes \& Koster, 2016). An increase in size of the property with $1 \mathrm{~m}^{2}$, leads to 0.7 percent price increase, while an additional room increases the price by 1.6 percent and an additional bathroom by 1.8 percent. The effects of different construction periods are heterogeneous, with only relatively new houses (built after 1980) increasing the price. Different amenities also increase the price, such as a 3.0 percent for a roof terrace, 6.2 percent for a parking lot, and 7.2 percent for a good garden. Proximity to a park is also valued $(-1.4 \%$ per $\mathrm{km})$.

Using this regression estimate, we predict the property prices based on the controls to see whether there are any differences in house prices over distance to the nearest school, without estimating the effect of distance itself. Appendix Figure 2.5a shows the mean predicted transaction price for each $50 \mathrm{~m}$ interval between 0 and $1.1 \mathrm{~km}$ of distance to school. We see that houses farther away from schools are more expensive, and we need to identify which characteristics can explain the difference in prices. We look at the relationship between different house characteristics from the baseline hedonic regression and distance to school. Appendix Figure 2.5b is constructed the same way as Appendix Figure 2.5a and shows that size of the property exhibits the same pattern as the predicted price, which means that houses farther away from schools are bigger on average. We 
also notice that they on average have more bathrooms and are more likely to be (semi) detached. Consequently, we conclude that buildings differ significantly in observed characteristics over distance to school, and therefore it is important that we control for them in our analysis.

\subsubsection{Estimation Results}

Tables 2.2 and 2.3 show the results of the hedonic model estimation including school information. In Table 2.2 we report results of estimating different specifications of equation (1). Here the variable of interest is linear distance to school. We start by having only basic control variables, construction periods, time and spatial fixed effects in column (1) and add more controls, such as type of house/apartment, maintenance condition, type of heating and isolation, and environmental controls (more detail in Appendix Table 2.7. The distance to school effect is $1.5 \%$ per $\mathrm{km}$ in the initial specification in column (1), but falls to $1.1 \%$ once we add more controls and stays constant up to the final specification (column 4).

The magnitude of the effect (taking $1 \mathrm{~km}$ distance as an example) is approximately similar to having an additional room or a bathroom, while having a roof terrace or a parking lot seems more attractive (3.0 and 6.2 percent respectively). In other words, there is a discount for living next to a school building, with real estate prices increasing with distance to school. For an average house next to a school building it will imply a 2,913 Euro discount and for an average apartment a 2,197 Euro discount compared to the same house at $1 \mathrm{~km}$ distance from a school.

Next, we add school quality to the model and report the results of estimating different specifications of the regression (2) in Table 2.3. The coefficients of the control variables are barely affected, while the effect of distance to school decreases to 0.6 percent in the full specification (column 4). This occurs because here we look at effects of different school qualities separately, while in Table 2.2 the coefficient of distance to school is picking up an average effect of all school qualities. 
Table 2.2

Regression Outputs I - Distance to School and House Price

\begin{tabular}{|c|c|c|c|c|}
\hline & $(1)$ & $(2)$ & $(3)$ & $(4)$ \\
\hline Distance to school & $0.015^{* * *}$ & $0.011^{* * *}$ & $0.011 * * *$ & $0.011^{* * *}$ \\
\hline$(\mathrm{km})$ & {$[0.001]$} & {$[0.001]$} & {$[0.001]$} & {$[0.001]$} \\
\hline Size & $0.008^{* * *}$ & $0.007 * * *$ & $0.007 * * *$ & $0.007^{* * *}$ \\
\hline$(\mathrm{m} 2)$ & {$[0.000]$} & {$[0.000]$} & {$[0.000]$} & {$[0.000]$} \\
\hline Garden size & $0.001^{* * *}$ & $0.001^{* * *}$ & $0.001^{* * *}$ & $0.001^{* * *}$ \\
\hline$(\mathrm{m} 2)$ & {$[0.000]$} & {$[0.000]$} & {$[0.000]$} & {$[0.000]$} \\
\hline Rooms & $0.012^{* * *}$ & $0.013^{* * *}$ & $0.016^{* * *}$ & $0.016^{* * *}$ \\
\hline (n) & {$[0.000]$} & {$[0.000]$} & {$[0.000]$} & {$[0.000]$} \\
\hline Bathrooms & $0.027^{* * *}$ & $0.027^{* * *}$ & $0.018^{* * *}$ & $0.018^{* * *}$ \\
\hline (n) & {$[0.000]$} & {$[0.000]$} & {$[0.000]$} & {$[0.000]$} \\
\hline D: Parking lot & $0.084^{* * *}$ & $0.069^{* * *}$ & $0.062^{* * *}$ & $0.062^{* * *}$ \\
\hline$(1=$ yes $)$ & {$[0.001]$} & {$[0.001]$} & {$[0.001]$} & {$[0.001]$} \\
\hline D: Apartment & $-0.287^{* * *}$ & $-0.278^{* * *}$ & $-0.292^{* * *}$ & $-0.291 * * *$ \\
\hline$(1=$ yes $)$ & {$[0.002]$} & {$[0.002]$} & {$[0.002]$} & {$[0.002]$} \\
\hline D: Roof terrace & $0.033^{* * *}$ & $0.036^{* * *}$ & $0.030^{* * *}$ & $0.030^{* * *}$ \\
\hline$(1=$ yes $)$ & {$[0.001]$} & {$[0.001]$} & {$[0.001]$} & {$[0.001]$} \\
\hline Observations & 790,085 & 790,085 & 790,085 & 790,085 \\
\hline R-squared & 0.75 & 0.76 & 0.78 & 0.79 \\
\hline Time fixed-effects & Yes & Yes & Yes & Yes \\
\hline Location fixed-effects & Yes & Yes & Yes & Yes \\
\hline Construction periods & Yes & Yes & Yes & Yes \\
\hline House/apart. type controls & No & Yes & Yes & Yes \\
\hline Extended quality controls & No & No & Yes & Yes \\
\hline Environmental controls & No & No & No & Yes \\
\hline
\end{tabular}

Notes: Dependent variable: $\ln$ (price). Standard errors in brackets. $* * * \mathrm{p}<0.01, * * \mathrm{p}<0.05, * \mathrm{p}<0.1$. $\mathrm{D}=$ dummy. Basic controls include house and total land size, number of rooms, bathrooms, dummies for number of floors, new house, farm, parking, garden (incl. quality), roof terrace. Construction periods reported in Appendix Table 2.7. Extended quality controls include dummies for type of heating, isolation, and condition of property interior and exterior. Environmental controls include distance to highway, forest, park, and a dummy for busy street. Time FE by sales year. Spatial FE by neighborhood level. Base values: Number of floors: 1, Construction = Construction before 1944 , House and Apart. type = ground floor apt, Apart. quality = average, Garden quality: bad, Heating $=$ no heating.

Regarding our hypothesis concerning additional proximity effects of the best performing schools, we find a small additional premium. This slightly increases with distance and goes from almost 0 up to 0.5 percentage points for houses at $1 \mathrm{~km}$ distance. The magnitude of this result is similar to the effect of the distance to school variable and is negligibly small. Comparing to our rough estimate from Section 2.4, this premium is much smaller (around 13\% of the hypothetical compensation for traveling time), and the line is almost flat leading to the conclusion that our first hypothesis is not supported. Our documented effects are significantly smaller compared to those of studies using catchment areas (Clapp et al., 2008). We therefore argue that people do not value living next to a high-quality schools in a free school choice system. Later we remove the linearity restriction to examine the effect more precisely.

For low performing schools the relationship with distance is significant, and houses 
closer to a school building have an additional discount of 1.0 percentage point. For an average house next to a worst performing school it translates into a total discount of 4,237 Euros, and for an average apartment 3,196 Euros. The discount disappears after 650 meters, which is farther away than we expected. We examine this distance cut off in more detail, relax the linearity assumption below.

Since there could be changes in the average CITO exit test score distribution in consequent years, we use three years' averages instead of yearly CITO exit test score to get a more stable ranking (Table 2.3, column 5). We document that the coefficient of the distance to school is barely affected, while the total effect of quality for worst performing schools become stronger, as the magnitude of the discount increases, showing a long-term effect of 1.5 percentage points. Although we notice that the sample size decreases by 30 percent, since this information is not available for all school years, the distribution of distances to schools of different qualities stays the same.

Table 2.3

Regression Outputs II - School Quality and House Price

\begin{tabular}{lccccc}
\hline & $(1)$ & $(2)$ & $(3)$ & $(4)$ & $(5)$ \\
\hline & & & & & \\
Distance to school & $0.011^{* * *}$ & $0.006^{* * *}$ & $0.005^{* * *}$ & $0.006^{* * *}$ & $0.004^{* *}$ \\
$(\mathrm{~km})$ & {$[0.002]$} & {$[0.002]$} & {$[0.002]$} & {$[0.002]$} & {$[0.002]$} \\
D: Best school & 0.001 & 0.000 & 0.000 & 0.000 & 0.001 \\
$(1=$ Yes $)$ & {$[0.001]$} & {$[0.001]$} & {$[0.001]$} & {$[0.001]$} & {$[0.001]$} \\
D: Worst school & $-0.010^{* * *}$ & $-0.010^{* * *}$ & $-0.010^{* * *}$ & $-0.010^{* * *}$ & $-0.015^{* * *}$ \\
$(1=$ Yes) & {$[0.001]$} & {$[0.001]$} & {$[0.001]$} & {$[0.001]$} & {$[0.001]$} \\
Distance * Best school & 0.003 & $0.004^{*}$ & $0.005^{* *}$ & $0.005^{* *}$ & $0.006^{* *}$ \\
$(\mathrm{~km})$ & {$[0.002]$} & {$[0.002]$} & {$[0.002]$} & {$[0.002]$} & {$[0.003]$} \\
Distance * Worst school & $0.015^{* * *}$ & $0.016^{* * *}$ & $0.015^{* * *}$ & $0.015^{* * *}$ & $0.025^{* * *}$ \\
$(\mathrm{~km})$ & {$[0.002]$} & {$[0.002]$} & {$[0.002]$} & {$[0.002]$} & {$[0.003]$} \\
& & & & & \\
Observations & 790,085 & 790,085 & 790,085 & 790,085 & 557,998 \\
R-squared & 0.75 & 0.76 & 0.78 & 0.79 & 0.78 \\
Time fixed-effects & Yes & Yes & Yes & Yes & Yes \\
Location fixed-effects & Yes & Yes & Yes & Yes & Yes \\
Construction periods & Yes & Yes & Yes & Yes & Yes \\
House/apart. controls & No & Yes & Yes & Yes & Yes \\
Quality controls & No & No & Yes & Yes & Yes \\
Environmental controls & No & No & No & Yes & Yes \\
\hline
\end{tabular}

Notes: Dependent variable: $\ln$ (price). Standard errors in brackets. $* * * \mathrm{p}<0.01, * * \mathrm{p}<0.05, * \mathrm{p}<0.1 . \mathrm{D}=$ dummy. Dummies for best and worst performing schools correspond to upper amd lower quartiles of annual CITO end test score distribution. Column (5) reports uses 3 year average CITO end test score instead. Basic controls include house and total land size (up to the second power), number of rooms, bathrooms, dummies for number of floors, new house, farm, parking, garden (incl. quality), roof terrace. Construction periods reported in Appendix Table 2.7. Extended quality controls include dummies for type of heating, isolation, and condition of property interior and exterior. Environmental controls include distance to highway, forest, park, and a dummy for busy street. Time FE by sales year. Spatial FE by neighborhood level. Base values: Number of floors: 1, Construction = Construction before 1944, House and Apart. type = ground floor apt, Apart. quality $=$ average, Garden quality: bad, Heating $=$ no heating.

We relax the assumption of a linear relationship between distance to school and housing prices to examine changes in the slope over distance. Figures 2.1 and 2.2 show 
the results of the interval dummies specification from the estimation of equation 2.7. We use houses with the nearest school of average quality within first $100 \mathrm{~m}$ as a reference group. We see in Figure 2.1 that for average schools the distance does not make any difference for house prices, so people are indifferent as to how far the school is as long as there is a school within biking distance. Since the confidence interval is very small, we conclude that there is no effect of distance to school on house prices. Interestingly, there is no prominent evidence of positive or negative externalities for houses very close to a school building.

Figure 2.1

Nonlinear school proximity effect over distance

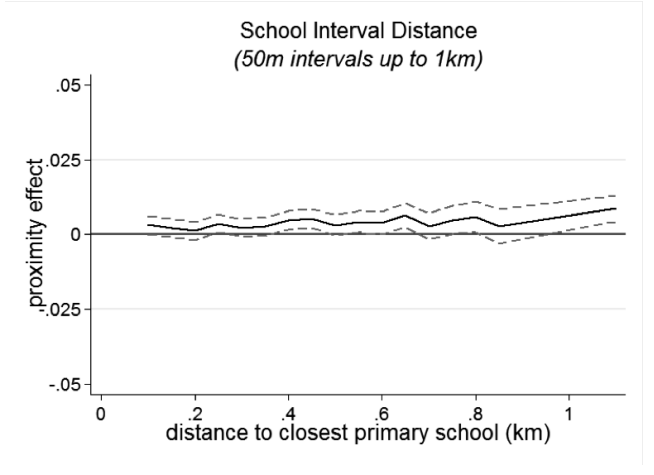

Notes: The graph represents exact relationship between house price and distance to school within each of 20 intervals of 50 $\mathrm{m}$ long between 0.1 and $1.1 \mathrm{~km}$, with first $0.1 \mathrm{~km}$ is a reference group.

Accounting for school quality, 2.2a shows the additional effect of interacting dummies for best performing schools with the distance dummies. We do not see any effect at any distance in this case, which implies that there is no additional effect of best performing schools. Figure 2.2b shows results of the estimation of the additional effect for worst performing schools. Similarly to the linear case, we find an additional discount for houses in the immediate proximity of worst performing schools, which ranges from 1.6 percentage points for houses next to the school building to 1 percentage point for houses $200 \mathrm{~m}$ away. For houses farther away the additional discount drops to zero, which supports our second hypothesis, since exposure to negative externalities is limited to houses within the first few hundred meters only.

Consequently, we reject our first hypothesis and conclude that people do not value living in the immediate proximity of best performing schools more than average ones. At the same time our second hypothesis is mildly supported, since we find a discount for houses within the first $200 \mathrm{~m}$ of worst performing schools, which must imply that those schools create bigger negative externalities (for example, loitering children or adverse parental behavior). 


\title{
Figure 2.2
}

Additional quality effects for best and worst performing schools

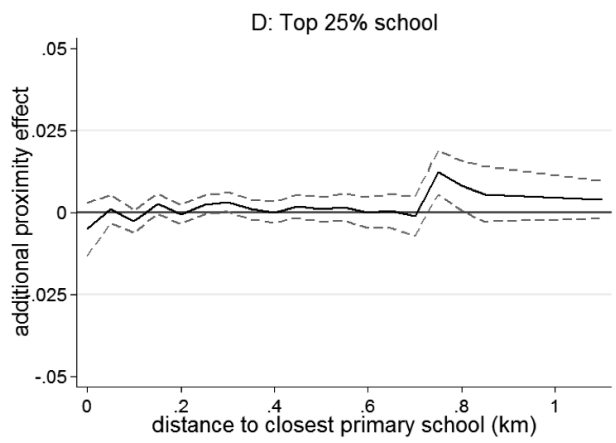

(a) Top $25 \%$

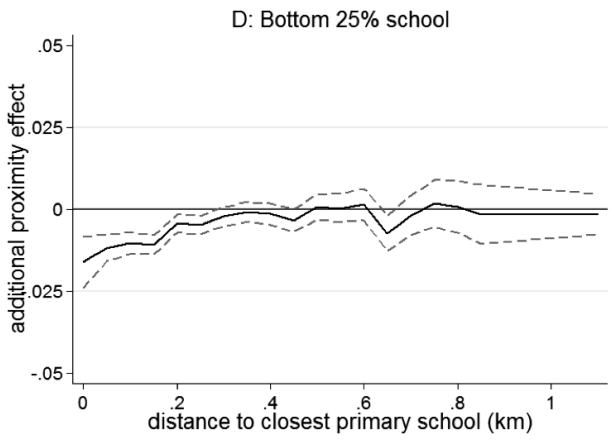

(b) Bottom $25 \%$

\begin{abstract}
Notes: The graph represents an additional proximity effect for best and worst performing school compared to an average
\end{abstract} school.

\subsubsection{Robustness Checks}

One potential concern could be that schools are not randomly placed and we might be estimating distance to some other amenity instead of capturing the effect of distance to school. To check this, we use a supermarket as a proxy of a local center. We use information about locations of all the supermarkets, grocery, and drug stores in the Netherlands from the telefoonboek.nl database. As a robustness check we calculate distances between 7,972 local centers and our housing transactions and add distance to the closest local center in our full specification. Reported in Table 2.4, we see that the coefficient of distance to school slightly decreases from 0.6 to 0.5 percentage points, and it is the only coefficient affected. We also calculate the correlation coefficient between distance to school and distance to supermarket, and it is 0.11. Even though distance to school and distance to supermarket seem to be weakly correlated, the distance to school coefficient is still significant and its magnitude does not change.

Another potential concern is that in our framework we only look at one closest school 
ignoring all others that are farther away. However, one can argue that people might care only about having a good school in the area, but it does not matter to them whether it is the closest to their house. To account for that, we add distance to next best performing school in the regression. Also in Table 2.4, we document that none of the coefficients are affected and the effect of distance to the next best performing school is zero, implying that people do not care about distance to the nearest best performing school, conditional on having one in the neighborhood.

Table 2.4

Robustness checks - Adding distance to a local center and second best performing school

\begin{tabular}{lccc}
\hline & $(1)$ & $(2)$ & $(3)$ \\
& Basic regression & Local center & Second best school \\
\hline & $0.006^{* * *}$ & $0.005^{* * *}$ & $0.006^{* * *}$ \\
Distance to school & {$[0.002]$} & {$[0.002]$} & {$[0.002]$} \\
$(\mathrm{km})$ & 0.000 & 0.000 & 0.000 \\
D: Best performing school & {$[0.001]$} & {$[0.001]$} & {$[0.001]$} \\
$(1=$ Yes $)$ & $-0.010^{* * *}$ & $-0.010^{* * *}$ & $-0.010^{* * *}$ \\
D: Worst performing school & {$[0.001]$} & {$[0.001]$} & {$[0.001]$} \\
$(1=$ Yes) & $0.005^{* *}$ & $0.005^{* *}$ & $0.005^{* *}$ \\
Distance ${ }^{*}$ Best school & {$[0.002]$} & {$[0.002]$} & {$[0.002]$} \\
$(\mathrm{km})$ & $0.015^{* * *}$ & $0.015^{* * *}$ & $0.015^{* * *}$ \\
Distance $*$ Worst school & {$[0.002]$} & {$[0.002]$} & {$[0.002]$} \\
$(\mathrm{km})$ & & $0.003^{* * *}$ & \\
Distance to local center & & {$[0.001]$} & \\
$(\mathrm{km})$ & & & $-0.000^{* * *}$ \\
Distance to 2 $2^{\text {nd }}$ best school & & & {$[0.000]$} \\
$(\mathrm{km})$ & & 790,085 & 790,085 \\
& & 0.79 & 0.79 \\
Observations & & Yes & Yes \\
R-squared & Yes & Yes & Yes \\
Quality house characteristics & Yes & Yes & Yes \\
Time and location fixed effects & Yes & Yes & Yes \\
Construction periods & Yes & & \\
Environmental controls & & & \\
\hline
\end{tabular}

Notes: Dependent variable: $\ln$ (price). Standard errors in brackets. ${ }^{*} * * \mathrm{p}<0.01, * * \mathrm{p}<0.05, * \mathrm{p}<0.1 . \mathrm{D}=\mathrm{dummy}$ Distance to nearest supermarket is used as proxy for distance to local center. Basic controls include house and total land size, number of rooms, bathrooms, dummies for number of floors, new house, farm, parking, garden (incl. quality), roof terrace. Construction periods reported in Appendix Table 2.7. Extended quality controls include dummies for type of heating, isolation, and condition of property interior and exterior. Environmental controls include distance to highway, forest, park, and a dummy for busy street. Time FE by sales year. Spatial FE by neighborhood level. Base values: Number of floors: 1, Construction = Construction before 1944, House and Apart. type = ground floor apt, Apart. quality = average, Garden quality: bad, Heating = no heating. 


\subsection{Discussion \& Conclusion}

In this paper, we analyze people's willingness to pay for school quality in a market without school boundaries. We apply a hedonic pricing method to represent house prices as a function of characteristics of the property itself and the surrounding amenities. We use data from the Netherlands, where parents are not restricted in their choice of primary schools. We use the linear distance to school as a proxy for access to education and exposure to negative externalities and estimate interval regression with dummies for each $50 \mathrm{~m}$ in our final specification. To control for unobserved heterogeneity, we use spatial fixed effects at the neighborhood level, as the Netherlands is divided into unique neighborhoods.

For a country with no catchment areas policy for schooling, we find that there is no price premium of high school quality on housing prices. However, we find a small discount for general school proximity and an additional discount of worst performing schools. Since people can freely choose a primary school for their children, they are not willing to pay extra to live close to a good school compared to an average school. In contrast, proximity to worst performing schools leads to a discount in house prices. These results are in line with previous findings, showing that schools are a source of externalities in the housing market and therefore affecting prices (Sah et al., 2016). At the same time, comparing our results to studies that exploit catchment areas (up to 7.2\%,(Clapp et al., 2008; Fack \& Grenet, 2010), we see that the effect of school quality in a setting without catchment areas is negligible for high quality, but to be considered for low quality.

To check that we are measuring distance to the nearest school and not some other amenities, we estimate a regression with a linear distance to school and add distance to a local center, proxied by a distance to the nearest supermarket. We find that these two distances are weakly correlated (0.11) but the magnitude of the coefficient of distance to school does not change, and the point estimate decreases from 0.6 to 0.5 percentage points. Our results are also robust to altered quality measures (3 year average CITO exit test score) and controlling for next nearest school. In both cases magnitudes of the results do not change.

The findings of this paper have implications for policy makers concerning the indirect costs of education. First, our results suggest that there is no evidence of good schools affecting the local housing market. Consequentially, placing a school of high quality should not be used as a tool to increase neighborhood attractiveness if access to the school is not limited to the nearby area. Second, we show that in close proximity of worst performing schools any negative externalities significantly outweigh any positive externalities of proximity and consequently decrease residential housing prices. Those negative externalities should be considered for optimal placement of primary schools. To provide an indication of the costs on the housing market generated by primary schools, we estimate the discount on an average house. With a discount of 1.6 percent for an average house price of $€ 264,845$ and an average apartment price $€ 199,762$ next to a worst performing school building, this translates into a discount of $€ 3,973$ for houses and $€ 2,996$ for apartments respectively. 


\subsection{Appendix}

Table 2.5

Population Share and Housing Transactions per Province (2016, in \%)

\begin{tabular}{lcc}
\hline Province & Population & $\begin{array}{c}\text { Housing } \\
\text { Transactions }\end{array}$ \\
\hline Groningen & 3.4 & 3.4 \\
Friesland & 3.8 & 3.7 \\
Drenthe & 2.9 & 3.5 \\
Overijssel & 6.7 & 6.5 \\
Flevoland & 2.4 & 2.5 \\
Gelderland & 12 & 12.5 \\
Utrecht & 7.5 & 9.4 \\
Noord-Holland & 16.4 & 18.9 \\
Zuid-Holland & 21.3 & 21.6 \\
Zeeland & 2.2 & 1.6 \\
Noord-Brabant & 14.7 & 13.2 \\
Limburg & 6.6 & 3.2 \\
\hline Total & 100 & 100
\end{tabular}

Notes: Source: CBS. The number of housing transactions per province for 2016 is closely following the population distribution, with only Limburg being underrepresented.

Table 2.6

School Quality Data (2007 - 2016)

\begin{tabular}{cccc}
\hline Year & CITO Average & $\begin{array}{c}\text { Worst schools } \\
\text { Cut-off }\end{array}$ & $\begin{array}{c}\text { Best schools } \\
\text { Cut-off }\end{array}$ \\
\hline 2007 & 534.5 & 532 & 537.6 \\
2008 & 534.7 & 532 & 537.7 \\
2009 & 534.8 & 532.3 & 537.7 \\
2010 & 535.1 & 532.8 & 537.9 \\
2011 & 535.2 & 532.9 & 537.9 \\
2012 & 535.1 & 532.8 & 537.7 \\
2013 & 534.7 & 532.2 & 537.6 \\
2014 & 534.5 & 531.9 & 537.3 \\
2015 & 534.8 & 532.5 & 537.6 \\
2016 & 534.4 & 532.1 & 537.2 \\
\hline
\end{tabular}

Notes: Source: Own analysis. The range for CITO end test score is between 500 and 550 . 
Table 2.7

Hedonic Regression - Control Variables

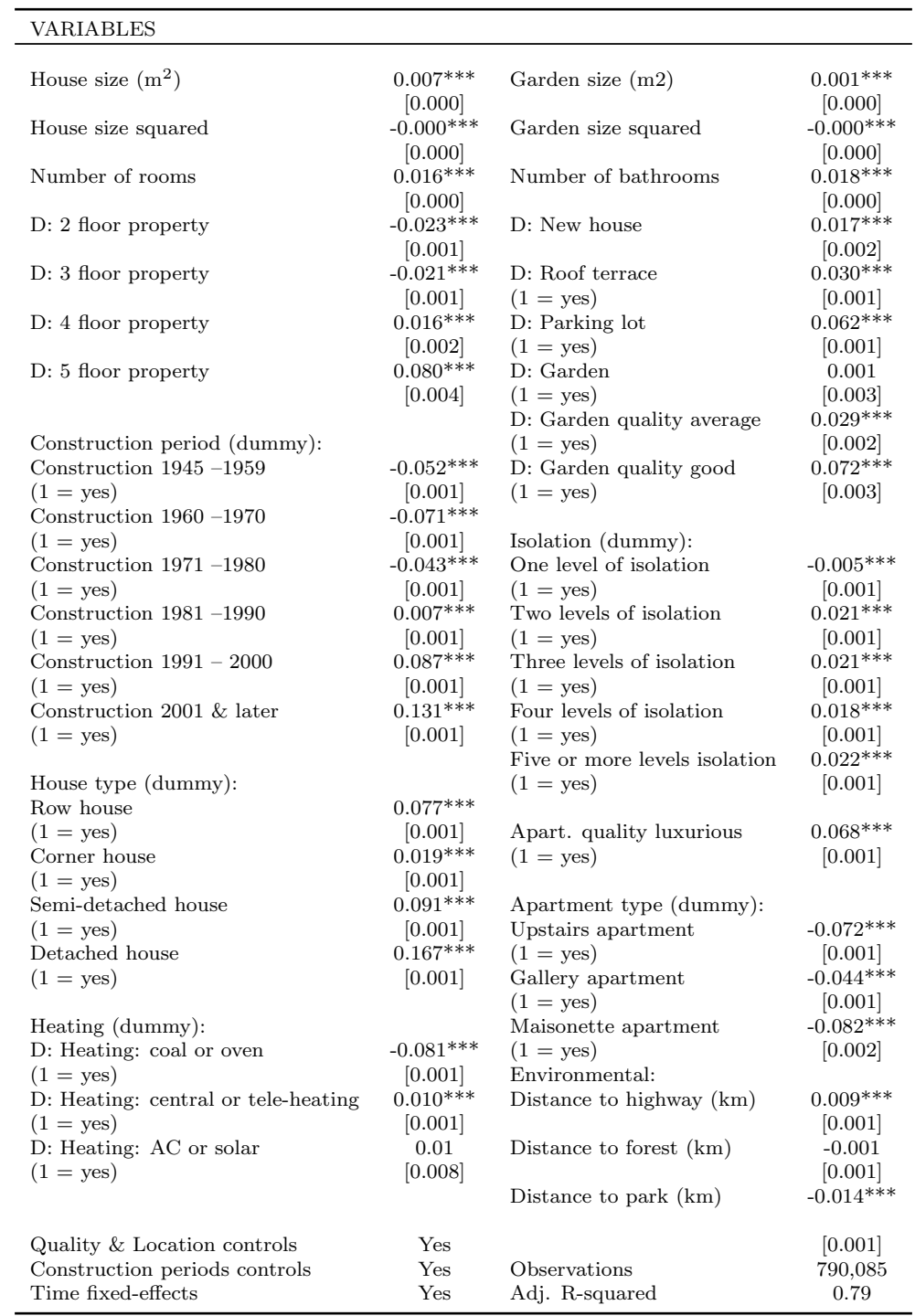

Notes: Standard errors in parentheses ${ }^{* * *} \mathrm{p}<0.01,{ }^{* *} \mathrm{p}<0.05,{ }^{*} \mathrm{p}<0.1 \mathrm{D}=$ dummy, Base values: Number of floors: 1 , Construction $=$ Construction before 1944, House and Apart. type $=$ ground floor apt, Apart. quality = average, Garden quality: bad, Heating = no heating. Time FE by sales year. Spatial FE by neighborhood level. 
Table 2.8

Houses in proximity of worst performing schools and total housing stock

\begin{tabular}{cccccc}
\hline & \multicolumn{3}{c}{$\begin{array}{c}\text { Observations within } 200 \mathrm{~m} \\
\text { of worst schools }\end{array}$} & Total sample & $\begin{array}{c}\text { Total housing stock } \\
\text { (CBS Statline) }\end{array}$ \\
\cline { 2 - 4 } Year & Houses & Apartments & Total & & \\
\hline & & & & & \\
2012 & 2,327 & 2,242 & 4,569 & 87,117 & $5,116,860$ \\
2013 & 1,996 & 1,822 & 3,818 & 73,508 & $5,172,052$ \\
2014 & 2,294 & 1,934 & 4,228 & 88,135 & $5,259,926$ \\
2015 & 2,413 & 2,045 & 4,458 & 94,943 & $5,283,459$ \\
2016 & 1,873 & 1,590 & 3,463 & 83,156 & $5,359,581$ \\
\hline
\end{tabular}

Notes: Source: own analysis and CBS Statline. The total housing stock does not include public housing (Woningcorporatie). The NVM sample contains on average $1.63 \%$ of total housing stock. 


\section{Figure 2.3}

Population Density and School Distance (2009)

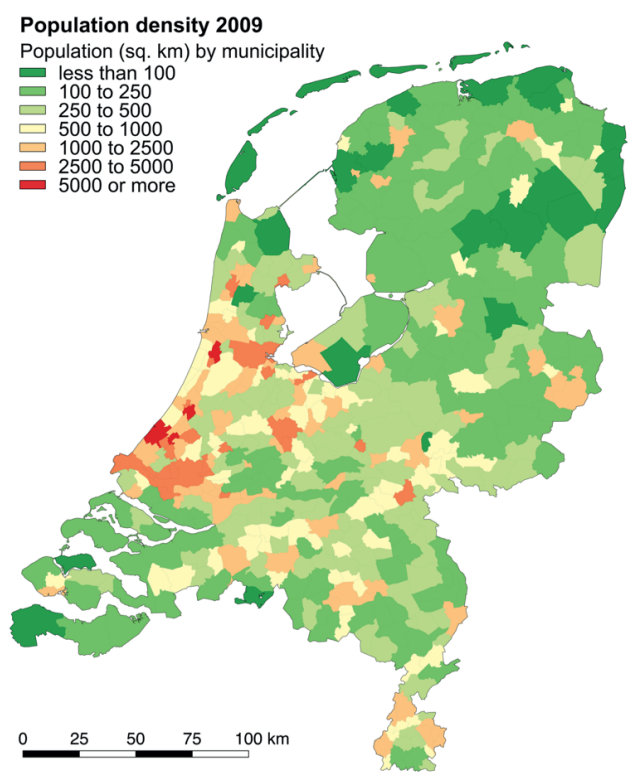

(a) Population density

\section{School density 2009}

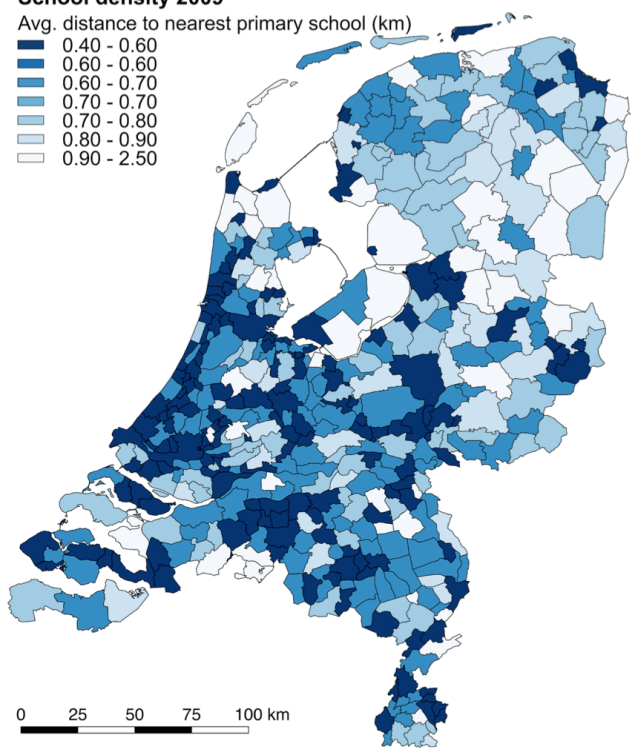

(b) Average school distance

Notes: The population density distribution is representative for all years throughout the sample period. In addition, the density distribution is representative for the sample distribution. For school distance, data per municipality are provided by the Central Statistics Office (CBS the average distance to the nearest primary school per municipality for 2009 , provided by CBS. 
Figure 2.4

School Distance over Time

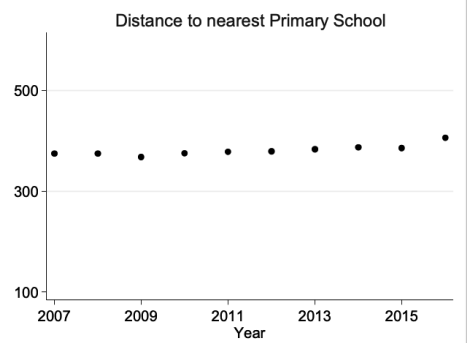

Notes: The average distance between houses and primary schools is rather consistent over time, with a slight increase after 2013, which can be explained by increased prevalence of closing existing schools (buildings) over opening new ones.

Figure 2.5

Relationship - Distance to school

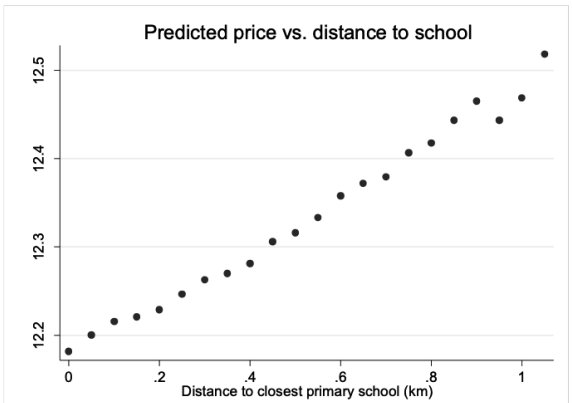

(a) Predicted price vs. distance to closest primary school

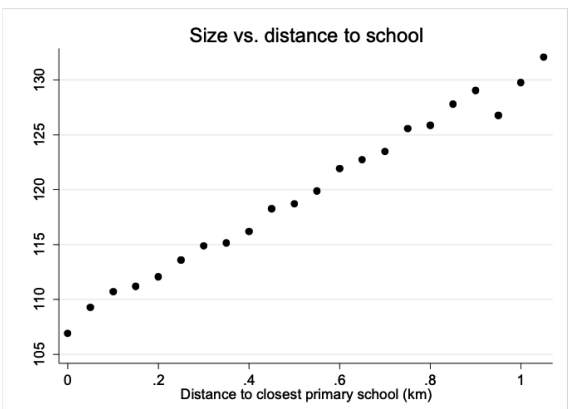

(b) Property size vs. distance to closest primary school

Notes: Figure 2.5a shows that houses further away from school building are more expensive. Price is predicted based on Appendix Table 2.7, so not controlling for distance to school.

Figure 2.5b shows that houses further away from schools building are bigger, which explains Appendix Figure 2.5a. 


\section{Chapter 3}

\section{Clean Electricity, Dirty Electricity: The Effect on Local House Prices*}

\subsection{Introduction}

Electricity consumption in the European Union is expected to increase by between 0.5 and 1 percent per year until 2030 (European Commission, 2013). To reliably handle this energy demand, a large fraction of electricity is currently generated by coal and gas-fired power plants. Such an increase will lead to significant environmental externalities. To combat this, there is a strong desire among policy makers to become less dependent on fossil fuels, and to decrease carbon emissions from power generation, mostly through the increasing use of renewable energy sources.

In Europe, the European Commission passed its Europe 2020 strategy, which binds all EU member states to reduce greenhouse gas emissions by 20 percent and to increase the share of renewable electricity production to 20 percent by the year 2020. Over recent years, the share of renewable electricity production in the EU-28 increased from 12.6 percent in 2003 to 22.4 percent in 2014 (European Commission, 2015, 2016; Eurostat, 2015b, 2015a). But, this average comes with significant variation across individual member states, putting pressure on some countries to more rapidly increase their share of renewables.

The question of whether renewable (or "green") electricity generation is a superior solution to conventional generation is a multi-dimensional question that involves a comprehensive cost-benefit analysis regarding electricity prices and production costs, available capacity, and environmental aspects. In order to compare the total costs of different types of electricity production, their external costs to the environment should also be incorporated in the calculations, in addition to direct costs (Ayres \& Kneese, 1969; Roth \& Ambs, 2004). Besides global environmental externalities, local effects of power generation on public health, as well as the effects of noise and sight for the nearby population are important to consider. Externalities on the local environment often lead to popular opposition when governments plan to expand on renewable energy generation (Breukers \& Wolsink, 2007; Wolsink, 2000, 2007; Wüstenhagen et al., 2007). However, EU member states have initiated a multitude of national policies to increase the share of renewable energy, often ignoring these local externalities.

This paper fills the research lacuna by analyzing the external effect of conventional power plants (coal and gas) and renewable power plants (wind and biomass) on local housing prices, determining the costs of different types of electricity generation for local home owners. We employ a comparable analytical framework within similar housing markets, using an extensive, longitudinal dataset of actual transaction prices. We focus on opening and closing effects of different energy generation types due to the importance of ex-ante location controls.

We address a comparability problem, since the current literature is mostly limited on

${ }^{*}$ This chapter is co-authored with Piet Eichholtz (Maastricht University), Nils Kok (Maastricht University) and Daan van Vuulpen. 
the external effects of a single type of electricity generation or the general effect of power plants, not distinguishing between types. Furthermore, existing studies often analyze just a few power plants at the time, use different and non-comparable analytical tools, or employ asking prices rather than transaction prices to assess effects on local house prices (Blomquist, 1974; Clark et al., 1997; Davis, 2011; Dröes \& Koster, 2016; Gamble \& Downing, 1982; Gibbons, 2015; Heintzelman \& Tuttle, 2012b; Lang \& Opaluch, 2013; Sunak \& Madlener, 2016). It is therefore difficult to draw a coherent conclusion about the relative effects of different types of electricity generation on local housing markets.

In any study of externalities and house prices, endogeneity is a critical issue in properly identifying effects. In our analysis, an endogeneity problem arises from the fact that placement decisions of power plants and wind turbines depend on factors like available infrastructure and local politics, but also on land values. Since electricity production requires significant space, land prices are a considerable factor in setup costs. Land value is also a determinant of house prices, so it could be argued that land values and house prices in affected areas are likely to already be lower before the placement of a power plant or wind turbine. This leads to an identification problem that is often neglected in the existing literature, when using hedonic models (Sunak \& Madlener, 2016).

This study focuses on the Netherlands, which is lagging behind other European countries, such as Sweden and Denmark, in renewable electricity generation. The share of Dutch renewable electricity production was 6 percent in 2014. Among renewables, biomass/renewable waste (5.3 percent) and wind ( 0.7 percent) are the dominant energy sources (Eurostat, 2015b). A critical goal of Dutch energy policy is to rapidly increase the share of renewable electricity sources. As wind is abundant along the Dutch coast, the plan is to have 6,000 megawatt (MW) of onshore wind capacity installed by 2020, increasing the number of wind turbines and partly replacing older, less efficient wind turbines (Londo \& Boot, 2013). Since the Netherlands is one of the most densely populated countries in Europe, electricity generation and urban areas are likely to further converge, raising the question of how external effects of different electricity generation types affect the housing market?

To address this question, we employ an extensive dataset of 2.3 million Dutch housing transactions between 1985 and 2015. In addition, we have data on all wind turbines, biomass plants and conventional power plants in the Netherlands. We focus on coal, gas, biomass and wind electricity generation facilities, since these are most significant for the Dutch electricity market. ${ }^{2}$ We match these information sources in order to measure the effects of proximity to electricity generation facilities on house prices, calculating distance measures for each individual transaction, using a variety of models to control for individual housing characteristics.

We document different external effects on nearby house prices for different energy types. We find negative external effects for gas plants and wind turbines. In contrast, we find positive price effects for biomass plants, conditionally on placement in ex-ante lower priced areas. We do not find any significant price effects for coal plants. ${ }^{3}$ All external

\footnotetext{
${ }^{2}$ Nuclear power contributes to the Dutch electricity market, but there is only one power plant in the Netherlands (the Borssele nuclear power plant). Due to its singularity, observations within externality distance would be limited and potential results hardly generalizable. We therefore exclude the nuclear plant from our analysis.

${ }^{3}$ Due to limited openings, we are only able to examine coal plant closings with sufficient observations.
} 
effects are generally negative in urban areas. Most effects are robust over time and do not vary with plant size. As plant size plays no role, the general negative effect might at least partially come from perception.

The remainder of this paper starts with a short discussion of the literature regarding the external effects of electricity generation on local housing markets. Section three presents a theoretical framework and the underlying methodology, which is followed by section four, providing the data and descriptive statistics. Sections five describe the results and section six of the paper offers a short conclusion.

\subsection{Literature Review}

\subsubsection{External effects of electricity generation}

Defining and pricing externalities of electricity generation facilities is a challenging task. Roth and Ambs (2004) provide a meta-study to quantify the externality costs of 14 different electricity generation types, focusing on air pollutants. They find a wide range of damage cost estimations of individual air pollutants, such as for carbon dioxide $\left(\mathrm{CO}_{2}\right)$, ranging from $\$ 9.90$ to $\$ 41.60$ per ton, with coal power plants having the highest external costs, followed by gas and combined cycle power plants. In contrast, biomass and wind appear to have only limited external costs. These results are in line with a study conducted by the European Commission (2003). However, despite a common agreement over the rank of air pollution emission among electricity generation types, cost estimates of different emissions vary widely, showing the difficulty of pricing the externalities of electricity generation.

Despite the lack of air pollution stemming from wind turbines, there are significant noise and visual effects. Reported health effects such as sleep disturbance, headache, anger fatigue and loss of motivation are acknowledged as factors that can be caused by the noise from wind turbines (Farboud et al., 2013). ${ }^{4}$ Visual effects seem to have an even stronger impact than noise (Bakker et al., 2012). Even though there is no scientific evidence about causal effects, people located near wind turbines have reported health effects, claiming those effects were due to photo-induced seizures (photosensitive epilepsy) and wind turbine blade flicker (Harding et al., 2008). In addition, households located nearby report a decrease in life-satisfaction after the installation of wind turbines (Krekel \& Zerrahn, 2017).

The increased number of self-reported health effects by people living near wind turbines merely seems to be caused by the annoyance over the presence of wind turbines itself, rather than originating from one aspect in particular, highlighting the difficulty to identify individual externalities (Pedersen \& Waye, 2007). ${ }^{5}$ People generally support wind energy, but oppose it if facilities are installed close to their homes (Breukers \& Wolsink, 2007; Wolsink, 2000, 2007; Wüstenhagen et al., 2007). Wolsink (2007) states that local residents are willing to accept wind turbines in their vicinity as long as they perceive the

\footnotetext{
${ }^{4}$ Other health effects mentioned in the study are: visceral, vibratory and/or vestibular dysfunction, dizziness, vertigo, unsteadiness, tinnitus, ear pressure or pain, external auditory canal sensation, memory and concentration deficits, and irritability.

${ }^{5}$ In the Netherlands, the noise and shadow effects of wind parks on nearby neighborhoods are assessed before opening, protecting nearby residents from increased exposure https://bit.1y/2X0yQfC. It is therefore difficult to pinpoint specific negative effects of wind turbines.
} 
general distribution of wind turbines as "fair". However, in the Netherlands local residents do not have the perception that they can influence the distribution of new wind turbine sites (Wüstenhagen et al., 2007). ${ }^{6}$ Similar results are found in the United Kingdom (Bell et al., 2005), the United States (Pasqualetti, 2011b), and Mexico (Pasqualetti, 2011a).

\subsubsection{Power plants and external effects on housing}

Since residential real estate is fixed in location, prices are highly sensitive to factors disrupting location quality (Hilber, 2005), making real estate a good identifier of local utility or disutility from externalities. As people choose locations according to their preferences and aversions (Tiebout, 1956), external factors, that arise from power plants and wind turbines, are incorporated in house prices (Rosen, 1974), allowing to assign monetary values to the external effects. ${ }^{7}$ However, since it is practically impossible determine and measure all external effects of different electricity generation facilities, we use distance (proximity) to properties as a measure in the Rosen (1974) framework. Using distance should theoretically reflect the net-external effects (Nelson, 2008).

Research focusing on local housing market effects of power plants dates back more than 40 years. However, most studies focus on the effects of individual power plants in small regional markets (Blomquist, 1974; Clark et al., 1997; Gamble \& Downing, 1982; Sunak \& Madlener, 2016). Large-scale studies tend to investigate just one type of electricity production, using different measures of property prices, such as transactionbased (Dröes \& Koster, 2016) or survey-based (Davis, 2011). Additionally, studies use different control variables, leading to varying empirical models. Due to the heterogeneous characteristics of housing markets, changes in electricity generation technology over time, and the focus on a single type of electricity generation, it is hard to draw a coherent conclusion about the relative effects of different electricity generation types on local house prices.

In most studies, the observed external effects for conventional power plants and wind turbines are either negative or insignificant. Blomquist (1974) finds a price decrease of 0.9 percent per 500 feet, within a 2-mile distance of a coal power plant. Davis (2011) finds a discount of 3 to 7 percent within 2 miles of plants, increasing with proximity and capacity. For wind turbines, negative external effects range between 5 percent within 0.5 miles (Lang \& Opaluch, 2013), 2 to 16 percent within 3 miles (Heintzelman \& Tuttle, 2012b), 1.2 to 2.6 percent within 2 kilometers (Dröes \& Koster, 2016) and 5 to 6 percent within 2 kilometers (Gibbons, 2015). Other studies find no evidence of significant effects (Carter, 2011; Hoen, 2014; Sims et al., 2008). Since the methodology, number of observations, research area and control variables differ widely between studies, it is not possible to directly compare these findings and to draw firm conclusions regarding the relative externality costs of different forms of electricity generation.

Overall, there is no study that simultaneously includes different types of electricity generation technology, uses a large number of observations, measures transaction-based house prices, and accounts for sufficient control variables to quantify external effects in a comparable manner. Furthermore, in any study addressing the effect of locally desirable or

\footnotetext{
${ }^{6}$ This perception is confirmed by the fact that the Dutch Ministry of Infrastructure and the Environment centrally determined eleven areas for the construction of new wind parks in 2014 . The official selection criteria were population density and wind speed (Feld et al., 2014).

${ }^{7}$ The main assumption is that people are free in their location choice.
} 
undesirable externalities on house prices, the main challenge is identification. In the case of power plants, both renewable and conventional, the locational choice is often driven by factors such as land values and (local) politics, rather than being fully random or based on exogenous factors such as proximity to waterways or exposure to a stiff breeze. Only a few, recent studies address this issue (Davis, 2011; Dröes \& Koster, 2016).

\subsection{Method}

\subsubsection{Theory \& sample construction}

We study the effects of different electricity generation methods on house prices within one market: The Netherlands. Our focus is on coal, gas, biomass, and wind energy, due to their significance for the local electricity market. Since the findings of previous studies differ widely, we are interested in the variation of external effects between different electricity generation facility types and the variation of findings due to different model specifications. We therefore test two specifications: a difference-in-difference (DID) approach using average area price changes (e.g. see Muehlenbachs et al., 2015; Pope \& Pope, 2015), and a DID repeated sales model.

For both approaches, we use a similar measure of externality exposure. Since we cannot determine and measure all potential externalities of the different electricity generation facilities, we assume that externalities spread over distance (Nelson, 2008). As we focus on local external effects of electricity generation facilities and neglect global effects, such as $\mathrm{CO}_{2}$ emissions, we focus on areas directly surrounding electricity generation facilities. However, it might be that different externalities spread differently over distance. In contrast to physical externalities such as noise and sight disturbance, economic externalities, such as employment effects, could reach further, leading to potentially unbalanced external effects over distance.

Assuming external effects spread over distance, we determine exposure to externalities by the linear distance to the closest electricity generation facility of every energy type, using longitude and latitude information. ${ }^{8}$ Based on a cut-off distance, we consider observations as either affected by externalities $(d=1)$ or not affected $(d=0)$. Based on empirical findings on conventional plants (Davis, 2011) and wind turbines (Dröes \& Koster, 2016), we use a cut-off distance of $2.5 \mathrm{~km}$ for all energy types. However, we further examine different cut-off distances and interval measures.

To avoid interference among affected and control observations, we omit observations in a ring-shaped area beyond the cut-off distance as illustrated in Figure 3.1. Using the externality cut-off distance of $2.5 \mathrm{~km}$, we consider observations within $2.5 \mathrm{~km}$ distance as affected $(d=1)$, comparing them with control observations beyond $2.5+z \mathrm{~km}$, where $z$ is the width of the omitted area. We begin with $z=1 \mathrm{~km}$, but test different lengths for robustness. Due to the heterogeneity of local residential markets, observations at externality distances do not necessarily share the same locational characteristics with observations far away. We therefore control for location fixed-effects and limit our control group to a maximum distance of $10 \mathrm{~km}(y=6.5 \mathrm{~km})$, omitting observations beyond 10

\footnotetext{
${ }^{8}$ Distances are calculated using the haversine formula, a common way to calculate the great-circle distance of two points on a sphere using longitude and latitude information.
} 
$\mathrm{km}$ distance from the analysis. ${ }^{9}$

We account for confounding factors from other electricity generation facilities. Observations within a $2.5 \mathrm{~km}$ distance of a nuclear power plant are omitted, since there is only one active plant in the Netherlands and we argue that the external effects from nuclear power plants differ from those of conventional plants (Gawande \& Jenkins-Smith, 2001). Furthermore, we exclude observations within a $2.5 \mathrm{~km}$ distance from the German and Belgium border, since we cannot fully account for power plants across the border. ${ }^{10}$

Figure 3.1

\section{Sample Construction Method}

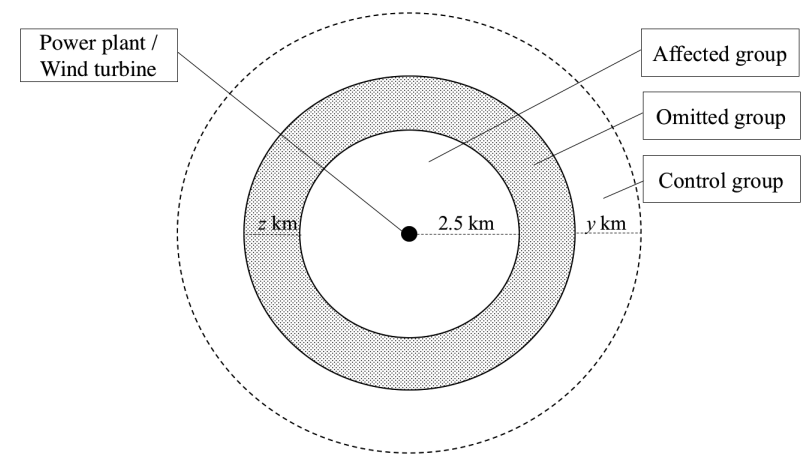

Notes: We cluster observations into affected, omitted and control groups depending on their location relative to a power plant or wind turbine. Observations located in the inner circle around a wind turbine or power plant are considered "affected". We use different radii, ranging from $2.5 \mathrm{~km}$ to $4 \mathrm{~km}$. For the omitted group, we use a radius extension of $z=1.5 \mathrm{~km}$. We consider all other observations as the control group, limiting the maximum distance to $20 \mathrm{~km}(y=16 \mathrm{~km})$.

\subsubsection{Difference-in-difference approach}

Since the placement of power plants and wind turbines is not random, a static model might be biased by an economic endogeneity problem of the price-effect relationship. Besides infrastructure factors, such as grid infrastructure or the closeness to gas pipelines and harbors, and political factors, such as local voter opposition, land value may also determine placement decisions. Low land values make it cheaper to build a power plant or to erect a wind turbine. Since land values strongly correlate with house prices, too, observed house price discounts nearby power plants or wind turbines might be the result of low ex-ante land prices instead (Kok et al., 2014).

Beside limiting the reach of our control group, we address this potential problem by using a difference-in-difference (DID) model, investigating the effects of facility openings and closings. Although our dataset is large, it contains just a limited number of repeated sales pairs. Due to more placements of power plants and wind turbines in remote locations

\footnotetext{
${ }^{9}$ We also test other maximum distances between 10 and $20 \mathrm{~km}$ for the control group, not markedly affecting the results.

${ }^{10}$ There are several wind turbines along the German side of the border and some conventional and nuclear power plants in Belgium, not far from the Dutch border.
} 
and imbalances in the number of facility openings and closings (e.g. few coal and biomass plant openings and wind turbine closings), we are not able to perform a DID analysis based on repeated sales for all facility types. Instead, we use a difference-in-difference model for geographic areas similar to Muehlenbachs et al. (2015), comparing the change in house prices of areas that experience facility openings / closings, with areas nearby (control areas), as illustrated in Figure 3.2.

Figure 3.2

DID for areas - Setup

(t)

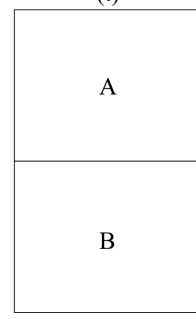

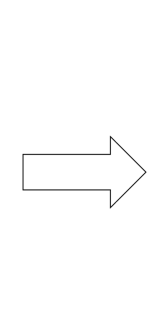

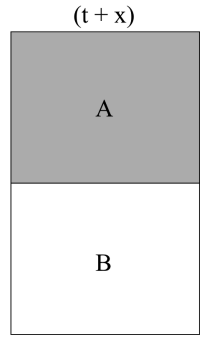

Notes: We investigate the average price change of homes in area $\mathrm{A}$ comparing it with area $\mathrm{B}$ between time $\mathrm{t}$ and $\mathrm{t}+\mathrm{x}$. Observations in area A experience the opening / closing of a electricity generation facility of type $\mathrm{k}$ and whereas observations in area $\mathrm{B}$ do not. We control for individual housing characteristics to avoid capturing systematic changes in housing characteristics of specifc areas.

Equation (3.1) shows the employed model, testing the effect of facility openings on average property prices, where $F A C_{k i}$ measures if observation $i$ is in proximity to an electricity generating facility of type $k$, either before or after opening, $\operatorname{post}_{k i t}(d=$ 1) measures transactions after opening of the closest facility of type $k$, and Treat kit $_{1}=$ $F A C_{k i t} *$ post $_{k i t}$ equals 1 for transactions in close proximity to a facility, after opening. Therefore, the coefficient of interest is $\gamma_{3 k}$, measuring the effect of facility type $k$ openings.

$$
\ln \left(p_{i t}\right)=\alpha+\sum_{k=1}^{K} \gamma_{1 k}\left(F A C_{k i t}\right)+\sum_{k=1}^{K} \gamma_{2 k}\left(\text { post }_{k i t}\right)+\sum_{k=1}^{K} \gamma_{3 k}\left(\text { Treat }_{k i t}\right)+X_{i t} \gamma_{4}+\epsilon_{i t}
$$

We control for unobserved differences in price-determining factors between areas over time and general time-trends, using $X_{i t}$, consisting of structural, environmental and neighborhood characteristics, as well as time fixed-effects (Rosen, 1974). Control variables are listed in Appendix Table 3.7. We further test for the assumption of common pretreatment trends (Kuminoff \& Pope, 2014). We account for potential spatial dependence and omitted variables by including neighborhood-fixed effects in $X_{i t}$, hereafter referred to as location FE (Anselin \& Bera, 1998; Kuminoff et al., 2010). ${ }^{11}$ As time-fixed effects

\footnotetext{
${ }^{11}$ We test location fixed effects at 4-digit, 5-digit and 6-digit postcode level, ranging from slightly over 4,000 postcode areas with on average 7,000 households per postcode area to 450,000 postcode areas with 17 households per postcode area. As the results do not change in signs and 6-digit postcode forces us to exclude a large number of observations to avoid individual fixed-effects, we focus on 4-digit postcode level fixed-effects.
} 
we use year dummies, measuring general house price dynamics over time (see e.g. Hoen, 2010, 2014). ${ }^{12}$ Standard errors are clustered by municipality and year.

The analysis is limited to facilities that open during the sample period. We exclude observations around plants that opened before. We only consider observations up to 10 years before and after facility openings, as it can be assumed that long-term price effects settle over time. ${ }^{13}$ To eliminate anticipation effects and effects from construction work, we omit transactions one to two years before openings, as well as the opening year, depending on facility types. ${ }^{14}$ We do not consider observations that experience a replacement, being within externality distance of another facility prior to opening of a new plant. Since the number of affected houses decreases through this filtering process, we also test a $3-\mathrm{km}$ cut-off distance throughout the analysis.

To examine the spatial heterogeneity of external effects, we test the external effects of different electricity generation types at different distance bands. As shown in equation (3.2), we form $J$ distance intervals of $1 \mathrm{~km}$ length up to a distance of $4 \mathrm{~km}$ for every energy type $K$. We use $1 \mathrm{~km}$ length to have sufficient observations in every interval. To reduce complexity, we do not use a holdout distance, meaning we distinguish between treated observations up to $4 \mathrm{~km}$ and control observations between 4 - $10 \mathrm{~km}$ distance.

$$
\begin{aligned}
\ln \left(p_{i t}\right)=\alpha+\sum_{j=1}^{J} \sum_{k=1}^{K} \gamma_{1 j k}\left(F A C_{j k i t}\right) & +\sum_{j=1}^{J} \sum_{k=1}^{K} \gamma_{2 j k}\left(\text { post }_{j k i t}\right)+\sum_{j=1}^{J} \sum_{k=1}^{K} \gamma_{3 j k}\left(\text { Treat }_{j k i t}\right) \\
& +X_{i t} \gamma_{4}+\epsilon_{i t}
\end{aligned}
$$

As property prices differ between urban and rural areas (DiPasquale \& Wheaton, 1996), the perception of external effects might differ due to the presence of confounding negative or positive externalities, such as from road noise in cities. We therefore investigate the urban-rural heterogeneity effect, by explicitly controlling for facility openings in urban areas. As shown in equation (3.3), we add an urban location control dummy in the control matrix $X_{i t}$ and add an urban-treatment interaction term represented by $\left(\right.$ Treat $_{k i t} *$ urban $\left._{i t}\right)$, where $\beta_{1 k}$ represents the additional effect of facility type $k$ opening in urban areas. ${ }^{15}$

Due to technical improvements and government regulation, conventional electricity generation facilities typically get cleaner, less noisy, and more efficient over time. ${ }^{16} \mathrm{We}$ therefore examine the heterogeneity of opening effects over time, testing subsets of 10-

\footnotetext{
${ }^{12}$ Additionally, we adjust house prices for inflation, using the CPI from the Dutch Central Statistics Office (CBS)

${ }^{13}$ We test an extension to 15 years, but do not find a significant difference in results.

${ }^{14}$ The average construction period for conventional plants is two years, whereas the construction period for wind turbines is much shorter, on average. We therefore use one year for wind turbines. Even though projects might be announced earlier, residents in the Netherlands have strong legal power to prolong or abort large projects. We try anticipation periods up to 4 years and adjustment periods up to 3 years, but do not find different results.

${ }^{15}$ As mentioned in Appendix Table 3.7, we also test alternative time fixed-effects, using yearmunicipality interaction terms. We use municipality as a location as urban-rural assignments are based on municipality, too. (see Section 3.4.3)

${ }^{16}$ See Buhre et al. (2005); Franco and Russo (2002); Meij and te Winkel (2006); Senior and Johnson (2005).
} 
year periods, moving in 5-year steps, as shown in equation (3.1). We use 10-year periods instead of individual years to have sufficient observations for every period, leading to the following, overlapping periods: 1985 - 1995, 1990 - 2000, 1995 - 2005, 2000 - 2010, and $2005-2015$.

$$
\begin{gathered}
\ln \left(p_{i t}\right)=\alpha+\sum_{k=1}^{K} \gamma_{1 k}\left(F A C_{k i t}\right)+\sum_{k=1}^{K} \gamma_{2 k}\left(\text { post }_{k i t}\right)+\sum_{k=1}^{K} \gamma_{3 k}\left(\text { Treat }_{k i t}\right) \\
+\sum_{k=1}^{K} \beta_{1 k}\left(\text { Treat }_{k i t} * \text { urban }_{i t}\right)+X_{i t} \gamma_{4}+\epsilon_{i t}
\end{gathered}
$$

Another potential source of heterogeneity is power plant size (Davis, 2011) or the number of wind turbines in a wind park (Dröes \& Koster, 2016). Davis (2011) argues to focus on power plants above $100 \mathrm{MW}$, since disamenities are likely to be stronger for these plants. We therefore differentiate for size, using capacity for conventional plants and the number of contiguous wind turbines within a wind park, as capacity differences for individual wind turbines are relatively small compared to power plants. Due to constraints in size variation, we are only able to examine size effects for gas plants and wind turbines. Based on the available variation, we distinguish three size categories for gas plants (<100MW, $100-400 \mathrm{MW},>400 \mathrm{MW})$, and four categories for wind turbines (single turbine, 2 to 9 turbines, 10 to 29 turbines, $30+$ turbines). ${ }^{17}$

Similar to openings, we investigate the effect of facility closings, examining the effect of externality removals. We focus on areas initially nearby electricity generation facilities, experiencing a closing and being outside externality distance thereafter. We compare the average price change with areas remaining in externality distance of facilities. Equation (3.4) shows the model, where Close $_{k i t}(=1)$ indicates observation $i$ being close to a closing facility of type $k$, post kit $(=1)$ indicates observation $i$ is transacted after the closing of facility type $k$, and Treat $_{k i t}=$ Close $_{k i t} *$ post $_{k i t}$, identifies observations nearby closing facilities after closing. Similar as in equation 3.1, we control for structural and environmental characteristics by $X_{i t}$. We further control for remaining facility types. ${ }^{18}$ Finally, we investigate heterogeneity in the effects, testing for facility size in a similar manner as before.

$$
\ln \left(p_{i t}\right)=\alpha+\sum_{k=1}^{K} \gamma_{1 k}\left(\text { Close }_{k i t}\right)+\sum_{k=1}^{K} \gamma_{2 k}\left(\text { post }_{k i t}\right)+\sum_{k=1}^{K} \gamma_{3 k}\left(\text { Treat }_{k i t}\right)+X_{i t} \gamma_{4}+\epsilon_{i t}
$$

\subsubsection{Repeat sales analysis}

One problem of the regional difference-in-difference approach presented Section 3.3.2 is that it relies on the assumption of similar housing characteristics over time. However, even though we control for housing characteristics, we cannot rule out that transactions in affected or control areas systematically differ over time. To overcome this issue, we use repeated sales of the same property. Within our sample, there are 457,547 observations with at least one repeated sale throughout the sample period, of which 109,692 observations are sold three times, 23,959 sold four times, and 4,749 sold five times. Using

\footnotetext{
${ }^{17}$ We use size intervals since external effects do not necessarily increase linearly with capacity.

${ }^{18}$ It is necessary to control for nearby facility type $k$ due to unbalanced closings among types.
} 
the same setup, cut-off distances and time restrictions as before, we use repeated sales to measure the change in price on the same house after facility openings and closings.

We follow the approach of Aydin et al. (2016) as shown in equation (3.5). As a dependent variable, we use the percentage change in price $\Delta p_{i(t+n)}$ of property $i$ between period $t$ and $n$. Based on the previously defined cut-off distances, we measure whether a facility of type $k$ opened (closed) between the two sales within externality distance, indicated by $\Delta F A C_{k i(t+n)}=1$. We control for changes in house quality and amenities around, using vectors of control variables. We distinguish for positive changes $\Delta Q_{i(t+n)}^{\prime+}$, such as added amenities or improvements in quality, and negative changes $\Delta Q_{i(t+n)}^{\prime-}$. We control for sales year $Y_{i t}^{\prime}$ and time between two sales $(n-t)$ interacted with sales year, indicated by control vector $\Theta_{i t}^{\prime}$.

$$
\Delta p_{i(t+n)}=\alpha+\Delta Q_{i(t+n)}^{\prime+} \gamma_{1}+\Delta Q_{i(t+n)}^{\prime-} \gamma_{2}+Y_{i t}^{\prime} \gamma_{3}+\Theta_{i t}^{\prime} \gamma_{4}+\sum_{k=1}^{K} \beta_{k} \Delta F A C_{k i(t+n)}+\epsilon_{i(t+n)}
$$

It can be assumed that the housing market adjusts to openings / closings over time. In order to investigate the adjustment of the market to the opening / closing of facilities nearby, we control for the time difference between property sales and facility opening / closing years. We measure the year difference of observation $i$ at $t+n$ and the opening (closing) year of the nearest facility of all types $K$, indicated by $z(k)$. Since we are interested in time difference effects of treated observations $\left(\triangle F A C_{k i(t+n)}=1\right)$, we interact the time difference with $\Delta F A C_{k i(t+n)}$, indicated by $\Lambda_{(t+n)-z(k)}$. The final model is shown in equation (3.6).

$$
\begin{aligned}
& \Delta p_{i(t+n)}=\alpha+\Delta Q_{i(t+n)}^{\prime+} \gamma_{1}+\Delta Q_{i(t+n)}^{\prime-} \gamma_{2}+Y_{i t}^{\prime} \gamma_{3}+\Theta_{i t}^{\prime} \gamma_{4}+\sum_{k=1}^{K} \beta_{k} \Delta F A C_{k i(t+n)} \\
& +\sum_{k=1}^{K} \beta_{2 k} \Lambda_{(t+n)-z(k)}+\epsilon_{i(t+n)}
\end{aligned}
$$

\subsection{Data}

\subsubsection{Power plants}

From various sources we collect detailed information on all major Dutch power plants, present between 1985 and 2015 and using coal, gas, biomass or a combination thereof. ${ }^{19}$ We subsequently verified and completed our data with the help of all major electricity suppliers in the Netherlands. Our data contains the number of electricity generation units, fuel types per unit, capacity per unit, year of operational start, year of closing (if applicable), and geocoded location. ${ }^{20}$ We exclude all cogeneration plants on industrial

\footnotetext{
${ }^{19}$ These sources include:

Bijvoet, N., (n.d.), Centrale Info, http://centraleinfo.net/Europa/Nederland/index.html

Enipedia, (2010), Netherlands/Powerplants, http://enipedia.tudelft.nl/wiki/Netherlands/Powerplants ECN, (2005), Monitoring Nederlandse elektriciteitscentrales 2000-2004, retrieved 2015 from: https://www.ecn.nl/docs/library/report/2005/c05090.pdf

${ }^{20} \mathrm{~A}$ power plant has usually two or more electricity generation units (e.g. turbines), allowing to adjust or maintain supply. Units can be of different size (e.g. to regulate peak supply) and / or different fuel
} 
sites, cogeneration plants focusing primarily on heat generation and plants that do not produce electricity for the public grid (e.g. industrial plants). ${ }^{21}$

The final sample includes 119 power generation units located on 45 different plant sites. Figure 3.3 shows the geographical distribution of the power plants in our sample. Power plants are not systematically located in low population density regions (so as to reduce possible negative externalities), but are placed rather close to urban areas, to keep supply distances in the grid short and to ensure supply stability to urban centers. Another important factor for coal and gas plants is the closeness to fuel transportation infrastructure, such as harbors or pipelines. It is therefore not surprising that a large number of plants are located in the Rotterdam harbor area, assuring direct access to overseas supply of gas and coal.

Panel A of Table 3.1 shows an overview of the number of power plants sorted by primary fuel type. Gas and coal plants are the most prevalent by number of plants and capacity, with coal providing more than ten times as much power as biomass, and gas almost three times as much as coal. However, the range of minimum and maximum capacity shows that capacity differences across power plants, for given fuel types, are quite large. For example, the smallest gas plant in our sample has a capacity of $13 \mathrm{MW}$, while the largest is almost 100 times larger. However, capacity distributions do not differ very much between fuel types. ${ }^{22}$

type (e.g. coal / biomass).

${ }^{21}$ Cogeneration plants on industrial sites use the byproduct hot steam to generate electricity. However, these plants are usually small and not visually recognizable within the industry complex, potentially distorting our results.

${ }^{22}$ While there are some plants that can use two fuel types, we classify plants by primary fuel type. To determine primary fuel type, electricity generation units must run at least 50 percent on that fuel type. Most plants were renovated and upgraded over time, to allow for a secondary fuel type. We argue that the perception and knowledge in the surrounding area is anchored to the primary fuel type (e.g. a local resident would not necessarily notice when a coal plant partly switches to biomass fuel). 
Figure 3.3

Distribution of Wind Turbines, Power Plants and Population Density

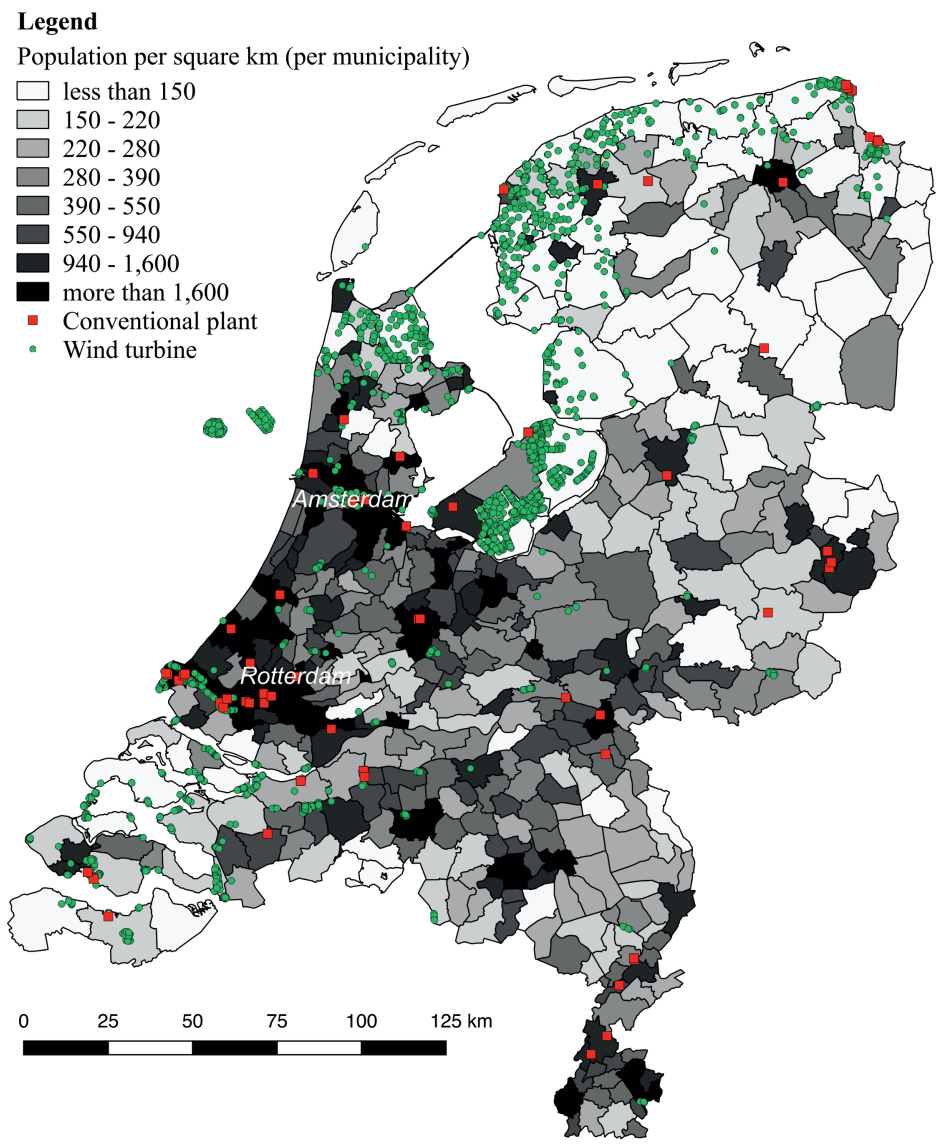

Notes: The map shows the sample area (The Netherlands). Population density per municipality is illustrated by 2006 data, retrieved from the Central Statistics Office (CBS). Offshore wind parks are illustrated on the map, but not considered in the analysis. 
Table 3.1

Conventional Power Plants and Wind Turbines

Characteristics by Primarily Fuel Type

\begin{tabular}{|c|c|c|c|c|c|}
\hline \multicolumn{6}{|c|}{ Panel A: Power plant types ${ }^{\mathrm{a}}$ (capacity in $M W$ ) } \\
\hline & (1) & $(2)$ & (3) & (4) & $(5)$ \\
\hline Type & $\begin{array}{l}\text { Number } \\
\text { of units }\end{array}$ & $\begin{array}{c}\text { Total } \\
\text { capacity }\end{array}$ & $\begin{array}{c}\text { Min. } \\
\text { capacity }\end{array}$ & $\begin{array}{c}\text { Mean capacity } \\
{[\mathrm{SD}]}\end{array}$ & $\begin{array}{c}\text { Max. } \\
\text { capacity }\end{array}$ \\
\hline Gas & 95 & 22,318 & 13 & $\begin{array}{c}235 \\
{[203]}\end{array}$ & 1,275 \\
\hline Coal & 19 & 8,313 & 120 & $\begin{array}{l}438 \\
{[288]}\end{array}$ & 1,100 \\
\hline Biomass & 5 & 936 & 25 & $\begin{array}{c}187 \\
{[343]}\end{array}$ & 800 \\
\hline \multicolumn{6}{|c|}{ Panel B: Wind turbine characteristics } \\
\hline & (1) & $(2)$ & $(3)$ & $(4)$ & $(5)$ \\
\hline Characteristics & $\begin{array}{l}\text { Number } \\
\text { of units }\end{array}$ & $\begin{array}{c}\text { Total } \\
\text { capacity }\end{array}$ & Minimum & $\begin{array}{l}\text { Mean } \\
{[\mathrm{SD}]}\end{array}$ & Maximum \\
\hline $\begin{array}{l}\text { Capacity } \\
\text { (in } \mathrm{kW} \text { ) }\end{array}$ & 2,117 & $2,946,321$ & 15 & $\begin{array}{c}1,393 \\
{[1,066]}\end{array}$ & 7,500 \\
\hline $\begin{array}{l}\text { Height } \\
\text { (in meter) }\end{array}$ & & & 18 & $\begin{array}{c}61.53 \\
{[22.24]}\end{array}$ & 136 \\
\hline $\begin{array}{l}\text { Rotor diameter } \\
\text { (in meter) }\end{array}$ & & & 9 & $\begin{array}{c}59.18 \\
{[24.07]}\end{array}$ & 127 \\
\hline Operational years $^{\mathrm{b}}$ & & & 2 & 13 & 20 \\
\hline
\end{tabular}

Notes: Standard deviation in brackets. $1 \mathrm{MW}=1,000 \mathrm{~kW}$

a Sorted by primary fuel type. ${ }^{\mathrm{b}}$ Based on 61 wind turbines that went out of operation.

Panel A of Figure 3.4 shows the installed capacity and the respective number of electricity generation units per fuel type per year. The majority of installed units during the sample period are gas units. The first plant primarily running on biomass was installed in 2000. The popularity of coal energy decreased over the same period, with no new facilities added for nearly 20 years between 1994 and 2014. Only in 2015 did the utility company Essent start operating the newly built Eemshavencentrale, the Netherlands' biggest and most modern coal plant. 
Figure 3.4

Yearly Installations of Power Generation Facilities

Panel A: Conventional Installed Capacity (Number of Units in Label) per Type

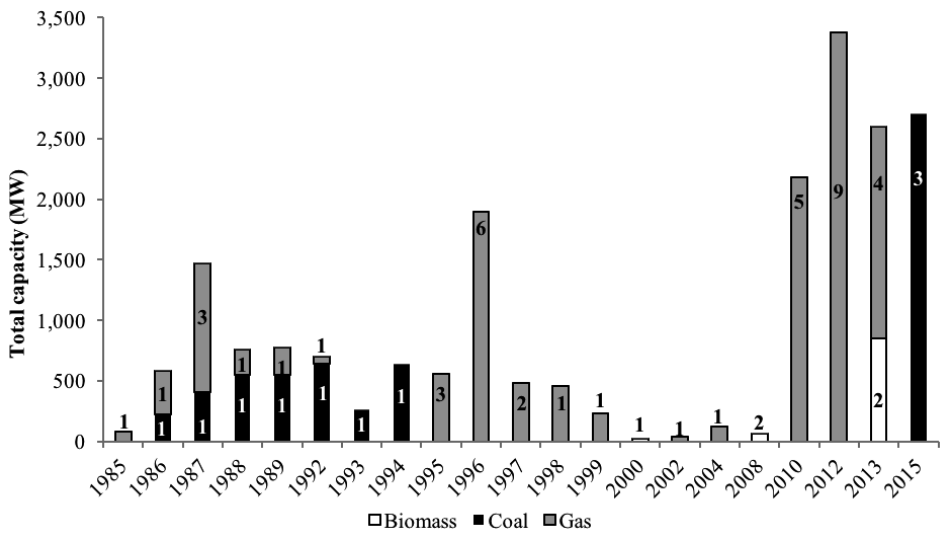

Panel B: Wind Turbine Placements and Average Capacity per Wind Turbine

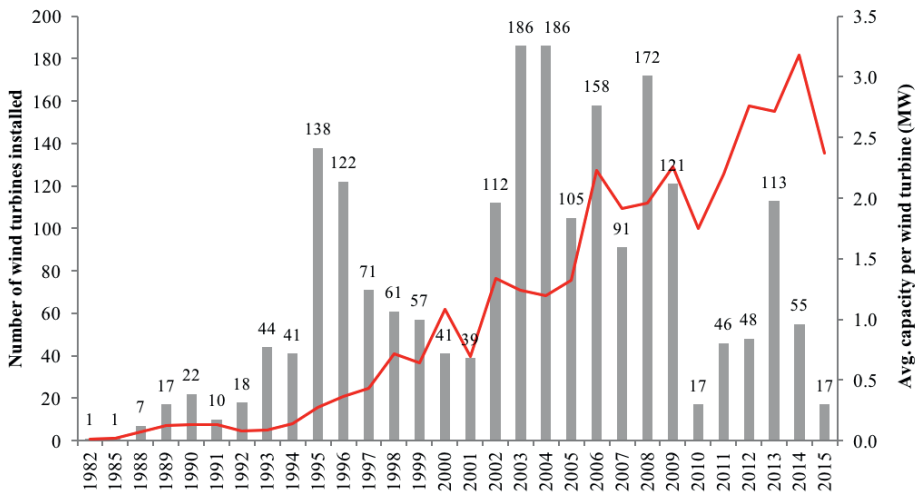

Wind turbines installed $\quad$ Avg. installed capacity

Notes: Panel A shows the total yearly installed capacity for biomass, coal and gas plants. In addition, the respective number of electricity generation units are shown to illustrate capacity magnitudes. Since there are years without power plant openings, there are gaps in the timeline.Panel B illustrates the average capacity per wind turbine, per year installed over the respective number of units.

\subsubsection{Wind turbines}

Information on wind turbines in the Netherlands is well-documented, including location, capacity, height, rotor diameter, setup year, dismantling year, and park affiliation. Using data from Windstats (2015), we consider all wind turbines that were operational at some point between 1985 and 2015. Our sample consist of 2,117 individual wind turbines, 
clustered in 217 wind parks. Figure 3.3 shows the geographical distribution of all wind turbines in the sample, compared to the distribution of conventional power plants and related to population density. Most wind turbines are located in the north-western coastal area, where wind speed is highest. Furthermore, wind turbines tend to be placed in relatively low-density areas, sometimes located close to densely populated areas.

As shown in Panel B of Table 3.1, the average wind turbine in the Netherlands has a capacity of 1.4 MW and the largest Dutch wind turbine has a capacity of $7.5 \mathrm{MW}$, which is less than the smallest power plant in our sample. The capacity distribution of wind turbines is widely spread compared to power plants, with the largest turbine having 500 times more capacity than the smallest. Panel B of Figure 3.4 shows the development of wind turbines installed in the Netherlands and the technological development over time. The average capacity per wind turbine increases over time, from $15 \mathrm{~kW}$ in 1982 to an average capacity of $3 \mathrm{MW}$. Modern wind turbines have not only more efficient generators but are also higher with larger rotor diameters. The average sample height is 61.5 meters and the average rotor diameter is 59 meter. During the sample period, 61 wind turbines were dismantled after an average life span of 13 years.

\subsubsection{Housing transactions}

We employ a detailed dataset of housing transactions, consisting initially of nearly 3 million observations between 1985 and the first quarter of 2015. The dataset is provided by the Dutch realtors' association (NVM), which covers around 70 percent of Dutch housing transactions. The dataset contains address, transaction price, structural and environmental information, as well as sales information, such as initial asking price and time on the market. We use Bing Maps through an Application Programming Interface (API) to determine longitude and latitude information per address. After excluding double entries, outliers, and observations with incomplete information, we end up with approximately 2.3 million transactions.

We match data on power plants, wind turbines and housing transactions based on longitude and latitude, using GIS. To control for systematic differences between locations, we add additional information on the municipal level to the dataset. The Dutch Statistics Office (CBS) provides information about population density and land use per municipality, which we use to identify urban centers and rural areas. ${ }^{23}$

At a cut-off distance of $2.5 \mathrm{~km}$, there are 339,931 houses within externality distance of electricity generation facilities, distributed by facility type as follows: 1,772 biomass, 10,779 coal, 152,093 gas, and 185,598 wind. ${ }^{24}$ We notice that the number of observations within "external effect" distance is limited for biomass and coal plants. Appendix Figure 3.5 shows the percentage of affected observations over time. The number of observations close to coal, gas and biomass plants does not change significantly over time, whereas the

\footnotetext{
${ }^{23}$ We use zoning and land use data, which are available for the years between 1996 and 2015 . For older years, we estimate data based on averages and time trends as land use stays relatively constant over time. Population density data are provided on the municipality level and provide a ranking from "very urbanized" to "rural". We use the first two levels ("very urbanized" and "urbanized") to define urban areas.

${ }^{24}$ Some observations are within externality distance of different electricity generation facility types (e.g. coal and wind), thus the sum of individual electricity generation facility exposures does not match the overall number of affected observations. We test for the interaction effect of being in external distance of different electricity generation facilities, but we do not find a significant effect.
} 
number of observations close to wind turbines changes markedly. Since the spatial distribution of houses is relatively stable over time, this implies that more wind turbines get positioned close to housing over time, confirming the convergence of renewable electricity generation and urban space.

Table 3.2 shows the average characteristics of houses and apartments in close proximity to power plants, as well as the characteristics of homes in the control sample (4 $\mathrm{km}<d<10 \mathrm{~km})$. There are relatively more apartments in the affected group. While apartments in both groups have roughly the same size, houses in the affected group are smaller than houses in the control group, on average. Apartments and houses tend to be lower priced in the affected group, both in absolute terms and on a per square meter basis. However, this is not necessarily due to quality characteristics or urban location, as both characteristics show that properties in affected areas are on average of better quality and in higher urbanized areas. ${ }^{25}$

Table 3.2

Descriptive Statistics: Housing Sample 1985 - 2015

\begin{tabular}{lcccc}
\hline & \multicolumn{2}{c}{$\begin{array}{c}\text { Generation facility } \\
(<2.5 \mathrm{~km})\end{array}$} & \multicolumn{2}{c}{$\begin{array}{c}\text { Generation facility } \\
(>4 \mathrm{~km})\end{array}$} \\
\hline Variable & Houses & Apartments & Houses & Apartments \\
No. of Observations & 222,399 & 117,532 & 739,818 & 343,926 \\
\hline Size & 126 & 86 & 133 & 86 \\
(in m2) & {$[42]$} & {$[27]$} & {$[43]$} & {$[27]$} \\
Price & 248,018 & 174,943 & 276,319 & 204,879 \\
(in Euro) & {$[145,761]$} & {$[83,094]$} & {$[181,513]$} & {$[122,548]$} \\
Price per m2 & 1,946 & 2,058 & 2,035 & 2,404 \\
(in Euro) & {$[727]$} & {$[717]$} & {$[841]$} & {$[1,032]$} \\
Housing inside quality & 3.04 & 2.96 & 2.98 & 2.85 \\
$(1=$ worst, $9=$ best) & {$[1.18]$} & {$[1.20]$} & {$[1.16]$} & {$[1.15]$} \\
Housing outside quality & 3.01 & 2.91 & 2.95 & 2.80 \\
$(1=$ worst, $9=$ best) & {$[1.09]$} & {$[0.93]$} & {$[1.08]$} & {$[0.88]$} \\
Highway within 200m & 0.08 & 0.11 & 0.07 & 0.12 \\
$(1=$ yes) & {$[0.27]$} & {$[0.31]$} & {$[0.26]$} & {$[0.32]$} \\
Urbanization & 2.58 & 1.38 & 2.98 & 1.87 \\
$(1=$ highest, $5=$ lowest $)$ & {$[1.38]$} & {$[0.72]$} & {$[1.15]$} & {$[0.88]$} \\
\hline
\end{tabular}

Notes: Standard deviation in brackets. All property type mean differences between groups are significant using Welch's t-test. Inside and outside quality are ratings performed by NVM on the overall condition of the property. Both variables are measured on a scale from $1=$ best, to $9=$ worst. Highway measures whether there is a highway within 200 meters of the observation. A higher average value, shows a higher likelihood of having a highway close to the observation. Urbanization measure the level of urbanization of the respective municipality on a scale from 1 (highest) to 5 (lowest). The externality group is defined by $2.5 \mathrm{~km}$ cut-off distance for all electricity generation types. The omission corridor is of $1.5 \mathrm{~km}$ length and the control group is included up to a distance of $10 \mathrm{~km}$.

\subsection{Results}

\subsubsection{Difference-in-difference results}

Appendix Table 3.8 shows the groupings of observations based on the described method in Section 3.3.2. We note a small number of observations for some facility types and

\footnotetext{
${ }^{25}$ Using Welch's t-test, all differences are statistically significant.
} 
times, forcing us to exclude coal plants from the opening analysis. ${ }^{26}$ Due to long lifespans of coal plants and the novelty of biomass and wind, we document less observations for facility closings than for openings. Appendix Figure 3.6 plots the average price per square meter per year over time, examining the simultaneous trend assumption, and we notice that pre-opening and pre-closing trends follow a quite similar trend. ${ }^{27}$

As shown in Table 3.3, we document a significant positive price effect for homes around gas plants, ranging from 4.0 to 4.6 percent and a negative price effect of 6.0 percent for homes around biomass plants, at a $3 \mathrm{~km}$ cut-off distance only. Homes in wind turbine areas show no significant price effect per se, meaning there is no ex-ante price difference. For openings, we document a negative price effect of 4.9 percent to 5.9 percent for gas plants and a negative price effect of 1.8 percent to 2.1 percent for wind turbines. In contrast, biomass plant openings lead to a positive price effect of 4.2 percent to 9.8 percent.

Examining the heterogeneity over distance, Table 3.4 shows the external effect results for different distance intervals. For gas plant openings, we document a positive opening effect at a distance of up to $1 \mathrm{~km}$ distance and significant negative opening effects thereafter. We do not observe enough observations within $1 \mathrm{~km}$ distance of biomass plants. Beyond this distance we document a positive opening effect thereafter. Wind turbine openings show a constant negative effect up to a distance of $4 \mathrm{~km}$. Overall, we document constant effects for wind turbines, decreasing effects for biomass plants and mixed effects for gas plants.

Differentiating urban and rural areas, we document significant location discounts for homes in biomass plant areas and wind turbine areas. ${ }^{28}$ In rural areas, we document a significant positive opening effect between 7.8 to 6.0 percent for gas plants, and 9.3 percent for biomass plant openings, while documenting a negative opening effect between 0.7 to 1.4 percent for wind turbine openings. In contrast, we document significant negative opening effects for all plant types in urban areas, ranging from an additive -14.1 to -10.7 percent for gas plants, -9.7 percent for biomass plants, and -1.2 percent for wind turbines. Our results show that electricity generation facilities are generally perceived negatively in urban areas.

Examining the interaction between plant openings and size, columns five and six differentiating for gas plant size (in capacity) and wind turbine park size (in number of turbines). We document a positive significant opening effect of 4.5 percent for small gas plants $(<100 \mathrm{MW})$ and an opening discount of 5.1 percent for large gas plants $(>400 \mathrm{MW})$. We do not document a significant opening effect for plans in the range of $100-400 \mathrm{MW}$. For wind turbine areas, we document negative opening effect of 2.4 percent for single turbines, 1.9 percent for parks up to 10 turbines, and 2.8 percent for parks with more than 30 turbines. Our results show that the negative external effects of electricity generation facility openings do not necessarily increase with facility size.

\footnotetext{
${ }^{26}$ The small number of observations for coal plant openings can be explained by three facts: the remote location of coal plants in general, the combined location with other facility types, such as gas plants, leading to an exclusion of observations from the pre-opening group, and the dearth of new coal plant openings over our sample period.

${ }^{27} \mathrm{Coal}$ plants are excluded from the analysis since we do not have enough observations per year.

${ }^{28}$ We find that 92 percent of gas plants are located in urban areas, compared to 55 percent of wind turbines and 25 percent of biomass plants, suggesting that differentiating for urban locations is important.
} 
Table 3.3

Results Area DID opening

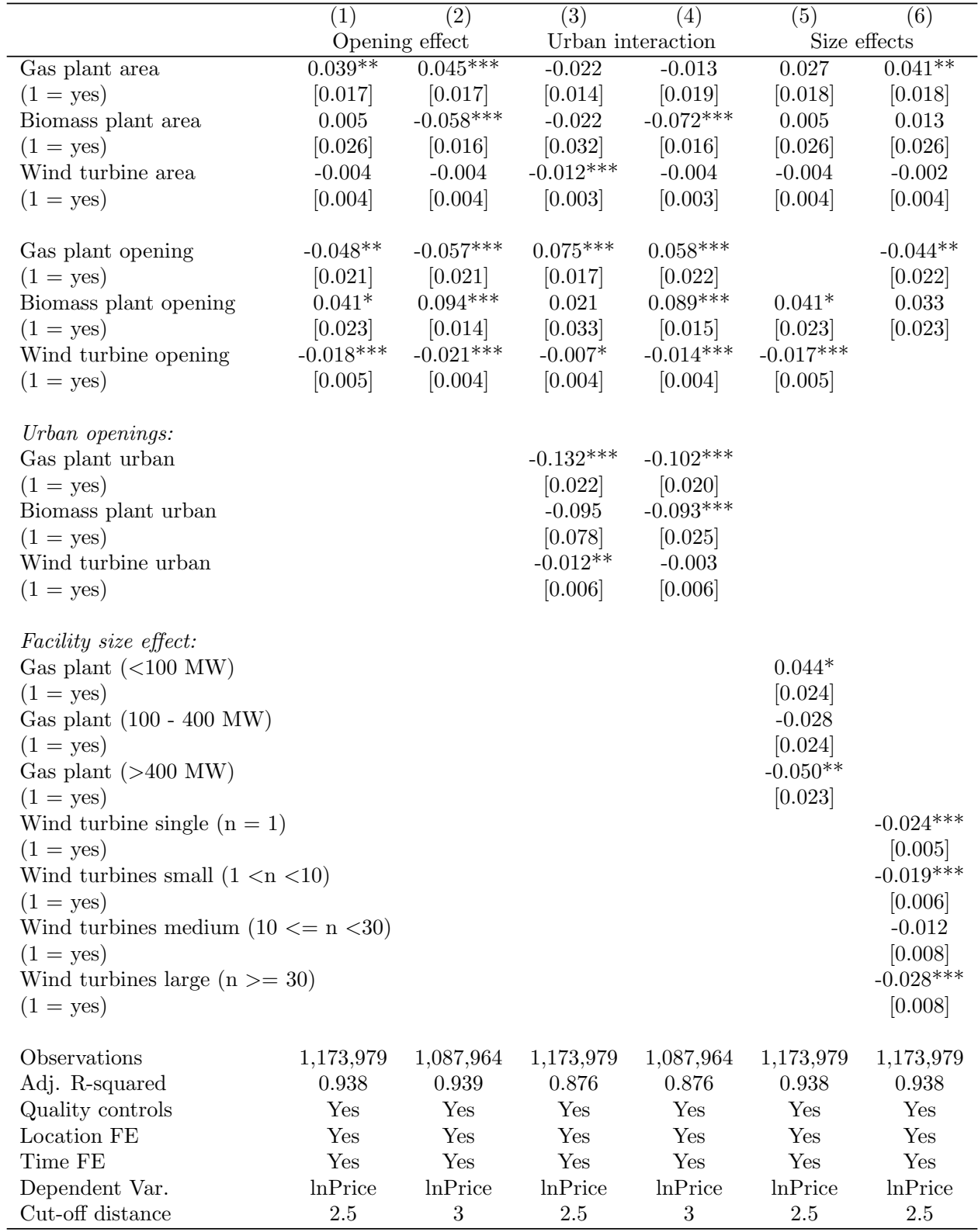

Notes: Standard errors in parentheses, ${ }^{* * *} \mathrm{p}<0.01,{ }^{*} * \mathrm{p}<0.05, * \mathrm{p}<0.1$. All distances in $\mathrm{km}$. The maximum distance considered is $10 \mathrm{~km}$, the holdout distance is $1 \mathrm{~km}$. The opening effect dummy for coal plants is omitted, due to the small group size. Urban effects are estimated by additional urban-treatment interaction terms. Urban area is defined by the level of urbanization of the respective municipality: scale from 1 (highest) to 5 (lowest). We define municipalities above a scale of 3 as urbanized. Column (5) distinguished for different gas plant sizes, using capacity as a size indicator. Column (6) uses the number of wind turbines per park. The results of column (5) and (6) are robust for a $3 \mathrm{~km}$ cut-off distance, but not reported due to space limitations. 
Table 3.4

Results Area DID opening

\begin{tabular}{|c|c|}
\hline & $\begin{array}{c}(1) \\
\text { Opening effect }\end{array}$ \\
\hline Gas plant opening $(0-1 \mathrm{~km})$ & $0.034^{* *}$ \\
\hline$(1=$ yes $)$ & {$[0.014]$} \\
\hline Gas plant opening $(1-2 \mathrm{~km})$ & $-0.045^{*}$ \\
\hline$(1=$ yes $)$ & {$[0.027]$} \\
\hline Gas plant opening $(2-3 \mathrm{~km})$ & $-0.059 * * *$ \\
\hline$(1=$ yes $)$ & {$[0.019]$} \\
\hline Gas plant opening $(3-4 \mathrm{~km})$ & $-0.047^{* *}$ \\
\hline$(1=$ yes $)$ & {$[0.018]$} \\
\hline Biomass plant opening $(1-2 \mathrm{~km})$ & -0.058 \\
\hline$(1=$ yes $)$ & {$[0.062]$} \\
\hline Biomass plant opening $(2-3 \mathrm{~km})$ & $0.094^{* * *}$ \\
\hline$(1=$ yes $)$ & {$[0.014]$} \\
\hline Biomass plant opening $(3-4 \mathrm{~km})$ & $0.036^{* *}$ \\
\hline$(1=$ yes $)$ & {$[0.016]$} \\
\hline Wind turbine opening $(0-1 \mathrm{~km})$ & $-0.020^{* * *}$ \\
\hline$(1=$ yes $)$ & {$[0.007]$} \\
\hline Wind turbine opening $(1-2 \mathrm{~km})$ & $-0.021^{* * *}$ \\
\hline$(1=$ yes $)$ & {$[0.005]$} \\
\hline Wind turbine opening $(2-3 \mathrm{~km})$ & $-0.020^{* * *}$ \\
\hline$(1=$ yes $)$ & {$[0.004]$} \\
\hline Wind turbine opening $(3-4 \mathrm{~km})$ & $-0.014^{* * *}$ \\
\hline$(1=$ yes $)$ & {$[0.003]$} \\
\hline Observations & $1,196,458$ \\
\hline Adj. R-squared & 0.938 \\
\hline Quality controls & Yes \\
\hline Location FE & Yes \\
\hline Time FE & Yes \\
\hline Dependent Var. & $\ln$ Price \\
\hline Max. distance considered & 10 \\
\hline \multicolumn{2}{|c|}{$\begin{array}{l}\text { Notes: Standard errors in parentheses, }{ }^{* * *} \mathrm{p}<0.01, \\
\mathrm{p}<0.05,{ }^{*} \mathrm{p}<0.1 . \text { All distances in } \mathrm{km} \text {. The maximum dis- } \\
\text { tance considered is } 10 \mathrm{~km} \text {. For space reasons, we only report } \\
\text { the coefficients of opening effects. Due a limited number of ob- } \\
\text { servations, there is no estimation for biomass plant openings } \\
\text { within } 0-1 \mathrm{~km} \text {. We do not use a holdout group in this setup. }\end{array}$} \\
\hline
\end{tabular}

Examining the heterogeneity of openings over time, we estimate our model for different sub-periods of 10 years length as shown in Appendix Table 3.9. We miss sufficient number of observations for some facility types and time periods. The results are mostly in line with previous findings or insignificant. We document significant negative opening effects for gas plants in the periods 1990 - 2000 (-9.5 percent) and $2005-2015$ (-5.1 percent). Biomass openings result in significant positive effects between 2.4 to 4.2 percent throughout all available periods. Wind turbine openings result in significant negative effects of -2.4 percent for the period 1995 to 2005, the first boom periods of wind turbines.

Table 3.5 presents the results for facility closings, comparing to areas with remaining facilities. ${ }^{29}$ We document no significant closing effect for coal plants. Gas plant closings,

\footnotetext{
${ }^{29}$ We do not document significant facility area price effects and do therefore not report estimates for
} 
show significant negative effects of -3.9 percent at a $3 \mathrm{~km}$ cut-off distance. For biomass plants, we document a significant negative closing effects between -7.7 and -6.0 percent. Wind turbine removals (closings) result in positive effect of 6.7 percent at a $2.5 \mathrm{~km}$ cut-off distance. Differentiating for gas plant size, we document that negative closing effects of gas plants are higher for plants above $100 \mathrm{MW}$, ranging from -6.6 to -5.4 percent. For gas plants below $100 \mathrm{MW}$, we document a negative closing effect at $3 \mathrm{~km}$ cut-off distance, significant at $10 \%$ level. ${ }^{30}$ Overall, we document positive closing effects for wind turbines and negative closing effects for biomass and gas plants, compared to areas remaining in proximity to these facilities.

Table 3.5

Results Area DID closing

\begin{tabular}{|c|c|c|c|c|}
\hline & (1) & $(2)$ & $(3)$ & (4) \\
\hline & \multicolumn{2}{|c|}{ Closing effect } & \multicolumn{2}{|c|}{ Size effects } \\
\hline Coal plant closing & $\overline{-0.047}$ & $\overline{-0.020}$ & 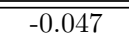 & 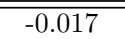 \\
\hline$(1=$ yes $)$ & {$[0.045]$} & {$[0.033]$} & {$[0.043]$} & {$[0.032]$} \\
\hline Gas plant closing & -0.028 & $-0.038 * * *$ & & \\
\hline (1 = yes $)$ & {$[0.018]$} & {$[0.014]$} & & \\
\hline Biomass plant closing & $-0.074^{* * *}$ & $-0.058 * * *$ & $-0.066^{* * *}$ & $-0.051^{* *}$ \\
\hline$(1=$ yes $)$ & {$[0.021]$} & {$[0.021]$} & {$[0.020]$} & {$[0.020]$} \\
\hline Wind turbine closing & $0.065^{* *}$ & 0.024 & $0.057^{*}$ & 0.017 \\
\hline$(1=$ yes $)$ & {$[0.032]$} & {$[0.024]$} & {$[0.032]$} & {$[0.023]$} \\
\hline \multicolumn{5}{|l|}{ Facility size interaction: } \\
\hline Gas plant $(<100 \mathrm{MW})$ & & & -0.012 & $-0.023^{*}$ \\
\hline$(1=$ yes $)$ & & & {$[0.017]$} & {$[0.013]$} \\
\hline Gas plant $(>100 \mathrm{MW})$ & & & $-0.053^{* *}$ & $-0.064^{* * *}$ \\
\hline (1 = yes $)$ & & & {$[0.022]$} & {$[0.019]$} \\
\hline Observations & 93,478 & 123,476 & 93,478 & 123,476 \\
\hline R-squared & 0.884 & 0.884 & 0.884 & 0.884 \\
\hline Quality controls & Yes & Yes & Yes & Yes \\
\hline Location FE & Yes & Yes & Yes & Yes \\
\hline Time FE & Yes & Yes & Yes & Yes \\
\hline Dependent Var. & $\ln$ Price & $\ln$ Price & $\ln$ Price & $\operatorname{lnPrice}$ \\
\hline Cut-off distance & 2.5 & 3 & 2.5 & 3 \\
\hline \multicolumn{5}{|l|}{$\mathrm{N}$ affected by closing: } \\
\hline Coal & 134 & 132 & 134 & 132 \\
\hline Gas & 18,814 & 23,688 & 18,814 & 23,688 \\
\hline Biomass & 463 & 585 & 463 & 585 \\
\hline Wind & 416 & 339 & 416 & 339 \\
\hline
\end{tabular}

Notes: Standard errors in parentheses, ${ }^{* * *} \mathrm{p}<0.01,{ }^{* *} \mathrm{p}<0.05,{ }^{*} \mathrm{p}<0.1$. All distances in $\mathrm{km}$. The maximum distance considered is $20 \mathrm{~km}$, the holdout distance is $1.5 \mathrm{~km}$. The closing effect dummy for coal plants was omitted, due to the small group size. Urban effects are estimated by additional urban-treatment interaction terms. Urban area is defined by the level of urbanization of the respective municipality: scale from 1 (highest) to 5 (lowest). We define municipalities above a scale of 3 as urbanized. Due to limited variation in size (only 30 observations with $>400 \mathrm{MW}$ ), we sort gas plants around the $100 \mathrm{MW}$ cutoff. For wind turbines, we do not observe closings for parks with more than 10 turbines.

space reasons. As for all tables, complete estimation tables are available upon request.

${ }^{30}$ Unfortunately, we do not have enough variation in the sample to differentiate for urban and rural areas, as most closings occur in rural areas. Similarly, most closings occur in the years between 2005 and 2015, not allowing to explore heterogeneity over time. 


\subsubsection{Repeated sales results}

Since the repeated sale model analysis differs slightly from the previous specifications, we examine the fit of our model in Appendix Table 3.10. We document that the explanatory power is slightly lower than of our previous model specifications. The coefficients make intuitive sense and are in line with former results. In general, adding amenities or increasing quality increases property value, whereas the removal of amenities, such as a terrace, diminishes property value.

Table 3.6 shows the estimation results for openings and closings. We document significant negative facility opening effects for gas plants and wind turbines. Gas plant openings in the area lead to a 9.5 percentage points lower price between sales, whereas wind turbine openings result in a 2.7 percentage points lower price. The effect is robust at $3 \mathrm{~km}$ cut-off distance, as shown in Appendix Table 3.11. Controlling for the time between facility openings and property sales, the negative opening effect of gas plants and wind turbines remains. However, the effect diminishes over time. For wind turbines, one year difference results in an increase of 0.4 percentage points. We also document a positive effect for biomass plants (1.1 percentage points) even though we do not document a general opening effect. We do not document a significant time difference-effect for gas plants.

Since we do not observe enough transactions to investigate other closings, we focus on gas plants only. In contrast to the DID closing analysis in section 3.5.1, we document positive closing effects of gas plants, ranging from 5.3 to 6 percentage points, not diminishing over time. However, the underlying sample of the closing analysis is small and the effects become nearly insignificant at $3 \mathrm{~km}$ cut-off distance (see Appendix Table 3.11 ) and should therefore be taken with caution. 
Table 3.6

Results Repeated Sales

\begin{tabular}{|c|c|c|c|c|}
\hline & $\begin{array}{c}(1) \\
\text { Opening }\end{array}$ & $\begin{array}{c}(2) \\
\text { Opening }\end{array}$ & $\begin{array}{c}(3) \\
\text { Closing }\end{array}$ & $\begin{array}{c}(4) \\
\text { Closing } \\
\end{array}$ \\
\hline $\begin{array}{l}\text { Gas plant opening } \\
\text { (1= yes) } \\
\text { Biomass plant opening } \\
\text { (1= yes) } \\
\text { Wind turbine opening } \\
\text { (1= yes) } \\
\text { Gas plant opening time difference } \\
\text { (no. years) } \\
\text { Biomass plant opening time difference } \\
\text { (no. years) } \\
\text { Wind turbine opening time difference } \\
\text { (no. years) }\end{array}$ & $\begin{array}{c}-0.095^{* * *} \\
{[0.026]} \\
0.021 \\
{[0.024]} \\
-0.027 * * * \\
{[0.006]}\end{array}$ & $\begin{array}{c}-0.107^{* * *} \\
{[0.028]} \\
-0.012 \\
{[0.024]} \\
-0.036^{* * *} \\
{[0.006]} \\
0.008 \\
{[0.010]} \\
0.011^{* *} \\
{[0.004]} \\
0.004^{* *} \\
{[0.002]}\end{array}$ & & \\
\hline $\begin{array}{l}\text { Closing analysis: } \\
\text { Gas plant closing } \\
(1=\text { yes) } \\
\text { Gas plant closing time difference } \\
\text { (no. years) }\end{array}$ & & & $\begin{array}{c}0.053^{* *} \\
{[0.024]}\end{array}$ & $\begin{array}{c}0.060^{* *} \\
{[0.027]} \\
0.004 \\
{[0.004]}\end{array}$ \\
\hline $\begin{array}{l}\text { Observations } \\
\text { Adj. R-squared } \\
\text { Location FE } \\
\text { Time Controls } \\
\text { Dependent Var. } \\
\text { Cut-off distance } \\
\text { Holdout distance } \\
\text { Max. distance }\end{array}$ & $\begin{array}{c}228,632 \\
0.726 \\
\text { Yes } \\
\text { Yes } \\
\Delta \text { Price } \\
2.5 \\
1.5 \\
20\end{array}$ & $\begin{array}{c}228,632 \\
0.726 \\
\text { Yes } \\
\text { Yes } \\
\Delta \text { Price } \\
2.5 \\
1.5 \\
20\end{array}$ & $\begin{array}{c}15,318 \\
0.715 \\
\text { Yes } \\
\text { Yes } \\
\Delta \text { Price } \\
2.5 \\
1.5 \\
20\end{array}$ & $\begin{array}{c}15,318 \\
0.715 \\
\text { Yes } \\
\text { Yes } \\
\Delta \text { Price } \\
2.5 \\
1.5 \\
20\end{array}$ \\
\hline
\end{tabular}

Notes: Standard errors in parentheses, $* * * \mathrm{p}<0.01,{ }^{*} \mathrm{p}<0.05, * \mathrm{p}<0.1$. Dependent variable is the percentage change in price between sales. The time difference accounts for the time between the opening / closing and a sale, if an observation was affected by an opening / closing. We only have enough observations to examine gas plant closings. The results are robust for a $3 \mathrm{~km}$ cut-off distance, as indicated in the Appendix.

\subsection{Discussion and conclusion}

This is the first study analyzing the effects of different electricity generation types on house prices, using an extensive dataset and testing different model specifications for plant openings and closings. Our results are in line with the literature (e.g. Davis, 2011; Dröes \& Koster, 2016; Gibbons, 2015). Wind turbines proximity and openings result in negative property price effect, whereas removals of wind turbines can result in positive effects. Coal plant proximity and closings do not result in significant price effects. Gas plant proximity results in positive price effects, however decomposing the effect for openings and closings, we find that gas plant areas are higher priced compared to other electricity generation facility areas, with openings resulting in negative effects. Biomass plant proximity and openings result in positive price effects, whereas closings result in negative price effects.

Whereas the external effects differ in general, we document solely negative price effects for all facility types in urban areas. We further document that size does not play a big role, except for very small conventional plants, which seem to cause fewer external ef- 
fects. Combining these two findings, we argue the external effects of electricity generation facilities do not depend on the size of the facility and negative effects outweigh potential positive effects in urban areas. We further document that some external effects, such as for coal plants, change over time, which could be due to technological developments.

The documented differences in external effects can have different reasons, such as environmental externalities (e.g. air pollution), perception, and economic effects. However, especially the latter play a big role in plant locations, since power plants generally create employment and infrastructure, such as streets (e.g. see Tourkolias et al., 2009). In contrast, wind turbines create limited local employment and infrastructure investments. Economic external effects are generally weaker in urban areas and constant per plant, which could explain constant effects by size and negative effects for urban areas, where other external effects, such as perception, dominate. ${ }^{31}$

The documented results have strong implications for the composition of local electricity supply and placement decisions. Not only do wind turbines create less local employment, their presence also results in value losses for local home owners. Considering the average house price in our sample and average opening effects, wind turbine placements result in value losses of $€ 3,680$ to $€ 4,732$ on local houses, on average. In contrast, the opening of conventional power plants, which could run on sustainable biomass fuel, lead to positive price effects of $€ 16,562$, on average. A potential idea to compensate the negative effects from wind turbines, is to offer local residents the opportunity to co-invest in nearby wind parks. This would create local financial benefits and affect the attitude towards nearby wind turbines (Warren \& McFadyen, 2010).

\footnotetext{
${ }^{31}$ Back-of-the-envelope estimations from our contacts at the biggest energy suppliers in the Netherlands result in 600 - 800 jobs being created from one conventional power plant. However, we cannot confirm these statistics, since we have no access to micro-level employment data.
} 


\subsection{Appendix}

\section{Figure 3.5}

Percentage of Observations Affected by Externalities (per Year)

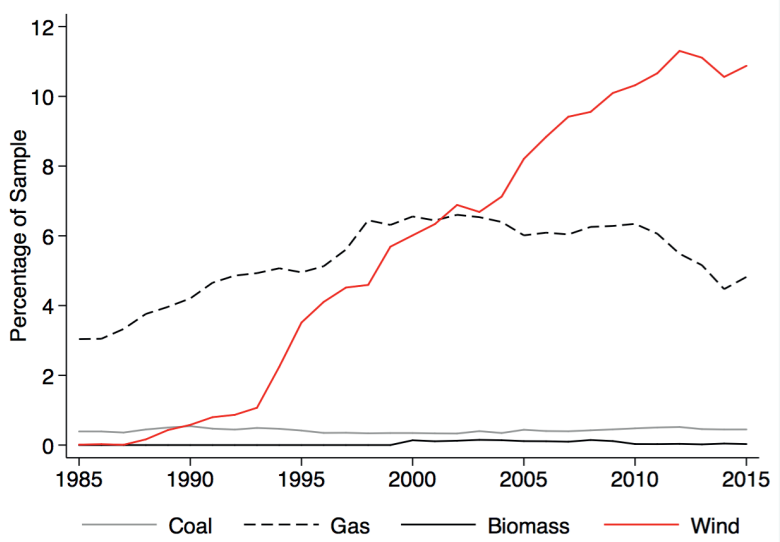

Notes: This figure shows the installation of new power plants and wind turbines, analyzing the convergence of energy generation and urban space. The yearly percentage of observations within externality distance $(2.5 \mathrm{~km})$ is illustrated. 
Figure 3.6

Simultaneous Trend Analysis

Average price per $\mathrm{m}^{2}$ around facility openings \& closings
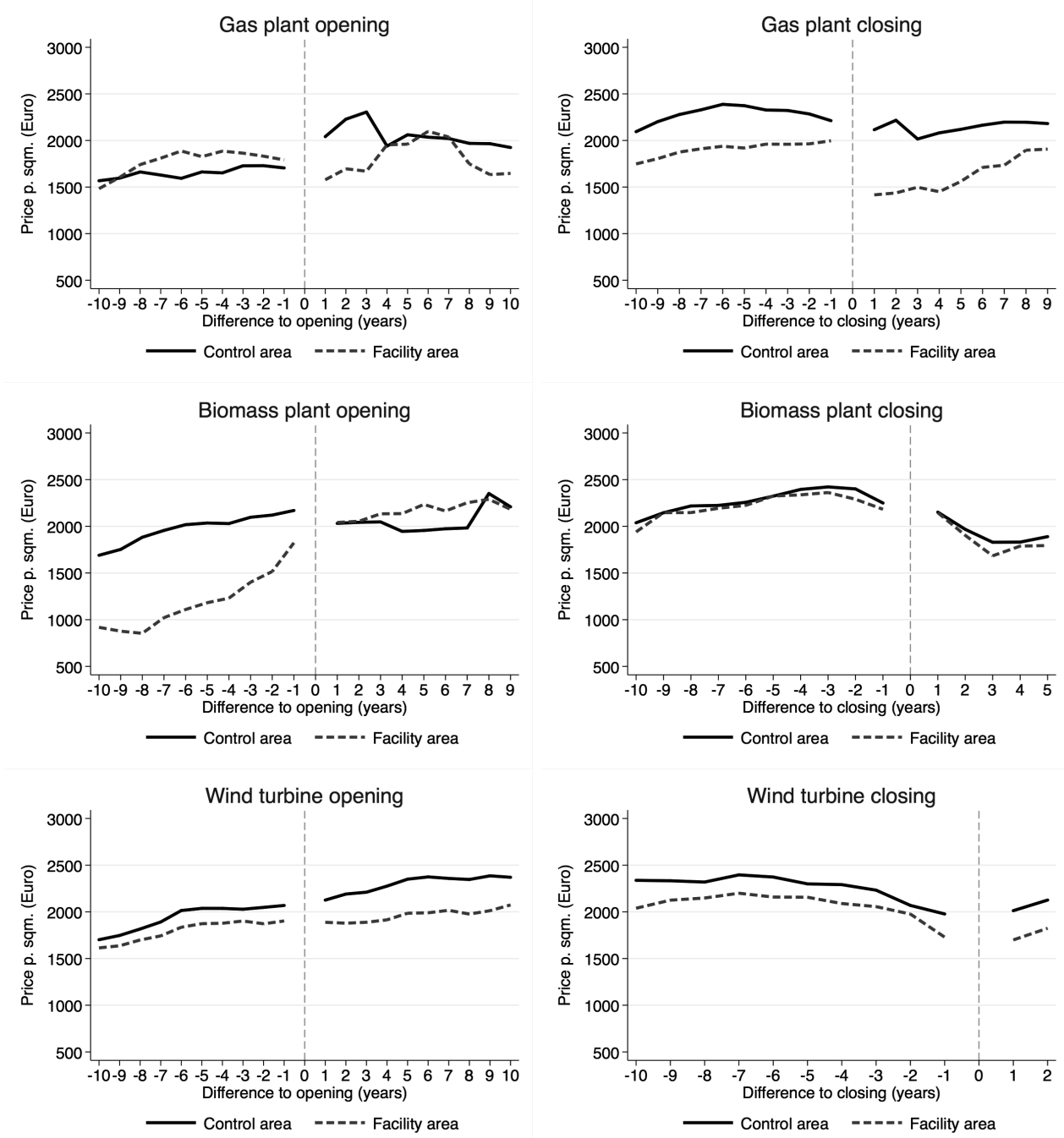

Notes: We compare the average price per $\mathrm{m}^{2}$ in the plant/turbine areas, prior to facility opening, with the average price per $\mathrm{m}^{2}$ in respective control areas nearby. Due to the limited number of observations, we exclude coal plant areas from the analysis. We do not have observations for all years around openings and closings, e.g. we only have observations two years after wind turbine closings. The opening / closing year is excluded from the analysis. 
Table 3.7

Control Variables

\begin{tabular}{|c|c|}
\hline Structural & Apartment type (dummy) \\
\hline Size $\left(\mathrm{m}^{2}\right)$ & Upstairs apartment \\
\hline Number of floors & Two-floor apartment \\
\hline Number of rooms & Maisonette apartment \\
\hline Number of bathrooms & Old block apartment \\
\hline D: Roof terrace & New block apartment (suburb) \\
\hline \multicolumn{2}{|l|}{ D: Parking lot } \\
\hline D: Garden & Apart. quality normal \\
\hline D: Garden quality bad & Apart. quality luxurious \\
\hline Construction period (dummy) & Heating type \\
\hline Construction 1906 - 1930 & D: Heating: coal or oven \\
\hline Construction 1931 - 1945 & D: Heating: central or tele-heating \\
\hline Construction 1945 - 1959 & D: Heating: $\mathrm{AC}$ or solar \\
\hline \multicolumn{2}{|l|}{ Construction $1960-1970$} \\
\hline Construction 1971 - 1980 & Insulation (dummy) \\
\hline Construction 1981 - 1990 & One level of insulation \\
\hline Construction 1991 - 2000 & Two levels of insulation \\
\hline \multirow[t]{2}{*}{ Construction 2001 and later } & Three levels of insulation \\
\hline & Four levels of insulation \\
\hline House type I (dummy) & Five or more levels of insulation \\
\hline \multicolumn{2}{|l|}{ Caravan } \\
\hline Living boat & House type II (dummy) \\
\hline Recreational home & Terraced house \\
\hline Single home & Corner house \\
\hline Grachtenpand (old house at canal) & Semi-detached house \\
\hline Manor house (without land) & Detached house \\
\hline \multicolumn{2}{|l|}{ Manor house (with land) } \\
\hline Old farm house & D: Close to highway $(<200 \mathrm{~m})$ \\
\hline Bungalow & D: Close to forest $(<500 \mathrm{~m})$ \\
\hline Villa & D: Close to park $(<100 \mathrm{~m})$ \\
\hline \multicolumn{2}{|l|}{ Landhouse } \\
\hline \multicolumn{2}{|l|}{ Other } \\
\hline \multicolumn{2}{|c|}{ Maintenance quality ratings (inside \& outside) } \\
\hline \multicolumn{2}{|c|}{ Property age (based on construction-sales year interaction) } \\
\hline \multicolumn{2}{|c|}{ Time fixed-effects (year) } \\
\hline \multicolumn{2}{|c|}{ Alternative: Time fixed-effects (year-municipality) } \\
\hline
\end{tabular}

Notes: Base values: Construction = Construction before 1906, House type $\mathrm{I}=$ row house, House type II = simple house, Apart. type = ground floor, Apart. quality = bad, Garden quality: normal, Heating = no heating, Insulation = no insulation. We test two time fixed-effects, using year and yearmunicipality interaction. Additionally, we use location fixed-effects as mentioned in Section 3.3.2. 
Table 3.8

Time Clustering - Difference-in-Difference Approach

\begin{tabular}{lccc}
\hline \multicolumn{4}{c}{ Number of Observations (2.5 km cut-off) } \\
\hline $\begin{array}{l}\text { Electricity } \\
\text { generation type }\end{array}$ & $\begin{array}{c}\text { Before opening } \\
(-10 y \text { to }-1 \mathrm{y})\end{array}$ & $\begin{array}{c}\text { Affected } \\
\text { (facility present })\end{array}$ & $\begin{array}{c}\text { After closing } \\
(+1 \mathrm{y} \text { to }+10 \mathrm{y})\end{array}$ \\
\hline Coal & 10 & 371 & 118 \\
Gas & 3,739 & 4,458 & 21,303 \\
Bio & 1,316 & 1,772 & 463 \\
Wind & 86,523 & 108,413 & 687 \\
\hline \multicolumn{4}{c}{ Number of Observations $(3 \mathrm{~km}$ cut-off $)$} \\
\hline Coal & 25 & 560 & 164 \\
Gas & 5,992 & 6,229 & 30,100 \\
Bio & 2,411 & 2,678 & 585 \\
Wind & 118,483 & 151,551 & 827 \\
\hline $\begin{array}{l}\text { Notes: Observations are considered up to a proximity cut-off distance of } 3 \text { km for all } \\
\text { energy types. We consider 10 years before opening up to } 6 \text { years after closing. }\end{array}$ \\
a Some observations are affected by several facilities of different electricity generation \\
types and therefore counted more than once. Furthermore, some observations are si- \\
multaneously in the affected group of one energy type and in the omitted group of \\
another type. Excluding double entries and observations that are simultaneously in an \\
omitted group, 159,009 unique observations are affected.
\end{tabular}




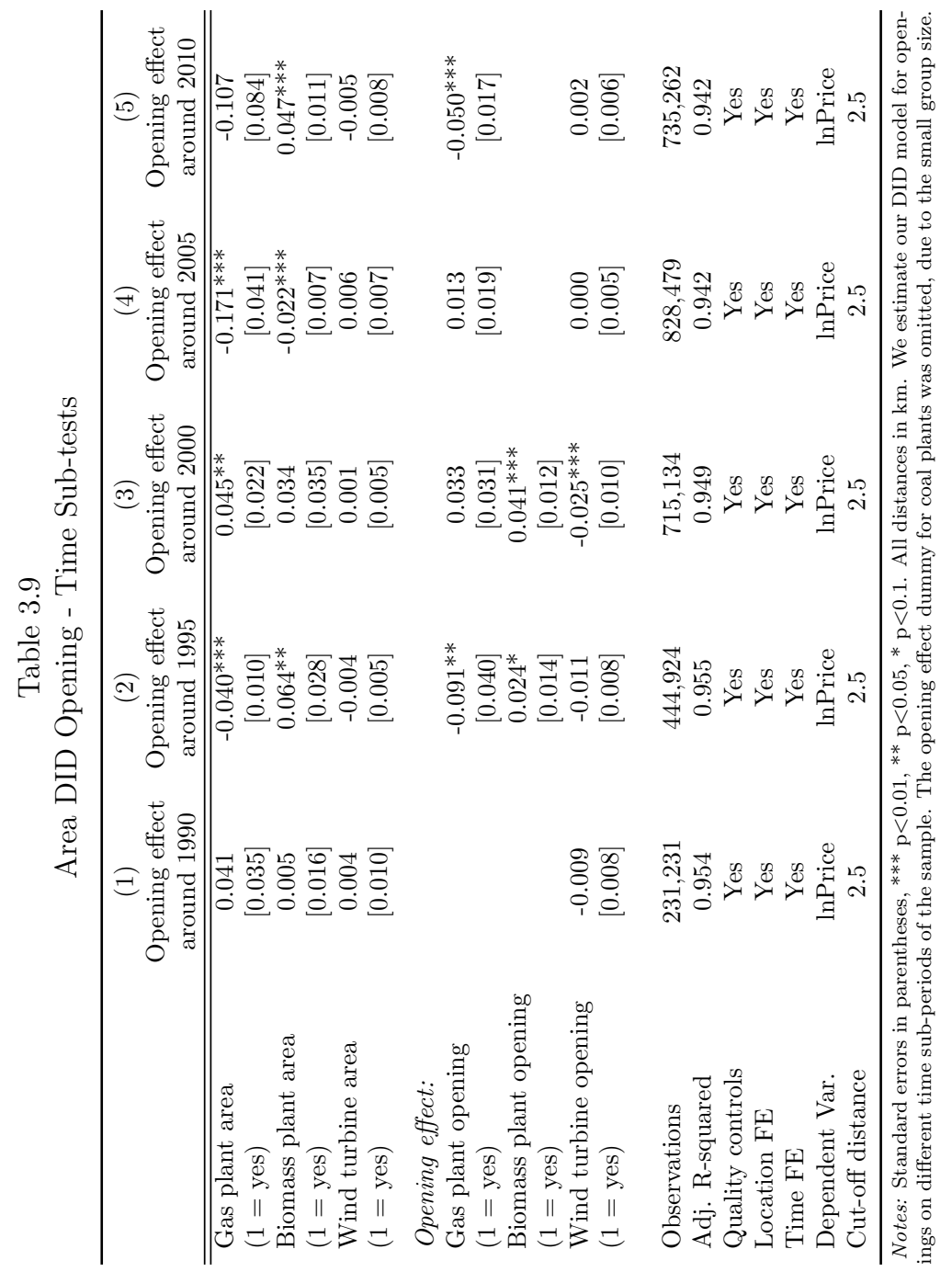


Table 3.10

Repeated Sales

Control Variables

\begin{tabular}{lc}
\hline & $(1)$ \\
VARIABLES & Controls \\
\hline \hline$\Delta$ size & $0.002^{* * *}$ \\
$\left(\mathrm{~m}^{2}\right)$ & {$[0.000]$} \\
$\Delta$ rooms & $0.013^{* * *}$ \\
(no. rooms) & {$[0.001]$} \\
Roof terrace removed & $-0.022^{* * *}$ \\
$(1=$ yes) & {$[0.003]$} \\
Roof terrace added & $0.029^{* * *}$ \\
(1 = yes) & {$[0.003]$} \\
Parking removed & $-0.006^{* * *}$ \\
(1 = yes) & {$[0.002]$} \\
Parking added & $0.032^{* * *}$ \\
(1 = yes) & {$[0.003]$} \\
Garden removed & 0.001 \\
(1 = yes) & {$[0.006]$} \\
Garden added & $0.040^{* * *}$ \\
(1 = yes) & {$[0.005]$} \\
$\Delta$ layer of isolation (added) & $0.012^{* * *}$ \\
(no. layers) & {$[0.001]$} \\
$\Delta$ layer of isolation (removed) & $-0.009^{* * *}$ \\
(no. layers) & {$[0.000]$} \\
& \\
Observations & 228,623 \\
Adj. R-squared & 0.725 \\
Location FE & Yes \\
Sales Year FE & Yes \\
Time difference $*$ sales year & Yes \\
Quality change & Yes \\
Dependent Var. & $\Delta$ Price \\
Cut-off distance & 2.5 \\
Holdout distance & 1.5 \\
Max. distance & 20 \\
\hline Notes: Standard & $* * *$ \\
\hline
\end{tabular}

Notes: Standard errors in parentheses, ${ }^{* * *} \mathrm{p}<0.01$, ${ }^{* *} \mathrm{p}<0.05,{ }^{*} \mathrm{p}<0.1$. Dependent variable is the percentage change in price between sales. We measure the changes in housing characteristics over time. Some houses expand in living area or the number of rooms due to e.g. renovations. We also control for changes in the interior and exterior maintenance quality. 
Table 3.11

Repeated Sales - 3 km cut-off distance

\begin{tabular}{|c|c|c|c|c|}
\hline VARIABLES & $\begin{array}{c}(1) \\
\text { Opening } \\
\end{array}$ & $\begin{array}{c}(2) \\
\text { Opening } \\
\end{array}$ & $\begin{array}{c}(3) \\
\text { Closing }\end{array}$ & $\begin{array}{c}(4) \\
\text { Closing }\end{array}$ \\
\hline Gas plant opening & $\begin{array}{c}-0.106^{* * *} \\
{[0.025]}\end{array}$ & $\begin{array}{c}-0.111^{* * *} \\
{[0.028]}\end{array}$ & & \\
\hline Biomass plant opening & $\begin{array}{c}0.015 \\
{[0.024]}\end{array}$ & $\begin{array}{l}-0.035 \\
{[0.025]}\end{array}$ & & \\
\hline Wind turbine opening & $\begin{array}{c}-0.024^{* * *} \\
{[0.005]}\end{array}$ & $\begin{array}{c}-0.033^{* * *} \\
{[0.006]}\end{array}$ & & \\
\hline Gas plant opening time differnce & & $\begin{array}{c}0.003 \\
{[0.009]}\end{array}$ & & \\
\hline Biomass plant opening time differnce & & $\begin{array}{c}0.015^{* * *} \\
{[0.004]}\end{array}$ & & \\
\hline Wind turbine opening time differnce & & $\begin{array}{c}0.005^{* * *} \\
{[0.002]}\end{array}$ & & \\
\hline Gas plant closing & & & $\begin{array}{c}0.043 \\
{[0.026]}\end{array}$ & $\begin{array}{l}0.048^{*} \\
{[0.028]}\end{array}$ \\
\hline Gas plant closing time differnce & & & & $\begin{array}{c}0.003 \\
{[0.004]}\end{array}$ \\
\hline Observations & 213,698 & 213,698 & 19,307 & 19,307 \\
\hline Adj. R-squared & 0.730 & 0.730 & 0.716 & 0.716 \\
\hline Location FE & Yes & Yes & Yes & Yes \\
\hline Time Controls & Yes & Yes & Yes & Yes \\
\hline Dependent Var. & $\Delta$ Price & $\Delta$ Price & $\Delta$ Price & $\Delta$ Price \\
\hline Cut-off distance & 3 & 3 & 3 & 3 \\
\hline
\end{tabular}

Notes: Standard errors in parentheses, ${ }^{* * *} \mathrm{p}<0.01,{ }^{* *} \mathrm{p}<0.05,{ }^{*} \mathrm{p}<0.1$. Dependent variable is the percentage change in price between sales. The time difference accounts for the time between the opening / closing and a sale, if an observation was affected by an opening / closing. We only have enough observations to examine gas plant closings. 


\section{Chapter 4}

\section{Getting High or Getting Low? The External Effects of Coffeeshops on House Prices*}

\subsection{Introduction}

Policy makers around the globe are changing their attitudes towards cannabis consumption, resulting in decriminalization, toleration, and even legalization policies. The World Health Organization (WHO) recently recommended to remove cannabis from the UN list of 'particularly harmful' substances. ${ }^{2}$ Countries like Canada, Uruguay, as well as several U.S. states have recently legalized recreational cannabis. ${ }^{3}$ In some other countries, including Portugal and the Netherlands, cannabis is decriminalized, meaning it remains illegal, but charges are usually not enforced. ${ }^{4}$

The motives for these changes in policies are manifold, including lack of evidence for cannabis-related crimes, fighting organized crime, and negative cost-benefit relationships of prosecution (Charilaou et al., 2017). However, little scientific evidence exists about the potential effects of toleration and legalization on society. Legalization produces new industries, providing employment opportunities and tax income. On the other hand, cannabis consumption might increase (Jacobi \& Sovinsky, 2016), potentially affecting long-run health care costs and/or productivity (Marie \& Zölitz, 2017). ${ }^{5}$ Since the number of cannabis dispensaries and related businesses increases, local residents are exposed to cannabis consumption, whether they share a liberal view on cannabis or not. In a recent court case, a Coloradan couple argued that their property lost value due to the opening of a nearby cannabis growing site, creating "pungent, foul odors". ${ }^{6}$

Empirical evidence on the external effects of local cannabis facilities is mixed, but mostly focused on crime. Hunt et al. (2018) document a slight increase in "driving under the influence" (DUI) arrests after dispensaries' openings, in addition to reduced crime rates. Focusing on the effect of dispensary closings on local crime, Chang and Jacobson (2017) document higher crime rates nearby in the short run. As the authors document similar effects for restaurant closings, they argue that retail activities are generally better than vacancy.

So far, only Conklin et al. (2017) and Cheng et al. (2018) examine the effect of legal cannabis dispensaries on property prices. Using the same research area and period, these sister studies examine the change of medical to recreational cannabis dispensaries

*This chapter is co-authored with Erdal Aydin (Sabanci University), Piet Eichholtz (Maastricht University) and Nils Kok (Maastricht University).

${ }^{2}$ Retrieved March 2018 from: https://bit.ly/2U140w8

${ }^{3}$ In example: https://reut.rs/2TlbMZF

${ }^{4}$ Cannabis remains illegal under EU law, which has primacy over national laws.

${ }^{5}$ Some studies show significantly positive effects on usage after cannabis decriminalization (Cerdá et al., 2012; Pacula et al., 2010; Wall et al., 2011), while others find no significant effects (Anderson \& Rees, 2014; Chu, 2015; Harper et al., 2012; Lynne-Landsman et al., 2013; Morris et al., 2014).

${ }^{6}$ https://dpo.st/2AxB5NG 
in Denver, Colorado. ${ }^{7}$ Both studies find a 6 to 8 percent increase in housing values for properties nearby dispensaries that switch from medical to recreational cannabis sales. These findings are contrary to previous studies examining the external effects of illegal drug sites, which found negative local house price effects. ${ }^{8}$

This paper adds to the ongoing debate regarding the societal effects of a less stringent cannabis policies, examining the implications of Dutch cannabis dispensaries, so-called "coffeeshops", on nearby property prices. Our study is the first to examine coffeeshop closings, following a recent exogenous regulatory change, in combination with a large micro-level database on house transaction prices. Studying exogenous closing events alleviates methodological concerns that hamper studies of the opening or presence of coffeeshops, such as endogenous location choice or anticipation effects. We build on the study of Chang and Jacobson (2017), who also look at cannabis dispensary closings, but only consider crime rates, one potential external effect.

To examine the effect of exogenous coffeeshop closings on nearby property prices, we employ a policy change. Closings were carried out in different waves between 2009 and 2017, providing substantial variation over time. ${ }^{9}$ This empirical setting provides an exogenous closing shock, independent of neighborhood perception and time-confounding factors, allowing for clean identification of the effects of cannabis dispensaries on local house prices.

We employ a sample of 115,248 housing transactions between 2000 and 2017 for the three biggest Dutch cities, Amsterdam, Rotterdam and The Hague, reflecting approximately 75 percent of all transactions in these cities. Besides transaction price, the dataset contains extensive information on dwelling characteristics, such as address, type, size, state of repair and time on the market. Furthermore, we have location and status information on all coffeeshops that operated in the Netherlands since 1999, 44 percent of which are located in the three major Dutch cities. We also have information on all school distance-related closings for each of these cities.

Compared to properties in the vicinity of coffeeshops that remain open, our differencein-difference results show a closing discount of 1.6 to 7.8 percent for homes nearby closing coffeeshops, with the effect getting larger when homes are nearer. This result is robust while controlling for the presence of potential nuisance-generators like local bars and nightclubs, and the effect remains after we include different holdout periods to control for potentially sticky prices in local housing markets. The results for the repeat sales analysis, in which we compare prices of the same dwellings before and after coffeeshop closings, have the same direction and magnitude. We find a price decrease of 10.8 percent. If we control for time after closing, the initial effect becomes bigger, but it subsequently decreases over time.

The remainder of the paper will first outline Dutch government policies with respect to cannabis sales, including a detailed discussion of the coffeeshop closing rules related to school proximity that have been introduced in the last decade. Section 4.3 provides

\footnotetext{
${ }^{7}$ Cheng et al. (2018) consider a bigger research area but measure municipality level data, whereas Conklin et al. (2017) focus on a more homogeneous sample using property transactions.

${ }^{8}$ Dealy et al. (2017) and Congdon-Hohman (2013) examine property prices nearby revealed meth labs, documenting property price discounts of 6.5 to 19 percent.

${ }^{9}$ The municipalities of The Hague and Rotterdam were the first to implement the school distance criterion, inspiring other municipalities and the national government.
} 
information regarding our dataset of housing transactions and the coffeeshop locations in Amsterdam, Rotterdam, and The Hague. The difference-in-difference and repeat sales methodologies, as well as the main results are presented in Section 4.4, and section 4.5 will explore potential causation channels. The paper ends with a short concluding section.

\subsection{Coffeeshops in the Netherlands}

\subsubsection{Government Policy on Coffeeshops}

In 1976, the Netherlands was the first country in Europe that made cannabis usage, possession and sale effectively legal. ${ }^{10}$ The intention of the policy was to "reduce the risk of cannabis users being exposed to hard drugs", such as cocaine and heroin (Wouters et al., 2012). In addition, the government wanted to reduce punishment of soft drug users. Even though cannabis possession is still officially illegal today, possession violations up to 5 grams are not enforced (MacCoun \& Reuter, 1997). In order to officially control the sale of cannabis, the government legally tolerated selling facilities, so called "coffeeshops". Since 1991, coffeeshops have to fulfil five criteria to stay open: no sales to minors, no sale of hard drugs, no advertising, no public nuisance, and restricted sales per person per day (Bieleman et al., 2015a; MacCoun \& Reuter, 1997; Tops et al., 2001). ${ }^{11}$

Coffeeshops were opened all over the Netherlands, reaching their peak between 1991 and 1995 with around 1,500 coffeeshops in the country (Bieleman et al., 1996). Neighboring countries complained about the supply opportunities just across the border and local politicians equally complained about nuisance from coffeeshops and their customers. In order to manage the situation, the Opium Act, the Dutch law regarding drugs, was changed in 1999, providing local politicians with more legislative power against coffeeshops. $\mathrm{Mu}-$ nicipalities could reduce tolerance of coffeeshops if they saw fit, allowing them to add operating criteria, to withdraw licenses, and to ultimately close coffeeshops (Bieleman et al., 2015a).

The law change resulted in a reduction in the number of coffeeshops (Tops et al., 2001) even as the number of municipalities with active coffeeshops hardly changed. By 2015, 582 coffeeshops remained. While many cities aimed to close coffeeshops, others added additional operating restrictions. One example of a restriction is the ban on simultaneous sales of alcohol and cannabis, leading to the closing of hasjcafés, a facility similar to a coffeeshop, but more focused on hospitality aspects. The criterion was later adapted nationally (Municipality of Amsterdam, 2007). Especially cities along the German and Belgium border attempted to reduce drug tourism, by restricting the sale of cannabis to local citizens only. However, local coffeeshops legally opposed the restrictions, arguing that they involve discrimination, and won the case (Marie \& Zölitz, 2017; van OoyenHouben et al., 2016).

In recent years, policies on coffeeshops became stricter, trying to tackle the so called "backdoor problem". In contrast to the strictly regulated retail trade of cannabis by coffeeshops (the "front door"), the cannabis supply chain ("the backdoor") is not regulated

\footnotetext{
${ }^{10}$ Officially, cannabis usage is just tolerated as it remains illegal under EU law.

${ }^{11}$ The criteria were tightened over time, increasing the minimum age from 16 to 18 , lowering the maximum amount per person per day and setting the maximum amount of supply per shop to 500 grams (Bieleman et al., 2015a).
} 
and still mostly illegal. Private cannabis cultivation is illegal in the Netherlands and legally provided cannabis does not match the sales amounts of coffeeshops. Therefore, nearly all coffeeshops source their cannabis from illegal dealers, from within or outside the country, supporting (organized) crime (Bieleman et al., 2015a; Leydon, 2014).

In 2003, a new law was implemented, aiming to halt coffeeshops' illegal activities. Among others, it gives local politicians the power to perform random screens and raids on coffeeshops in the case of suspicion. However, the law is contentious, since it might have been used as a pretence to close coffeeshops for other reasons (e.g. in gentrification projects). Additionally, the "backdoor problem" is still prevalent (Leydon, 2014).

\subsubsection{Effects on the Community}

The main reason for the liberal policy on coffeeshops is to protect soft drugs users from hard drugs by controlling cannabis sales. Although there is no direct empirical evidence for the effect of this policy on hard drug usage rates, there are some studies showing that coffeeshop availability decreases the likelihood of illegal cannabis sourcing, thereby decreasing the risk of hard drugs exposure. Conducting a survey among 773 cannabis users, Wouters and Korf (2009) document that, in cities with fewer coffeeshops, cannabis users, especially males and minors, are more likely to buy from illegal dealers.

On the other hand, the presence of coffeeshops might increase soft drug usage, potentially causing negative externalities on society. Investigating the effect of nearby coffeeshops on soft drug usage, Wouters et al. (2012) find no evidence of more cannabis users in coffeeshop proximity. However, users buying in coffeeshops consume cannabis more frequently and in higher amounts. Studying long-term usage effects of the Dutch policy on drugs, Tops et al. (2001) notice that the lifetime prevalence of cannabis use increased by 13.1 percent between 1987 and 1997, which corresponds with the timing of the growth in the number of coffeeshops. These results are in line with MacCoun and Reuter (1997), who compare countries' policies on drugs and show that the commercialization of cannabis access correlates with growth in the drug-using population.

Coffeeshops are disputed in Dutch society, as they seem to be a source of negative external effects, such as from drug consumers and tourists, crowding and creating noise, as well as traffic and odor-related nuisance. Illegal drug dealers sometimes loiter in the area, acting as competition or circumventing daily sales limits. And as discussed, the cannabis wholesale business remains illegal, making supply chains partly illegal and therefore relating coffeeshops to organized crime. Appendix Figure 4.6 presents street-scene impressions of coffeeshops.

Surveying the neighbors of coffeeshops in Rotterdam regarding specific nuisance externalities, Bieleman et al. (2010) identify smell, noise, traffic, and groups of loitering teenagers as the main problems. They report that nuisance from soft and hard drug users are higher around coffeeshops compared to other neighborhoods of Rotterdam. Based on survey participants perception, theft and vandalism-related crimes are higher as well.

Local coffeeshop associations claim that coffeeshops operate according to national businesses standards, contributing equally to the local economy and creating positive economic spillover effects. Coffeeshops are profitable businesses with an estimated total 
revenue of $€ 1$ billion, or $€ 1.7$ million per shop on average, in 2008. ${ }^{12}$ Based on these estimates, coffeeshops pay more than $€ 200$ million in annual taxes. Additionally, according to the Maastricht association of coffeeshops, local drug tourists in 2008 spent $€ 140$ million in other local businesses, such as restaurants. ${ }^{13}$

\subsubsection{The Distance Criterion}

In the early 2000s, several municipalities contemplated to restrict the presence of coffeeshops around schools to protect children and teenagers from drug usage. The city of The Hague proposed a distance criterion (afstandscriterium) already in 2007, forcing coffeeshops within a linear distance of 500 meters from secondary schools to close (Municipality of Amsterdam, 2007). ${ }^{14}$ However, due to opposition it took time for implementation and the effective distance was reduced to 250 meters, leading to the closure of one coffeeshop in January 2009.

The national government proposed to implement the distance criterion all over the country as of January 2014. However, municipalities were free to adapt the distance criterion and to change its specifications, such as distance. The government proposed to close coffeeshops within 250 meters of secondary schools and coffeeshops with visible shopfronts around primary schools (Bieleman et al., 2015a). Among 103 municipalities that tolerate coffeeshops, 78 implemented the criterion formally, of which 43 used the proposed criteria. By the beginning of 2015, 44 coffeeshops were affected by the criteria, mostly located in Amsterdam and Rotterdam (Bieleman et al., 2015a, 2010).

Amsterdam and Rotterdam handled the situation quite differently. The city of Rotterdam can be considered as a forerunner regarding the policy, advocating for it since the beginning and closing coffeeshops as of June 2009, shortly after The Hague. ${ }^{15}$ In contrast, the city of Amsterdam was rather critical towards the criterion and instead considered a new access control system to prevent minors from entering. ${ }^{16}$ The city hesitated to close the 27 coffeeshops affected by the school distance criterion, but implemented the criterion slowly in four stages, stepping up restrictions at every stage. ${ }^{17}$

Stage one was implemented as of January $1^{\text {st }}, 2014$ and restricted the opening hours of all 27 coffeeshops nearby schools, allowing them to only open after schools' closings (6 pm on weekdays). In July 2014, stage two became effective, closing eight coffeeshops that were in visibility of schools. In January 2015, stage three became effective, closing three coffeeshops that were located within 150 meters walking distance of schools. One shop had to close in April 2015 and one shop was eventually closed due to law violations, instead. After a forced break due to resistance of the local coffeeshop lobby, stage four became

\footnotetext{
${ }^{12}$ There are no official numbers, these were estimated by a national newspaper: https://bit.1y/2T9fGpe. Other estimations range from $€ 800$ million to $€ 1.2$ billion, as mentioned in the article.

${ }^{13}$ Retrieved 2017 from: https : //bit.1y/2SDoD4I. Nevertheless, the city of Maastricht banned tourists from coffeeshops permanently, by permitting access only to local residents.

${ }^{14}$ There are two types of schools in the Netherlands: Primary (basis) schools and secondary (VO) schools. Secondary education starts at the age of 12 and lasts until age 16 to 18 .

${ }^{15}$ One of the key advocates during this time was Ivo Opstelten, mayor of Rotterdam (1999 - 2009) and later Minister of Security and Justice (2010 - 2015), among others responsible for the national policy on coffeeshops.

${ }^{16}$ This so called "weed pass" was not implemented at the end.

${ }^{17}$ https://bit.1y/2NACEiM
} 
effective in January 2017, resulting in the closing of eight additionally coffeeshops within 250 meters of schools. Due to moving plans of a local school, six shops were reassessed and given time until July 2017, when one shop had to close and five were allowed to stay open.

\subsection{Data}

\subsubsection{Data Sources}

Our initial dataset consists of all open and closed coffeeshops in the Netherlands. We retrieve information on all coffeeshops from the Amsterdam Coffeeshop Directory in July 2017. Despite its name, this directory provides information on all coffeeshops in the Netherlands. ${ }^{18}$ The database goes back to 1997 and is maintained and used mainly by cannabis users. It contains information on coffeeshop address and opening status, but does not contain information on closing reasons and dates. Since closed shops are removed after a while, we only observe recently closed coffeeshops.

Table 4.1 provides an overview of the number of coffeeshops in our sample, showing that Amsterdam does not only have the most coffeeshops, but also the most school distance related closings. The table also shows that Dutch coffeeshops are concentrated in the three biggest cities: Amsterdam, Rotterdam, and The Hague.

Since our data source does not provide information on closing dates, we contacted municipalities individually. As described in section 4.2.3, different municipalities implemented the distance criterion differently. To verify our data, we contact the ten biggest cities to get information on coffeeshops and closing dates. We confirm that only the three major cities Amsterdam, Rotterdam and The Hague experienced closings due to the distance criterion, and we therefore concentrate our analysis on these three cities.

Table 4.1

Coffeeshop Sample Overview (2000 - 2017)

\begin{tabular}{lcccc}
\hline & \multicolumn{2}{l}{ Number of Coffeeshops } & & \\
\cline { 2 - 3 } City & Open & Closed & $\begin{array}{c}\text { Closed due to } \\
\text { distance criterion }\end{array}$ & Total \\
\hline Amsterdam & 171 & 166 & $21^{*}$ & 337 \\
The Hague & 55 & 24 & $1^{* *}$ & 79 \\
Rotterdam & 38 & 30 & 17 & 68 \\
Others & 345 & 144 & - & 489 \\
\hline Total: & 609 & 364 & 39 & 973 \\
\hline
\end{tabular}

Notes: Number of coffeeshops in our sample, including opening status per July 2017 (after last closing wave). Shown are the three biggest cities in terms of number of coffeeshops, focus of our analysis. * Initially, 27 shops were affected, but one closed due to law-violations and five did not have to close as the nearby school moved away. ** One coffeeshop was affected by the 250 meters criteria. However instead of closing, it was moved to a different location, which became available due to the law-related closing of another shop. We still consider the closing location in our analysis.

The underlying housing dataset consist of transactions across the Netherlands and

\footnotetext{
${ }^{18}$ http: //www. coffeeshopdirect. com/index.htm
} 
comes from the Dutch Realtors Association (NVM), representing a market share of around 75 percent. The Dutch Realtors Association is a network of realtors, storing an extensive data set on Dutch housing transactions. In our analysis, we use transactions from 2000 up to and including 2017, covering the full period of school distance related coffeeshop closings. ${ }^{19}$ Our final data set consists of 115,248 housing transactions in Amsterdam, Rotterdam and The Hague, representing 44 percent of the national dataset. For each transaction, we have detailed information on location, transaction price, time-on-themarket, housing type, structural characteristics, and quality assessments from realtors, leading to a large set of control variables.

\subsubsection{Sample Selection and Descriptive Statistics}

To account for potential external effects of coffeeshops on the neighborhood, we use the linear distance between the coffeeshops and transacted homes as a proxy for the net effect of externalities. We geocode all housing transactions and coffeeshop locations to obtain information on latitude and longitude. Figure 4.1 shows the distance distribution of observations and nearest coffeeshop in our three cities (up to 1,000 meters). We document a high density of coffeeshops in these cities, with average housing-coffeeshop distances lying between 250 meters and 400 meters.

Figure 4.1

Property-Coffeeshop Distance Distribution

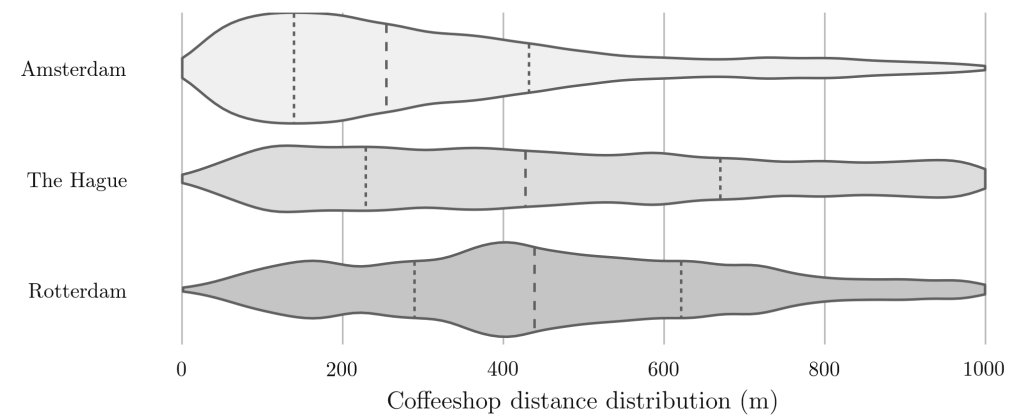

Notes: This graph shows the distance distribution of sample observations in quantiles (dashed lines), considering properties up to 1,000 meters coffeeshop distance.

Since the determination of an externality cut-off distance is rather arbitrary, we choose different distances supported by three sources. First, Conklin et al. (2017) find significant external effects for cannabis dispensaries up to a cut-off distance of 0.1 miles or 161 meters. Second, as discussed in section 4.2.3, all municipalities that enforced the distance criterion to coffeeshops used at least 150 meters as a cut-off distance (Bieleman et al., 2015a). Third, Figure 4.1 shows the first quartile of the house-coffeeshop distance distribution at a distance of 160 meters to 250 meters. Based on these three observations, we choose 150 meters as an externality cut-off distance.

\footnotetext{
${ }^{19}$ To exclude potential outliers, we remove the highest and lowest $1 \%$ of observations based on transaction price.
} 
Due to the high density of coffeeshops, we can also employ smaller cut-off distances: 100 meters, 50 meters, as well as the 6-digit postcode level. For the 6-digit postcode level, we consider a transaction to be within externality distance if it shares the postcode with a coffeeshop. In urban areas in the Netherlands, a 6-digit postcode is usually shared by half-a-street (around 17 households), ensuring direct visibility. Figure 4.2 illustrates the distance definitions, using a sample of observations over a land registry map of Amsterdam and showing a 50 meters radius around a coffeeshop (star), as well as the reach of the postcode matching (white squares). A detailed breakdown per cut-off distance per city is shown in Table 4.2, documenting how the number of observations becomes smaller with proximity.

Appendix Figure 4.8 illustrates the location of coffeeshops within the three biggest cities, Amsterdam, Rotterdam, and The Hague. We document that coffeeshops are generally located in the city center. In order to examine the distribution with respect to income and social status, we use the share of social benefit ("welfare") recipients as provided by the Dutch Statistics Office as a proxy, as local income statistics are not available at a granular level. We document that coffeeshops in Rotterdam and The Hague are likely to be located in neighborhoods with a high share of social benefit recipients, whereas coffeeshops in Amsterdam tend to be located in the city center, which is rather affluent, and has a lower share of social benefit recipients. Outside of Amsterdam's city center, however, coffeeshops are mostly located in poorer neighborhoods.

Figure 4.2

Illustration of Clustering

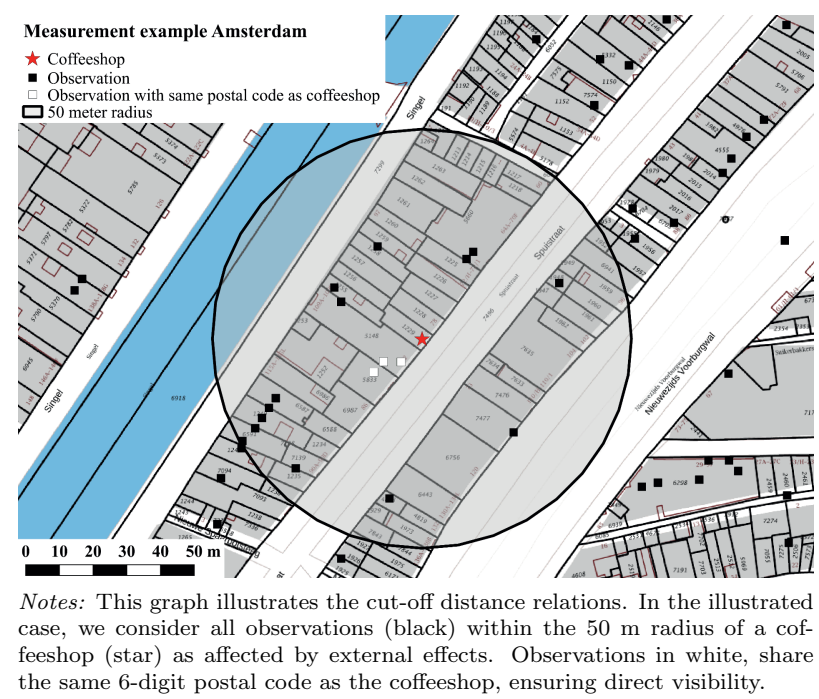


Table 4.2

Observations per distance, area and property type

\begin{tabular}{lcccc}
\hline & $\begin{array}{c}\text { within } \\
150 \mathrm{~m}\end{array}$ & $\begin{array}{c}\text { within } \\
100 \mathrm{~m}\end{array}$ & $\begin{array}{c}\text { within } \\
50 \mathrm{~m}\end{array}$ & $\begin{array}{c}\text { same } \\
\text { postcode }\end{array}$ \\
\hline \hline Amsterdam & & & \\
Apartments & 23,838 & 13,656 & 4,725 & 1,075 \\
Houses & 880 & 553 & 220 & 63 \\
\hline The Hague & & & \\
Apartments & 4,660 & 2,387 & 628 & 150 \\
Houses & 985 & 504 & 167 & 46 \\
\hline $\begin{array}{l}\text { Rotterdam } \\
\text { Apartments }\end{array}$ & 2,929 & 1,244 & 283 & 108 \\
Houses & 342 & 196 & 67 \\
\hline $\begin{array}{l}\text { Notes: } \text { This table documents the number of property transactions } \\
\text { within the different cut-off distances. Due to additional filters, such }\end{array}$ \\
as time-periods, the number of homes in the analysis might decrease.
\end{tabular}

To get a general overview of the characteristics of properties in our sample, Table 4.3 summarizes property characteristics of single-family houses and apartments nearby coffeeshops $(d<150 \mathrm{~m})$, compared to observations further away (up to 500 meters). There are relatively more apartments than houses nearby coffeeshops, potentially due to the central locations. Homes and apartments do not differ significantly in size and maintenance quality (inside and outside) from observations further away. Homes and apartments nearby coffeeshops are more expensive than homes and apartments further away, both in price and price per square meter.

Table 4.3

Descriptive Statistics Housing Transactions

Amsterdam, Rotterdam, The Hague (2000 - 2017)

\begin{tabular}{lcccc}
\hline & \multicolumn{2}{c}{$\begin{array}{c}\text { Externality group } \\
(<150 \mathrm{~m})\end{array}$} & \multicolumn{2}{c}{$\begin{array}{c}\text { Further away } \\
(150 \mathrm{~m}-500 \mathrm{~m})\end{array}$} \\
\hline & Apartments & Houses & Apartments & Houses \\
No. of observations: & 31,427 & 2,207 & 75,317 & 6,297 \\
\hline Size 79 & 159 & & 82 & 151 \\
$\left(\right.$ in $\left.\mathrm{m}^{2}\right)[32]$ & {$[71]$} & & {$[31]$} & {$[70]$} \\
Price & 286,556 & 445,898 & 259,352 & 381,670 \\
(in Euro) & {$[138,075]$} & {$[217,094]$} & {$[138,412]$} & {$[209,778]$} \\
Price per $\mathrm{m}^{2}$ & 3,755 & 3,003 & 3,256 & 2,608 \\
(in Euro) & {$[1,294]$} & {$[1,326]$} & {$[1,319]$} & {$[1,078]$} \\
Housing inside quality & 7.28 & 6.66 & 7.14 & 6.80 \\
$(1=$ worst, $9=$ best) & {$[1.22]$} & {$[1.62]$} & {$[1.21]$} & {$[1.46]$} \\
Housing outside quality & 7.31 & 6.90 & 7.19 & 6.98 \\
$(1=$ worst, $9=$ best) & {$[0.91]$} & {$[1.32]$} & {$[0.87]$} & {$[1.17]$} \\
\hline
\end{tabular}

Notes: Standard deviation in brackets. Inside and outside quality are ratings performed by NVM on the condition of the property. Both variables are measured on a scale from $1=$ worst to $9=$ best. The externality group is defined by the $150 \mathrm{~m}$ cut-off distance. We compare characteristics to observations within 500 $\mathrm{m}$ distance. We remove the top and bottom $1 \%$ observations in terms of transaction price from the data. Prices are adjusted for inflation into 2017 values, using the CPI from the Dutch Statistics Office (CBS). 


\subsection{Methodology and Results}

We use local house prices to assess the external effects of coffeeshops. Following the hedonic pricing theory, coffeeshop externalities, such as from nuisance, are expected to be reflected in nearby property prices (Tiebout, 1956; Rosen, 1974). The underlying theory assumes that people can choose location freely, allowing them to sort into specific neighborhoods and homes. As people sort according to their preferences, structural and socio-demographic aspects, location and nearby externalities should be reflected in local house prices (Rosen, 1974; Tiebout, 1956), allowing us to measure the willingness-to-pay for external effects of coffeeshops through nearby house prices.

\subsubsection{Difference-in-Difference Analysis}

Since coffeeshops are unlikely to be randomly distributed, any study into their external effects faces endogeneity issues. It may well be the case that coffeeshops try to avoid vocal local opposition, and therefore chose locations where neighbors do not complain much, e.g. due to social status, education, or simply liberal attitudes. In such locations, house prices might have been lower ex-ante. In addition, many coffeeshops are suspected to have connections to organized crime, resulting in a careful decision on their location. ${ }^{20}$

Coffeeshop closings offer an alternative, but might be endogenous, too. In practice, coffeeshops close for two reasons: due to violation of the law, or due to regulations such as the school distance criterion. Since law violations have to be reported by someone, the resulting closings could be the result by complaining neighbors or of gentrification. ${ }^{21} \mathrm{We}$ therefore focus solely on exogenous school distance-related closings, so employing a quasiexperimental setup. As described in section 4.2.3, the school distance criterion is not only arbitrary in terms of cut-off distance, but does not consider previous coffeeshops' popularity in the neighborhood, a prime reason why affected coffeeshops loudly complained against the legislation. We therefore argue that school distance-related closings create exogenous variation for proper identification of coffeeshops' externality removals.

Similar to Muehlenbachs et al. (2015), Pope and Pope (2015), McMillen and McDonald (2004), and Conklin et al. (2017), we use a spatial difference-in-differences (DID) framework, grouping transactions based on their spatial distance and transaction date relative to closings into four different groups: pre-nearby, pre-far, post-nearby, post-far. Since we do not just employ repeated sales, we cannot rely on the assumption that transactions do not systematically vary over time and we therefore include hedonic control characteristics, controlling for structural and neighborhood attributes.

The employed model is shown in equation (4.1), where $X_{i t}^{\prime}$ combines structural, neighborhood, and maintenance characteristics of property $i$ at time $t$ as well as sales time. $N e a r b y_{i t}$, where $d=1$ indicates that property $i$ at time $t$ is located nearby a closing coffeeshop and Post ${ }_{i t}$, where $d=1$ indicates a property transaction after the closing of the closest closing coffeeshop. ${ }^{22}$ We test four different distance cut-off points to define

\footnotetext{
${ }^{20}$ E.g. coffeeshops need to ensure proper supply-chain, even though it is mostly illegal https://bit.1y/2EttEYH

${ }^{21}$ We tried to investigate these closings further, but are not able to determine the exact reasons behind law related closings.

${ }^{22}$ For Post ${ }_{i t}$ we use the closing date of the closest closing coffeeshop, ensuring that every treatment area has a respective control area.
} 
Nearby $_{i t}$ : 150 meters, 100 meters, 50 meters, and 6-digit postcode. Nearby $y_{i t} *$ Post $_{i t}$, measures the interaction of two former terms, where $d=1$ indicates a transaction nearby a closing coffeeshop after closing.

$$
\ln \left(p_{i t}\right)=\alpha_{i t}+b X_{i t}^{\prime}+\gamma_{1} \text { Nearby }_{i t}+\gamma_{2} \text { Post }_{i t}+\gamma_{3} \text { Nearby }_{i t} * \text { Post }_{i t}+\epsilon_{i t}
$$

To account for potential spatial dependence and omitted variables, we include location fixed-effects (Anselin \& Bera, 1998; Kuminoff et al., 2010), using detailed postcode information. In Dutch urban areas a 6-digit postcode is shared by 17 households on average. However, we do not have sufficient observations for this level of location fixed effects, and it would result in single-observation fixed-effects. Therefore, we use 5-digit postcode areas instead, for which we have 12 observations per postcode area, on average, in our sample. We use year dummies as time fixed-effects and cluster standard errors by municipality and year. ${ }^{23}$

Since homes located near coffeeshops may systematically differ from those in the general market, we use homes around remaining coffeeshops as a control group instead of homes far away. Homes in both treatment and control groups are within the same cut-off distance of coffeeshops, sharing common attributes and therefore making them similar as they are initially all near a coffeeshop. Figure 4.3 illustrates the setup. To increase comparability further, housing transaction around every remaining coffeeshop are assigned as control group to one nearest closing coffeeshop, using linear distance. So a control group is always within the same city.

\section{Figure 4.3}

\section{Difference-in-Difference Setup}
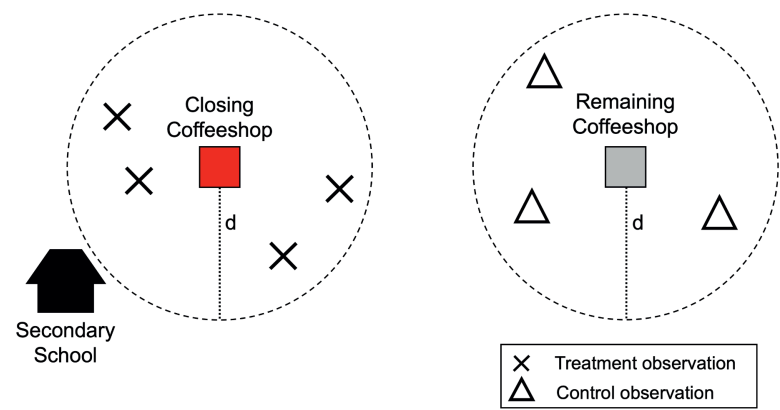

Notes: Illustration of analysis setup. We use homes nearby remaining coffeeshops as control group and compare the price changes before and after coffeeshop closings, testing different cut-off distances $d$ between 150 meters and 6-digit postcode level.

We consider observations up to four years before and after closings. We verify our comparability assumption between treatment and control areas, by examining parallel trends. Considering expectations and adjustments of markets, we create a 90 days holdout window around coffeeshop closings (30 days before and 60 days after closings), which we later adjust to examine long-term closing effects. Furthermore, we only include closing

\footnotetext{
${ }^{23}$ We also employ Year*City interaction dummies, showing no difference.
} 
coffeeshops for which there is at least one transaction in every group (pre-treatment, post-treatment, pre-control, post-control) ${ }^{24}$

Examining the similar trend assumption, Figure 4.4 plots the adjusted price per square meter of homes in treatment (gray) and control group (red) for the different closing waves, using a $150 \mathrm{~m}$ cut-off distance. We also plot trend lines for both groups: solid lines for the treatment groups and dotted lines for the control groups. Closing waves show different pre-post patterns, which is related to circumstances such as the financial crisis. However, except for January 2015, the overall price trends for the treatment and control groups are similar.

\section{Figure 4.4}

DID Similar Trend Graphs (150 m)
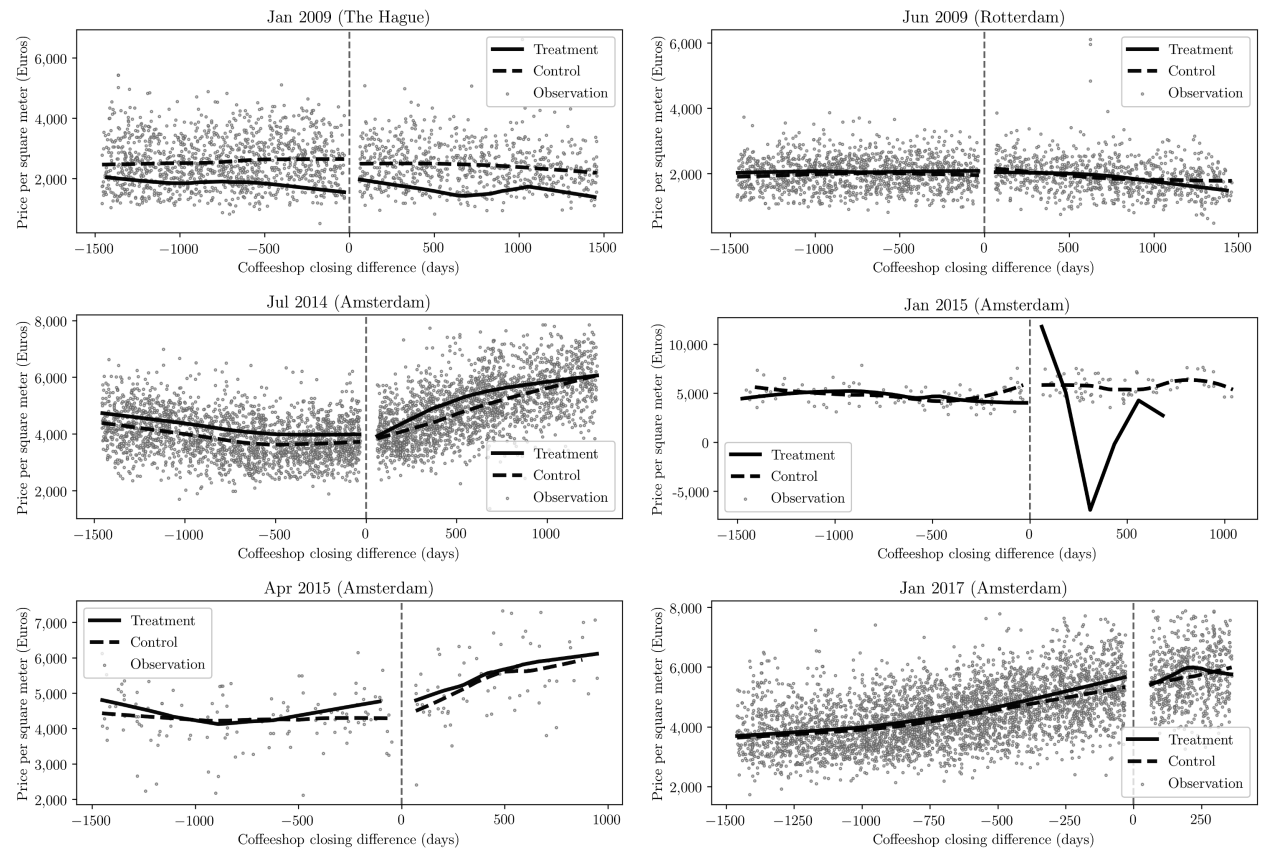

Notes: We compare treatment and control group price trends around coffeeshop closings (4 years before and after), estimating non-parametric trend lines, using locally weighted scatterplot smoothing (LOWESS) with a quadratic polynomial. Transactions within 30 days before and 60 days after closing are excluded from the analsis. We plot the adjusted price per square meter of observations over time to illustrate the calculation base of the trend lines. A detailed overview of the number of observations per closing wave is documented in Appendix Table 4.10. Due to missing post-closing observations, July 2017 closings are excluded from the analysis.

Table 4.4 shows the first set of regression results, using different cut-off distances. Rather surprisingly, homes near closed coffeeshops show a price discount after closing of 1.6 to 7.9 percent compared to homes near remaining coffeeshops. The effects increase with proximity. When we look at the coefficient for $N$ earby $y_{i t}=1$, we observe no significant effects, which implies that there is no significant price difference between homes near

\footnotetext{
${ }^{24}$ Appendix Table 4.9 provides more information regarding treatment and control groups, specifically regarding the observation numbers we have around coffeeshop closings and the effect of different externality cut-off distances. Appendix Table 4.10 provides this information by closing date and location.
} 
remaining coffeeshops and homes near closing coffeeshops, showing that homes in both groups are similar in general. For both groups we document positive price-time trends between 2.3 and 6.7 percent $\left(\right.$ Post $\left._{i t}=1\right)$.

Table 4.4

Difference-in-difference analysis

\begin{tabular}{lcccc}
\hline & $(1)$ & $(2)$ & $(3)$ & $(4)$ \\
& $150 \mathrm{~m}$ & $100 \mathrm{~m}$ & $50 \mathrm{~m}$ & Postcode \\
\hline \hline Nearby Coffeeshop & -0.009 & 0.006 & 0.032 & -0.005 \\
$(1=$ yes $)$ & {$[0.008]$} & {$[0.017]$} & {$[0.028]$} & {$[0.068]$} \\
Nearby Coffeeshop * Post-closing & $-0.016^{*}$ & $-0.030^{* *}$ & $-0.074^{* * *}$ & $-0.076^{* *}$ \\
$(1=$ yes $)$ & {$[0.009]$} & {$[0.013]$} & {$[0.021]$} & {$[0.031]$} \\
Post-closing & $0.029^{* *}$ & $0.023^{*}$ & 0.018 & $0.065^{* * *}$ \\
$(1=$ yes $)$ & {$[0.013]$} & {$[0.013]$} & {$[0.020]$} & {$[0.018]$} \\
& & & & \\
Observations & 12,412 & 6,765 & 1,979 & 598 \\
Treatment Group & 1,838 & 909 & 269 & 118 \\
Adj. R-squared & 0.79 & 0.79 & 0.81 & 0.80 \\
Quality \& Location controls & YES & YES & YES & YES \\
Time-Fixed effects & YES & YES & YES & YES \\
\hline
\end{tabular}

Notes: Standard errors in parentheses, ${ }^{* * *} \mathrm{p}<0.01,{ }^{*} \mathrm{p}<0.05,{ }^{*} \mathrm{p}<0.1$. Nearby Coffeeshop refers to closing coffeeshop. Treatment group is reported as part of total observations. Homes nearby closing coffeeshops but within $150 \mathrm{~m}$ of a remaining coffeeshop are excluded from the analysis. Standard errors clustered by municipality-year. Control group cut-off distance is similar to the treatment group cut-off distance $(150 \mathrm{~m}, 100 \mathrm{~m}$, etc. $)$, as illustrated in Figure 4.3. Location controls are 5-digit postcode level fixed-effects (around 17 observations per postcode in sample).

It is likely that coffeeshops are located to other forms of entertainment that could lead to local nuisance, like bars and nightclubs, and their presence could influence our findings. We therefore repeat the analysis, controlling for potential nuisance venues nearby, distinguishing for bars, pubs, and nightclubs. We download all locations of pubs, bars and nightclubs via Overpass API using OpenStreetMap data. ${ }^{25}$ All three entertainment venues serve alcohol. However, pubs generally also serve food and have a relaxed atmosphere, whereas bars have a more noisy and vibrant atmosphere and nighclubs (discos) focus on dancing.

Table 4.5 reports the results for the analysis including proximity to bars, pubs and nightclubs. Coffeeshop closing effects remain negative and are hardly affected, ranging from -1.6 to -7.5 percent for homes within 150 meters to 50 meters. Baseline treatment and control group pricing differences $\left(N_{\text {earby }}=1\right)$ remain insignificant and general post-closing time effects diminish. We document a negative proximity effect for bars of -4.6 percent, but only when houses are located within 50 meters. For nightclubs, we find an effect of up to -26.3 percent, but no negative proximity effect for pubs, which might be due to their more social aspect, such as serving food.

\footnotetext{
${ }^{25}$ Retrieved 2017 from https://www . openstreetmap.org/\#map=12/52.3563/4.8532
} 
Table 4.5

DID Analysis - Controlling for other nuisance venues

\begin{tabular}{lccc}
\hline & $(1)$ & $(2)$ & $(3)$ \\
& $150 \mathrm{~m}$ & $100 \mathrm{~m}$ & $50 \mathrm{~m}$ \\
\hline \hline Nearby Coffeeshop & -0.010 & 0.002 & 0.021 \\
$(1=$ yes $)$ & {$[0.008]$} & {$[0.018]$} & {$[0.029]$} \\
Nearby Coffeeshop * Post-closing & $-0.016^{*}$ & $-0.030^{* *}$ & $-0.075^{* * *}$ \\
$(1=$ yes $)$ & {$[0.009]$} & {$[0.013]$} & {$[0.021]$} \\
Post-closing & $0.028^{* *}$ & 0.020 & 0.019 \\
$(1=$ yes $)$ & {$[0.013]$} & {$[0.013]$} & {$[0.020]$} \\
D: Bar & 0.001 & -0.007 & $-0.045^{* * *}$ \\
$(1=$ yes $)$ & {$[0.006]$} & {$[0.014]$} & {$[0.015]$} \\
D: Pub & 0.008 & -0.003 & 0.009 \\
$(1=$ yes $)$ & {$[0.006]$} & {$[0.008]$} & {$[0.010]$} \\
D: Nightclub & -0.013 & $-0.094^{* * *}$ & $-0.263^{* * *}$ \\
$(1=$ yes $)$ & {$[0.012]$} & {$[0.023]$} & {$[0.077]$} \\
& & & \\
Observations & 12,412 & 6,765 & 1,979 \\
Adj. R-squared & 0.79 & 0.79 & 0.81 \\
Quality \& Location controls & YES & YES & YES \\
Time-Fixed effects & YES & YES & YES \\
\hline Notes: Standard errors in parentheses, ${ }^{* * *} \mathrm{p}<0.01, * * \mathrm{p}<0.05, * \mathrm{p}<0.1$. & Estimation is \\
similar to the main DID analysis, with outputs presented in Table 4.4 However, we control \\
for proximity to bars, pubs, and nightclubs in this specification. Proximity to these venues \\
is defined by the same cut-off distance as for coffeeshops $(150 \mathrm{~m}, 100 \mathrm{~m}$, etc.).
\end{tabular}

Since housing markets are sticky in the short run, closing effects might change with different holdout periods. We therefore test different holdout periods, excluding transactions within 5 to 365 days after coffeeshop closings from the analysis. Estimations of closing effects (Nearby Coffeeshop * Post-closing) for different holdout periods are presented in Table 4.6. Closing effects remain robust for different holdout periods (base holdout period highlighted). However, our results suggest that house prices are indeed somewhat sticky in the short run, as coffeeshop closing effects become statistically significant and a bit higher in magnitude for longer holdout periods. 
Table 4.6

DID Analysis - Heterogeneity of holdout period

\begin{tabular}{lcccc}
\hline & $(1)$ & $(2)$ & $(3)$ & $(4)$ \\
Nearby Coffeeshop * Post-closing & $150 \mathrm{~m}$ & $100 \mathrm{~m}$ & $50 \mathrm{~m}$ & Postcode \\
\hline \hline post-5 days holdout & -0.014 & $-0.023^{*}$ & $-0.063^{* * *}$ & $-0.073^{* *}$ \\
& {$[0.010]$} & {$[0.013]$} & {$[0.020]$} & {$[0.029]$} \\
post-10 days holdout & -0.013 & $-0.022^{*}$ & $-0.060^{* * *}$ & $-0.073^{* *}$ \\
& {$[0.010]$} & {$[0.013]$} & {$[0.021]$} & {$[0.029]$} \\
post-30 days holdout & -0.013 & $-0.021^{*}$ & $-0.062^{* * *}$ & $-0.073^{* *}$ \\
& {$[0.010]$} & {$[0.013]$} & {$[0.020]$} & {$[0.029]$} \\
post-60 days holdout & $-0.016^{*}$ & $-0.030^{* *}$ & $-0.074^{* * *}$ & $-0.076^{* *}$ \\
& {$[0.009]$} & {$[0.013]$} & {$[0.021]$} & {$[0.031]$} \\
post-90 days holdout & $-0.018^{*}$ & $-0.030^{* *}$ & $-0.067^{* * *}$ & $-0.067^{* *}$ \\
& {$[0.009]$} & {$[0.013]$} & {$[0.021]$} & {$[0.029]$} \\
post-180 days holdout & $-0.018^{*}$ & $-0.038^{* * *}$ & $-0.075^{* * *}$ & $-0.067^{*}$ \\
& {$[0.010]$} & {$[0.014]$} & {$[0.021]$} & {$[0.035]$} \\
\hline $\begin{array}{c}\text { Notes: } \text { Standard errors in parentheses, } * * * \text { p }<0.01, * * \mathrm{p}<0.05, * \mathrm{p}<0.1 . \\
\text { before is used, except that we adjust the holdout period, excluded from the estimation. The base hold- }\end{array}$ \\
out period of 60 days is highlighted for comparison reasons. In a different analysis, we also estimate the \\
model for varying pre-closing holdout periods, but do not observe changes in the effects.
\end{tabular}

\subsubsection{Repeated Sales Model}

Even though the presented difference-in-difference setup allows to control for individual property characteristics, it relies on the assumption that transacted properties before and after closings are similar. However, this assumption could be violated by systematic changes in unobserved characteristics. Therefore, we verify our previous findings by applying a repeated sales approach, using repeated sales pairs at different locations relative to coffeeshops, one sale taking place before and one after closings. Since we use the same property before and after coffeeshop closings, we can be more certain that property characteristics stay constant. Furthermore, we control for time-varying characteristics in our model, such as improvements and decay.

Filtering for repeated sales only and excluding sales pairs selling more than once in the same year, our dataset consists of 15,289 properties that sold twice during the sample period, 2,545 properties that sold three times, and 249 properties that sold four times during the sample period. ${ }^{26}$ As in the DID approach, we compare homes nearby closing coffeeshops with homes nearby remaining coffeeshops. We use the same cut-off distances, the same time window (+/- 4 years), and the same holdout period (30 days before and 60 days after coffeeshop closings). After filtering, the number of repeated sales available decreases significantly.

As shown in equation (4.2), we use the percentage change in transaction price $\Delta p_{i(t+n)}$ of property $i$ between date $t$ and $t+n$ as the dependent variable. We control for changes in property characteristics, such as refurbishments, changes in size, maintenance quality and insulation, as well as changes in the surrounding area, such as distance to (dis)amenities.

\footnotetext{
${ }^{26} 20$ properties sell more than 4 times during the sample period and are excluded from the analysis, considered as outliers.
} 
We divide all changes into additions and improvements, measured by $\Delta Q_{i(t+n)}^{\prime+}$ and removals and decay, measured by $\Delta Q_{i(t+n)}^{\prime-}$.

We control for time effects using time fixed effects $Y_{i(t+n)}^{\prime}$, indicating the sales year $t+n$ of property $i$. Additionally, we control for the time period $n$ between two sales, for location, using the 5-digit neighborhood post-code $\left(\Theta_{i n}^{\prime}\right)$, and for closing coffeeshops fixed-effects. The change in coffeeshop distance of property $i$ between $t$ and $t+n$ is measured by $\Delta C S_{i(t+n)} \in\{0,1\}$, where $\Delta C S_{i(t+n)}=1$ indicates a change in coffeeshop distance due to closings, our variable of interest.

$$
\Delta p_{i(t+n)}=\alpha+\Delta Q_{i(t+n)}^{\prime+} \gamma_{1}+\Delta Q_{i(t+n)}^{\prime-} \gamma_{2}+Y_{i(t+n)}^{\prime} \gamma_{3}+\Theta_{i n}^{\prime} \gamma_{4}+\gamma_{5} \Delta C S_{i(t+n)}+\epsilon_{i(t+n)}
$$

Since local housing markets may take time to incorporate closing effects, we also test for the time difference between the sales of treatment homes and coffeeshop closings, indicated by $\Lambda_{i(t+n)}$ as shown in equation (4.3).

$$
\begin{gathered}
\Delta p_{i(t+n)}=\alpha+\Delta Q_{i(t+n)}^{\prime+} \gamma_{1}+\Delta Q_{i(t+n)}^{\prime-} \gamma_{2}+Y_{i(t+n)}^{\prime} \gamma_{3} \\
+\Theta_{i n}^{\prime} \gamma_{4}+\gamma_{5} \Delta C S_{i(t+n)}+\gamma_{6} \Lambda_{i(t+n)}+\epsilon_{i(t+n)}
\end{gathered}
$$

Where $\Lambda_{i(t+n)}$ is the difference in days between $t+n$ and $z$, the closing date of the closest coffeeshop.

$$
\Lambda_{i(t+n)}= \begin{cases}(t+n)-z & \text { if } \Delta C S_{i(t+n)}=1 \\ 0 & \text { if } \Delta C S_{i(t+n)}=0\end{cases}
$$

Since a linear specification of the time difference might not be fully adequate, we additionally test a quadratic day difference, $\Phi_{i(t+n)}$, accounting for diminishing effects over time.

Applying the analysis setup as described above, there are 57 repeated sales pairs left within $150 \mathrm{~m}$ distance to closing coffeeshops, which experience a coffeeshop closing between sales. We therefore limit our analysis to the 150 meters cut-off distance. When we look at the percentage change in price between sales pairs over the coffeeshop closing time difference for treatment and control groups, we observe no systematic difference between groups. The majority of homes in both groups generally increases in value over time.

Table 4.7 first shows the result of the estimation of (4.2) in Column (1). We document that homes experiencing a coffeeshop closing between the first and second sale fall on average 10.75 percent in value compared to homes nearby remaining coffeeshops. When we subsequently estimate (4.3), controlling for the linear and quadratic time differences in days between coffeeshop closings and second home sales at $t+n$, we document a general price drop of 18.7 to 34.9 percent. However, prices seem to recover over time, albeit at a diminishing rate.

Even though we consider this last analysis as meaningful, there are some important limitations to consider. The number of repeated sales pairs is limited, leading to a small treatment group. Furthermore, we are not able to perform any sub-tests and robustness checks. So even though our DID findings are confirmed, we should interpret the magnitude of the estimated coefficients in the repeat sales analysis with some caution. 
Table 4.7

Repeated sales analysis

\begin{tabular}{lccc}
\hline & $(1)$ & $(2)$ & $(3)$ \\
\hline \hline$\Delta C S_{i(t+n)}$ & $-10.754^{* *}$ & $-18.723^{* *}$ & $-34.857^{* * *}$ \\
$(1=$ coffeeshop closing $)$ & {$[4.957]$} & {$[9.044]$} & {$[12.170]$} \\
$\Lambda_{i(t+n)}$ & & 0.012 & $0.071^{* *}$ \\
$($ days after closing) & & {$[0.008]$} & {$[0.030]$} \\
$\Phi_{i(t+n)}$ & & $-0.000^{* *}$ \\
$\left((\text { days after closing })^{2}\right)$ & & {$[0.000]$} \\
& & & \\
Observations & 373 & 373 & 373 \\
Adj. R-squared & 0.53 & 0.53 & 0.53 \\
Cut-off distance & $150 \mathrm{~m}$ & $150 \mathrm{~m}$ & $150 \mathrm{~m}$ \\
$\begin{array}{l}\text { Quality \& Location controls } \\
\text { Time-fixed effects }\end{array}$ & YES & YES & YES \\
Notes: Standard errors in parentheses, ${ }^{* * *} \mathrm{p}<0.01,{ }^{* *} \mathrm{p}<0.05,{ }^{*} \mathrm{p}<0.1$. & The depen- \\
Nont variable percentage is the change in price. Control group are homes nearby re- \\
$\begin{array}{l}\text { maining coffeeshops at 150 } \mathrm{m} \text { cut-off distances. We control for sales years and location } \\
\text { fixed-effects are based on 5-digit postcode level. }\end{array}$
\end{tabular}

\subsection{Discussion - Channels \& Mechanisms}

Our results consistently document house price decreases for homes near closing coffeeshops compared to homes near remaining ones in the same city. In order to understand our findings, we shift the focus of our analysis to potential causation channels. A first channel could be related to changes in local nuisance. Two survey studies regarding exogenous coffeeshop closings in Rotterdam and Amsterdam explore local nuisance effects. Bieleman et al. (2010) conduct a survey among teenagers and local residents regarding the effects the forced coffeeshop closings in Rotterdam. They find a significant general reduction of negative externalities over time for both groups, but no specific effect due to the closing of coffeeshops. The percentage of teenagers using cannabis does not change after closings, and neither does their sourcing behavior, as they still receive cannabis from older friends.

In a follow-up study in Amsterdam, Bieleman et al. (2015b) find an increase in customers for remaining coffeeshops, but no increase in reported negative externalities. The majority of neighbors indicate that they like their neighborhood and that perceived safety does not change after closings. Nuisance complaint reports before and after exogenous coffeeshop closings remain constant. Overall, only five to seven percent of neighbors directly relate coffeeshops to nuisance-related problems in their neighborhood.

Chang and Jacobson (2017) find that cannabis dispensary closings in Los Angeles lead to higher crime rates nearby, especially in the short run. ${ }^{27}$ Since the effect also holds for restaurant closings, they argue that, in general, "retail establishments, when operational, provide informal security through their customers," which is in line with the "eyes upon the street" theory (Jacobs, 1961). This finding is in line with Koster and Rouwendal (2012), who examine the effects of retail activities on house prices in the Netherlands,

\footnotetext{
${ }^{27}$ We also tried to examine the relation between coffeeshop closings and local crime rates, but due to data limitations we do not have sufficient variation for a convincing analysis.
} 
finding positive price effects for homes near retail activities. This would suggest that our documented closing effects are not driven by the disappearance of coffeeshops itself, but by the circumstances of the post-closing situation (operational retail versus an empty store).

To test for the influence of the post-closing situation, we examine the developments of the former coffeeshop locations over time. We visited all closed coffeeshop locations in Rotterdam and Amsterdam to collect information on post-closing usage as well as the time it took for the vacant store to be re-used. We did this by interviewing new shop owners and neighbors. Additionally, we examined all locations on Google Street View, allowing us to virtually "walk the streets". Google updates Street View images on an irregular base, but publishes all previous images, allowing us to go virtually back in time and track coffeeshop locations over time (at irregular intervals).

It turns out that most former coffeeshop properties are vacant for a significant amount of time before being re-used. Often, the coffeeshop storefront remains as long as the site is vacant. Appendix Figure 4.7 presents some images of vacant coffeeshops. On average, it takes around 781 days until a new business is opened in the former coffeeshop space. Figure 4.5 shows the first usage of closed coffeeshop locations. We document that most coffeeshops turn into shisha bars (similar to a pub but focusing on smoking the hookah, only open at night), cafes (bistro type), restaurants (proper restaurant). However, most locations change their use at least once afterwards, and quite a number remain vacant.

We test whether vacancy has an effect on our results by distinguishing between vacant and non-vacant post-closing locations, considering the status at transaction time $t$ of property $i^{28}$ Building on the DID model, equation (4.4) shows the model for our analysis, where Vacant $_{i t}=1$ indicates that the coffeeshop location is vacant at postclosing transaction time $t$. As we only look at post-closing locations, Vacant $_{i t}=1$ implies that Nearby $_{i t} *$ Post $_{i t}=1$.

$$
\ln \left(p_{i t}\right)=\alpha_{i t}+b X_{i t}^{\prime}+\gamma_{1} \text { Nearby }_{i t}+\gamma_{2} \text { Post }_{i t}+\gamma_{3} \text { Nearby }_{i t} * \text { Post }_{i t}+\gamma_{4} \text { Vacant }_{i t}+\epsilon_{i t}
$$

Table 4.8 shows the result for the estimation of (4.4). Overall, we do not find significant price differences for vacant and non-vacant post-closing states. Only at a $150 \mathrm{~m}$ cut-off distance and a 10\% significance level do we document a positive effect for homes nearby vacant places compared to homes nearby non-vacant coffeeshop locations. Our results regarding the effect of the coffeeshop closings are hardly affected by including the vacancy information in the analysis. Reasons for our findings could be quality differences of succeeding businesses, such as Shisha lounges.

\footnotetext{
${ }^{28}$ We realize that there are business quality differences for non-vacant locations, but the small number of observations and examples of exceptions prevent us from distinguishing further by business type.
} 
Figure 4.5

Post-closing coffeeshop location usage

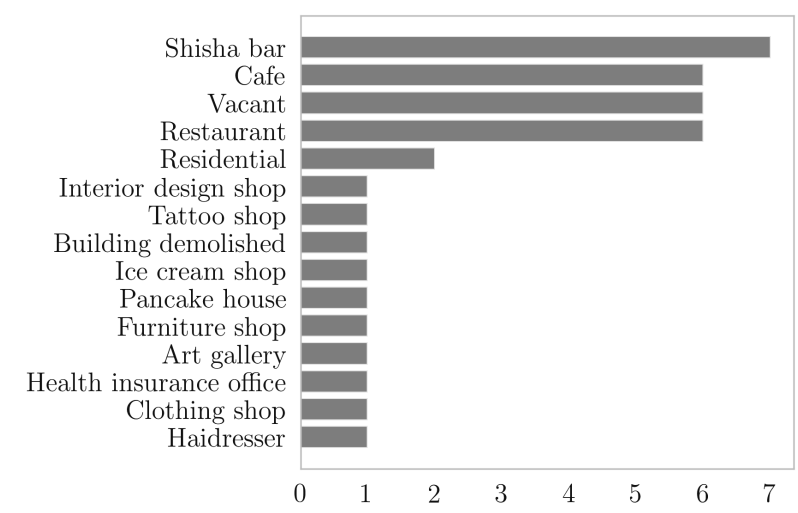

Notes: Displayed are the usages of closed coffeeshop locations in Rotterdam and Amsterdam. We group different usage cases together where possible. One coffeeshop could not be inspected.

Table 4.8

Vacancy analysis

\begin{tabular}{lccc}
\hline & $(1)$ & $(2)$ & $(3)$ \\
& $150 \mathrm{~m}$ & $100 \mathrm{~m}$ & $50 \mathrm{~m}$ \\
\hline \hline Nearby Coffeeshop & -0.010 & 0.010 & 0.012 \\
$(1=$ yes $)$ & {$[0.008]$} & {$[0.017]$} & {$[0.024]$} \\
Nearby Coffeeshop * Post-closing & $-0.030^{* *}$ & $-0.035^{* *}$ & $-0.064^{* *}$ \\
$(1=$ yes $)$ & {$[0.012]$} & {$[0.017]$} & {$[0.025]$} \\
Post-closing & $0.034^{* * *}$ & $0.027^{* *}$ & 0.017 \\
$(1=$ yes $)$ & {$[0.011]$} & {$[0.011]$} & {$[0.015]$} \\
Vacant & $0.025^{*}$ & 0.009 & -0.011 \\
$(1=$ yes $)$ & {$[0.013]$} & {$[0.014]$} & {$[0.030]$} \\
& & & \\
Observations & 9,632 & 5,344 & 1,585 \\
Adj. R-squared & 0.80 & 0.81 & 0.84 \\
Quality \& Location controls & YES & YES & YES \\
Time-Fixed effects & YES & YES & YES \\
\hline
\end{tabular}

Notes: Standard errors in parentheses, ${ }^{* *} \mathrm{p}<0.01,{ }^{* *} \mathrm{p}<0.05, * \mathrm{p}<0.1$. Vacant controls for vacant post-closing coffeeshop locations at the time of transactions. Once a business sets up in the location, it is no longer considered as vacant. Homes nearby closing coffeeshops but within $150 \mathrm{~m}$ of a remaining coffeeshop are excluded from the analysis. Standard errors clustered by municipality-year.

\subsection{Implications \& Conclusion}

While considered a dangerous hard drug by some, many governments around the world have moved to legalize recreational use of cannabis. The Netherlands has over 40 years of experience in decriminalized cannabis sales. We explore the exogenous closing of Dutch 
coffeeshops due to proximity to schools, and investigate the local external effects on house prices. Focusing on Amsterdam, Rotterdam and The Hague, we perform difference-indifference and repeat sales analyses around these coffeeshop closings, avoiding the endogeneity concerns that would hamper a more traditional hedonic setup. By using a dataset of house prices and characteristics, we can adjust properly for changes in housing quality.

Perhaps surprisingly, we document negative local house price effects when nearby coffeeshops close. In the difference-in-difference analysis, the effect ranges from -1.6 percent for homes located up to 150 meters away to -7.4 percent for homes up to 50 meters away, and -7.6 percent for homes within the same 6-digit postal code area, all compared to homes near the closest coffeeshop that remains open. This result is robust to the inclusion of other entertainment with possible local nuisance effects, such as bars and nightclubs, and the effect remains when we consider differently holdout periods, taking care of potential price stickiness in local housing markets.

The repeat sales analysis tells a similar story in terms of direction and magnitude. Comparing the prices of the same dwelling before and after the exogenous closing of a coffeeshop, we observe a 10.8 percent decrease in price. When we control for time since closing, we observe a larger initial negative effect, but prices subsequently recover, albeit at a diminishing rate.

We subsequently explore potential causation channels for these effects. Chang and Jacobson (2017) show that closings of medical cannabis dispensaries in the US leads to more local crime, and this could also be the case in the three Dutch cities we study, since the properties in which the closed coffeeshops were housed remain vacant for more than two years after closing, reducing the informal security that customers of active retail establishments create. Also, coffeeshop owners have an incentive to reduce nuisance so as to maintain smooth operations. We therefore empirically investigate whether the vacancy resulting from coffeeshop closing is associated with the negative house price effects we find, but we don't find convincing evidence that vacancy increases the negative effect of coffeeshop closings.

The findings in this paper have some implications for policymakers and homeowners. Contrasting expectations, and perhaps intuition, once a coffeeshop is in operation, closing it may be detrimental to local house prices. While we do not study coffeeshop openings, our findings suggest some amenity value in cannabis dispensaries, potentially benefiting some neighborhoods. Of course, further research is needed on the effect of cannabis dispensary openings. 


\subsection{Appendix}

\section{Figure 4.6}

Street scene impressions of open coffeeshops
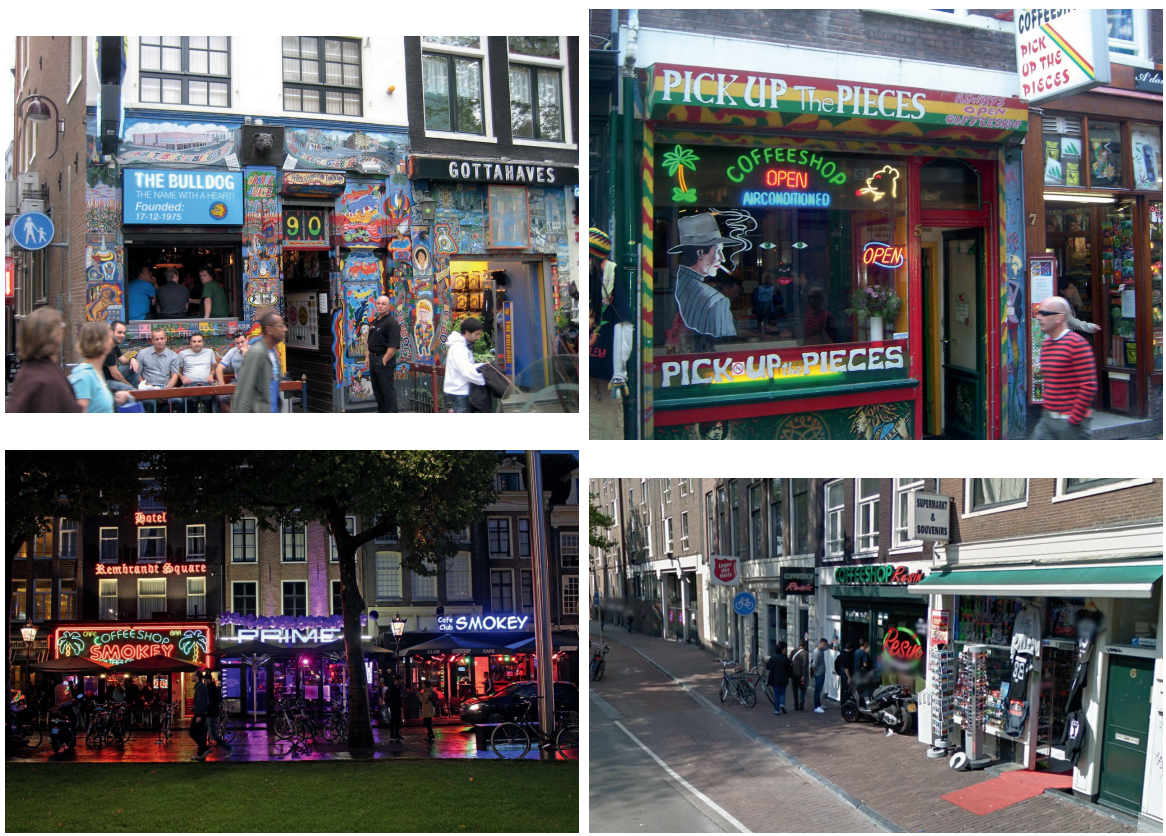

Notes: Street scene images of coffeeshops in Amsterdam. Sources: Wikimedia Commons, www.flickr.com (Terrazzo, Travelmag.com), Google Street View 
Figure 4.7

Impressions of closed and vacant coffeeshops
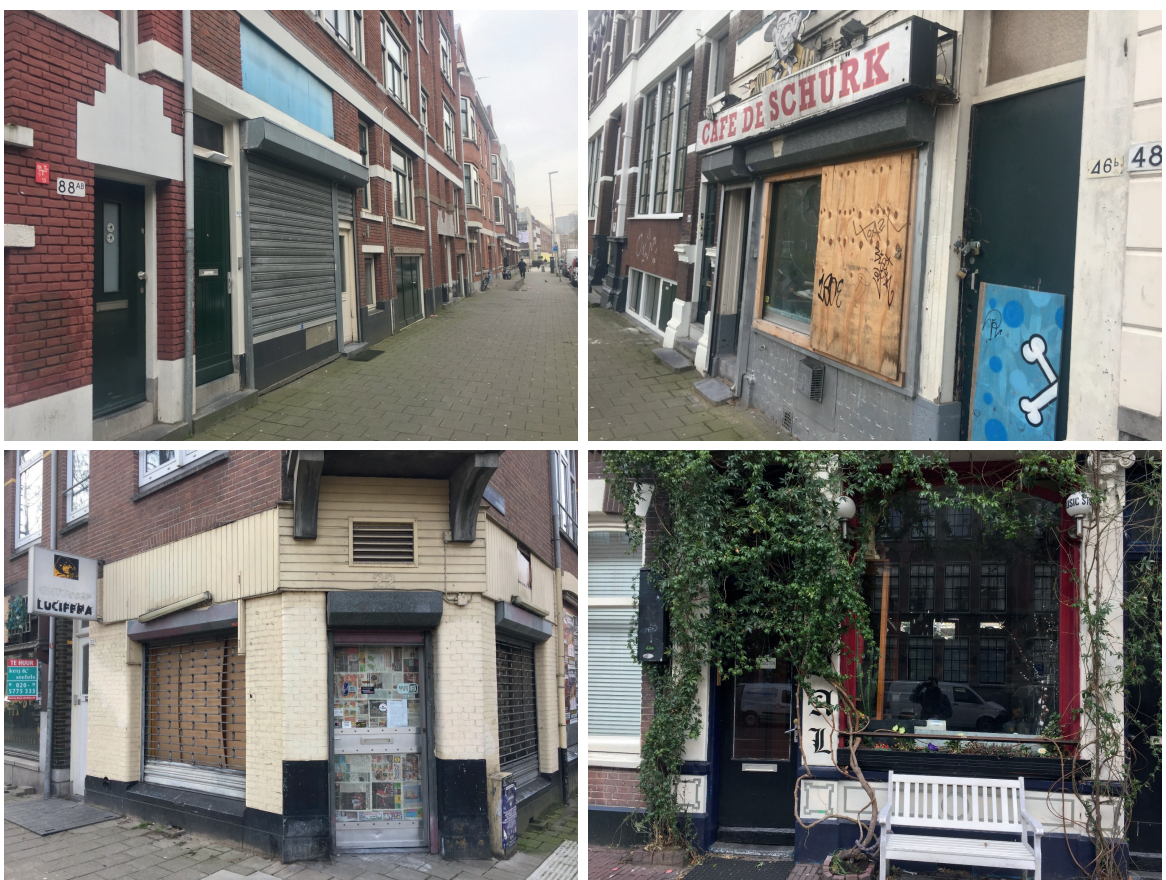

Notes: Images of coffeeshops in Amsterdam and Rotterdam. Images taken by the authors in March 2018. 
Figure 4.8

Coffeeshop Distribution in Amsterdam, Rotterdam, and The Hague

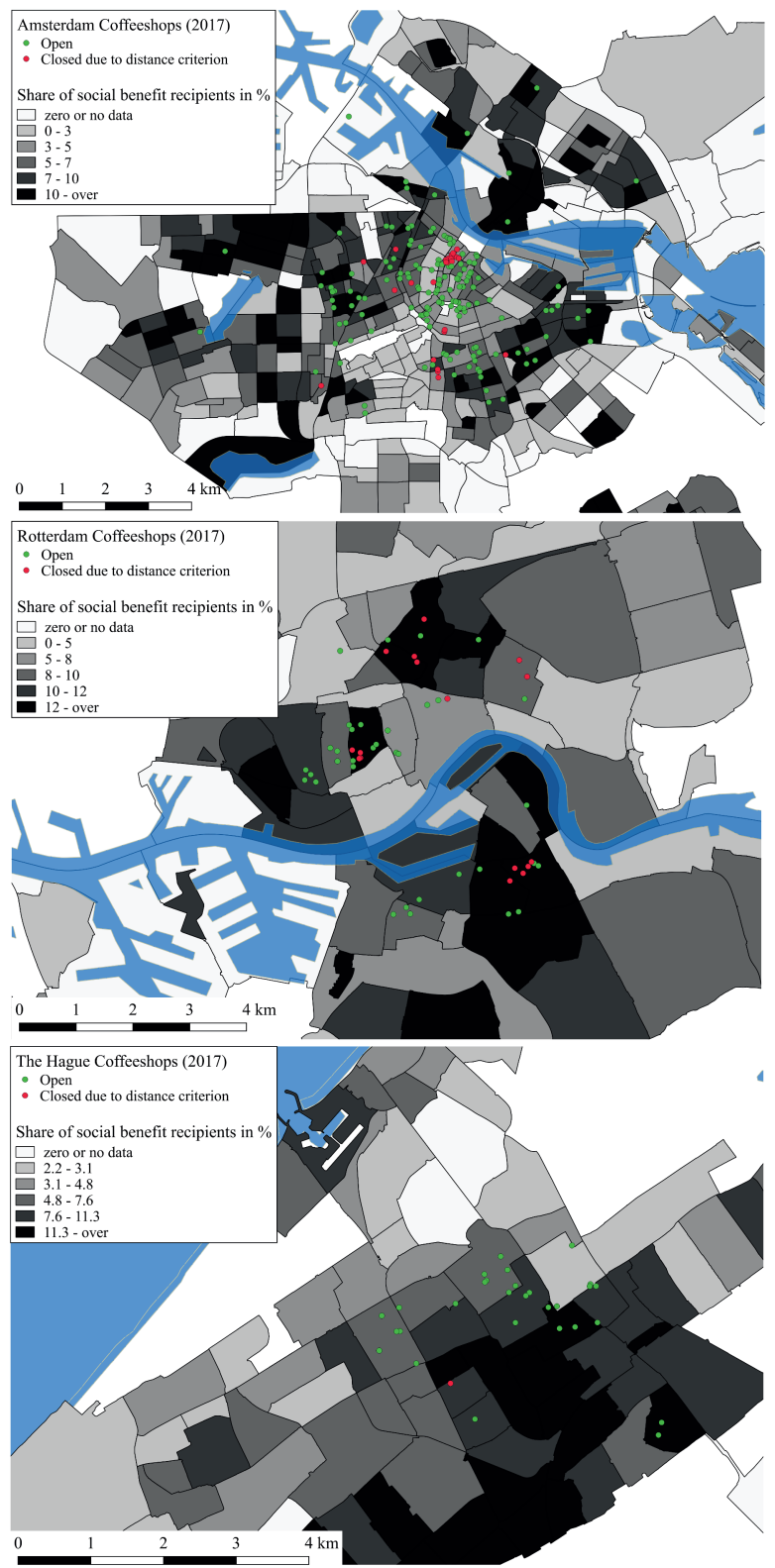

Notes: Illustrated are the locations of coffeeshops over different neighborhoods in the three biggest cities. We focus on coffeeshops that are open today (late July 2017) and coffeeshops that closed due to the distance criterion. We use the percentage of social benefit recipients (unemployment benefits and long-term benefits), as a proxy for social status of neighborhoods. 


\subsubsection{Difference-in-Difference Analysis}

Table 4.9

Difference-in-Difference: Groupings

\begin{tabular}{lcccc}
\hline & \multicolumn{2}{c}{ Treatment } & \multicolumn{2}{c}{ Control } \\
\cline { 2 - 5 } Cut-off & & Post-Closing & Pre-Closing & Post-Closing \\
Pre-Closing & & & 6,991 & 3,583 \\
\hline $150 \mathrm{~m}$ & 1,304 & 534 & 3,902 & 1,954 \\
$100 \mathrm{~m}$ & 598 & 311 & 1,170 & 540 \\
$50 \mathrm{~m}$ & 169 & 100 & 342 & 138 \\
Postcode & 80 & 38 & \\
\hline
\end{tabular}

Notes: Control group: Homes nearby remaining coffeeshops at the same cut-off distance as the treatment group.

Table 4.10

Observations by closing time and place

(150 m cut-off)

\begin{tabular}{lccc}
\hline Closing date & Amsterdam & Rotterdam & The Hague \\
\hline \hline \multicolumn{4}{c}{ Treatment group } \\
\hline Jan 2009 & 0 & 0 & 51 \\
Jun 2009 & 0 & 610 & 0 \\
Jul 2014 & 540 & 0 & 0 \\
Jan 2015 & 41 & 0 & 0 \\
Apr 2015 & 59 & 0 & 0 \\
Jan 2017 & 786 & 0 & 0 \\
\hline Total & 1,426 & 610 & 51 \\
\hline \multicolumn{4}{c}{ Control group } \\
\hline Jan 2009 & 0 & 0 & 1,845 \\
Jun 2009 & 0 & 1,397 & 0 \\
Jul 2014 & 3,715 & 0 & 0 \\
Jan 2015 & 126 & 0 & 0 \\
Apr 2015 & 132 & 0 & 0 \\
Jan 2017 & 3,510 & 0 & 0 \\
\hline Total & 7,483 & 1,397 & 1,845 \\
\hline
\end{tabular}

Notes: Based on the grouping definitions explained in Section 4.4.1, we document the number of transactions im the treatment group ( $150 \mathrm{~m}$ cutoff distance) and control group, divided by different closing dates and cities (see Section 4.2.3 for details). Closing date is always first day of the month. We document that closing times are location dependent. 
Table 4.11

Difference-in-difference analysis - excluding The Hague

\begin{tabular}{lcccc}
\hline & $(1)$ & $(2)$ & $(3)$ & $(4)$ \\
& $150 \mathrm{~m}$ & $100 \mathrm{~m}$ & $50 \mathrm{~m}$ & Postcode \\
\hline \hline Treatment & -0.005 & 0.009 & 0.011 & 0.075 \\
& {$[0.008]$} & {$[0.017]$} & {$[0.023]$} & {$[0.054]$} \\
Post_Treat & $-0.015^{*}$ & $-0.026^{* *}$ & $-0.062^{* * *}$ & $-0.091^{* * *}$ \\
& {$[0.008]$} & {$[0.012]$} & {$[0.018]$} & {$[0.030]$} \\
Post & $0.031^{* * *}$ & $0.023^{* *}$ & 0.007 & $0.059^{* * *}$ \\
& {$[0.011]$} & {$[0.011]$} & {$[0.016]$} & {$[0.020]$} \\
Observations & & & & \\
Adj. R-squared & 10,537 & 5,771 & 1,707 & 532 \\
Quality \& Location controls & 0.81 & 0.81 & 0.84 & 0.83 \\
Time-Fixed effects & YES & YES & YES & YES \\
\hline
\end{tabular}

Notes: Standard errors in parentheses, ${ }^{* * *} \mathrm{p}<0.01,{ }^{* *} \mathrm{p}<0.05,{ }^{*} \mathrm{p}<0.1$. Nearby Coffeeshop refers to closing coffeeshop. Treatment group is reported as part of total observations. Homes nearby closing coffeeshops but within $150 \mathrm{~m}$ of a remaining coffeeshop are excluded from the analysis. Standard errors clustered by municipality-year. Control group cut-off distance is similar to the treatment group cut-off distance $(150 \mathrm{~m}, 100 \mathrm{~m}$, etc.), as illustrated in Figure 4.3. Location controls are 5-digit postcode level fixed-effects (around 17 observations per postcode in sample).

\subsubsection{Repeated Sales Analysis}

Figure 4.9

Repeated sales - price difference over post-closing time $(<150 \mathrm{~m})$

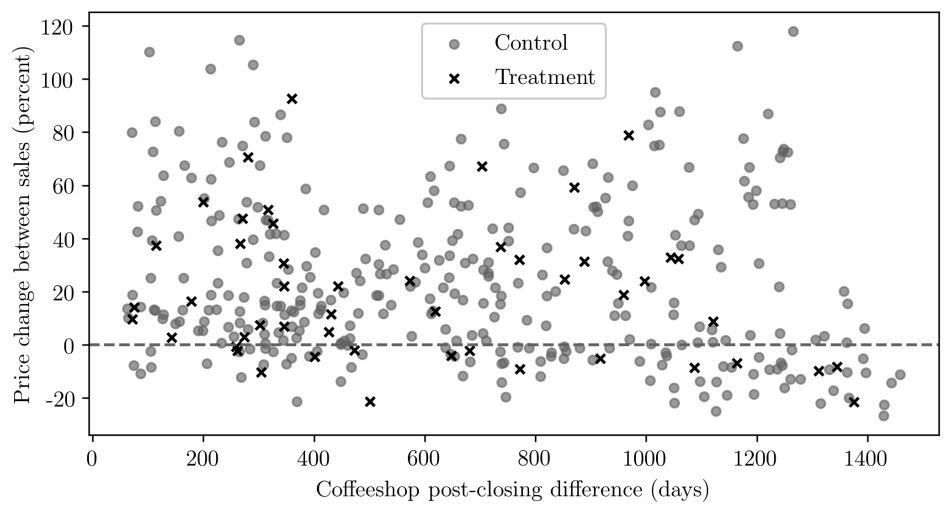

Notes: Cut-off distance: $150 \mathrm{~m}$. Plotted is the price difference between repeated sales in percent over the post-closing time difference. We only consider repeated sales occurring over coffeeshop closing and measure the change in price between sales. Treatment group are repeated sales nearby closing coffeeshops, control group are repeated sales nearby remaining coffeeshops (both within $150 \mathrm{~m}$ ). 
Table 4.12

Repeated Sales - Control Variables

\begin{tabular}{|c|c|c|c|}
\hline \multicolumn{2}{|l|}{ Variables } & \multicolumn{2}{|l|}{ Variables } \\
\hline Sales date difference & 0.001 & $\Delta \mathrm{m}^{2}$ & -0.002 \\
\hline (days) & {$[0.005]$} & & {$[0.120]$} \\
\hline$\Delta$ inside maintenance & $3.721 * *$ & $\Delta$ outside maintenance & 0.204 \\
\hline (level) & {$[1.460]$} & (level) & {$[1.080]$} \\
\hline$\Delta$ insulation & 0.364 & & \\
\hline (layers) & {$[0.531]$} & & \\
\hline Additions & & Removals & \\
\hline Room added & 0.690 & Room removed & 3.694 \\
\hline$(1=$ yes $)$ & {$[2.230]$} & $(1=$ yes $)$ & {$[4.104]$} \\
\hline Roof terrace added & 4.812 & Roof terrace removed & $9.737^{*}$ \\
\hline$(1=$ yes $)$ & {$[4.787]$} & $(1=$ yes $)$ & {$[5.642]$} \\
\hline Attic added & -2.755 & Attic removed & -6.781 \\
\hline$(1=$ yes $)$ & {$[6.351]$} & $(1=$ yes $)$ & {$[7.434]$} \\
\hline Monument status added & 10.045 & Monument status removed & $-22.353^{* * *}$ \\
\hline$(1=$ yes $)$ & {$[14.625]$} & $(1=$ yes $)$ & {$[2.444]$} \\
\hline Garden added & 3.301 & Garden removed & 3.795 \\
\hline$(1=$ yes $)$ & {$[3.854]$} & $(1=$ yes $)$ & {$[5.783]$} \\
\hline Garage added & 1.431 & Garage removed & 6.215 \\
\hline$(1=$ yes $)$ & {$[6.221]$} & $(1=$ yes $)$ & {$[12.563]$} \\
\hline Carport added & -0.000 & Carport removed & 3.440 \\
\hline$(1=$ yes $)$ & {$[0.000]$} & {$[1=$ yes $)$} & {$[10.717]$} \\
\hline Garage \& carport added & $28.293^{* *}$ & Garage \& carport removed & -0.000 \\
\hline$(1=$ yes $)$ & {$[13.904]$} & $(1=$ yes $)$ & {$[0.000]$} \\
\hline Multigarage added & $23.545^{* * *}$ & Multigarage removed & 0.000 \\
\hline$(1=$ yes $)$ & {$[7.975]$} & $(1=$ yes $)$ & {$[0.000]$} \\
\hline Parkinglot added & $-9.581^{*}$ & Parkinglot removed & -2.667 \\
\hline$(1=$ yes $)$ & {$[5.610]$} & $(1=$ yes $)$ & {$[7.465]$} \\
\hline $\mathrm{CV}$ or distance heating added & $12.806^{* *}$ & $\mathrm{CV}$ or distance heating removed & -0.187 \\
\hline$(1=$ yes $)$ & {$[5.614]$} & $(1=$ yes $)$ & {$[4.879]$} \\
\hline $\mathrm{AC}$ or solar added & -0.000 & $\mathrm{AC}$ or solar removed & -0.000 \\
\hline$(1=$ yes $)$ & {$[0.000]$} & $(1=$ yes $)$ & {$[0.000]$} \\
\hline Location improvements & & Location worsen & \\
\hline Forest now nearby & $0.000^{* * *}$ & Forest not nearby anymore & 0.000 \\
\hline$(1=$ yes $)$ & {$[0.000]$} & $(1=$ yes $)$ & {$[0.000]$} \\
\hline Park now nearby & -3.617 & Park not nearby anymore & 1.508 \\
\hline$(1=$ yes $)$ & {$[6.090]$} & $(1=$ yes $)$ & {$[12.296]$} \\
\hline Now located next to water & 8.621 & Not located next to water anymore & $-9.201^{*}$ \\
\hline$(1=$ yes $)$ & {$[6.996]$} & $(1=$ yes $)$ & {$[5.029]$} \\
\hline Free view & 0.597 & No free view anymore & -3.871 \\
\hline$(1=$ yes $)$ & {$[3.142]$} & $(1=$ yes $)$ & {$[3.319]$} \\
\hline No busy road nearby anymore & 0.990 & Busy road now nearby & 7.927 \\
\hline$(1=$ yes $)$ & {$[2.978]$} & $(1=$ yes $)$ & {$[7.023]$} \\
\hline Located on a quiet road & 3.464 & Not located on a quiet road anymore & -1.116 \\
\hline$(1=$ yes $)$ & {$[3.410]$} & $(1=$ yes $)$ & {$[3.968]$} \\
\hline Time-fixed effects & YES & Observations & 373 \\
\hline Location controls & YES & Adj. R-squared & 0.53 \\
\hline
\end{tabular}

Notes: Standard errors in parentheses $* * * \mathrm{p}<0.01,{ }^{*} * \mathrm{p}<0.05,{ }^{*} \mathrm{p}<0.1$ Dependent variable: percentage change in house price. Standard errors are clustered by municipality and year. D = dummy, location controls by coffeeshop fixed-effects. Time fixed effects by sales year. 


\section{Chapter 5}

\section{Deep Learning in Real Estate: Object Detection in the Built Environment}

\subsection{Introduction}

Real estate markets are an important part of the economy as everyone participates in them. Houses are often the biggest household asset, and for local governments property taxes are an important factor to finance public investments. Additionally, the average transaction volume in real estate is substantial compared to other asset classes, necessitating accurate real estate valuations. However, due to limited available data, real estate markets inherently suffer from substantial asymmetric information, making them less efficient than other asset markets (Case \& Shiller, 1989). As a result, real estate valuations are often inaccurate, leading to high search and transaction costs, and a substantial risk of mispricing (Kok et al., 2017).

There is arguable a need for better valuations, reducing information asymmetries, and improving appraisals and property tax calculations. By decomposing peoples' willingnessto-pay for different property characteristics, the hedonic property pricing theory provides a solid foundation for proper valuations, modeling real estate prices as a function of its structural and location characteristics (Rosen, 1974). However, even though hedonic models are sound in theory they require good property data for unbiased estimations, which are usually scarce, limiting the practical potential of hedonic models. To improve property valuations, it is therefore necessary to increase the availability of good property data, first. ${ }^{1}$

In this paper, I propose a new method to collect structural property data at a large scale, using machine learning to extract property characteristics from images. Computer vision, the application of machine learning on images, offers many opportunities for data mining and is already used in various applications, such as autonomous driving (Dickmanns \& Zapp, 1987), medicine (Obermeyer \& Emanuel, 2016), and agriculture (Costa et al., 2011). With the increasing availability of urban images, such as through Google Street View, computer vision offers an opportunity to collect visible property characteristics through images. I examine the capabilities of object detection, a technique of computer vision, to collect structural property characteristics, using Google Street View images of the underlying properties.

Using a sample of 15,000 Dutch single-family homes, including detailed structural controls and location, I retrieve Google Street View images through address information. I train an object detection model (a computer vision technique) based on 5,000 observations to detect facades, roofs, windows and doors in property images. For testing, I apply the model to the images of the remaining 10,000 observations to detect the trained objects and use the relative location and size of objects to estimate simple property characteristics. First, I count the number of vertically aligned windows within a facade to determine the

\footnotetext{
${ }^{1}$ Another approach is to use more advanced valuation approaches, such as automated valuation models (e.g. Kok et al., 2017). However these techniques require high quality real estate data, too.
} 
number of floors and compare the estimations to the underlying actual. Second, I measure the ratio of window to facade surface area, creating a new characteristic as a potential proxy for interior brightness.

The models shows a good performance at relatively little model training effort. I document limitations of Google Street View images, such as view-blocking obstacles or missing addresses, and document an image usability of approximately $70 \%$. Showing two example applications, the models estimate the number of floors correctly for approximately 51 percent of the properties, systematically underestimating properties by one floor. I find the main reason for underestimations are view-blocked floors or floors not visible from the street. Comparing the floor estimations with results from an image classification model, I show that accuracy differences are small while object detection models are less sensitive, making use of more images. Last, I estimate the window-surface ratio and show that this measure cannot be explained by other structural characteristics.

Previous studies have tested computer vision in the urban environment, using property images and image classification, an alternative computer vision technique. Using image classification, Lindenthal and Johnson (2018) estimate architectural styles of properties, Zeppelzauer et al. (2018) estimate building age, Koch et al. (2018) estimate building conditions, and You et al. (2017) predict property prices based on images. Law et al. (2018) combine aerial and GSV images in a generic approach to predict housing prices, using different parameters and Glaeser, Kincaid, and Naik (2018) use computer vision to examine the change in maintenance quality of properties over time. These studies show that computer vision can help to collect property characteristics from images. However, the studies apply image classification, a technique with higher image quality requirements (e.g. close up, homogeneous content), allowing only to classify one aspect at a time only. Additionally, only a few studies describe the applied image filtering process, giving little understanding of image quality requirements.

In contrast, this is the first study to propose a model based on object detection instead of image classification, a technique which allows to gather multiple property characteristics simultaneously with the same model. Due to the attribute of being more robust to complex image content, object detection does not require to filter images before applying the model, making the model more suitable to data mining applications at a large scale (Everingham et al., 2010). I present two potential applications of the proposed model, but leave it to the creativity of future researchers to explore different usages of the model.

There are several economic implications of using object detection to extract data from images. First, building accurate property pricing models requires sufficient data. The proposed method presents a solution to approximate data on individual structures, if this data is not available or incomplete. Second, the proposed model can easily be retrained for other visible aspects, such as solar panels, giving researchers a cost-effective and effective tool to examine new aspects of housing markets. ${ }^{2}$ Third, the method could be used in markets with little or no information, such as developing countries, to remotesense property markets and their developments (similar to Henderson et al., 2011). ${ }^{3}$

\footnotetext{
${ }^{2}$ Some visible aspects, such as cars, could be used as proxies for preferences (e.g. Kahn, 2007).

${ }^{3}$ For example, to proxy economic wealth and developments (https://bit.1y/2XsQA20).
} 


\subsection{Review: Computer Vision \& Urban Applications}

\subsubsection{Image Classification and Object Detection}

Image classification and object detection are computer vision techniques, making computers recognize digital image content, such as a house, through deep neural networks(Sonka et al., 2014). ${ }^{4}$ As illustrated in Appendix Figure 5.9a, deep neural networks are multi-layer testing frameworks, in which probability estimates of preceding layers are weighted inputs for subsequent layers. Through the network layers converge into a final test layer, assigning probabilities to the desired outcome, such as house vs. no-house (Haykin, 1994). ${ }^{5}$ As image data require special tests compared to other input data, such as text or audio, a special class of deep neural networks are convolutional neural networks (CNNs), which include layers (tests) especially designed for image processing. ${ }^{6}$

To achieve a high prediction accuracy, the weightings of the CNN layers are adjusted in a trial and error process defined as training and validating, illustrated in Appendix Figure 5.9b. The process is similar for nearly all CNN models and requires image data that are labeled upfront, mostly by manual work. Images are randomly split into training and validation data, and in an iterated sequential process the CNN analyzes training images, adjusting the layer weightings in every iteration. Every iteration ends with a prediction test, using the validation data and comparing overall accuracy to the previous iteration. This process is defined as model training and continues until accuracy between iterations cannot further be improved (see Ciresan et al., 2011, for more details).

The two major techniques of computer vision are image classification and object detection. $^{7}$ Both techniques are similar as they build on CNN architectures and assign probability scores as an outcome. The main difference between the techniques is in the intended outcomes. Image classification models classify images based on their content as a whole, assigning one probability score to the image. In contrast, object detection models localize and classify objects within an image, assigning individual probability scores to objects (Everingham et al., 2010; Harzallah et al., 2009). For illustration, Figure 5.1 shows the hypothetical outcomes of image classification (b) and object detection (c), for image (a). As illustrated, object detection models classify multiple, different objects, whereas image classification models identify images based on the object with the highest prediction probability.

\footnotetext{
${ }^{4}$ For more general background on computer vision, please see (Hartley \& Zisserman, 2003).

${ }^{5}$ The term "deep" refers to a high number of testing layers, even though there is no general definition how many layers define a "deep" neural network.

${ }^{6}$ For more information on CNNs see Krizhevsky et al. (2012) or https://bit.1y/2b0WHmJ.

${ }^{7}$ Additional approaches are, among other, object tracking, semantic segmentation, and instance segmentation. However most of these techniques focus on video analyses or are unnecessarily complex for many applications (Drayer \& Brox, 2016).
} 
Figure 5.1

Illustration the difference of Image Classification and Object Detection

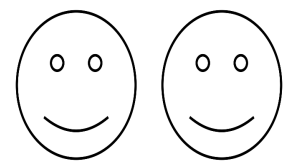

(a) Base image

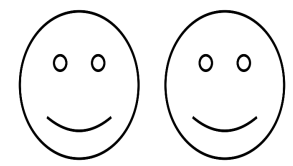

97.5\% Face

(b) Image classification

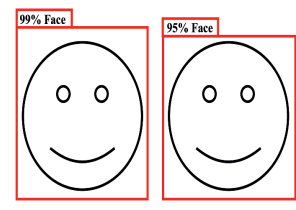

(c) Object detection

Notes: Applying computer vision on image (a) to detected image content results in different outcomes. Image classification (b) classifies the image content of an image as a whole, whereas object detection (c) localizes objects of interest within the image and classifies them individually.

Both techniques have advantages and disadvantages and model selection depends on the underlying application and image data. Image classification models require low initial effort as image labeling requires only one label per image. Additionally, computing requirements are low, reducing the model training time. Despite lower requirements, accuracy can still be high as image classification works well for single-object images, such as close-ups. However, image classification models do not deal well with complex images, detecting multiple objects and/or determine the relative location and size of image content. Image classification works well in A/B testing applications, such as in medicine, and broader content recognition, such as in reversed image search.

In contrary, object detection models require a higher initial effort as all objects need to be marked and classified within the image. Additionally, more computing power is required in the training process, which can be time-consuming and costly. However, due to the localization and ability to handle multiple objects simultaneously, object detection models can deal better with complex image content, such as multiple objects of different size and confounding objects as in urban scenes and satellite images. Object detection models are used, among others, in autonomous driving, face recognition, and activity tracking.

\subsubsection{Computer Vision in the Urban Environment}

Recent studies have tested applications of computer vision techniques in the urban environment. Naik et al. (2014) combine a survey with street scene images to generate a perceived safety score for street scenes ("Streetscore"). Using the same images, the authors build an image classification model, which is able to predict Streetscores automatically. As the Streetscore shows high correlation with population density, household income, and income inequality, the model can be used to approximate these characteristics using street scene images only (Naik et al., 2016; Glaeser, Kominers, et al., 2018). Other studies focus on the measure of physical appearance of street scenes (Naik et al., 2017) or the detection of green areas (Seiferling et al., 2017).

Focusing on property characteristics, Glaeser, Kincaid, and Naik (2018) and Koch et al. (2018) develop image classification models to predict outside building conditions, using Google Street View (GSV) and private images. Measuring changes in the condition for repeated sales, (Glaeser, Kincaid, \& Naik, 2018) show that quality improvements 
detected by these models increase property prices. In a similar manner, Poursaeed et al. (2018) assign luxury scores to interior and exterior Zillow images and develop a image classification model to predict luxury scores. Including luxury scores into pricing models leads to better prediction results, reducing the Median Error Rate (MER) to 5.6\%.

Lindenthal and Johnson (2018) explore the value of architectural style, developing an image classification model based on GSV images to predict styles for residential houses. Other studies develop models to assess building instances, such as office and retail, (Kang et al., 2018) and determine building age using high resolution images (Zeppelzauer et al., 2018). Other studies try to connect property appearance and value directly. You et al. (2017), as well as Law et al. (2018), train a classification model, labeling property images with property prices. The developed models are able to predict property prices at a high accuracy, using images and location only, reducing the mean absolute percentage error (MAPE) by approximately 10 percentage points (You et al., 2017). However, as the developed models are unsupervised, it is unclear which image features determine price.

Overall, most existing studies focus on one particular property aspect only, solely applying image classification models. Even though little information is provided on this matter, it can be assumed that specific, pre-selected images are used as image classification models require close-up images of properties. This might limit the general usability of the proposed techniques and leads to false conclusions on the quality of Google Street View as an image source. ${ }^{8}$ Additionally, most studies focus on unobserved or unrecorded property aspects, such as maintenance quality or style elements. As quality definitions and architectural styles differ across markets, it can be assumed that models are limited in their applicability across markets.

This paper extends the existing literature in various dimensions. This is the first study using object detection instead of image classification, offering new data mining opportunities. Due to the localization, detection models can help to assess the relative position and size of image objects. It is therefore possible to collect structural and nonvisible information, such as property size. Furthermore, I compare the performance of object detection and classification models, documenting that both models show similar accuracy. However, detection models deal better with unfiltered images, allowing to use more images, saving time and increasing the generalizability. Additionally, this study provides insides about the quality of Google Street View as an image data source for similar exercises.

\subsection{Methodology}

To demonstrate the potential applications of object detection, I train a model to detect simple property aspects in images, namely windows, roofs, and facades. Using the position and relative size of these objects, I show two example applications. I estimate the number of floors as a structural characteristic, counting the number of vertically aligned windows. Furthermore, I estimate the window-surface ratio as a measure to create a new structural characteristic, which can potentially be a proxy for interior brightness of properties.

Figure 5.2 illustrates the model training and application process. First, the object detection model is trained, as illustrated in Sub-Figure 5.2a. To get property images

\footnotetext{
${ }^{8}$ Only Lindenthal and Johnson (2018) discuss the practical limitations of Google Street View.
} 
for the training process, I use actual housing transactions and request corresponding images from Google Street View, using the address of the house. The received Google Street View images are manually labeled, using the RectLabel annotation software. An example of an annotated image is shown in Appendix Figure 5.10. The annotated image dataset is split into training and validation data, and the training process is started. Once accuracy cannot be improved further, the training process is stopped and the model can be employed.

Illustrated in Sub-Figure 5.2b, the trained model is used for object detection applications. Again, property transactions are used as the basis to get property images from Google Street View. The images are then assessed by the objected detection model, extracting property information. Based on a unique identifier, extracted property information can be linked to the initial property transaction data. I present two example applications in this paper, showing the potential of object detection models for data mining exercises. In contrast to the training process, the application process is fully automated, showing the strength of the object detection model.

\section{Figure 5.2}

Process diagram: Model training and application

(a) Model training process

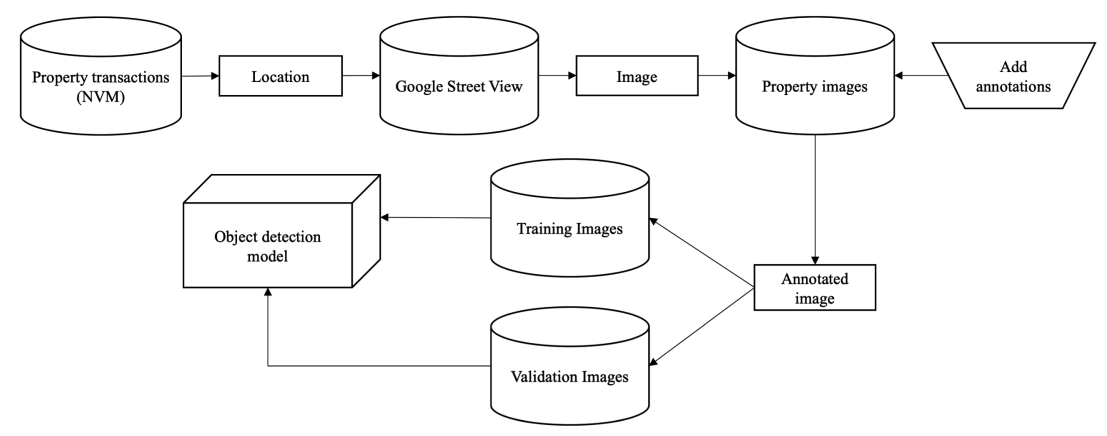

(b) Model application process

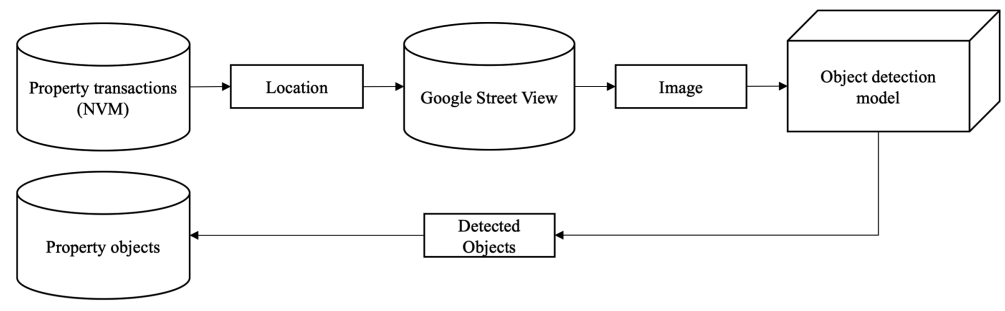

Notes: Databases are illustrated as cylinders, transmitted information in rectangle boxes and manual input as trapezoid. Subfigure 5.2a illustrates the model training process, while subfigure $5.2 \mathrm{~b}$ illustrates the application of the prepared model to collect property characteristics, such as number of floors. 


\subsubsection{Model Selection and Training}

Developing object detection models for individual tasks from scratch is a costly task, requiring significant time and labeled image data. ${ }^{9}$ Even though there are some open-access image databases, providing labeled images, image labels usually do not fit custom applications, requiring to relabel images manually. ${ }^{10}$ Besides, newly developed models might not reach the performance of existing models, developed with high effort. In an annual benchmark competition, research teams compete with their newest CNN architectures on accuracy and some architectures lead the field for consecutive years. ${ }^{11}$ It is therefore questionable that a bottom-up developed object detection model outperforms existing models in efficiency.

To keep development effort reasonable while benefiting from state-of-the-art CNN research, this study applies transfer learning. ${ }^{12}$ During transfer learning an existing, pretrained model is retrained to detect new object classes, such as detecting houses instead of cars. Only higher-level CNN layers are retrained for new objects while deep layers, containing more basic tests, remain unchanged. This process enables to build on efficient, state-of-the-art CNN architecture with low training effort (Oquab et al., 2014). However, as transfer learning builds on existing models, initial model selection can significantly affect the final performance, requiring to test different models for development.

I only consider object detection models pre-trained on the COCO (Common objects in context) database, as these models generally show a high performance and are trained to distinguish 91 different object classes, none related to real estate though (Lin et al., 2014). At the time of writing, there are around 25 pre-trained object detection models for the COCO data available, differing in the localization approach and CNN architecture. ${ }^{13}$

Model selection depends on various factors, but boils down to a trade-off between detection accuracy and speed (Bianco et al., 2018; Huang et al., 2017). Speed generally varies with model complexity, image data resolution and employed hardware, while accuracy is largely dependent on image quality. Benchmarks are provided for image databases, such as COCO. In object detection, accuracy is two-dimensional and therefore measured using the mean average precision (mAP) at different Intersection over Union (IoU) cutoffs, measuring classification accuracy at different localization accuracy cut-offs (He et al., 2016). Appendix 5.7.1 illustrates the IoU and mAP measures further.

Based on the COCO benchmark accuracy and speed trade-offs, I select two object detection models for retraining: The Faster Region-based Convolutional Neural Network (R-CNN) and Single Shot Detection (SSD) (Liu et al., 2016). ${ }^{14}$ The major difference between the selected models is the localization technique. Faster R-CNN follows a two-step approach, first localizing potential objects and then classifying them. For localization, Faster R-CNN applies a convolution network layer (Regional Proposal Network), "proposing" the most relevant regions for classification. As illustrated in Appendix Figure 5.11,

\footnotetext{
${ }^{9}$ A simple model could be trained within 10 days on multiple computers with high-end GPUs.

${ }^{10}$ In example, the COCO (Common Objects in Context) dataset is open source, providing 330,000 images of which over 200,000 are labeled for 91 different object classes http://cocodataset.org.

${ }^{11}$ Large Scale Visual Recognition Challenge (ILSVRC), http: //www . image-net . org/challenges/LSVRC/

${ }^{12}$ Using existing, publicly available models additionally allows researchers to easily replicate the model training.

${ }^{13} \mathrm{An}$ up-to-date model overview is available here: https://bit.1y/2EtFj JP.

${ }^{14} \mathrm{I}$ am currently expanding this selection, results will be available in the online Appendix.
} 
Faster R-CNN uses anchor boxes to capture the best aspects and size, classifying the proposed regions at three fixed aspect ratios and three sizes(Girshick et al., 2014; Ren et al., 2015). Due to the ninefold classification, Faster R-CNN is considered as accurate but relatively slow.

In contrast, SSD performs detection and classification in one step, increasing speed significantly Liu et al. (2016). Images are passed through CNN layers, classifying image regions of different size directly. SSD also uses anchor boxes to optimize accuracy. Instead of using fixed ratios, as in Faster R-CNN, anchor box ratios and size are determined by objects in the underlying training data. Therefore, SSD models localize objects based on pre-defined ratios, speeding up the detection process significantly. However, this might come at a cost of accuracy if training objects differ much from application objects in the aspect and size.

As object detection models localize and classifying objects, models do not only differ in the localization approach, but also in the classification architecture. In recent years, CNN architectures showing the best accuracy results are ResNet, VGGNet, and GoogleNet/Inception (Bianco et al., 2018). However, as these architectures aim for accuracy, some are of limited practical use due to high computational complexity. Therefore, mobile CNN architectures such as MobileNet are developed to copy high-performing architectures in a resource-reduced way. Considering the speed-accuracy trade-off, I select a Faster R-CNN model with Inception V2 architecture and an SSD model with MobileNetV2 architecture.

I retrain both models to detect four object classes: roof, facade, and window. These basic aspects allow to estimate further structural characteristics (see Section 5.3.2). Additionally, these aspects are rather homogeneous in appearance for properties in general, increasing the accuracy of the model for out-of-sample images. All visible objects are labeled manually within the training images, using RectLabel annotation software. I split the data into training and validation records at the common ratio of 85:15 (e.g. You et al., 2017; Zeppelzauer et al., 2018). Lastly, the training process is performed in the TensorFlow library on Google Cloud.

\subsubsection{Estimating Structural Characteristics}

\section{Number of Floors}

Considering structural factors determining property prices, one structural characteristic is the number of floors, providing information about building size. I estimate the number of floors based on the relative location of visible facade and window objects. Assuming that every floor has at least one window, I approximate the number of floors of properties by counting the number of vertically aligned windows along a facade. Since all bounding boxes in the detection process are rectangles, facades and windows can be modeled in a two-dimensional space as illustrated in Figure 5.3. The coordinates $\left(x 1_{w}, y 1_{w}\right)$ and $\left(x 2_{w}, y 2_{w}\right)$ determine the corners of the detected property facade and every window $i$ has corner coordinates $\left(x 1_{i}, y 1_{i}\right)$ and $\left(x 2_{i}, y 2_{i}\right)$ with $\left\{\left(x_{i}, y_{i}\right) \in\left(X_{i}, Y_{i}\right) \mid\left(X_{i}, Y_{i}\right) \in\left(X_{w}, Y_{w}\right)\right\}$. 
Figure 5.3

Illustration of floor estimation

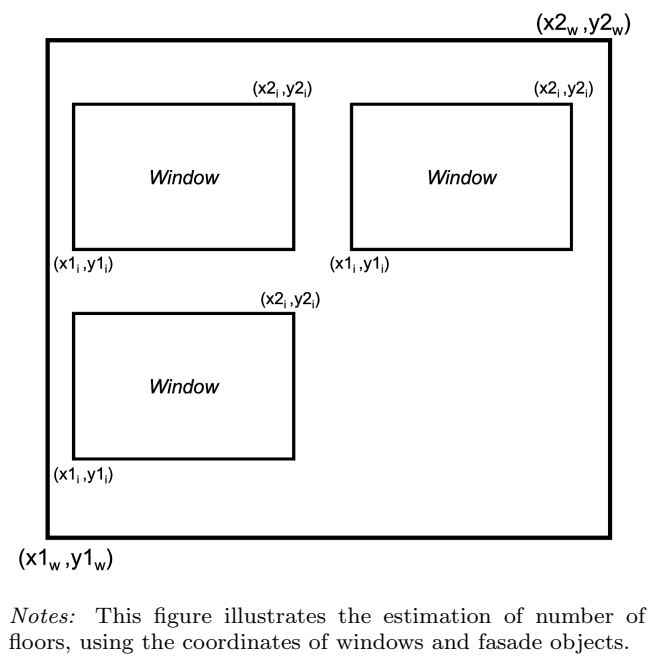

Considering all windows within a facade $w$, I build a simple search algorithm to determine all possible combinations of vertically aligned windows. The estimated number of floors is defined as $\hat{F}_{w}$, with

$$
\hat{F}_{w}=\max \left(\left\{l_{1}, l_{2}, l_{3}, \ldots l_{z}\right\}\right)
$$

where $l_{n}$ is the number of windows in path $z$. The number of windows in path $z$ is determined by

$$
l_{z}=\max \left(1, \sum_{i}^{I} C_{i}\right)
$$

subject to: $\quad\left\{i \neq j \mid Y_{i} \neq Y_{j}\right\}, \quad y 2_{i}<y 1_{j}$.

where $C_{i}$ is the largest corner coordinate of bounding box $i,\left(x 2_{i}, y 2_{i}\right)$. The constraint in Equation (5.2) states that windows cannot overlap on the y-axis and the y-values of window $j$ have to be higher than those of window $i$, forcing the algorithm to search from low to high. In Figure 5.3 this would result in the possibile combinations $\{1,1,2,2\}$, with $\hat{F}_{w}=2$.

A floor is not necessarily bound to a facade, but could also be under the roof. I therefore also use detected roofs in the calculation. If a window is detected within a detected roof, one floor is added to the estimated number of floors $\hat{F}_{w}$. The number of windows is not considered, as houses usually have only one floor below the roof.

Since images might show multiple facades and roofs, such as from neighboring houses, the facade with the largest surface area is selected. The roof with the biggest surface area, vertically above the facade is selected. Accuracy is determined by the difference between estimated and actual number of floors out of the underlying property database. 


\section{Window-Surface Ratio}

Object detection models could help to gather new property characteristics that are currently not considered but might show some price effects. As an example, I estimate the window-surface ratio of facades. I argue that a higher window-surface ratio leads to a higher level of interior brightness through natural light, which has been shown to affect health and well-being. ${ }^{15}$ However, a higher window-surface ratio also exposes the interior more to the outside, a potentially unwanted fact. Additionally, large, especially old windows are less insulating than walls, potentially reducing energy efficiency. ${ }^{16}$

To estimate the window-surface ratio I calculate the surface area of all windows within a facade over the surface area of the facade, as indicated in equation (5.3). The sum of all window surface areas $I$ is estimated over the surface area of facade $w$. Only windows within the boundaries of facade $w$ are considered, as indicated by $\phi_{i}=1$.

$$
\hat{B}_{w}=\frac{\sum_{i=1}^{I}\left(x 2_{i}-x 1_{i}\right)\left(y 2_{i}-y 1_{i}\right) \phi_{i}}{\left(x 2_{w}-x 1_{w}\right)\left(y 2_{w}-y 1_{w}\right)}
$$

where

$$
\begin{array}{r}
\{(x, y) \in(X, Y) \mid(X, Y) \in \mathbb{R}\} \\
\phi_{i}= \begin{cases}1 & \text { for } X_{i} \in X_{w} \wedge Y_{i} \in Y_{w}, \\
0 & \text { otherwise. }\end{cases}
\end{array}
$$

To control for overestimated and overlapping detected windows, overlapping bounding box areas $J$ are excluded from the surface area, resulting in the final approximation as shown in equation (5.4).

$$
\begin{gathered}
\hat{B}_{w}=\frac{\left(\sum_{i=1}^{I}\left(x 2_{i}-x 1_{i}\right)\left(y 2_{i}-y 1_{i}\right) \phi_{i}\right)-\left(\sum_{j=1}^{J}\left(x 2_{j}-x 1_{j}\right)\left(y 2_{j}-y 1_{j}\right)\right)}{\left(x 2_{w}-x 1_{w}\right)\left(y 2_{w}-y 1_{w}\right)} \\
\left\{\left(X_{J}, Y_{J}\right) \in\left(X_{I}, Y_{I}\right)\right\}
\end{gathered}
$$

The proposed method has some limitations. Since I am not aware of any studies assessing a similar measure, it is impossible to verify the potential findings other than in some random spot-checks. Since Google Street View only provides one image, the measure can only be applied to one facade. This might underestimate the true window-surface ratio as especially backsides of houses usually contain larger windows.

\subsection{Input Data}

To collect property data through the proposed method only two data inputs are required, addresses and property images. I use Dutch residential property transactions provided by the Dutch Realtor Association (NVM), covering around 75 percent of all Dutch residential transactions until 2017. The dataset has been used in numerous studies, including but not limited to Brounen and Kok (2011); Brounen et al. (2012); Dröes and Koster (2016). The dataset includes a rich panel of structural characteristics, such as size and number of

\footnotetext{
${ }^{15}$ For more information on the effects of brightness on human feelings, see Marsden (1969).

${ }^{16}$ See: https://bit.1y/2ZdhIGS
} 
floors, and contains address and transaction price. Using this rich dataset enables me to examine relationships between approximated and actual structural characteristics.

To retrieve property images, I use the Google Street View Application Programming Interface (API), providing Google Street View images for requested locations. Google Street View provides street images taken by special cars with mounted panorama cameras, covering a 360 degree perspective. To receive an image for a specific address, an algorithm determines the best coverage within the nearest panorama and returns the best image that shows the property. However, Lindenthal and Johnson (2018) show that the algorithm often fails to find the best image, especially for densely located addresses, such as for row houses and apartment buildings. Nevertheless, Google Street View offers a generally wide coverage, being present on all six continents. It is therefore used in many urban image studies (e.g. Naik et al., 2014; Glaeser, Kincaid, \& Naik, 2018).

Constrained by the availability of Google Street View in the Netherlands, I focus on transactions between 2011 and 2017. I only consider free-standing houses with less than five floors, as these are more likely to be captured on a single image and more likely to be identified by the Google Street View algorithm compared to apartments or attached houses. The resulting sample consists of 115,490 observations, or 16,499 observations per year, on average. Since labeling images for the model training involves substantial manual work, I draw a random sub-sample of 5,000 observations and request Google Street View images for the model training. ${ }^{17}$ Additionally, I draw a second, mutually exclusive sub-sample of 10,000 observations to demonstrate the model applications.

For the model training sample and application test sample, 4,513 and 9,042 images are received, respectively, demonstrating a Google Street View address coverage of approximately 90 percent. There is no significant difference in geographic sample distribution, as shown in Appendix Figure 5.12. However, there are small clusters of unsuccessful image downloads in rural areas. Table 5.1 provides descriptive statistics for both samples, showing that properties in both samples have similar characteristics. Examining missing observations, I document that properties with Google Street View images are on average bigger, have more floors, and are more expensive than properties without images.

\footnotetext{
${ }^{17} \mathrm{I}$ am currently extending the number of model training images/observations.
} 
Table 5.1

Samples - Descriptive statistics

\begin{tabular}{lccccc}
\hline \multirow{2}{*}{ Sample } & \multicolumn{2}{c}{ Model training } & & \multicolumn{2}{c}{ Application test } \\
\cline { 2 - 3 } \cline { 5 - 6 } GSV images & No & Yes & & No & Yes \\
$\mathrm{N}$ & 487 & 4,513 & & 958 & 9,042 \\
\hline Size & 150.90 & 160.61 & & 152.82 & 160.65 \\
$\left(\mathrm{~m}^{2}\right)$ & {$[58.57]$} & {$[56.10]$} & & {$[60.54]$} & {$[54.43]$} \\
Number of floors & 2.22 & 2.41 & & 2.23 & 2.42 \\
$(\mathrm{n})$ & {$[0.66]$} & {$[0.66]$} & & $0.69]$ & {$[0.65]$} \\
D: Attic & 0.20 & 0.26 & & 0.23 & 0.25 \\
$(1=$ Yes $)$ & {$[0.40]$} & {$[0.44]$} & & $0.42]$ & {$[0.44]$} \\
Sales year & 2014 & 2014 & & 2014 & 2015 \\
& {$[2.03]$} & {$[1.93]$} & & {$[1.93]$} & {$[1.94]$} \\
Price & 337,055 & 359,117 & & 335,501 & 357,192 \\
(Euro) & {$[150,357]$} & {$[160,539]$} & & {$[148,334]$} & {$[156,358]$} \\
\hline
\end{tabular}

Notes: Descriptive statistics for properties in the two samples, grouped successful GSV image retrieval. Documented is the mean with standard deviation in brackets.

\subsection{Results}

\subsubsection{Stylized facts and model performance}

All 4,513 retrieved images of the model training sample are manually annotated, highlighting windows, roofs and walls. As shown in Table 5.2, a total of 28,905 objects are annotated. On average, there are 4.5 windows, 1.3 facades, and 0.5 roofs per image. However, only 3,940 images show an object and 3,467 images show a facade, resulting in a effective usage ratio of $69.3 \%$ for Google Street View images. An example of unsuitable images without objects is shown in Appendix Figure 5.13. For the model training process, images showing at least one object (e.g. a roof) are considered $(\mathrm{N}=3,940) .{ }^{18}$ Appendix Figure 5.14 shows the final data flow diagram.

Table 5.2

Training sample - Object classes and number of records

\begin{tabular}{llc}
\hline Object class & Definition & Number of records \\
\hline window & A visible window in facade & 20,297 \\
wall & A house facade & 5,888 \\
roof & A fully visible roof of a house & 2,398 \\
\hline Total records & & $\mathbf{2 8 , 5 8 3}$ \\
\hline
\end{tabular}

Notes: Three object classes are defined for the model: window, facade, and roof. The results are based on 4,513 Google Street View images. There can be multiple facades per image due to neighboring houses.

The sample is split at a rate of 85:15 into training and validation records, resulting

\footnotetext{
${ }^{18}$ For model training it is not necessary to only consider pictures with a facade as objects are assessed individually, too.
} 
in 24,569 training and 4,336 validation records. Both models are trained on the Google Cloud AI Engine until no further improvement in training accuracy can be observed. The training process is stopped after 24,791 iterations for the SSD model and 75,684 iterations for the Faster R-CNN model. Using the same hardware, the SSD model training time takes approximately three times as long as the Faster R-CNN model. Lastly, both models are applied to the images of the application test sample.

As illustrated in Figure 5.2b, both models are applied to the application test sample. Figure 5.4 shows example images for the object detection results, based on the SSD model. As every image object is localized and classified, the model assigns a classification probability score to objects. To measure performance, I consider the number of detected facades at different cut-off scores, as facades are the basic objects for the applications. The maximum number of facades considered per image is one. Based on the results of the training sample, approximately $77 \%(3,467 / 4,513)$ of images show houses, which should result in approximately 6,946 images with detectable facades.

Figure 5.5 shows the number of detected facades at different classification cut-offs. At a cut-off probability of 0.5 , the models detect facades in 7,646 and 6,587 images, respectively. Given that there should be approximately 6,946 images with visible facades, the Faster R-CNN model is slightly overestimating the number of facades while the SSD model underestimates them. For the applications, I only consider cut-off scores between 0.7 and 0.9 as the number of detected facades is reasonable in this range. A higher minimum cut-off would result in a sharp decrease of number of observations. 
Figure 5.4

Example images of object detection results
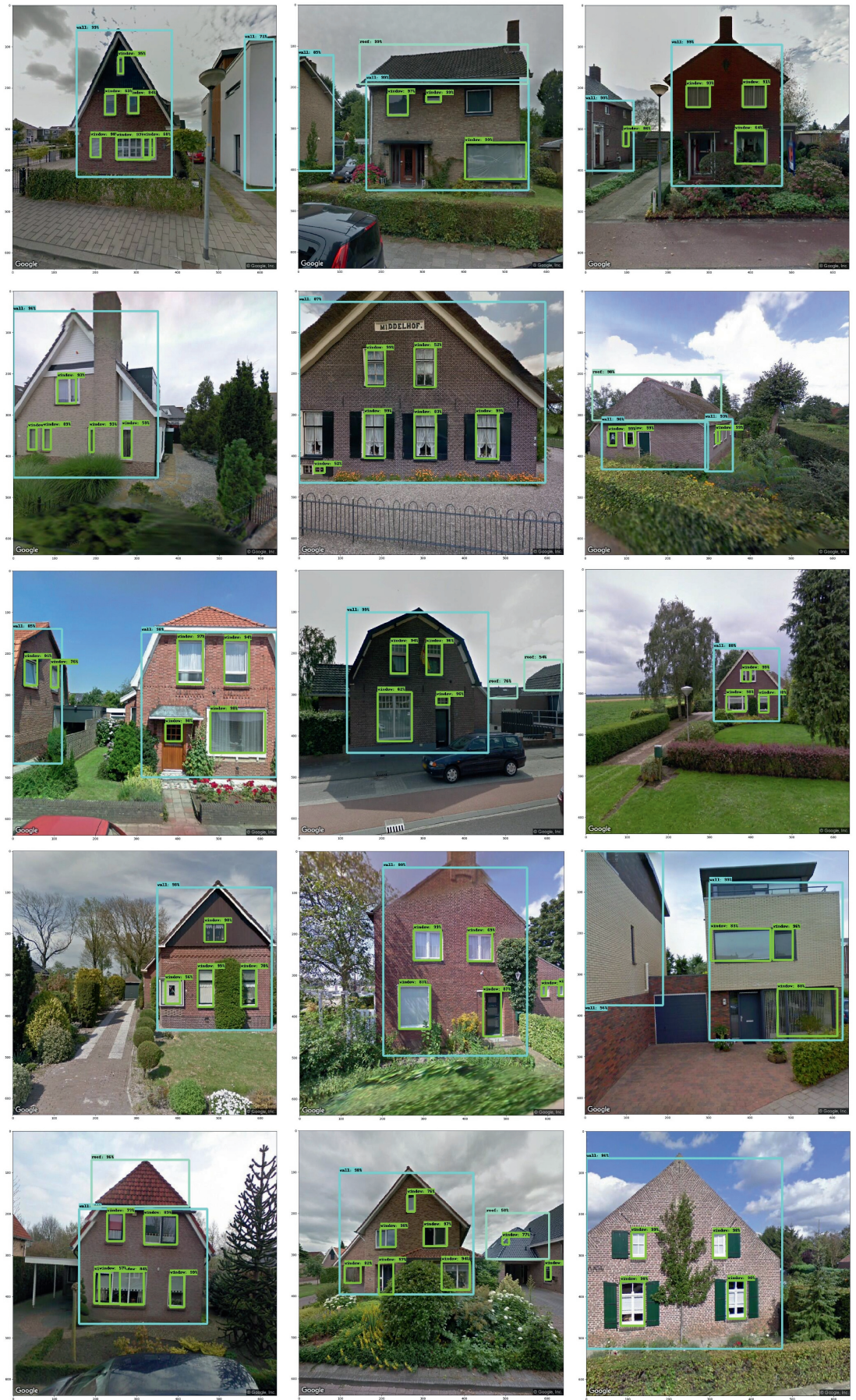

Notes: Examples of visual object detection results based on trainined SSD MobileNetV2 model, with 10,177 steps. 
Figure 5.5

Detected houses - Application test sample

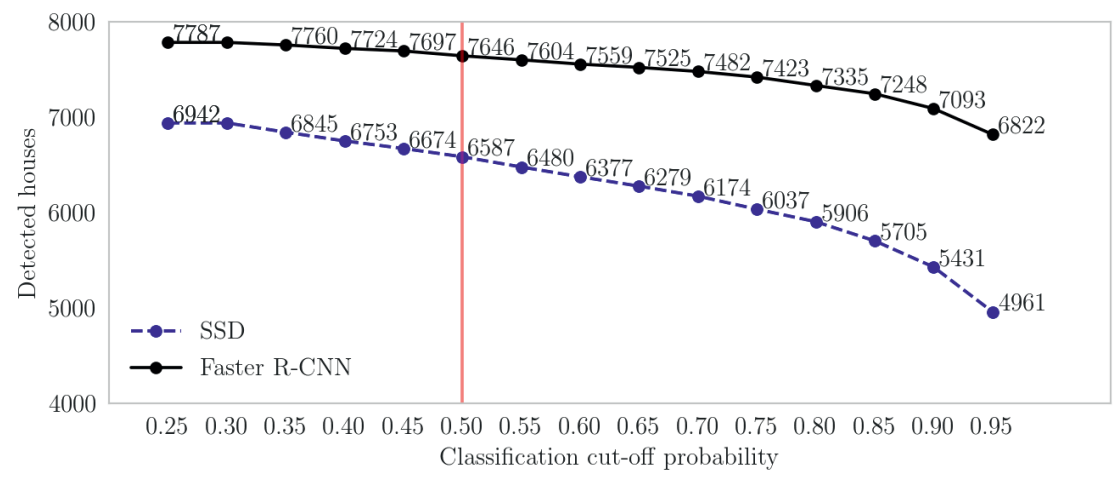

Notes: The figure shows the number of successully detected houses at different probability cut-off levels. The results are based on the number of detected facades, the base object for the analysis. Totally, 9,042 images are received from Google Street View.

\subsubsection{Floor Estimation}

As described in Section 5.3.2, the number of floors is estimated using the relative location of windows and facades. Appendix Figure 5.15 shows the distribution of actual number of floor, indicating that the majority of houses have two or three floors. As a accuracy measure I compare the estimation results to the actual number of floors, testing at different facade detection cut-off scores.

Figure 5.6 shows the deviations between estimated and actual number of floors at different detection cut-offs. Between 43.8 and 53.5 percent of floor estimations lead to correct results, decreasing with cut-off scores. The models generally underestimate the number of floors by 1 . The combined share of correct predictions and predictions underestimated by one floor ranges from 90.5 to 86 percent. Appendix Table 5.4 shows the mean floor deviation and standard deviations for different actual number of floors and cut-off levels, indicating that four floor houses are underestimated the most while one floor houses are slightly overestimated.

Overall, the model underestimates the number of floors, especially for higher houses (as of two floors). I perform random eyeball-checks on images with floor deviations, documenting two main reasons for deviations as illustrated in Appendix Figure 5.16. In many cases (Appendix Figure 5.16a), one floor is blocked in view either by a hedge, a tree, or a car. Similarly, in many cases there is no visible window in the roof, but neighboring houses indicate the existence of a floor under the roof (Appendix Figure 5.16b). In the illustrated example, it is obvious from the neighboring house that there are two instead of one floors. Furthermore, the models fail to constantly detect all windows at high cut-off levels. As a result, some windows are not considered in the estimations. A solution to overcome these problems is to use better property images and increase the model training sample. 
Figure 5.6

Floor estimation accuracy

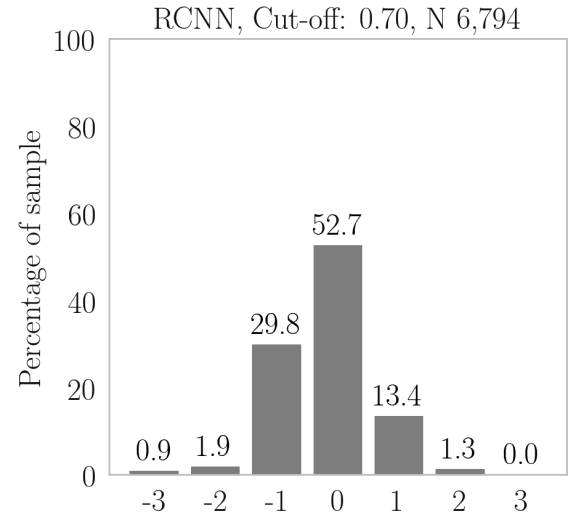

Floor deviation (estimated - actual)

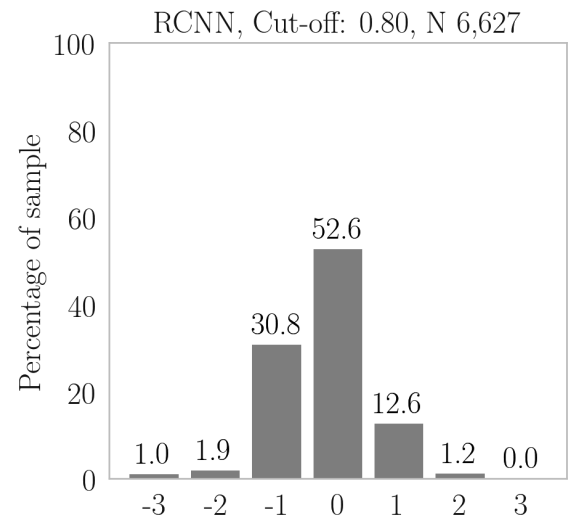

Floor deviation (estimated - actual)

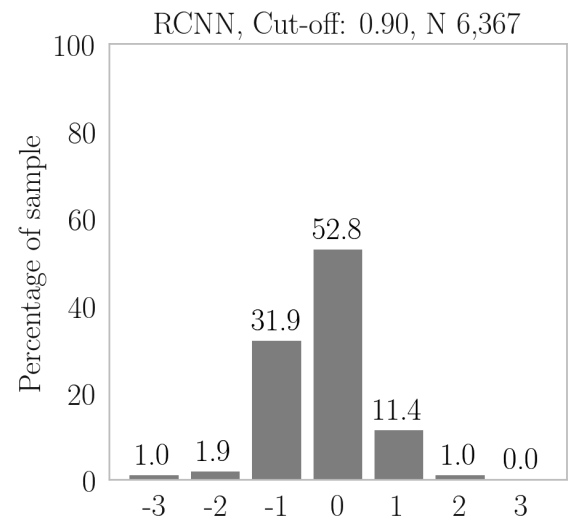

Floor deviation (estimated - actual)

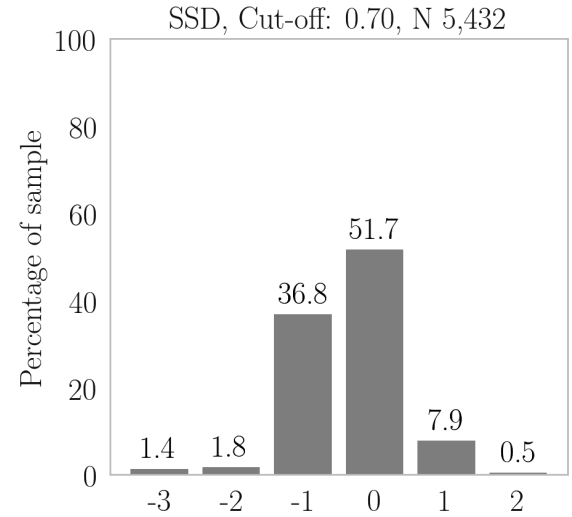

Floor deviation (estimated - actual)

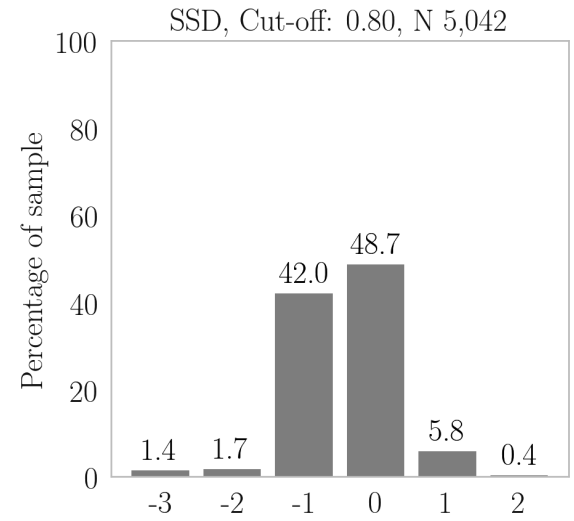

Floor deviation (estimated - actual)

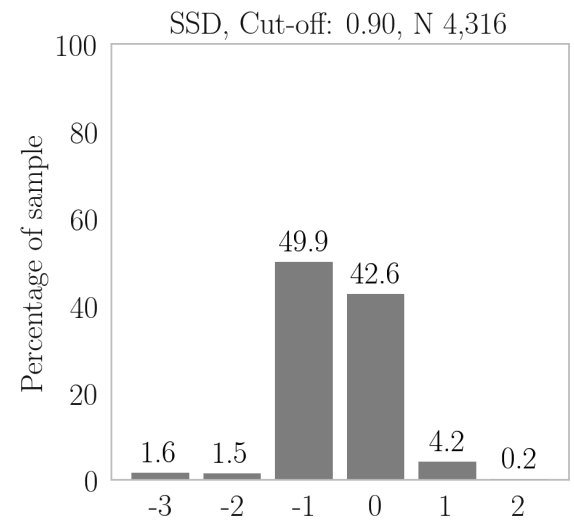

Floor deviation (estimated - actual)

Notes: Floors are approximated as described in Section 5.3.2, using different classification cut-offs. Presented are the number of floor deviations (estimated number of floors - actual number of floors) at different cut-off levels. 


\subsubsection{Window-Surface Ratio}

I estimate the window-surface ratio as described in Section 5.3.2. Figure 5.7 shows the window-surface ratio distribution at different classification cut-off scores. The distribution ranges from 0 to approximately 0.35 , with 79 properties above 0.35 . There is a significant number of houses with a window surface ratio equal to 0 , increasing with cut-off. The reason are houses with no visible windows in the front and non-detected windows. For houses with detected windows, average the window-surface ratio ranges between 0.07 and 0.12 for different models and cut-offs.

To examine the distribution of window-surface ratio further, I use the underlying property data and regress structural variables on the window-surface ratio. Observations with a estimated window-surface ratio of 0 are excluded. Table 5.3 shows the outcome of the regression for both models and different cut-offs. Overall, the model shows a poor fit, with an adjusted R-squared between 0.02 and 0.03 . Increasing size in square meter slightly decreases the window-surface ratio. More floors increases the ratio, which makes intuitive sense as higher facades usually have more windows. Controlling for different building periods, houses built between 1981 and 2000 generally show lower window-surface ratio compared to houses built between 1906 and 1930. Even though some periods show higher window-surface ratios in general, it can concluded that the measure cannot be explained properly by existing structural characteristics. 
Figure 5.7

Window-surface ratio distribution
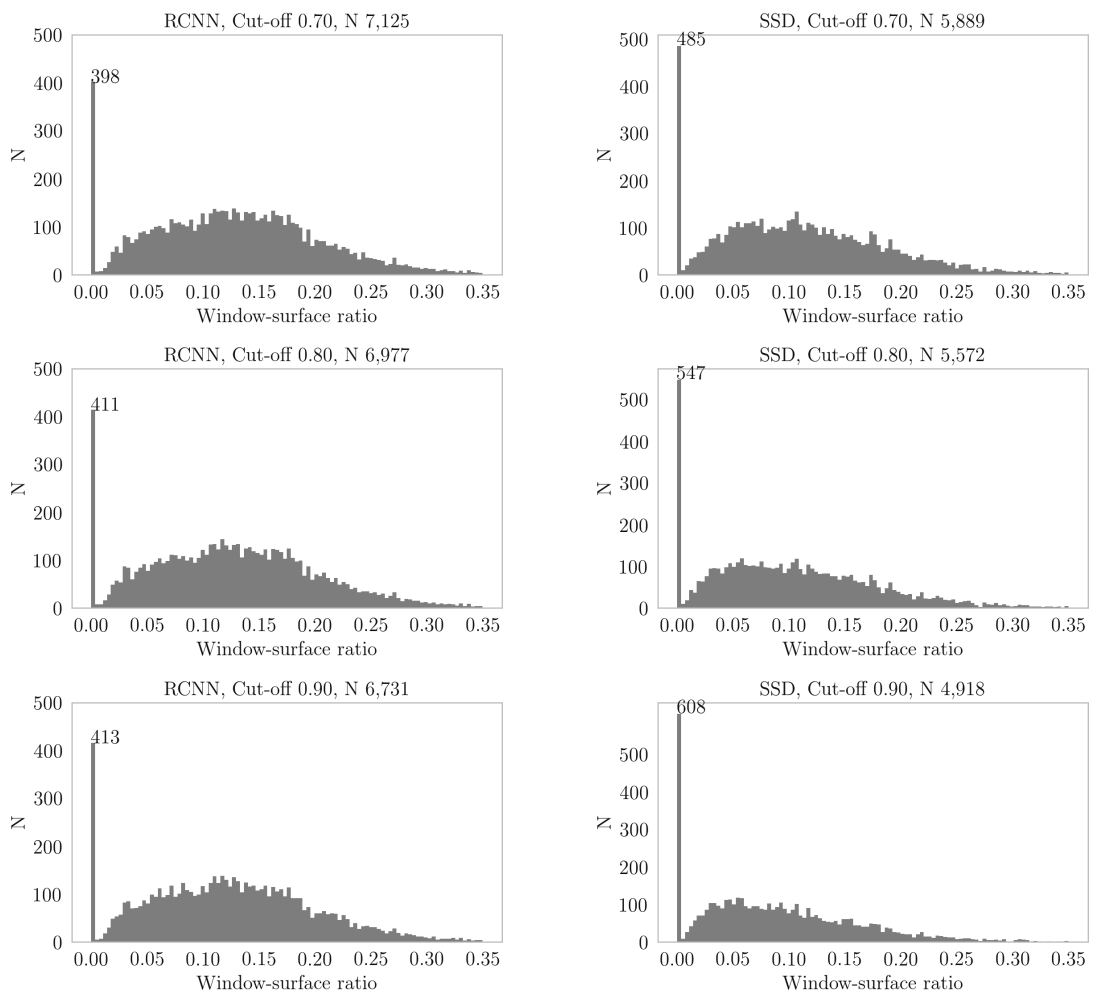

Notes: The graphs show the distribtuion of the estiamted window-surface ratio, using the two detection models and different classificaiton cut-off probabilities. In case windows are not detected within a facacde, the estimated window-surface ratio is equal to zero. 
Table 5.3

Explaining window-surface ratio by structure

\begin{tabular}{|c|c|c|c|c|c|c|}
\hline \multirow[b]{3}{*}{ Cut-off: } & (1) & $(2)$ & (3) & (4) & (5) & (6) \\
\hline & \multicolumn{3}{|c|}{ Faster R-CNN } & \multicolumn{3}{|c|}{ SSD } \\
\hline & 0.7 & 0.8 & 0.9 & 0.7 & 0.8 & 0.9 \\
\hline \multirow[t]{2}{*}{$\mathrm{m}^{2}$} & $-0.000^{* * *}$ & $-0.000^{* * *}$ & $-0.000^{* * *}$ & $-0.000^{* *}$ & -0.000 & -0.000 \\
\hline & {$[0.000]$} & {$[0.000]$} & {$[0.000]$} & {$[0.000]$} & {$[0.000]$} & {$[0.000]$} \\
\hline \multirow[t]{2}{*}{ N Floors } & 0.002 & 0.002 & $0.003^{*}$ & $0.004^{* * *}$ & $0.002^{*}$ & 0.000 \\
\hline & {$[0.001]$} & {$[0.001]$} & {$[0.001]$} & {$[0.001]$} & {$[0.001]$} & {$[0.001]$} \\
\hline \multicolumn{7}{|c|}{ Building period (dummies) } \\
\hline \multirow[t]{2}{*}{ D: $1931-1944$} & -0.003 & -0.003 & -0.002 & $-0.008^{* * *}$ & $-0.006^{* *}$ & -0.004 \\
\hline & {$[0.003]$} & {$[0.003]$} & {$[0.003]$} & {$[0.003]$} & {$[0.003]$} & {$[0.003]$} \\
\hline \multirow[t]{2}{*}{ D: 1945 - 1959} & $-0.007^{* *}$ & $-0.007 * *$ & $-0.007 * *$ & $-0.013^{* * *}$ & $-0.012^{* * *}$ & $-0.007^{* *}$ \\
\hline & {$[0.003]$} & {$[0.003]$} & {$[0.003]$} & {$[0.003]$} & {$[0.003]$} & {$[0.003]$} \\
\hline \multirow[t]{2}{*}{ D: 1960 - 1970} & -0.001 & -0.000 & -0.001 & $-0.006^{* *}$ & -0.004 & -0.001 \\
\hline & {$[0.003]$} & {$[0.003]$} & {$[0.003]$} & {$[0.003]$} & {$[0.003]$} & {$[0.003]$} \\
\hline \multirow[t]{2}{*}{ D: $1971-1980$} & $-0.010^{* * *}$ & $-0.010^{* * *}$ & $-0.007 * *$ & $-0.013^{* * *}$ & $-0.011^{* * *}$ & $-0.009 * * *$ \\
\hline & {$[0.003]$} & {$[0.003]$} & {$[0.003]$} & [0.003] & [0.003] & {$[0.003]$} \\
\hline \multirow[t]{2}{*}{ D: $1981-1990$} & $-0.023^{* * *}$ & $-0.023^{* * *}$ & $-0.023^{* * *}$ & $-0.023^{* * *}$ & $-0.022^{* * *}$ & $-0.018^{* * *}$ \\
\hline & {$[0.003]$} & {$[0.003]$} & {$[0.003]$} & {$[0.003]$} & {$[0.003]$} & {$[0.003]$} \\
\hline \multirow[t]{2}{*}{ D: $1991-2000$} & $-0.025^{* * *}$ & $-0.024^{* * *}$ & $-0.023^{* * *}$ & $-0.027^{* * *}$ & $-0.025^{* * *}$ & $-0.020^{* * *}$ \\
\hline & {$[0.003]$} & {$[0.003]$} & {$[0.003]$} & [0.003] & [0.003] & [0.003] \\
\hline \multirow[t]{2}{*}{ D: after 2001} & $-0.014^{* * *}$ & $-0.013^{* * *}$ & $-0.011^{* * *}$ & $-0.016^{* * *}$ & $-0.015^{* * *}$ & $-0.014^{* * *}$ \\
\hline & {$[0.003]$} & [0.003] & {$[0.003]$} & {$[0.003]$} & {$[0.003]$} & {$[0.003]$} \\
\hline \multirow[t]{2}{*}{ Constant } & $0.139^{* * *}$ & $0.137^{* * *}$ & $0.133^{* * *}$ & $0.108^{* * *}$ & $0.101^{* * *}$ & $0.092^{* * *}$ \\
\hline & {$[0.004]$} & {$[0.004]$} & {$[0.004]$} & {$[0.004]$} & {$[0.004]$} & {$[0.004]$} \\
\hline Observ & 6,253 & 6,050 & 5,675 & 5,410 & 5,065 & 4,416 \\
\hline Adj. R-squared & 0.02 & 0.02 & 0.02 & 0.03 & 0.02 & 0.02 \\
\hline
\end{tabular}

Notes: Dependent variable: window-surface ratio. Standard errors in brackets. ${ }^{* * *} \mathrm{p}<0.01,{ }^{* *} \mathrm{p}<0.05,{ }^{*} \mathrm{p}<0.1 . \mathrm{D}$ = dummy. Baseline building period: D: Built $1906-1930$.

\subsubsection{Classification Comparison}

To compare the proposed methods with an image classification model used in previous studies, I estimate the number of floors with a image classification model directly. Using the same 3,940 images as in the object detection model training, images are labeled by the actual number of floors of the underlying property and split into training and validation images at a ratio of 85:15. In 10,000 iterations I retrain a Inception $V 3$ model pre-trained on ImageNet data and considered one of the top models in classification accuracy (Bianco et al., 2018). The CNN architecture is the successor of the Inception V2 architecture used in the Faster R-CNN model. During the training the model converges quickly to a training accuracy of $82 \%$, showing a speed advantage of image classification.

Using the retrained model, 9,042 images of the application sample are classified based on the number of floors. However, in contrast to object detection models, image classification models always assign probability scores $p_{c}$ to every class $c$, with $\sum_{c=1}^{C} p_{c}=1$. Considering the highest assigned probability as correct would overstate the accuracy, as it is already clear from Section 5.5.1 that not all images show properties correctly. I therefore test the model performance by counting the number of classifications above the 
cut-off at different probability cut-offs, using the highest assigned probability for a single class:

$$
\text { Classification success }= \begin{cases}y e s & \text { if } \max \left(p_{c 1}, p_{c 2}, \ldots p_{c n}\right) \geq \text { cut-off } \\ n o, & \text { otherwise } s\end{cases}
$$

Appendix Figure 5.17 shows the number of successfully classified images at different cut-off levels. At a cut-off probability of 0.5, 6,693 images are classified successfully, which is in line the approximately 6,946 images showing actual properties. However, the number of detected properties decrease much faster than for both object detection models. Between the cut-off level of 0.6 to 0.9 the number of images decreases from 4,341 to 278, showing a high sensitivity of the model to unfiltered images. Here the object detection models clearly outperform the classification model.

Figure 5.8 shows the accuracy of floor classifications at different probability cut-offs. Considering classifications with minimum probabilities between 0.6 and 0.9 , the model correctly predicts floors for 51.6 to 53.5 percent of the sample. This performance is in line with the estimation of the object detection models ranging between 43.8 to 53.5 percent. Given the lower effort compared to object detection models, this measure is quite good. However, the distribution of false classifications is wider, ranging from -3 to 3 with more overestimations. 
Figure 5.8

Classification model accuracy - Number of floors
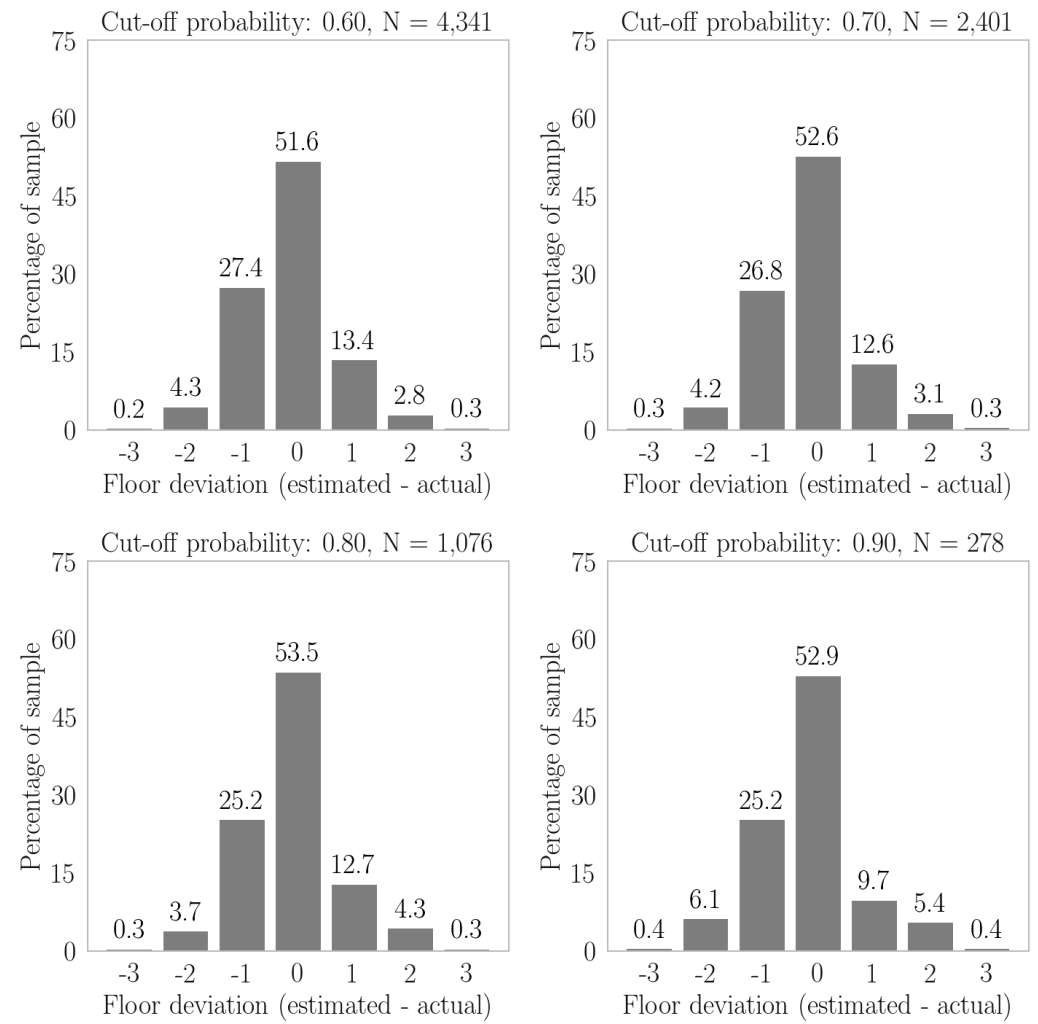

Notes: Comparing the outputs of the classification model, classifiying images by number of floors, with the actual number of floors. Tests at different minimum probability cut-offs.

\subsection{Discussion \& Conclusion}

In this paper, I present a novel data mining approach for real estate markets and urban economics, using object detection on residential property images. In contrast to previous studies, using image classification, the proposed object detection model offers more flexibility and robustness by requiring less image filtering. Multiple, different image objects are detected simultaneously, including information about their relative position and size. This aspect offers a lot of freedom to researchers, allowing to build custom data mining algorithms. I present two applications, estimating the number of floors by counting the number of vertically aligned windows and estimating the window-surface ratio.

Admittedly, the developed models work well, but are far from perfect, showing an accuracy slightly above average. This problem could be overcome by increasing the invested effort, preparing more training data and run more iterations. Additionally, Google Street View data is a bottleneck, allowing me to only use approximately $70 \%$ of images. The image resolution is capped to a maximum of $640 \times 640$ pixels, which does not allow to examine details and smaller objects. Furthermore, the angle of the image is often not 
optimal, not showing the entire property or the front. For higher accuracy, one should therefore try to take better images, such as from real estate websites.

The proposed method has some limitations. It only allows to mine characteristics that are deductible from visible aspects. Images and address information are required input data even though the model could be used to examine characteristics on a neighborhood level by using public address databases. Processes within the CNN remain a black box and might be case sensitive. It is therefore not recommendable to apply deep neural networks to aggregated measures, such as property prices. Lastly, the required computer hardware is not to underestimate, forcing the user onto cloud computing services.

This paper shows that it is possible to develop a data mining model for real estate research at little effort. Using object detection models on urban images enable researchers and policy makers to remotely collect property information at low cost. The proposed approach could be used to analyze new property characteristics, such as the spread of solar panels or building states of properties. Additionally, it could be used to take inventory of property markets with limited information, such as developing countries. The method is not restricted to street scenes, but could be combined with aerial images. 


\subsection{Appendix}

Figure 5.9

Illustration of Neural Network Setup and Training

$\begin{array}{cccc}\text { Input } & \text { Hidden } & \text { Hidden } & \text { Output } \\ \text { layer } & \text { layer } 1 & \text { layer } 2 & \text { layer }\end{array}$

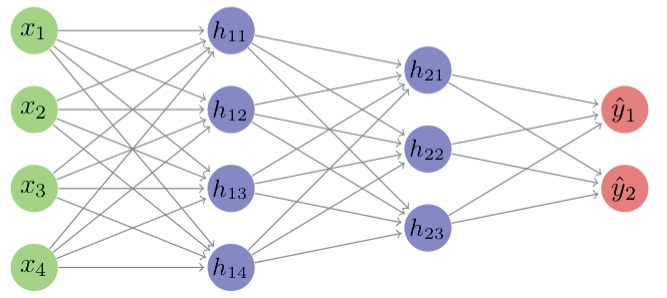

(a) Neural Network Illustration

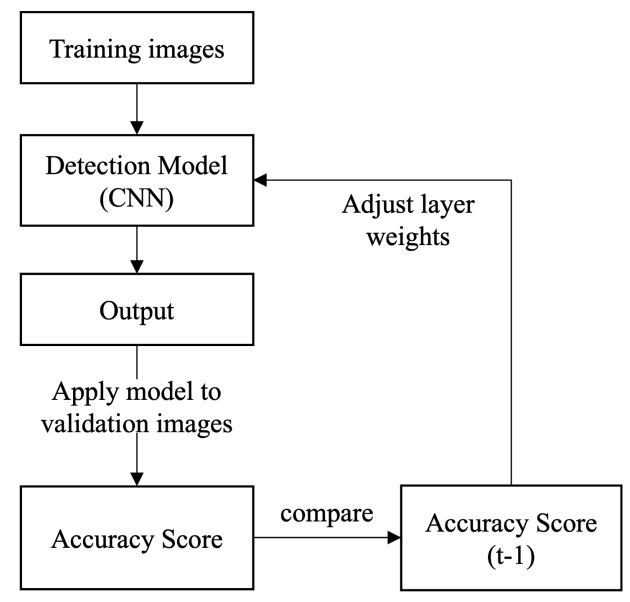

(b) Model training process

Notes: Figure 5.9a illustrates a neural network with 2 hidden layers. Figure 5.9b illustrates the model training process. 
Figure 5.10

Example of annotated image

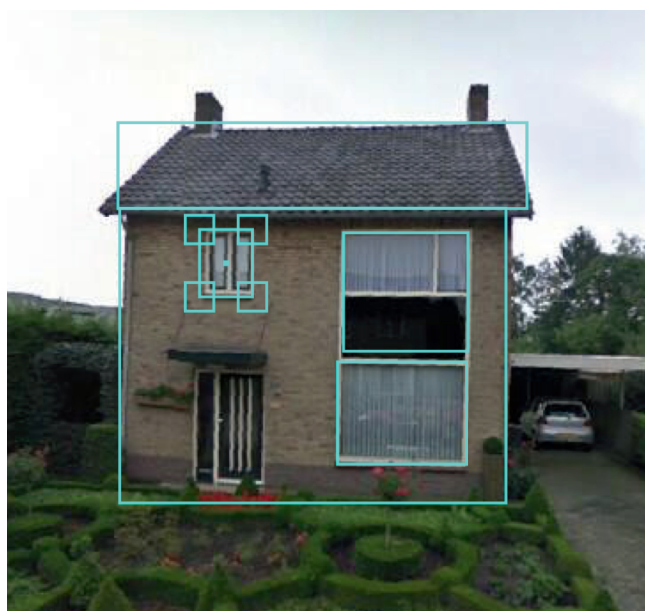

Notes: This figure shows an example of an annotated image, highlighting windows, the fascade and roof of a property. Annotations are performed in the RectLabel software.

Figure 5.11

Illustration of Faster R-CNN anchor boxes

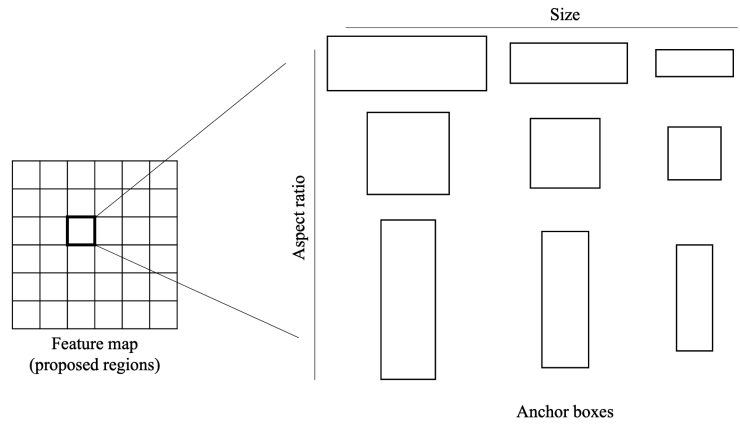

Notes: Faster R-CNN models use nine anchor boxes for classification, fixing three aspect ratios and three sizes (Ren et al., 2015). 
Figure 5.12

Geographical distribution samples

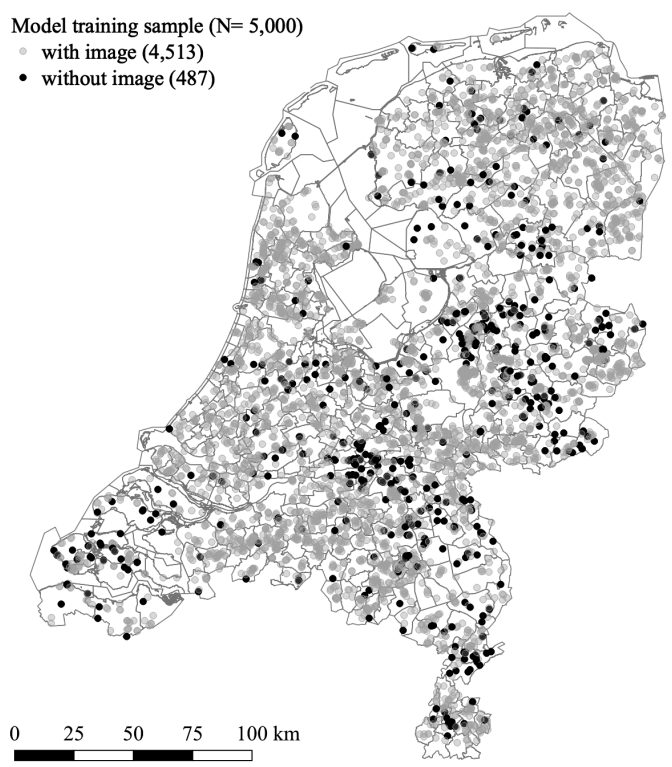

(a) Model training sample

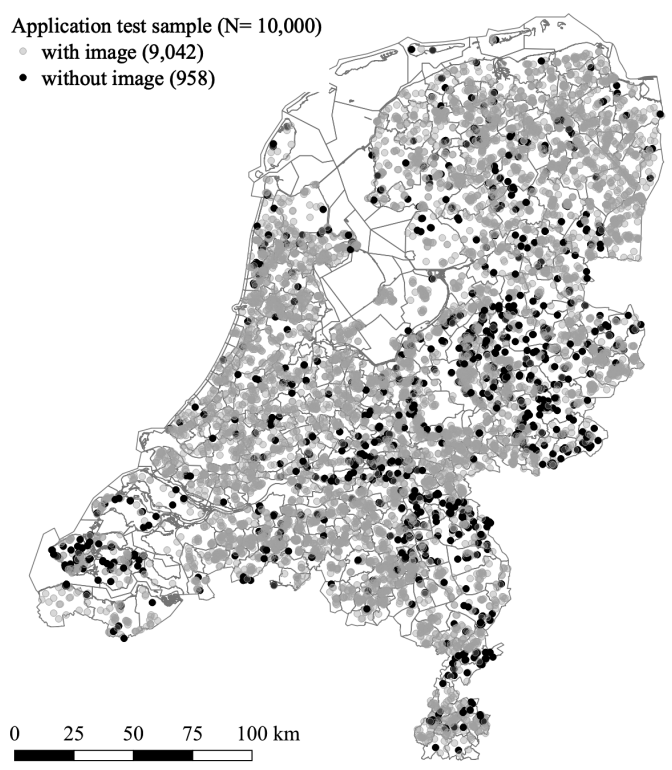

(b) Application test sample

Notes: The map shows the distribution of the samples across the Netherlands, divided by observations with and without GSV images. 
Figure 5.13

Examples of bad GSV outputs
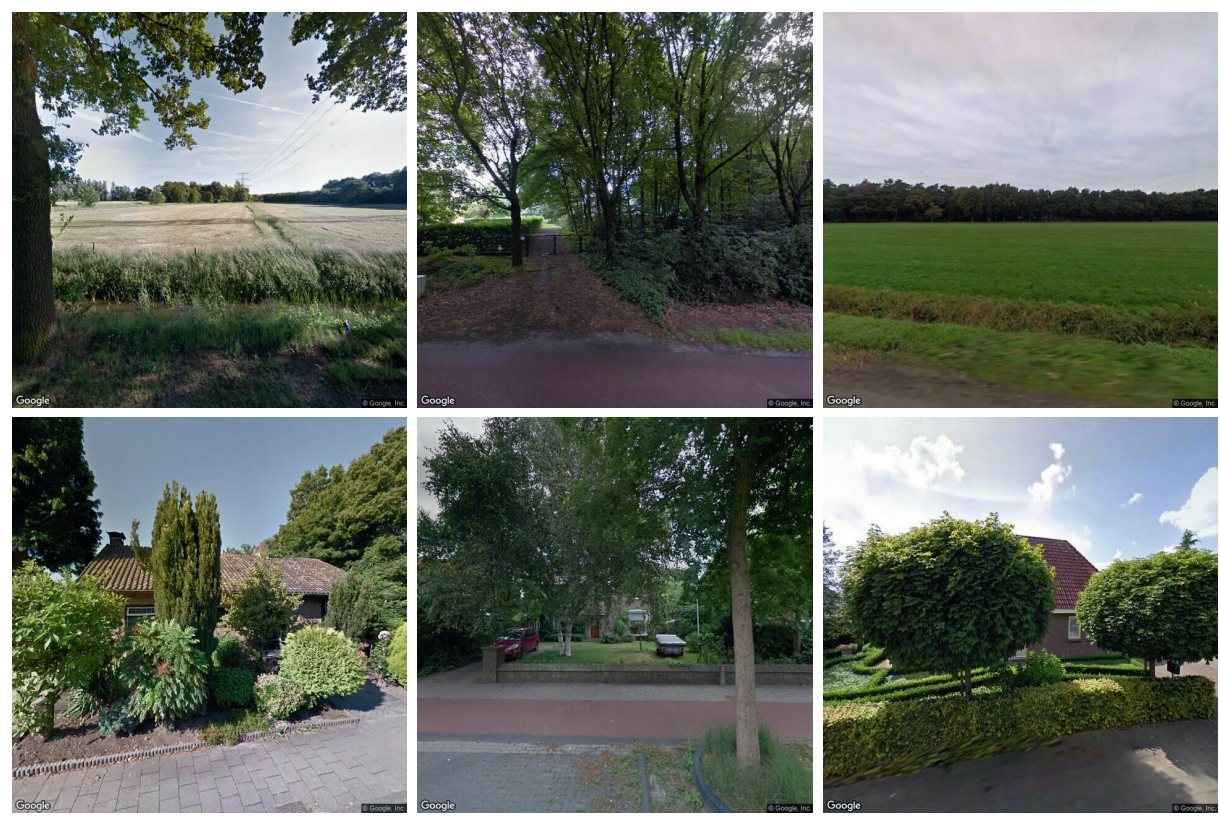

Notes: Examples of bad GSV images, failing to show properties for requested locations.

Figure 5.14

Data flow diagram

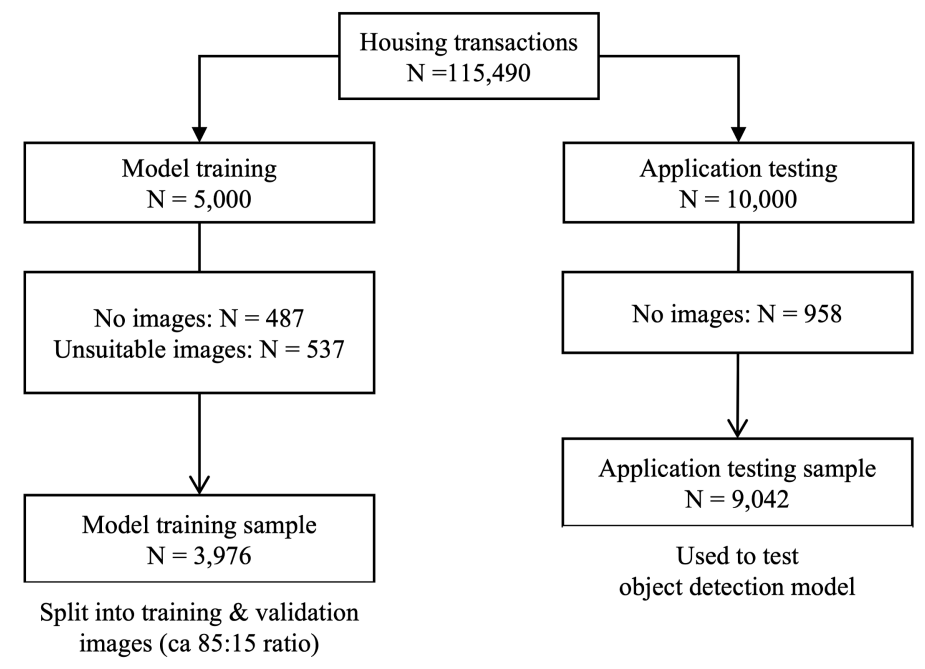

Notes: This Figure illustrates the data flow. 
Figure 5.15

Distribution number of floors

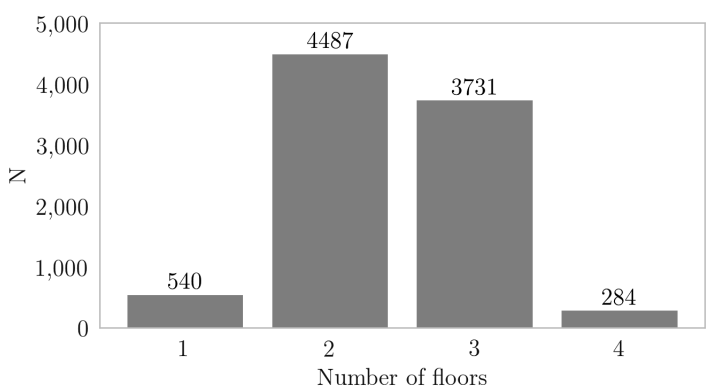

Notes: This figure shows the distribution of number of floors in the application test sample based on a total of 9,042 images.

Table 5.4

Mean floor deviation at floor levels

\begin{tabular}{|c|c|c|c|c|}
\hline \multirow[b]{2}{*}{ Cut-off score } & \multicolumn{4}{|c|}{ Actual number of floors } \\
\hline & 1 & 2 & 3 & 4 \\
\hline \multicolumn{5}{|c|}{ Faster R-CNN } \\
\hline \multirow[t]{2}{*}{0.7} & 0.35 & -0.34 & -0.12 & -2.20 \\
\hline & {$[0.61]$} & {$[0.60]$} & {$[0.67]$} & {$[0.65]$} \\
\hline \multirow[t]{2}{*}{0.8} & 0.33 & -0.39 & -0.17 & -2.26 \\
\hline & {$[0.58]$} & {$[0.58]$} & {$[0.66]$} & {$[0.64]$} \\
\hline \multirow[t]{2}{*}{0.9} & 0.29 & -0.45 & -0.25 & -2.33 \\
\hline & {$[0.54]$} & {$[0.57]$} & {$[0.63]$} & {$[0.62]$} \\
\hline \multicolumn{5}{|c|}{ SSD } \\
\hline \multirow[t]{2}{*}{0.7} & 0.40 & -0.36 & -0.17 & -2.21 \\
\hline & {$[0.64]$} & {$[0.60]$} & {$[0.69]$} & {$[0.70]$} \\
\hline \multirow[t]{2}{*}{0.8} & 0.39 & -0.43 & -0.23 & -2.28 \\
\hline & {$[0.64]$} & {$[0.60]$} & {$[0.67]$} & {$[0.69]$} \\
\hline \multirow[t]{2}{*}{0.9} & 0.38 & -0.51 & -0.36 & -2.41 \\
\hline & {$[0.65]$} & {$[0.56]$} & {$[0.64]$} & {$[0.65]$} \\
\hline
\end{tabular}

Notes: Shown is the mean deviation of actual and estimated number of floors at different actual number of floors and cutoff levels, with standard deviation in brackets. 
Figure 5.16

Examples of floor deviations

(a) Blocked floor level

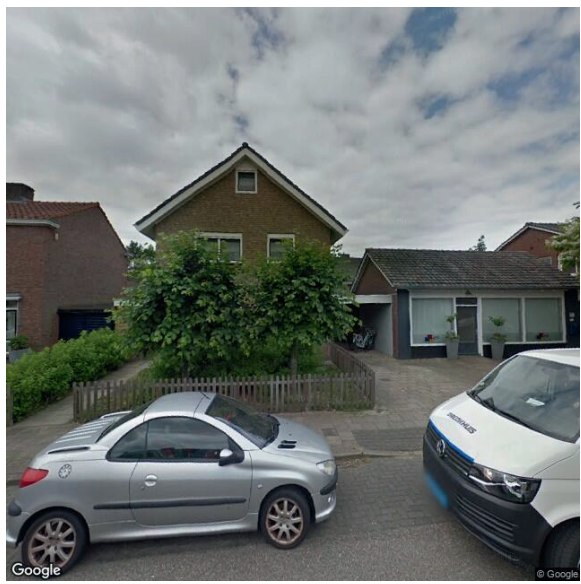

(b) Big roof without window

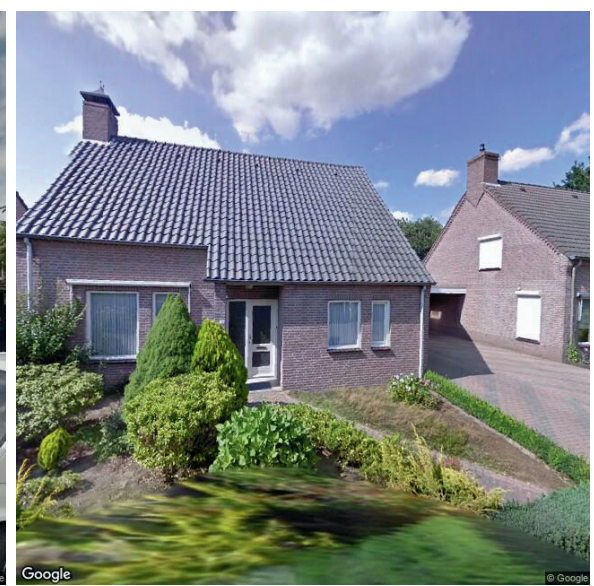

Notes: Examples of floor deviations. Source: Google Street View

Figure 5.17

Classifications at different cut-off scores

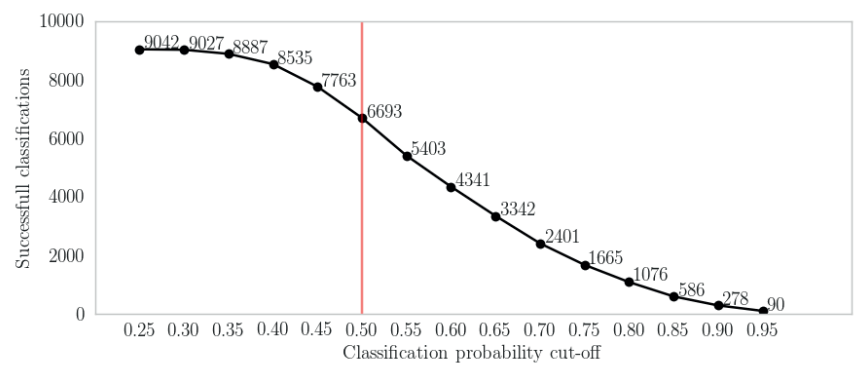

Notes: A classification is considered as successfull if the assigned probability of a single class is higher than the cut-off. If there is no class with a score higher than the cut-off the classification is considered as unsuccessfull. There are 4 classes and 9,042 images.

\subsubsection{IoU and mAP}

Intersection over union ( $\mathrm{IoU}$ ) is a measure to evaluate the localization accuracy of the model, showing how good predicted localization matches actual localization. ${ }^{19}$ The IoU is calculated by

$$
I o U=\frac{\text { Area of Overlap }}{\text { Area of Union }}
$$

where Area of Overlap is the area of intersection between the actual location and the predicted location, and Area of Union is the total area of the actual and predicted location.

\footnotetext{
${ }^{19}$ For more details see https://bit.ly/2QWgBoa
} 
The concept is further illustrated in Figure 5.18, showing the intersecting and union area of the predicted and actual object location.

Figure 5.18

Illustration Intersection over Union

Area of Intersection

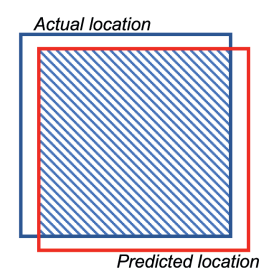

Notes: Illustrated is the concept of Area of Overlap (left) and Area of Union (right)

Average precision $(A P)$ is based on two measures, Precision and Recall, which are negatively correlated to each other. Precision is defined as

$$
\text { Precision }=\frac{\text { Correctly observed }}{(\text { Correctly observed }+ \text { Wrongly observed })}
$$

where Correctly observed measures the number of correctly identified objects (True positive) and Wrongly observed measures the number of wrongly identified objects (False positive). A lower Precision indicates low efficiency, as the algorithm detects a lot of boxes that are correct. Recall is defined as

$$
\text { Recall }=\frac{\text { Correctly observed }}{(\text { Correctly observed }+ \text { Not observed })}
$$

where Correctly observed measures the number of correctly identified objects (True positive) and Not observed measures the number of objects not detected by the algorithm (False negative). A low Recall indicates low effectiveness, as the algorithm misses a lot of boxes that should be detected.

All sample bounding boxes are ranked according to the IoU and for every IoU threshold Precision and Recall are calculated. This allows to plot a Precision-Recall (PR) curve as illustrated in Figure 5.19. $A P$ is calculated as

$$
A P=\int_{0}^{1} \operatorname{Precision}(r) d r
$$

where Precision(r) illustrates that Precision is plotted as a function of Recall level $r$. However, in practice AP can be approximated by

$$
A P=\frac{1}{R} \sum_{r=1}^{R} P_{\text {interpolate }}(r)
$$


where $P_{\text {interpolate }}(r)$ is the interpolated, maximum precision for a Recall level $\hat{r}$.

$$
P_{\text {interpolate }}(r)=\max _{\hat{r} \geq r} \operatorname{Precision}(\hat{r})
$$

Since it is common to use comparable Recall levels, normally 10 equal levels are chosen for $r$ so $r \in\{0,0.1, \ldots 1\}$, resulting in: ${ }^{20}$

$$
A P=\frac{1}{11} \sum_{r=0,1}^{1} P_{\text {interpolate }}(r)
$$

Finally, the mean average precision $m A P$ can be defined as the average $A P$ over different objects classes $c$ :

$$
m A P=\frac{\sum_{c=1}^{C} A P(c)}{C}
$$

$A P$ and $m A P$ are usually reported with corresponding IoU threshold level or range, such as $A P @ .60$ or $A P @[.5: 1: .9]$, reporting the $A P$ at an IoU of 0.6 or at an IoU range between 0.5 and 0.9 with steps of 0.1 .

Figure 5.19

Precision-Recall (PR) curve illustration

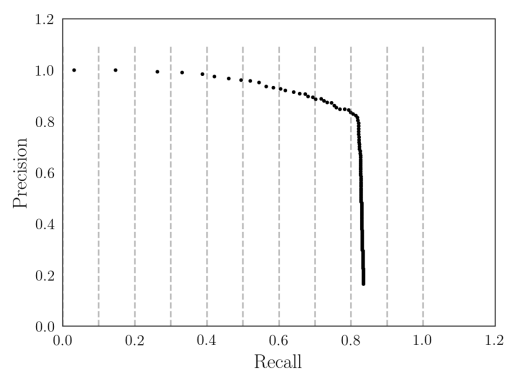

Notes: Illustration of PR curve with 170 PrecisionRecall pairs.

\footnotetext{
${ }^{20}$ This origins from the challenge to develop superior models for one of the most common open-source data-sets http://cocodataset.org/\#detection-eval.
} 


\section{Chapter 6}

\section{Concluding Remarks}

\subsection{External Effects}

This thesis explores the effects of externalities on house prices and it introduces a novel approach on how to improve price measurements through machine learning. Externalities affect our daily lives and shape location preferences. Positive external effects, such as a nearby park, increase our willingness-to-pay for locations, while negative external effects, such as noise, lower it. Residential real estate markets offer a good measure for this willingness-to-pay, as property prices are strongly affected by location values. By controlling for other priced characteristics with a hedonic framework, real estate prices enable us to value external effects on the nearby area.

There is a big advantage in using real estate prices as an externality measure. Namely, with real estate prices we are able to measure net-external effects, examine the reach of external effects and monetize them. A traditional cost-benefit assessment of externality sources is usually problematic, since it is difficult to pin down individual external effects and their reach. However, locations are usually affected by both positive and negative external effects and therefore reflect net effects (Nelson, 2004). Hence, real estate prices offer policy makers an unbiased measure for a cost-benefit analysis, considering the effect on surrounding houses.

Chapter 2 examines the effect of primary schools and school quality on house prices. Generally, the willingness-to-pay for living nearby good schools is higher and results in location premiums (Black, 1999). However, I show that this is not the case in the absence of school districts, which force parents to live within the district boundaries to let children attend the respective school. There are no external effects for house prices nearby high quality schools when school choice is free. However, for houses within $200 \mathrm{~m}$ of low quality schools, I document a price discount of approximately 1.6 percent. These results are in line with previous findings, showing that schools are a source of relevant externalities (both positive and negative) in the housing market (Sah et al., 2016). However, comparing the results to studies exploiting catchment areas, I show that the effect of school quality is negligible without catchment areas.

Chapter 3 focuses on a more controversial topic: energy production. Energy production is a complex topic for cost-benefit assessments as there are long term global effects but short term local external effects. There is little evidence on the short term external costs to residents, but this does not stop people from forming strong opinions on it. As these subjective views are often based on an isolated single effect (instead of taking a holistic view) and every form of electricity production has some disadvantage, there are protests against every type of electricity production: coal, wind, nuclear, etc. Chapter 3 takes into account that we will always need some form of electricity production and therefore assesses the local external effects of different energy production facilities on property prices.

The results show the complexity of the problem; I find mixed effects per energy production type. House prices seem to be negatively affected by wind turbines and gas 
plants, and unaffected by the closing of coal plants. Interestingly, house prices increase when biomass plants open, and fall when these plants close. Thus, some conventional power plants do not necessarily show negative price effects - whereas green energy produced by wind turbines always decreases house prices. However, policymakers in rural areas tend to be positive about the building of new power plants in their region, since it not only affects house prices - it can also boost infrastructure and offer employment.

Chapter 4 focuses on cannabis sales and house prices, and I find counterintuitive results based on a popular policy intervention in the Netherlands. I examine the effect of nearby coffeeshops (ie. cannabis sales points) on house prices, by exploiting an exogenous policy intervention which abruptly closed down all coffeeshops within $250 \mathrm{~m}$ of secondary schools. I find that the closing of a nearby coffeeshop actually decreased house prices. The effect ranges from -7.6 percent for homes close to the shop, to -1.6 percent for homes located up to 150 meters away. Not only did the policy have an unintended negative house price effect, it also failed to deliver on its intended effect. Namely, first studies show that the closing of these coffeeshops, did not significantly change teenager's cannabis usage.

These three Chapters illustrate the complexity of local external effects, leading to misconceptions. I show that proximity to high-quality schools does not increase house prices in itself (Chapter2), energy production facilities are not necessarily depreciating location values (Chapter 3), and removing coffeeshops lowers location values (Chapter 4). Clarifications on common misconceptions can help policymakers to make better placement decisions and improve urban planning.

\subsection{Computer Vision}

Hedonic property pricing models offer the possibility to assess property prices and examine externalities. This helps policy makers with more accurate tax assessments and residential decision making. However, available micro-level data are often the bottleneck. In Chapter 5 , I tackle the problem of missing information. I propose to use computer vision, a machine learning technique, to mine property data from images. This technique offers countless of opportunities, such as: better structural controls to hedonic property pricing models, examining new markets, or even examine pricing effects of new measures.

My findings show that Google Street View offers a great coverage but images are of limited quality. However, even with the available image quality at hand and with limited effort, it is possible to develop an object detection model that can be employed for data mining applications. The model offers high flexibility and allows for gathering multiple characteristics at the same time, which I demonstrate in the two example applications. Running a horse-race comparison with simpler models, I show that object detection is more robust to confounding factors in unfiltered images.

In the future, the possibilities of machine learning models should be examined even further as I am convinced that they will deliver new insights into property markets. This will help to run better hedonic studies, examine new markets and eventually make real estate markets more efficient. It allows researchers to remotely examine residential real estate markets, independent of local policy barriers. 


\section{Chapter 7}

\section{Valorization}

The motivation for this thesis origins in the desire to better understand the dynamics behind real estate markets. Why are some neighborhoods considered as attractive, while others are not? There are countless discussions how individuals sites are affecting neighborhood values, but often these discussions are not based on scientific evidence. I analyzed three policy topics out of these discussions, contributing to the understanding of housing price determinants and the understanding around around individual policy discussions: the cost of education, energy production and cannabis sales points.

Chapter 2 shows that there is no evidence of average and good schools affecting local housing markets. Consequentially, placing a school of high quality should not be used as a tool to increase neighborhood attractiveness. Furthermore, it is shown that external effects of schools are versatile and in proximity of worst performing schools negative externalities significantly outweigh positive and consequently decrease residential housing prices. The previous literature often neglects the distance between properties and schools, focusing on the position within or outside school district boundaries only.

Chapter 3 adds to the discussion on energy production. In recent years, many studies exploring the effects of wind turbines emerged. However, due to the heterogeneity in study areas, times and methods, they were not able to set the findings in relation to other energy sources. In this study, I cover all energy production facilities of a whole country over nearly 30 years. The results show that some energy production facilities have a positive effect on house prices, some a negative and some a negligible effect.

Chapter 4 focuses on the external effects of cannabis sales facilities. Due to a trend in wider acceptance of cannabis use and legalization, policy makers are confronted with a complex choice: where to locate cannabis sales facilities. Chapter 4 explores the spillover effects of such facilities in a market with long experience: the Netherlands. I find that house prices do not increase after cannabis sales facilities are exogenously closed down. Rather, I find that house prices decrease. Residents thus do not seem to experience cannabis sales facilities as a nuisance to their neighborhood.

Throughout the chapters I am constantly confronted with potential endogeneity problems. I therefore explore different methods to measure external effects. This thesis therefore also adds to the discussion on valuation model choices. Only by using difference-indifference or repeated sales models we are able to establish causal relationships. However, these models require sufficient available data, which are often scarce.

The aforementioned data scarcity leads to the question how we can collect new data? Chapter 5 takes a step into the deep - by exploring future ways of using machine learning to help policymakers reflect on residential housing market decisions. The chapter tackles the bottlenecks of current housing studies, with methods from computer science. In a novel approach, I apply machine learning techniques to property images, estimating property characteristics. I examine the image quality of Google Street View for this purpose and show two example applications of the proposed method. This method has a wide array of possible usages, among the most promising is its application to data scarce settings - such as urbanization in low-income countries, or accurate tax assessments in these countries. 
"Alles Wissen und alles Vermehren unseres Wissens endet nicht mit einem Schlußpunkt, sondern mit einem Fragezeichen." - Hermann Hesse 


\section{References}

Abbott, J. K., \& Klaiber, H. A. (2011). An embarrassment of riches: Confronting omitted variable bias and multi-scale capitalization in hedonic price models. Review of Economics and Statistics, 93(4), 1331-1342.

Anderson, D. M., \& Rees, D. I. (2014). The Legalization of Recreational Marijuana: How Likely Is the Worst-Case Scenario? Journal of Policy Analysis and Management, $33(1), 221-232$.

Anselin, L., \& Bera, A. K. (1998). Spatial Dependence in Linear Regression Models with an Introduction to Spatial Econometrics. Statistics Textbooks and Monographs, 155, $237-290$.

Aydin, E., Brounen, D., \& Kok, N. (2016). Information Asymmetry and Energy Efficiency: Evidence from the Housing Market. Working Paper.

Ayres, R. U., \& Kneese, A. V. (1969). Production, Consumption, and Externalities. The American Economic Review, 59 (3), 282-297.

Bakker, R. H., Pedersen, E., van den Berg, G. P., Stewart, R. E., Lok, W., \& Bouma, J. (2012). Impact of Wind Turbine Sound on Annoyance, Self-Reported Sleep Disturbance and Psychological Distress. Science of the Total Environment, 425, $42-51$.

Bayer, P., Ferreira, F., \& McMillan, R. (2004). Tiebout sorting, social multipliers and the demand for school quality (Tech. Rep.). National Bureau of Economic Research.

Bayer, P., Ferreira, F., \& McMillan, R. (2007). A unified framework for measuring preferences for schools and neighborhoods. Journal of political economy, 115(4), $588-638$.

Bell, D., Gray, T., \& Haggett, C. (2005). The 'Social Gap' in Wind Farm Siting Decisions: Explanations and Policy Responses. Environmental Politics, 14(4), 460-477.

Bianco, S., Cadene, R., Celona, L., \& Napoletano, P. (2018). Benchmark analysis of representative deep neural network architectures. IEEE Access, 6, 64270-64277.

Bieleman, B., Biesman, S., Snippe, J., \& de Bie, E. (1996). Quick Scan: Ontwikkeling in Aantal Coffeeshops in Nederland. Groningen: Intraval.

Bieleman, B., Mennes, R., \& Sijtstra, M. (2015a). Coffeeshops in Nederland 2014. Groningen: Intraval.

Bieleman, B., Mennes, R., \& Sijtstra, M. (2015b). Monitor Afstandscriterium Coffeeshops Amsterdam. Groningen: Intraval.

Bieleman, B., Nijkamp, R., \& Schaap, L. (2010). Monitor coffeeshopbeleid rotterdam. 


\section{Groningen-Rotterdam: Intraval.}

Black, S. E. (1999). Do better schools matter? parental valuation of elementary education. The Quarterly Journal of Economics, 114(2), 577-599.

Blomquist, G. (1974). The Effect of Electric Utility Power Plant Location on Area Property Value. Land Economics, 50(1), 97-100.

Borghans, L., Golsteyn, B. H., \& Zölitz, U. (2015). Parental preferences for primary school characteristics. The BE Journal of Economic Analysis 6 Policy, 15(1), 85-117.

Breukers, S., \& Wolsink, M. (2007). Wind Power Implementation in Changing Institutional Landscapes: An International Comparison. Energy Policy, 35 (5), 2737-2750.

Brounen, D., \& Kok, N. (2011). On the economics of energy labels in the housing market. Journal of Environmental Economics and Management, 62(2), 166-179.

Brounen, D., Kok, N., \& Quigley, J. M. (2012). Residential energy use and conservation: Economics and demographics. European Economic Review, 56(5), 931-945.

Buhre, B. J. P., Elliott, L., Sheng, C. D., Gupta, R. P., \& Wall, T. F. (2005). Oxy-Fuel Combustion Technology for Coal-Fired Power Generation. Progress in Energy and Combustion Science, 31(4), 283-307.

Carter, J. (2011). The Effect of Wind Farms on Residential Property Values in Lee County, Illinois. Normal, IL.

Case, K. E., \& Shiller, R. J. (1989). The efficiency of the market for single-family homes. The American Economic Review, 79(1), 125.

Cerdá, M., Wall, M., Keyes, K. M., Galea, S., \& Hasin, D. (2012). Medical Marijuana Laws in 50 States: Investigating the Relationship Between State Legalization of Medical Marijuana and Marijuana Use, Abuse and Dependence. Drug and Alcohol Dependence, 120(1), 22-27.

Chang, T., \& Jacobson, M. (2017). Going to Pot? The Impact of Dispensary Closures on Crime. Journal of Urban Economics, 100, 120-136.

Charilaou, P., Agnihotri, K., Garcia, P., Badheka, A., Frenia, D., \& Yegneswaran, B. (2017). Trends of Cannabis Use Disorder in the Inpatient: 2002 to 2011. The American Journal of Medicine, 130(6). Retrieved from http://dx.doi.org/10.1016/j.amjmed.2016.12.035 doi: 10.1016/j.amjmed.2016.12.035

Cheng, C., Mayer, W. J., \& Mayer, Y. (2018). The effect of legalizing retail marijuana on housing values: Evidence from colorado. Economic Inquiry, 56(3), 1585-1601.

Chin, H. C., \& Foong, K. W. (2006). Influence of school accessibility on housing values. 
Journal of urban planning and development, 132(3), 120-129.

Choi, J., Zhu, J., Goodman, L., Ganesh, B., \& Strochak, S. (2018). Millennial homeownership: Why is it so low and how can we increase it. Washington DC: Urban Institute. Retrieved August, 3, 2018.

Chu, Y.-W. L. (2015). Do Medical Marijuana Laws Increase Hard-Drug Use? The Journal of Law and Economics, 58(2), 481-517.

Ciresan, D. C., Meier, U., Masci, J., Maria Gambardella, L., \& Schmidhuber, J. (2011). Flexible, high performance convolutional neural networks for image classification. In Ijcai proceedings-international joint conference on artificial intelligence (Vol. 22, p. 1237).

Clapp, J. M., Nanda, A., \& Ross, S. L. (2008). Which school attributes matter? the influence of school district performance and demographic composition on property values. Journal of urban Economics, 63(2), 451-466.

Clark, D. E., Michelbrink, L., Allison, T., \& Metz, W. C. (1997). Nuclear Power Plants and Residential Housing Prices. Growth and Change, 28(4), 496-519.

Congdon-Hohman, J. M. (2013). The Lasting Effects of Crime: The Relationship of Discovered Methamphetamine Laboratories and Home Values. Regional Science and Urban Economics, 43(1), 31-41.

Conklin, J., Diop, M., \& Li, H. (2017). Contact high: The external effects of retail marijuana establishments on house prices. Real Estate Economics.

Costa, C., Antonucci, F., Pallottino, F., Aguzzi, J., Sun, D.-W., \& Menesatti, P. (2011). Shape analysis of agricultural products: a review of recent research advances and potential application to computer vision. Food and Bioprocess Technology, 4(5), 673-692.

Cropper, M. L., Deck, L. B., \& McConnell, K. E. (1988). On the choice of funtional form for hedonic price functions. The review of economics and statistics, 668-675.

Davis, L. W. (2011). The Effect of Power Plants on Local Housing Values and Rents. Review of Economics and Statistics, 93(4), 1391-1402.

Dealy, B. C., Horn, B. P., \& Berrens, R. P. (2017). The Impact of Clandestine Methamphetamine Labs on Property Values: Discovery, Decontamination and Stigma. Journal of Urban Economics, 99, 161-172.

Dickmanns, E. D., \& Zapp, A. (1987). Autonomous high speed road vehicle guidance by computer vision. IFAC Proceedings Volumes, 20(5), 221-226.

DiPasquale, D., \& Wheaton, W. C. (1996). Urban economics and real estate markets (Vol. 23) (No. 7). Prentice Hall Englewood Cliffs, NJ. 
Drayer, B., \& Brox, T. (2016). Object detection, tracking, and motion segmentation for object-level video segmentation. arXiv preprint arXiv:1608.03066.

Dröes, M. L., \& Koster, H. R. (2016). Renewable Energy and Negative Externalities: The Effect of Wind Turbines on House Prices. Journal of Urban Economics, 96, $121-141$.

Emerson, F. C. (1972). Valuation of residential amenities: an econometric approach. Appraisal journal, 40, 268-278.

Esteva, A., Kuprel, B., Novoa, R. A., Ko, J., Swetter, S. M., Blau, H. M., \& Thrun, S. (2017). Dermatologist-level classification of skin cancer with deep neural networks. Nature, 542(7639), 115.

European Commission. (2003). External Costs - Research Results on Socio-Environmental Damages due to Electricity and Transport. Brussels: Office for Official Publications of the European Communities.

European Commission. (2013). EU Energy, Transport and GHG Emissions - Trends to 2050. Brussels: Office for Official Publications of the European Communities.

European Commission. (2015). 2020 Climate \& Energy Package. Retrieved from https://bit.1y/2Ng17fe

European Commission. (2016). Climate Action - Paris Agreement. Retrieved 2016-01-01, from https://bit.ly/30hJteR

Eurostat. (2015a). Electricity Production, Consumption and Market Overview. Retrieved 2015-01-01, from https://bit.1y/2HbicTK

Eurostat. (2015b). Renewable Energy Statistics. Retrieved 2015-01-01, from https://bit.1y/2Z8hstP

Everingham, M., Van Gool, L., Williams, C. K., Winn, J., \& Zisserman, A. (2010). The pascal visual object classes (voc) challenge. International Journal of Computer Vision, 88(2), 303-338.

Fack, G., \& Grenet, J. (2010). When do better schools raise housing prices? evidence from paris public and private schools. Journal of public Economics, 94 (1-2), 59-77.

Farboud, A., Crunkhorn, R., \& Trinidade, A. (2013). 'Wind Turbine Syndrome': Fact or Fiction? The Journal of Laryngology 8 Otology, 127(3), 222-226.

Feld, J., van der Weijden, C., \& Wildeboer, L. (2014). Legal Developments in Wind Energy in the Netherlands. Retrieved 2015-01-01, from https://bit.1y/2Mo7y04

Franco, A., \& Russo, A. (2002). Combined Cycle Plant Efficiency Increase Based on the Optimization of the Heat Recovery Steam Generator Operating Parameters. 
International Journal of Thermal Sciences, 41(9), 843-859.

Gabriel, S., Hearey, O., Kahn, M. E., \& Vaughn, R. K. (2016). Public school quality valuation over the business cycle (Tech. Rep.). National Bureau of Economic Research.

Gamble, H. B., \& Downing, R. H. (1982). Effects of Nuclear Power Plants on Residential Property Values. Journal of Regional Science, 22(4), 457-478.

Gawande, K., \& Jenkins-Smith, H. (2001). Nuclear Waste Transport and Residential Property Values: Estimating the Effects of Perceived Risks. Journal of Environmental Economics and Management, 42(2), 207-233.

Gibbons, S. (2015). Gone With the Wind: Valuing the Visual Impacts of Wind Turbines through House Prices. Journal of Environmental Economics and Management, 72, $177-196$.

Gibbons, S., Machin, S., \& Silva, O. (2013). Valuing school quality using boundary discontinuities. Journal of Urban Economics, 75, 15-28.

Girshick, R., Donahue, J., Darrell, T., \& Malik, J. (2014). Rich feature hierarchies for accurate object detection and semantic segmentation. In Proceedings of the ieee conference on computer vision and pattern recognition (pp. 580-587).

Glaeser, E. L., Kincaid, M. S., \& Naik, N. (2018, October). Computer vision and real estate: Do looks matter and do incentives determine looks (Working Paper No. 25174). National Bureau of Economic Research. Retrieved from http://www.nber.org/papers/w25174 doi: 10.3386/w25174

Glaeser, E. L., Kominers, S. D., Luca, M., \& Naik, N. (2018). Big data and big cities: The promises and limitations of improved measures of urban life. Economic Inquiry, $56(1), 114-137$.

Gyourko, J., Mayer, C., \& Sinai, T. (2013). Superstar cities. American Economic Journal: Economic Policy, 5(4), 167-99.

Harding, G., Harding, P., \& Wilkins, A. (2008). Wind Turbines, Flicker, and Photosensitive Epilepsy: Characterizing the Flashing that May Precipitate Seizures and Optimizing Guidelines to Prevent them. Epilepsia, 49(6), 1095-1098.

Harper, S., Strumpf, E. C., \& Kaufman, J. S. (2012). Do Medical Marijuana Laws Increase Marijuana Use? Replication Study and Extension. Annals of Epidemiology, 22(3), 207-212.

Hartley, R., \& Zisserman, A. (2003). Multiple view geometry in computer vision. Cambridge university press.

Harzallah, H., Jurie, F., \& Schmid, C. (2009). Combining efficient object localization and 
image classification. In Computer vision, 2009 ieee 12th international conference on (pp. 237-244).

Haykin, S. (1994). Neural networks: a comprehensive foundation. Prentice Hall PTR.

He, K., Zhang, X., Ren, S., \& Sun, J. (2016). Deep residual learning for image recognition. In Proceedings of the ieee conference on computer vision and pattern recognition (pp. $770-778)$.

Heintzelman, M. D., \& Tuttle, C. M. (2012a). Values in the wind: a hedonic analysis of wind power facilities. Land Economics, 88(3), 571-588.

Heintzelman, M. D., \& Tuttle, C. M. (2012b). Values in the Wind: A Hedonic Analysis of Wind Power Facilities. Land Economics, 88(3), 571-588.

Henderson, V., Storeygard, A., \& Weil, D. N. (2011). A bright idea for measuring economic growth. American Economic Review, 101 (3), 194-99.

Hilber, C. A. (2005). Neighborhood Externality Risk and the Homeownership Status of Properties. Journal of Urban Economics, 57(2), 213-241.

Hoen, B. (2010). The Impact of Wind Power Projects on Residential Property Values in the United States: A Multi-Site Hedonic Analysis. Lawrence Berkeley National Laboratory: Lawrence Berkeley National Laboratory. Retrieved from https://escholarship.org/uc/item/0gk965bg

Hoen, B. (2014). A Spatial Hedonic Analysis of the Effects of Wind Energy Facilities on Surrounding Property Values in the United States. Lawrence Berkeley National Laboratory: Lawrence Berkeley National Laboratory. Retrieved from https://escholarship.org/uc/item/5gx7k135

Huang, J., Rathod, V., Sun, C., Zhu, M., Korattikara, A., Fathi, A., .. others (2017). Speed/accuracy trade-offs for modern convolutional object detectors. In Ieee cvpr (Vol. 4).

Hunt, P., Pacula, R. L., \& Weinberger, G. (2018). High on crime? exploring the effects of marijuana dispensary laws on crime in california counties. IZA Discussion Paper No. 11567.

Hwang, J. W., Kuang, C., \& Bin, O. (2019). Are all homeowners willing to pay for better schools? evidence from a finite mixture model approach. The Journal of Real Estate Finance and Economics, 58(4), 638-655.

Jacobi, L., \& Sovinsky, M. (2016). Marijuana on Main Street? Estimating Demand in Markets with Limited Access. The American Economic Review, 106 (8), 2009-2045.

Jacobs, J. (1961). The death and life of great american cities. New York, NY: Random House. 
Kahn, M. E. (2007). Do greens drive hummers or hybrids? environmental ideology as a determinant of consumer choice. Journal of Environmental Economics and Management, 54(2), 129-145.

Kane, T. J., Riegg, S. K., \& Staiger, D. O. (2006). School quality, neighborhoods, and housing prices. American law and economics review, 8(2), 183-212.

Kang, J., Körner, M., Wang, Y., Taubenböck, H., \& Zhu, X. X. (2018). Building instance classification using street view images. ISPRS Journal of Photogrammetry and Remote Sensing.

Koch, D., Despotovic, M., Sakeena, M., Döller, M., \& Zeppelzauer, M. (2018). Visual estimation of building condition with patch-level convnets. arXiv preprint arXiv:1804.10113.

Kok, N., Koponen, E.-L., \& Martínez-Barbosa, C. A. (2017). Big data in real estate? from manual appraisal to automated valuation. The Journal of Portfolio Management, 43(6), 202-211.

Kok, N., Monkkonen, P., \& Quigley, J. M. (2014). Land use regulations and the value of land and housing: An intra-metropolitan analysis. Journal of Urban Economics, $81,136-148$.

Koster, H. R., \& Rouwendal, J. (2012). The impact of mixed land use on residential property values. Journal of Regional Science, 52(5), 733-761.

Krekel, C., \& Zerrahn, A. (2017). Does the Presence of Wind Turbines have Negative Externalities for People in their Surroundings? Evidence from Well-Being Data. Journal of Environmental Economics and Management, 82(Supplement C), 221 238.

Krivo, L. J., \& Kaufman, R. L. (2004). Housing and wealth inequality: Racial-ethnic differences in home equity in the united states. Demography, 41(3), 585-605.

Krizhevsky, A., Sutskever, I., \& Hinton, G. E. (2012). Imagenet classification with deep convolutional neural networks. In Advances in neural information processing systems (pp. 1097-1105).

Kuminoff, N. V., Parmeter, C. F., \& Pope, J. C. (2010). Which Hedonic Models Can We Trust to Recover the Marginal Willingness to Pay for Environmental Amenities? Journal of Environmental Economics and Management, 60(3), 145-160.

Kuminoff, N. V., \& Pope, J. C. (2014). Do "Capitalization Effects" for Public Goods Reveal the Public's Willingness to Pay? International Economic Review, 55(4), $1227-1250$.

Lang, C., \& Opaluch, J. (2013). Effects of Wind Turbines on Property Values in Rhode Island (Tech. Rep.). Rhode Island: University of Rhode Island. 
Law, S., Paige, B., \& Russell, C. (2018). Take a look around: Using street view and satellite images to estimate house prices. arXiv preprint arXiv:180\%.07155.

Levitt, S. D., \& Syverson, C. (2008). Market distortions when agents are better informed: The value of information in real estate transactions. The Review of Economics and Statistics, 90(4), 599-611.

Leydon, M. (2014). Front Door/Back Door: The Paradox of the Netherlands' Cannabis Policy. Retrieved from https://bit.ly/2HfiOrx

Li, M. M., \& Brown, H. J. (1980). Micro-neighborhood externalities and hedonic housing prices. Land economics, $56(2)$.

Lin, T.-Y., Maire, M., Belongie, S., Hays, J., Perona, P., Ramanan, D., ... Zitnick, C. L. (2014). Microsoft coco: Common objects in context. In European conference on computer vision (pp. 740-755).

Lindenthal, T., \& Johnson, E. B. (2018). Machine learning, building vintage and property values. Working Paper.

Liu, W., Anguelov, D., Erhan, D., Szegedy, C., Reed, S., Fu, C.-Y., \& Berg, A. C. (2016). Ssd: Single shot multibox detector. In European conference on computer vision (pp. $21-37)$.

Londo, H. M., \& Boot, P. A. (2013). Het Energieakkoord: Wat Gaat het Betekenen? Inschatting van de Gemaakte Afspraken. ECN Policy Studies.

Loring, J. M. (2007). Wind energy planning in england, wales and denmark: Factors influencing project success. Energy policy, 35(4), 2648-2660.

Lynne-Landsman, S. D., Livingston, M. D., \& Wagenaar, A. C. (2013). Effects of State Medical Marijuana Laws on Adolescent Marijuana Use. American Journal of Public Health, 103(8), 1500-1506.

MacCoun, R., \& Reuter, P. (1997). Interpreting Dutch Cannabis Policy: Reasoning by Analogy in the Legalization Debate. Science, $278(5335), 47-52$.

Marie, O., \& Zölitz, U. (2017). "high" achievers? cannabis access and academic performance. The Review of Economic Studies, 84(3), 1210-1237.

Marsden, A. (1969). Brightness - a review of current knowledge. Lighting Research \&6 Technology, 1(3), 171-181.

McMillen, D. P., \& McDonald, J. (2004). Reaction of house prices to a new rapid transit line: Chicago's midway line, 1983-1999. Real Estate Economics, 32(3), 463-486.

Meij, R., \& te Winkel, H. (2006, sep). Mercury Emissions from Coal-Fired Power Stations: The Current State of the Art in the Netherlands. Science of the Total Environment, 
368(1), 393-396.

Morris, R. G., TenEyck, M., Barnes, J. C., \& Kovandzic, T. V. (2014). The Effect of Medical Marijuana Laws on Crime: Evidence from State Panel Data, 1990-2006. PloS one, 9(3), e92816.

Muehlenbachs, L., Spiller, E., \& Timmins, C. (2015, dec). The Housing Market Impacts of Shale Gas Development. The American Economic Review, 105(12), 3633-3659.

Municipality of Amsterdam. (2007). Fact Sheet - Minder Coffeeshops in Amsterdam (Tech. Rep.). Amsterdam: Dienst Onderzoek en Statistiek.

Naik, N., Kominers, S. D., Raskar, R., Glaeser, E. L., \& Hidalgo, C. A. (2017). Computer vision uncovers predictors of physical urban change. Proceedings of the National Academy of Sciences, 114(29), 7571-7576.

Naik, N., Philipoom, J., Raskar, R., \& Hidalgo, C. (2014). Streetscore-predicting the perceived safety of one million streetscapes. In Proceedings of the ieee conference on computer vision and pattern recognition workshops (pp. 779-785).

Naik, N., Raskar, R., \& Hidalgo, C. A. (2016). Cities are physical too: Using computer vision to measure the quality and impact of urban appearance. American Economic Review, 106 (5), 128-32.

Nelson, J. P. (2004). Meta-analysis of airport noise and hedonic property values. Journal of Transport Economics and Policy (JTEP), 38(1), 1-27.

Nelson, J. P. (2008). Hedonic Property Value Studies of Transportation Noise: Aircraft and Road Traffic. In Hedonic methods in housing markets (pp. 57-82). New York: Springer.

Nguyen-Hoang, P., \& Yinger, J. (2011). The capitalization of school quality into house values: A review. Journal of Housing Economics, 20(1), 30-48.

Nusche, D., Braun, H., Halász, G., \& Santiago, P. (2014). Oecd reviews of evaluation and assessment in education: Netherlands 2014. OECD Publishing. Retrieved from http://dx.doi.org/10.1787/9789264211940-en

Obermeyer, Z., \& Emanuel, E. J. (2016). Predicting the future -big data, machine learning, and clinical medicine. The New England journal of medicine, 375(13), 1216.

Oquab, M., Bottou, L., Laptev, I., \& Sivic, J. (2014). Learning and transferring mid-level image representations using convolutional neural networks. In Proceedings of the ieee conference on computer vision and pattern recognition (pp. 1717-1724).

Owusu-Edusei, K., Espey, M., \& Lin, H. (2007). Does close count? school proximity, school quality, and residential property values. Journal of Agricultural and Applied 
Economics, 39(1), 211-221.

Pacula, R. L., Kilmer, B., Grossman, M., \& Chaloupka, F. J. (2010). Risks and Prices: The Role of User Sanctions in Marijuana Markets. The BE Journal of Economic Analysis \& Policy, 10(1), 11.

Pasqualetti, M. J. (2011a). Opposing Wind Energy Landscapes: A Search for Common Cause. Annals of the Association of American Geographers, 101 (4), 907-917.

Pasqualetti, M. J. (2011b). Social Barriers to Renewable Energy Landscapes. Geographical Review, $101(2), 201-223$.

Pedersen, E., \& Waye, K. P. (2007). Wind Turbine Noise, Annoyance and Self-Reported Health and Well-Being in Different Living Environments. Occupational and Environmental Medicine, 64 (7), 480-486.

Piketty, T. (2014). Capital in the Twenty-First Century. Cambridge Massachusetts: The Belknap Press of Harvard University Press.

Pope, D. G., \& Pope, J. C. (2015). When walmart comes to town: Always low housing prices? always? Journal of Urban Economics, 87, 1-13.

Poursaeed, O., Matera, T., \& Belongie, S. (2018). Vision-based real estate price estimation. Machine Vision and Applications, 29(4), 667-676.

Quigley, J. M. (2002). Transactions costs and housing markets.

Ren, S., He, K., Girshick, R., \& Sun, J. (2015). Faster r-cnn: Towards real-time object detection with region proposal networks. In Advances in neural information processing systems (pp. 91-99).

Rosen, S. (1974). Hedonic prices and implicit markets: Product differentiation in pure competition. Journal of Political Economy, 82(1), 34-55.

Rosiers, F. D., Lagana, A., \& Theriault, M. (2001). Size and proximity effects of primary schools on surrounding house values. Journal of Property Research, 18(2), 149-168.

Roth, I. F., \& Ambs, L. L. (2004). Incorporating Externalities Into a Full Cost Approach to Electric Power Generation Life-Cycle Costing. Energy, 29(12), 2125-2144.

Sah, V., Conroy, S. J., \& Narwold, A. (2016). Estimating school proximity effects on housing prices: The importance of robust spatial controls in hedonic estimations. The Journal of Real Estate Finance and Economics, 53(1), 50-76.

Seiferling, I., Naik, N., Ratti, C., \& Proulx, R. (2017). Green streets- quantifying and mapping urban trees with street-level imagery and computer vision. Landscape and Urban Planning, 165, 93-101. 
Senior, C. L., \& Johnson, S. A. (2005, may). Impact of Carbon-in-Ash on Mercury Removal across Particulate Control Devices in Coal-Fired Power Plants. Energy 86 Fuels, 19(3), 859-863.

Sims, S., Dent, P., \& Oskrochi, G. R. (2008). Modelling the Impact of Wind Farms on House Prices in the UK. International Journal of Strategic Property Management, 12(4), 251-269.

Sonka, M., Hlavac, V., \& Boyle, R. (2014). Image processing, analysis, and machine vision. Cengage Learning.

Sunak, Y., \& Madlener, R. (2016). The impact of wind farm visibility on property values: A spatial difference-in-differences analysis. Energy Economics, 55, 79-91.

The Dutch Inspectorate of Education. (2014). The state of education in the Netherlands. Retrieved from https://bit.1y/33G4RfK

Tiebout, C. M. (1956). A Pure Theory of Local Expenditures. The Journal of Political Economy, 64(5), 416-424.

Tops, D., Svensson, B., \& Veldhoen, G. (2001). The Drug Policies of the Netherlands and Sweden: How Do They Compare? Brussels: European Parliament.

Tourkolias, C., Mirasgedis, S., Damigos, D., \& Diakoulaki, D. (2009). Employment Benefits of Electricity Generation: A Comparative Assessment of Lignite and Natural Gas Power Plants in Greece. Energy Policy, 37(10), 4155-4166.

van Ooyen-Houben, M. M. J., Bieleman, B., \& Korf, D. J. (2016). Tightening the Dutch Coffee Shop Policy: Evaluation of the Private Club and the Residence Criterion. International Journal of Drug Policy, 31, 113-120.

Wall, M. M., Poh, E., Cerdá, M., Keyes, K. M., Galea, S., \& Hasin, D. S. (2011). Adolescent Marijuana Use from 2002 to 2008: Higher in States with Medical Marijuana Laws, Cause Still Unclear. Annals of Epidemiology, 21(9), 714-716.

Warren, C. R., \& McFadyen, M. (2010). Does community ownership affect public attitudes to wind energy? a case study from south-west scotland. Land use policy, 27(2), 204-213.

Windstats. (2015). Statistieken over Windenergie in Nederland. Retrieved 2015-01-01, from http://www.windstats.nl

Wolsink, M. (2000). Wind Power and the NIMBY-Myth: Institutional Capacity and the Limited Significance of Public Support. Renewable Energy, 21 (1), 49-64.

Wolsink, M. (2007). Wind Power Implementation: The Nature of Public Attitudes: Equity and Fairness Instead of 'Backyard Motives'. Renewable and Sustainable Energy Reviews, 11(6), 1188-1207. 
Wouters, M., Benschop, A., van Laar, M., \& Korf, D. J. (2012). Cannabis Use and Proximity to Coffee Shops in the Netherlands. European Journal of Criminology, $9(4), 337-353$.

Wouters, M., \& Korf, D. J. (2009). Access to Licensed Cannabis Supply and the Separation of Markets Policy in the Netherlands. Journal of Drug Issues, 39(3), 627-651.

Wüstenhagen, R., Wolsink, M., \& Bürer, M. J. (2007). Social Acceptance of Renewable Energy Innovation: An Introduction to the Concept. Energy Policy, 35(5), 26832691.

You, Q., Pang, R., Cao, L., \& Luo, J. (2017). Image-based appraisal of real estate properties. IEEE Transactions on Multimedia, 19(12), 2751-2759.

Zahirovic-Herbert, V., \& Turnbull, G. K. (2009). Public school reform, expectations, and capitalization: what signals quality to homebuyers? Southern Economic Journal, 1094-1113.

Zeppelzauer, M., Despotovic, M., Sakeena, M., Koch, D., \& Döller, M. (2018). Automatic prediction of building age from photographs. In Proceedings of the $2018 \mathrm{acm}$ on international conference on multimedia retrieval (pp. 126-134). 


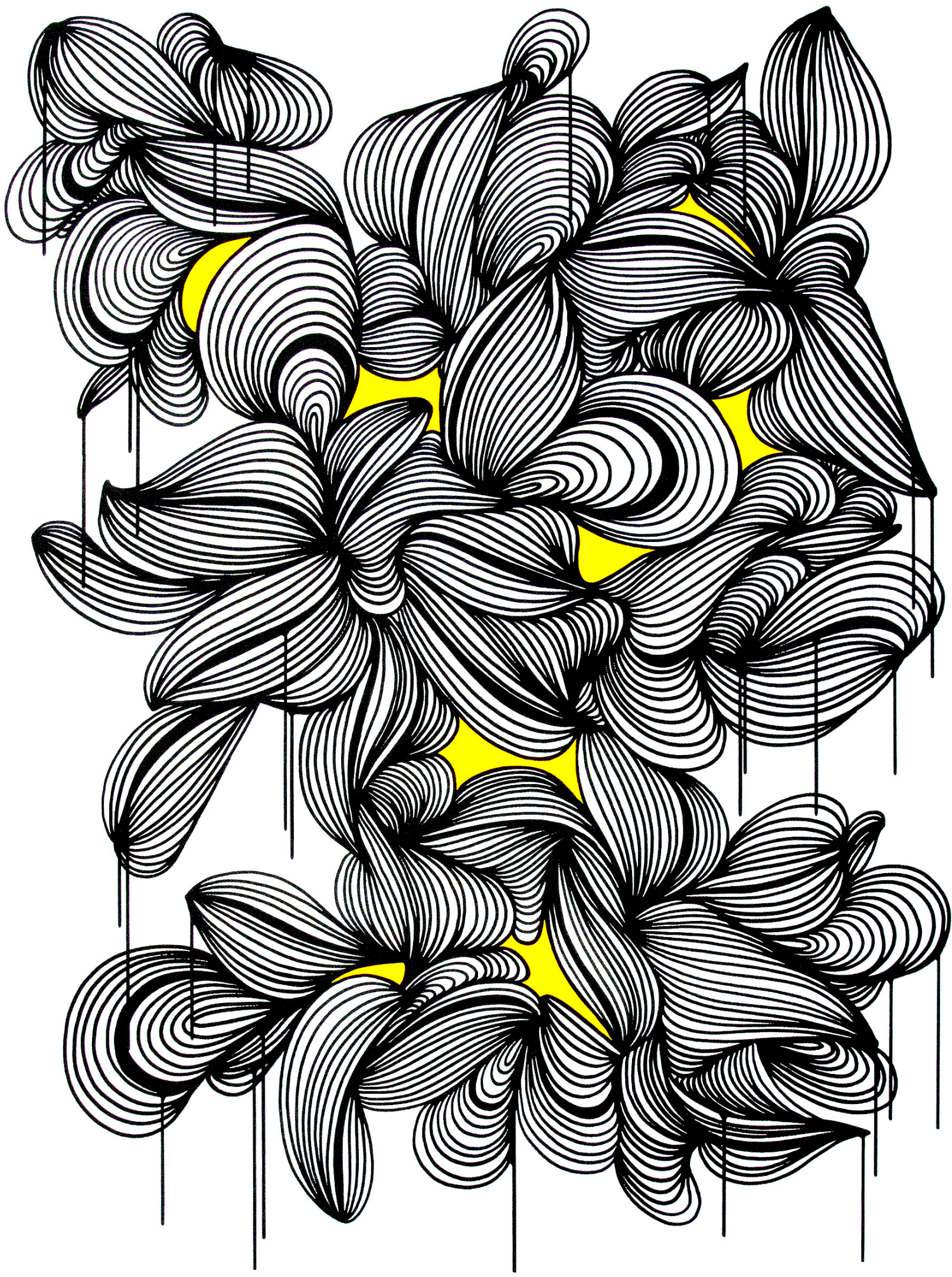

